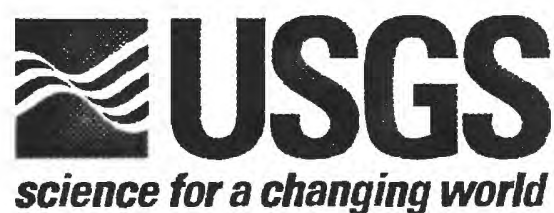

\title{
MAGNETOTELLURIC DATA ALONG THE TALKEETNA MOUNTAINS TRANSECT, ALASKA
}

\author{
by \\ Jay A. Sampson \\ and \\ Brian D. Rodriguez ${ }^{1}$
}

Open-File Report 00-486

2000

This report is preliminary and has not been reviewed for conformity with U.S. Geological Survey editorial standards and stratigraphic nomenclature. Any use of trade, product, or firm names is for descriptive purposes only and does not imply endorsement by the U.S. Government.

\section{U.S. DEPARTMENT OF THE INTERIOR}

U.S. GEOLOGICAL SURVEY

${ }^{1}$ Denver, Colorado 


\section{TABLE OF CONTENTS}

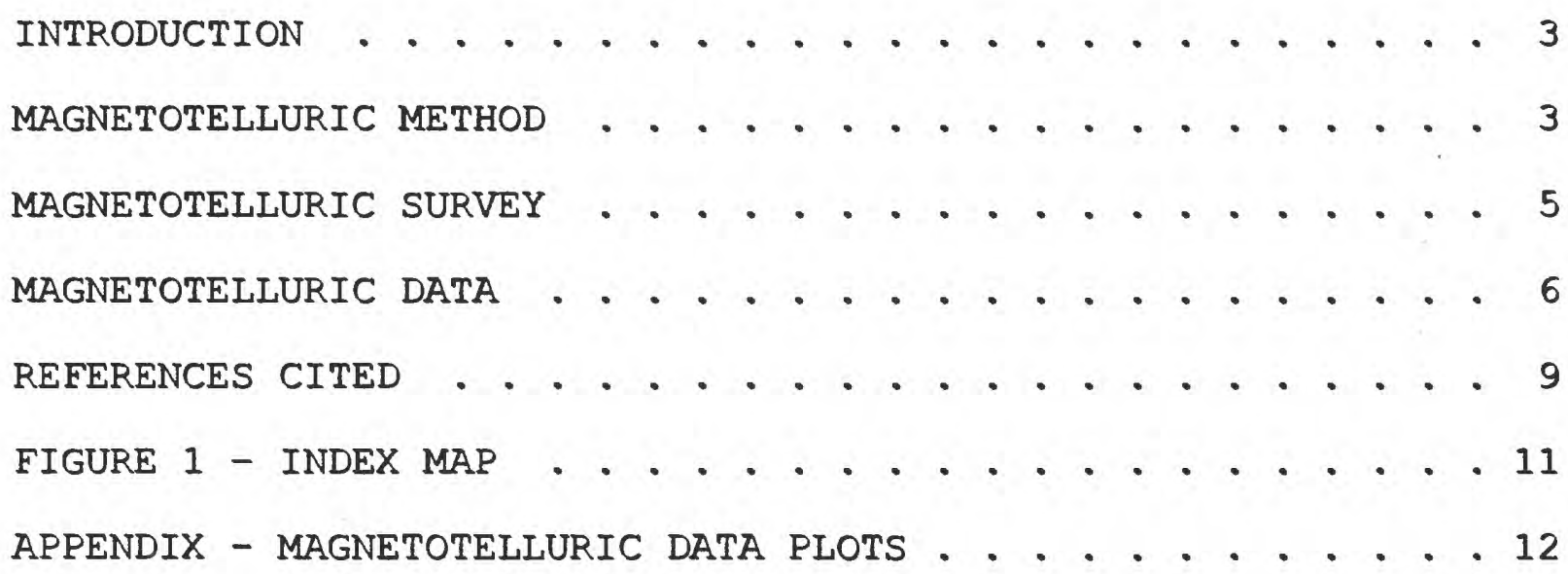




\section{INTRODUCTION}

The northwest to southeast, $20 \times 100 \mathrm{~km}$ long, Talkeetna Mountains transect (Figure 1) crosses the boundaries between 3 major lithotectonic terranes (Silberling and others, 1994). In the Kahiltna terrane, a flysch basin is intruded by exposed and buried granitoid plutons. This flysch also has uncertain structural relationships with the adjacent Maclaren metamorphic belt (off Figure 1 - to the east), and with rocks interpreted as overthrust, but non-metamorphosed flysch. The Wrangellia terrane consists primarily of upper Paleozoic metasedimentary, metagranitic, marine volcanic, and sedimentary rocks, along with upper Triassic submarine and subaerial basalt, and both mafic and ultramafic intrusive rocks (Nokleberg and others, 1994). The Peninsular terrane consists chiefly of Jurassic marine sedimentary, volcanic, and granitic rocks. Our understanding of both the structural nature of terrane boundaries and the distribution of intrusive bodies in the flysch basin should benefit from the 3-dimensional subsurface data provided by the 94 $\mathrm{km}$ long magnetotelluric (MT) survey profile (M-M'), which was acquired in June of 2000 .

The MT survey permits interpretation of structures and lithologic packages to greater depths than is produced by surface mapping alone. With the addition of deep, 3-dimensional MT data, the potential field geophysics (aeromagnetic, resistivity and gravity data) of the region surrounding the transect can also be modelled in greater detail than would be possible from surface geologic observations alone.

\section{MAGNETOTELLURIC METHOD}

The magnetotelluric method is a passive surface geophysical technique that uses the earth's natural electromagnetic fields to investigate the resistivity structure of the subsurface. The resistivity of geologic units is largely dependent upon their fluid content, porosity, fracturing, temperature, and conductive mineral content (Keller and Frischknecht, 1966). Fluids, especially saline fluids, within the pore spaces and fracture openings can reduce resistivities in a resistive rock matrix. Also, resistivity can be lowered by the presence of conductive clay minerals, graphitic carbon, and metallic mineralization. It is common for altered volcanic rocks to contain authigenic minerals that have resistivities ten times lower than those of the surrounding rocks (Nelson and Anderson, 1992). Increased temperatures cause higher ionic mobility and mineral activation energy, reducing rock resistivities significantly. Unaltered, unfractured igneous rocks are normally very resistive (typically 1,000 ohm-m or greater), whereas faults will show low resistivity (less than $100 \mathrm{ohm}-\mathrm{m}$ ) when they are comprised of rocks fractured 
enough to have hosted fluid transport and consequent mineralogical alteration. Carbonate rocks are moderately to highly resistive (hundreds to thousands of ohm-m) dependent upon their fluid content, porosity, fracturing, and impurities. Marine shales, mudstones, and clay-rich alluvium are normally very conductive (a few ohm-m to tens of ohm-m). Metamorphic rocks (non-graphitic) are moderately to highly resistive (hundreds to thousands of ohm-m). Tables of electrical resistivity for a variety of rocks, minerals and geological environments may be found in Keller (1987) and Palacky (1987).

The MT method allows us to probe the crust from depths of tens of meters to tens of kilometers (Vozoff, 1991). Natural variations of the Earth's magnetic and electric field are measured and recorded at each MT station. World-wide lightning activity at frequencies of $10,000 \mathrm{~Hz}$ to $1 \mathrm{~Hz}$ and geomagnetic micropulsations at frequencies of $1 \mathrm{~Hz}$ to $0.0001 \mathrm{~Hz}$ are the main frequency bands used by the MT method. The natural electric and magnetic fields propagate vertically in the earth because the very large resistivity contrast between the air and the earth causes a vertical refraction of both fields transmitted into the earth (Vozoff, 1972).

Using a computer-based data-acquisition and processing system, the natural electric and magnetic fields are recorded in two orthogonal, horizontal directions (the vertical magnetic field is also recorded). The resulting time-series signals are used to derive earth tensor apparent resistivities and phases by first converting them to complex cross-spectra using FFT (fast-Fouriertransform) techniques and least-squares, cross-spectral analysis (Bendat and Piersol, 1971) to solve for a tensor-transfer function. The calculated function relates the observed electric fields to the magnetic fields under the assumption that the Earth consists of a two-input, two-output, linear system with the magnetic fields as input and the electric fields as output (Rodriguez and others, 1996). Prior to conversion to apparent resistivity and phase, the tensor is normally rotated into principal directions that usually correspond to the direction of maximum and minimum apparent resistivity. For a two-dimensional (2-D) Earth, the MT fields can be decoupled into transverse electric (TE) and transverse magnetic (TM) modes; 2-D modeling is generally done to fit both modes. When the geology satisfies the 2-D assumption, the MT data for the TE mode is assumed to represent the situation when the electric field is along the geologic strike, and the data for the TM mode is assumed to represent the situation when the electric field is across strike. The MT method is well-suited for studying complicated geological environments because the electric and magnetic relations are sensitive to vertical and horizontal variations in resistivity. The method is capable of establishing whether the electromagnetic 
fields are responding to subsurface rock bodies of effectively 1, 2-, or 3-dimensions. An introduction to the MT method and references for a more advanced understanding are contained in Dobrin and Savit (1988) and Vozoff (1991).

\section{MAGNETOTELLURIC SURVEY}

Fourteen MT soundings were located along the Talkeetna Mountains Transect (Figure 1). Spacing between soundings varied from 5.6 to $10.7 \mathrm{~km}$. The profile orientation is approximately perpendicular to the known geologic strike. Horizontal electric fields were sensed using copper-sulfate electrodes placed in an L-shaped, three-electrode array with dipole lengths of $30 \mathrm{~m}$. The orthogonal, horizontal magnetic fields in the direction of the electric-field measurement array were sensed using permalloycored induction coils. At station TA013, the horizontal magnetic fields were mistakenly measured 23 degrees west of the electric field dipoles instead of parallel to them. This results in erroneous MT parameters and will need to be corrected before this station can be used in any subsequent modeling. Frequencies sampled ranged from 70 to $0.004 \mathrm{~Hz}$ using single station recordings of both orthogonal horizontal components of the electric and magnetic fields, along with the vertical magnetic field. Sampling these frequencies in the Talkeetna Mountains transect allowed us to probe the crust from depths of hundreds of meters to depths of possibly tens of kilometers.

The recorded time-series data were transformed to the frequency domain and Fourier analyzed to determine a two-dimensional apparent resistivity and phase tensor at each site. The data were rotated to maximum and minimum apparent resistivity directions so that propagation modes for the signals were decoupled into TE and TM modes. Local reference sensors, normally used to help reduce bias in the impedance determinations due to instrument or environmental noise (Gamble and others, 1979; Clarke and others, 1983), were not used at any of the stations in this survey, because of field-helicopter logistics. Although remote reference techniques were not used in our survey, we did sort cross-power files to select optimal signal-to-noise data sets.

The effects of near-surface resistivity anomalies cause "static shifts" (Sternberg and others, 1988) in the data. Static shifts affect most of this data set and range from 0.0 to 1.0 of a log decade. Stations TA010, TA011, TA012, TA004, TA013, TA014, TA009, TA008, and TA007 had static shifts larger than one-third of a log decade. The remainder of the stations had very minor static shifts. The larger static shifts should be accounted for in any subsequent modeling of the data. 


\section{MAGNETOTELLURIC DATA}

The following table shows fourteen magnetotelluric (MT) station locations (from northwest to southeast) as recorded using a global positioning system during field acquisition. Coordinates are referenced to the 1866 Clarke spheroid and North American 1927 Alaska datum. Longitude and latitude format below is degrees-minutes-seconds. Rotation angle is described below.

$\begin{array}{llll}\text { Station } & \text { Longitude } & \text { Latitude } & \text { Rotation Angle } \\ \text { TA016 } & \text { W149-27-30 } & \text { N63-07-00 } & \text { Impedance Maximum } \\ \text { TA010 } & \text { W149-18-27 } & \text { N63-06-02 } & \text { Impedance Maximum } \\ \text { TA011 } & \text { W149-09-57 } & \text { N63-03-39 } & \text { Impedance Maximum } \\ \text { TA012 } & \text { W149-01-55 } & \text { N63-01-24 } & \text { Impedance Minimum } \\ \text { TA004 } & \text { W148-54-28 } & \text { N62-59-58 } & \text { Impedance Maximum } \\ \text { TA005 } & \text { W148-50-15 } & \text { N62-56-54 } & \text { Impedance Minimum } \\ \text { TA003 } & \text { W148-42-04 } & \text { N62-54-21 } & \text { Impedance Minimum } \\ \text { TA013 } & \text { W148-41-20 } & \text { N62-52-59 } & \text { Impedance Minimum } \\ \text { TA015 } & \text { W148-32-55 } & \text { N62-47-31 } & \text { Impedance Minimum } \\ \text { TA014 } & \text { W148-28-43 } & \text { N62-45-02 } & \text { Impedance Maximum } \\ \text { TA009 } & \text { W148-23-53 } & \text { N62-41-13 } & \text { Impedance Minimum } \\ \text { TA008 } & \text { W148-16-05 } & \text { N62-38-33 } & \text { Impedance Minimum } \\ \text { TA007 } & \text { W148-10-00 } & \text { N62-36-42 } & \text { Impedance Minimum } \\ \text { TA006 } & \text { W148-04-12 } & \text { N62-35-30 } & \text { Impedance Minimum }\end{array}$

The figures in the Appendix represent the raw field MT data for each station after the time series data was converted to the frequency domain and least-squares, cross-spectral analysis (Bendat and Piersol, 1971) was used to solve for a tensortransfer function. This tensor transfer function was used to rotate the tensor into principal directions that correspond to the direction (rotation angle) of maximum and minimum apparent resistivity. Apparent resistivity and impedance phase were then calculated.

For each station, nine separate graph plots are given:

1. Apparent Resistivity for two modes,

2. Impedance Phase for two modes,

3. Rotation Angle for the impedance tensor,

4. Impedance skew for the impedance tensor,

5. Multiple Coherency for two modes of the electric field,

6. Impedance Polar Plots (at 12 selected frequencies),

7. Tipper Magnitude for the vertical magnetic field,

8. Tipper strike for the vertical magnetic field, and

9. $\mathrm{HzHx}$ ( $\mathrm{x}$ symbol) and HzHy (o symbol) Coherency. 
Each of these graphs plots the above quantity versus frequency. The Apparent Resistivity, Impedance Phase, and Multiple Coherency plots use $x$ and 0 symbols to distinguish the two tensor modes. During the interpretation phase, still to come, these modes will be identified as TE and TM. The $x$ and $O$ symbols on the $\mathrm{HzHx}$ and HzHy Coherency plot represent $\mathrm{HzHx}$ and HzHy coherency, respectively. Error bars are probable errors within one standard deviation of the sample variance (Gamble and others, 1978).

Apparent resistivity is a measure of the magnitude of the electric field strength over the magnetic field strength for a given frequency. The impedance phase is proportional to the slope of the apparent resistivity curve on a log-log scale, but from a baseline at -45 degrees (Vozoff, 1991). A measure of the dimensionality for MT data is provided by the impedance skew of the impedance tensor (Vozoff, 1972). If the effective measured resistivity response to the geology beneath a MT station is truly 1-D or 2-D, then the skew will be zero. Both instrument and environmental sources of noise contribute to non-zero skew values, but are typically small (about 0.1) for relatively low noise level recordings. Higher skews (above 0.2) are an indication of either 3-D resistivity responses to the geology or higher levels of noise. Man-made electrical noise, such as power lines, power generators, moving vehicles and trains can have a negative effect on MT data quality. All these local disturbances produce an incoherent noise mainly affecting higher frequencies, usually above $1 \mathrm{~Hz}$. Other man-made electrical noise, such as direct current electric trains and active cathodic protection of pipelines produce coherent electromagnetic signals mainly affecting frequencies below $1 \mathrm{~Hz}$.

The Talkeetna Mountains Transect survey area is remote. Power lines, power generators, pipelines, railroads, steam-driven trains, moving vehicles, and mining operations, were not a noise factor in most of this survey. Station TA016 is located less than $100 \mathrm{~m}$ east of the George Parks highway, south of Cantwell. Vehicle traffic and power lines near this station were sources of noise. No Alaska Railroad train passed during the recordings for this sounding. This site was located far enough away from the railroad tracks, which are on the west side of the highway, that the metal in the tracks were probably not a source of noise. Local lightning, wind, and rainstorms can also degrade data quality, but these were avoided by not recording during active thunderstorm periods. Wind noise was minimized by burying the magnetic induction coils.

Predicted values of the electric field can be computed from the measured values of the magnetic field (Vozoff, 1991). The coherence of the predicted electric field with the measured electric field is a measure of the signal-to-noise ratio provided 
in the multiple coherency plot. Values are normalized between 0 and 1 , where values at 0.5 signify signal levels equal to noise levels. For this data set, coherencies were generally at an acceptable level, except at times in the "dead band" 10.1 to 1 $\mathrm{Hz}$ ). The lower frequency ionospheric signals are related to sunspot activity whose levels typically follow an 11 year cycle. The sunspot activity was near the highest level of the cycle during this survey.

The figures in the Appendix represent the raw field MT data at each station, which includes some data scatter and poor signalto-noise ratios. Our only effort at removing noisy data points was to visually inspect and select the best signal-to-noise field data to combine into the final data plots.

The impedance polar plots provide a measure of the MT data dimensionality (Reddy and others, 1977). For 1-D resistivity structures, the principal impedance polar diagrams are circles. For 2-D or 3-D resistivity structures, the principal impedance polar diagrams (dashed lines) elongate either parallel or perpendicular to strike direction. Over resistors, the principal impedance polar diagrams elongate perpendicular to strike direction and over conductors, the principal impedance polar diagrams (solid lines) elongate parallel to strike direction. Also, for 2-D resistivity structures, the additional impedance polar diagrams attain the shape of a symmetric clover leaf. For 3-D resistivity structures, the additional impedance polar diagrams elongate in one direction and their amplitudes are comparable to those of principal impedances. Sites whose polar plots indicated $3-D$ character in the lower frequencies were MT stations TA010, TA004, TA005, TA003, TA015, TA014, TA008, and TA006.

The tipper can be solved for when the vertical component of the magnetic field is measured. The tipper magnitude is a measure of the tipping of the magnetic field out of the horizontal plane (Vozoff, 1991). The magnitude is zero for the 1-D case and typically increases between 0.1 to 0.5 , and rarely as great as 1 , as it responds to vertical and sub-vertical structures. The tipper strike is typically used to help resolve the 90-degree ambiguity in the impedance rotation angle. The vertical component of the magnetic field was measured at all MT stations. The tipper magnitude of these stations was typically 0.2 to 0.4 over the lower frequencies indicating vertical structure at depth. The HzHx and HzHy coherency is a measure of the signalto-noise ratio of the vertical magnetic field with respect to each of the orthogonal horizontal magnetic field directions. Values are normalized between 0 and 1 , where values at 0.5 signify signal levels equal to noise levels. These threecomponent magnetic field coherencies provide a check on the 
signal-to-noise ratio of the measured values in the tipper magnitude and tipper strike plots.

\section{REFERENCES CITED}

Bendat, J.S., and Piersol, A.G., 1971, Random Data: Analysis and Measurement Procedures: New York, Wiley Interscience, $407 p$.

Clarke, J., Gamble, T.D., Goubau, W.M., Koch, R.H., and Miracky, R.F., 1983, Remote-reference magnetotellurics: Equipment and procedures: Geophysical Prospecting, vol. 31, p. 149-170.

Dobrin, M.D., and Savit, C.H., 1988, Introduction to Geophysical Prospecting (4th ed.): New York, McGraw-Hill, $867 \mathrm{p}$.

Gamble, T.D., Goubau, W.M. and Clarke, J., 1979, Magnetotellurics with a remote magnetic reference: Geophysics, v. 44, no. 1, p. 53-68.

Gamble, T.D., Goubau, W.M. and Clarke, J., 1979, Error analysis for remote reference magnetotellurics: Geophysics, v. 44, no. 5, p. 959-968.

Keller, G.V. and Frischknecht, F.C., 1966, Electrical methods in geophysical prospecting: Pergamon Press, New York, 517 p.

Keller, G.V., 1987, Rock and mineral properties, in Electromagnetic Methods in Applied Geophysics Theory: M.N. Nabighian, Ed., Society of Exploration Geophysicists, Tulsa, Oklahoma, v. 1, p. 1351.

Nelson, P.H. and Anderson, L.A., 1992, Physical properties of ash flow tuff from Yucca Mountain, Nevada: Journal of Geophysical Research, vol. 97, no. B5, p. 6823-6841.

Palacky, G.J., 1987, Resistivity characteristics of geologic targets, in Electromagnetic Methods in Applied Geophysics Theory: M.N. Nabighian, Ed., Society of Exploration Geophysicists, Tulsa, Oklahoma, vol. 1, p. 53129.

Reddy, I.K., Rankin, D., and Phillips, R.J., 1977, Threedimensional modelling in magnetotelluric and magnetic variational sounding: Geophysics Journal of the Royal Astronomical Society, vol. 51, p. 313-325. 
Rodriguez, B.D., Stanley, W.D., and Williams, J.M., 1996, Axial structures within the Reelfoot rift delineated with magnetotelluric surveys: U.S. Geological Survey Professional Paper $1538-\mathrm{K}, 30 \mathrm{p}$.

Silberling, N.J., Jones, D.L., Monger, J.W.H., Coney, P.J., Berg, H.C., and Plafker, G., 1994, Lithotectonic terrane map of Alaska and adjacent parts of Canada: Geology of North America; vol. G-1, Plate 3, published by Geological Society of America.

Sternberg, B.K., Washburne, J.C., and Pellerin, L., 1988, Correction for the static shift in magnetotellurics using transient electromagnetic soundings: Geophysics, vol. 53, p. 1459-1468.

Vozoff, K., 1972, The magnetotelluric method in the exploration of sedimentary basins: Geophysics, vol. 37, p. 98-141.

Vozoff, K., 1991, The magnetotelluric method, in Electromagnetic methods in applied geophysics: M.N. Nabighian, Ed., Society of Exploration Geophysicists, Tulsa, Oklahoma, vol. 2, part B, p. 641-711. 


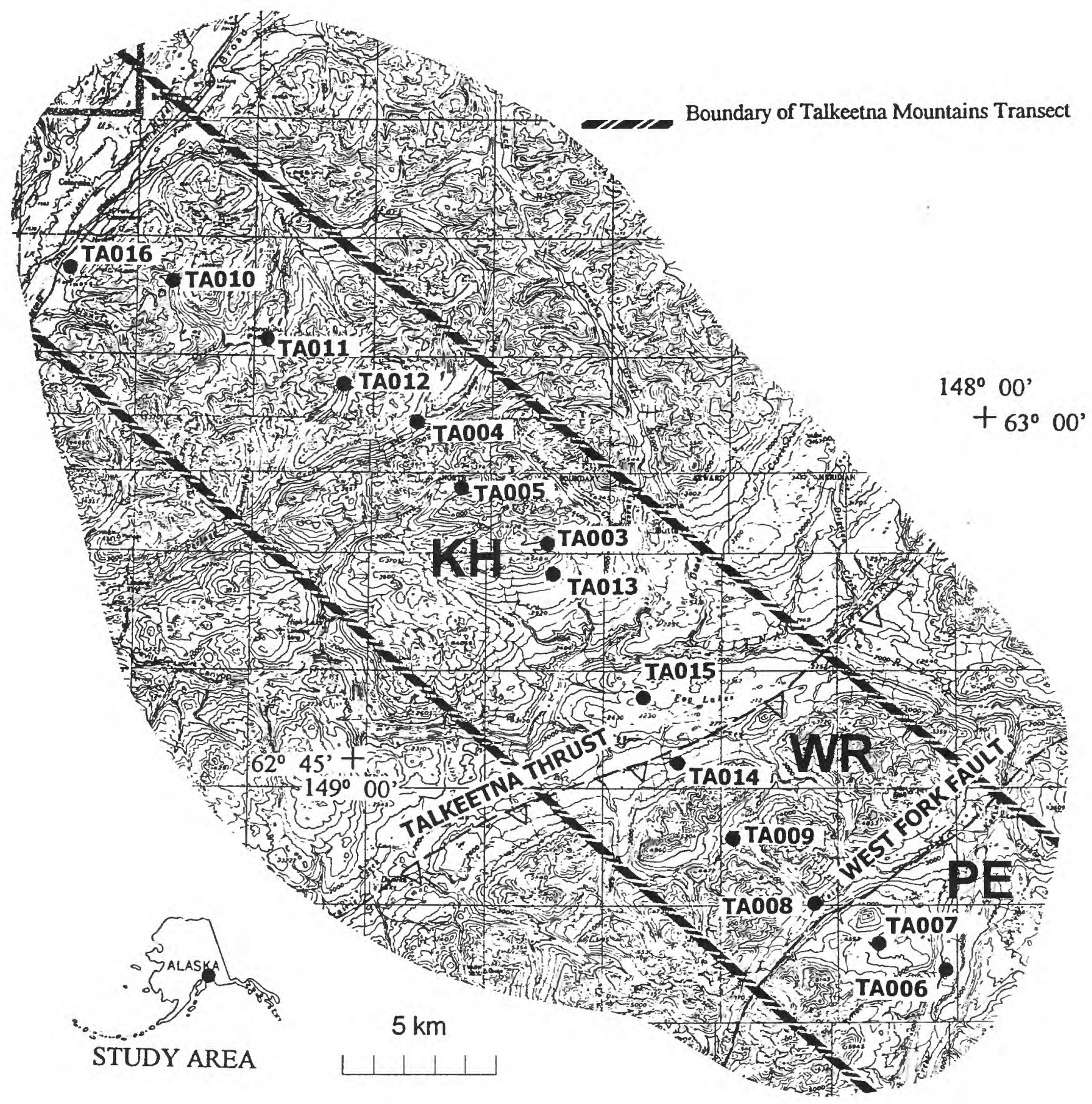

Figure 1. Index map showing the location of fourteen magnetotelluric (MT) stations acquired in June of 2000 along the 20 by $100 \mathrm{~km}$ northwest to southeast Talkeetna Mountains transect in southern Alaska. The profile of MT stations crosses the Talkeetna Thrust and West Fork Fault. Labeled terranes are Kahiltna (KH), Wrangellia (WR), and Peninsular (PE). The map scale is 1:500,000 with north at the top of the figure. Base maps used for this figure are the Healy and Talkeetna Mountains, Alaska 1:250,000 U.S. Geological survey topographical maps. 
APPENDIX

\section{MAGNETOTELLURIC DATA PLOTS}

For each station, there are nine separate graph plots:

10. Apparent Resistivity for two modes,

11. Impedance Phase for two modes,

12. Rotation Angle for the impedance tensor,

13. Impedance skew for the impedance tensor,

14. Multiple Coherency for two modes of the electric field,

15. Impedance Polar Plots (at 12 selected frequencies),

16. Tipper Magnitude for the vertical magnetic field,

17. Tipper Strike for the vertical magnetic field, and

18. $\mathrm{HzHx}$ (x symbol) and HzHy (o symbol) Coherency.

Refer to the "Magnetotelluric Data" section in this report for an explanation of these plots. 


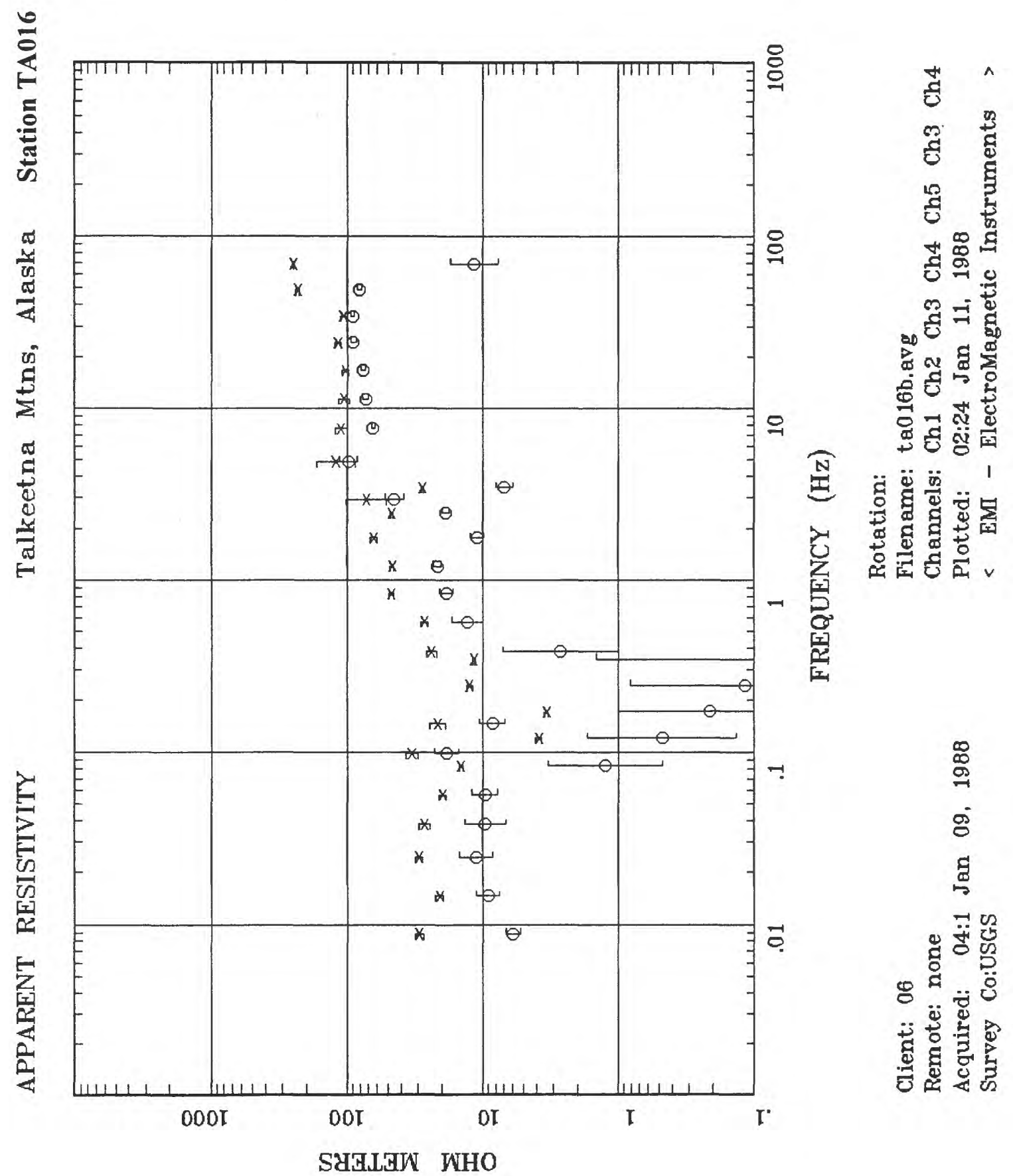




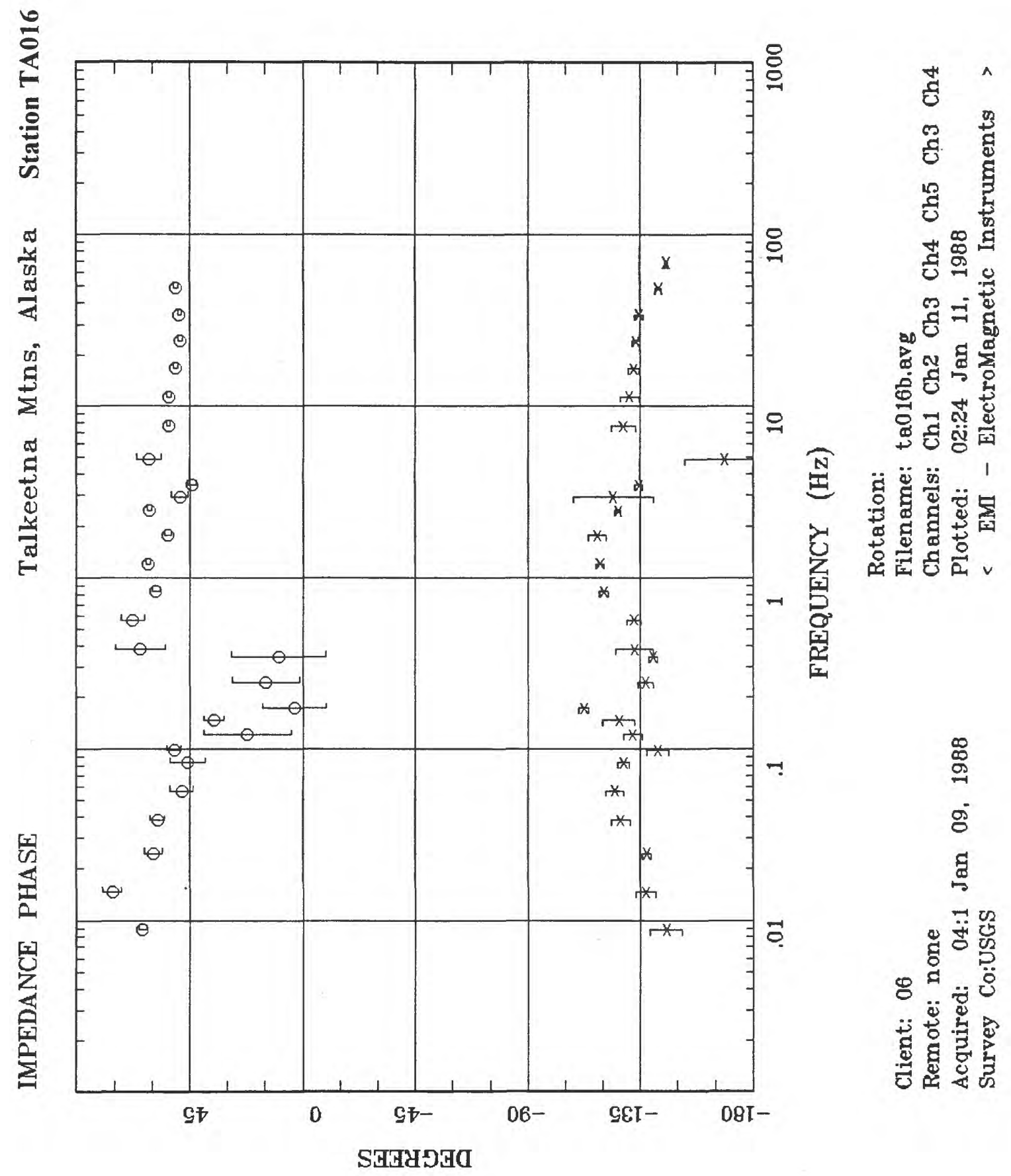




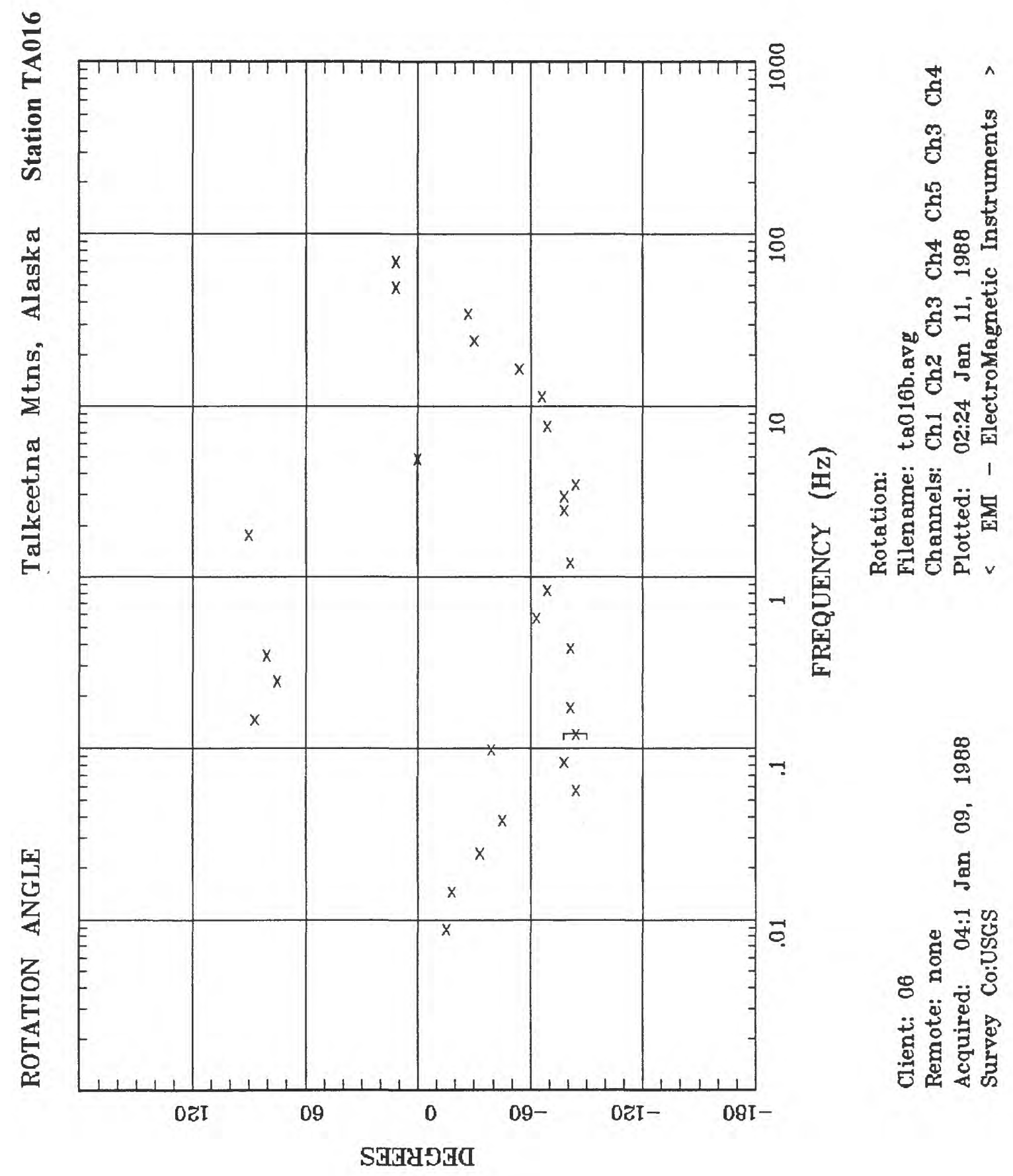




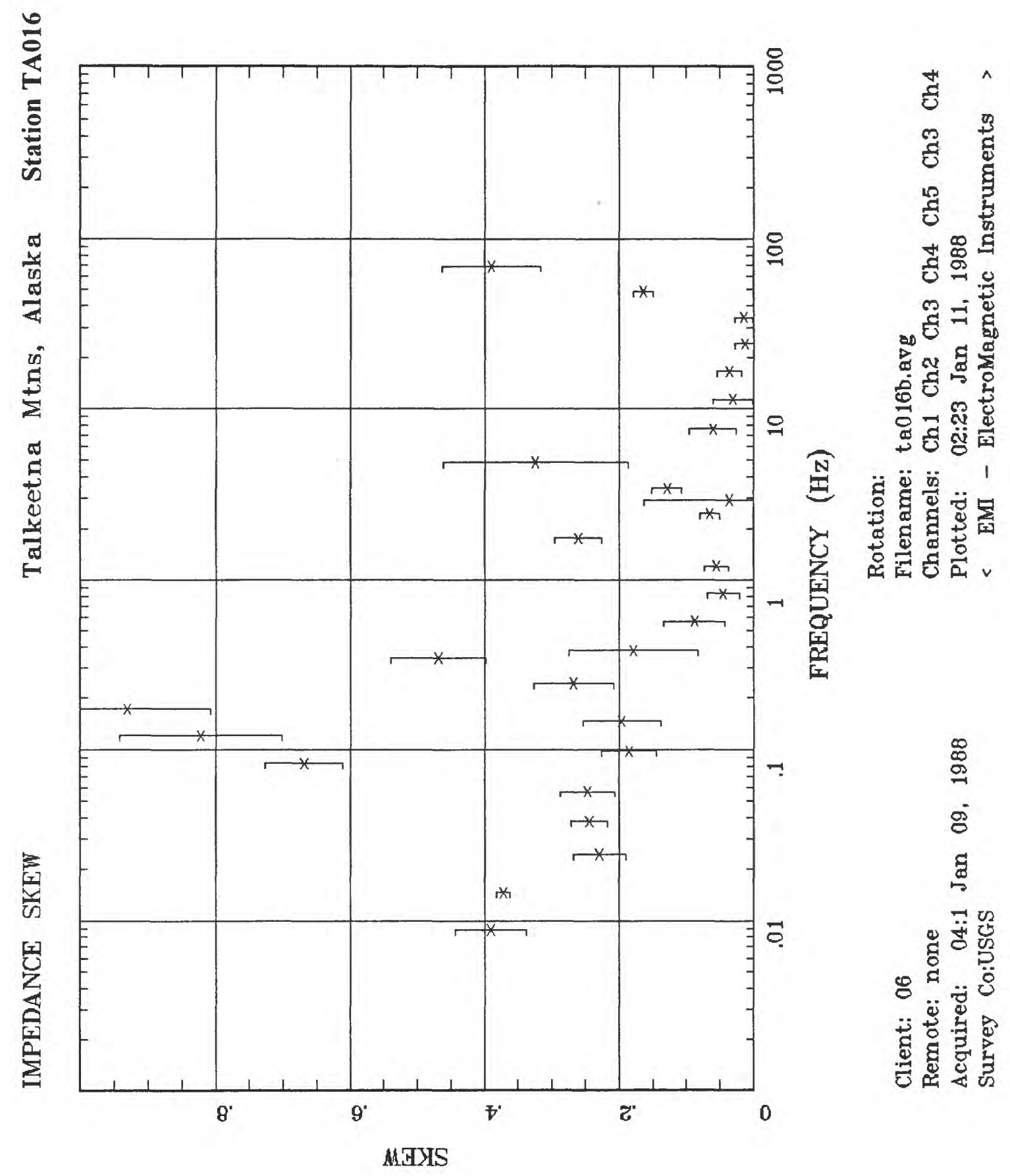




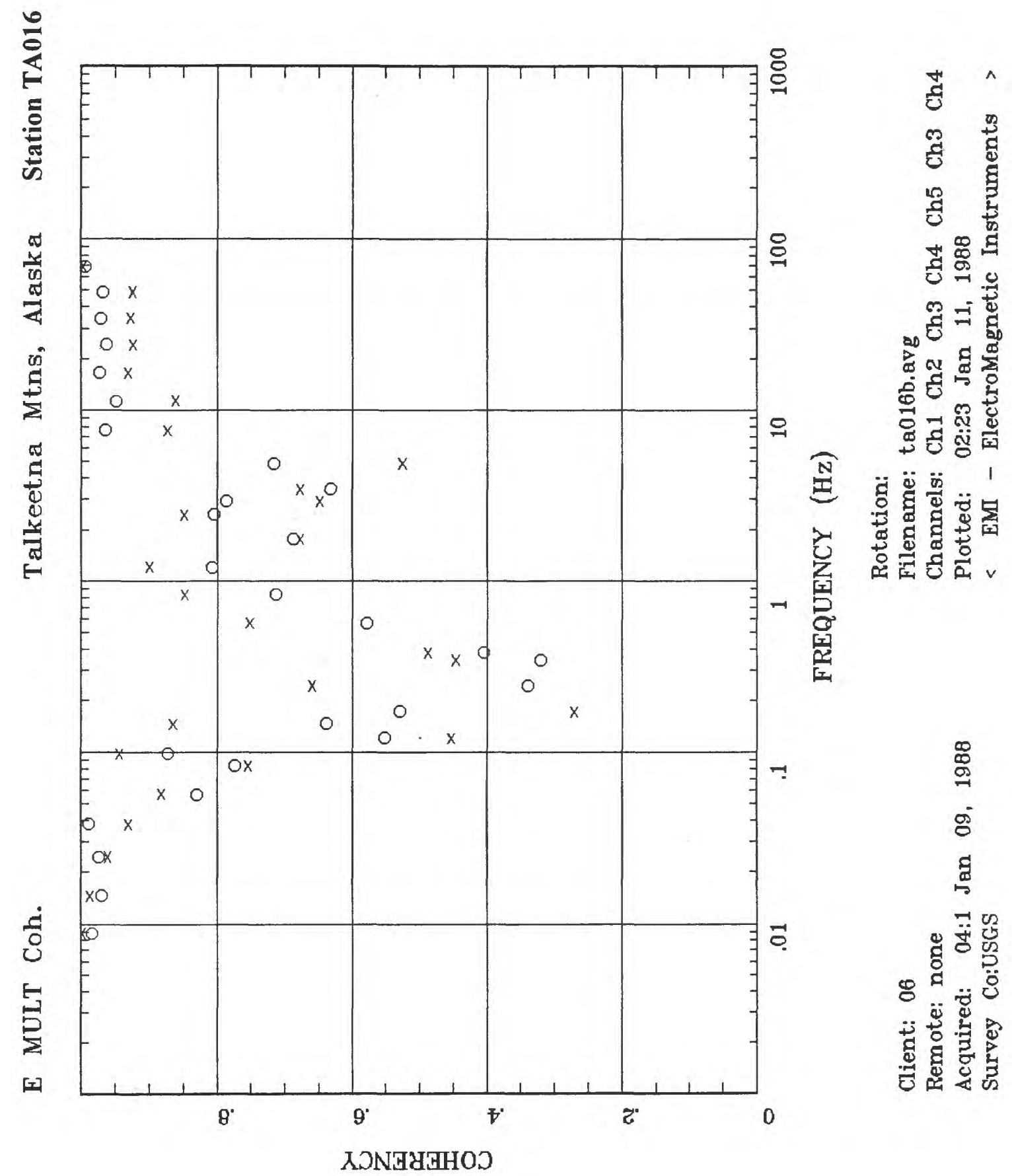




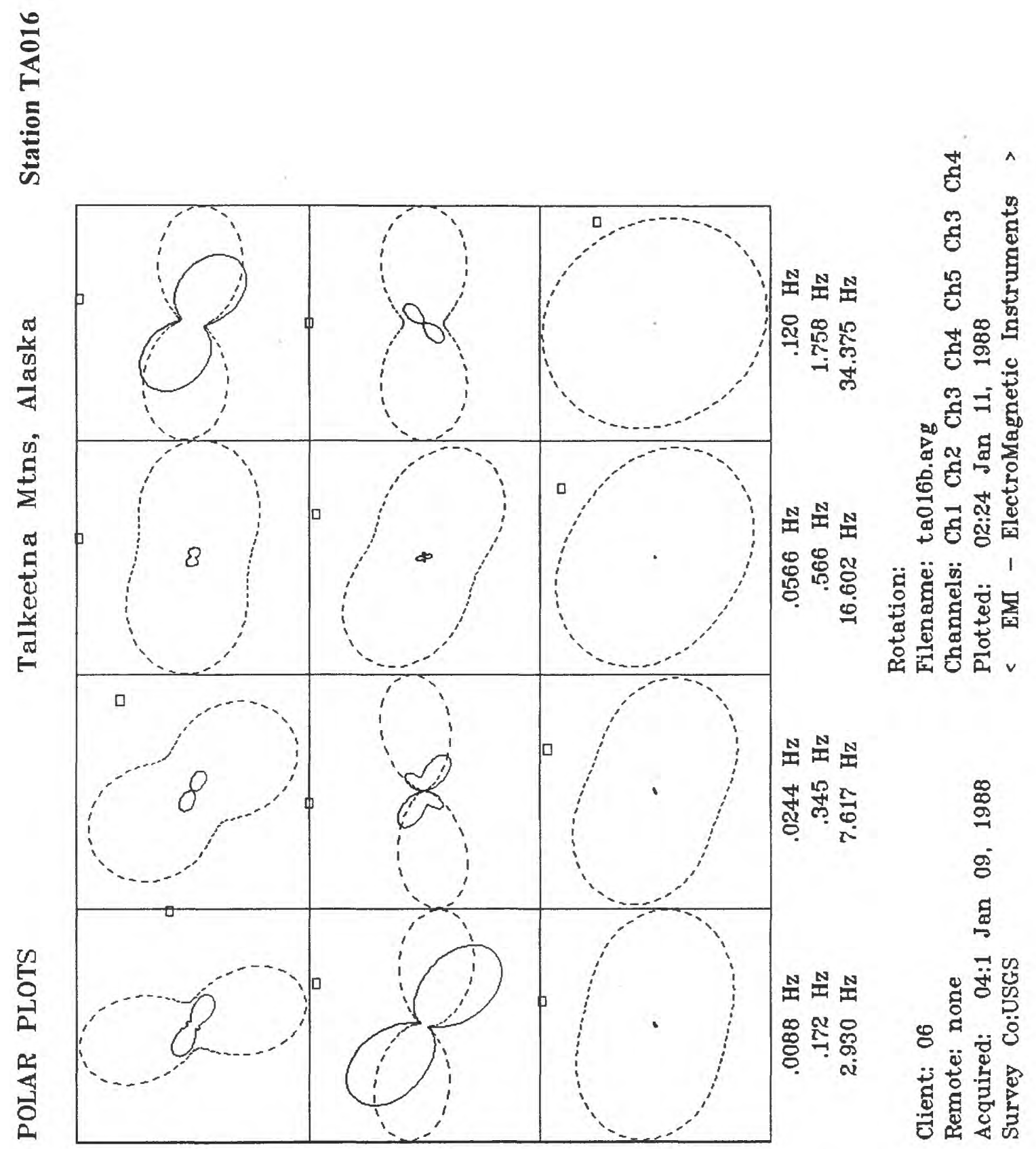




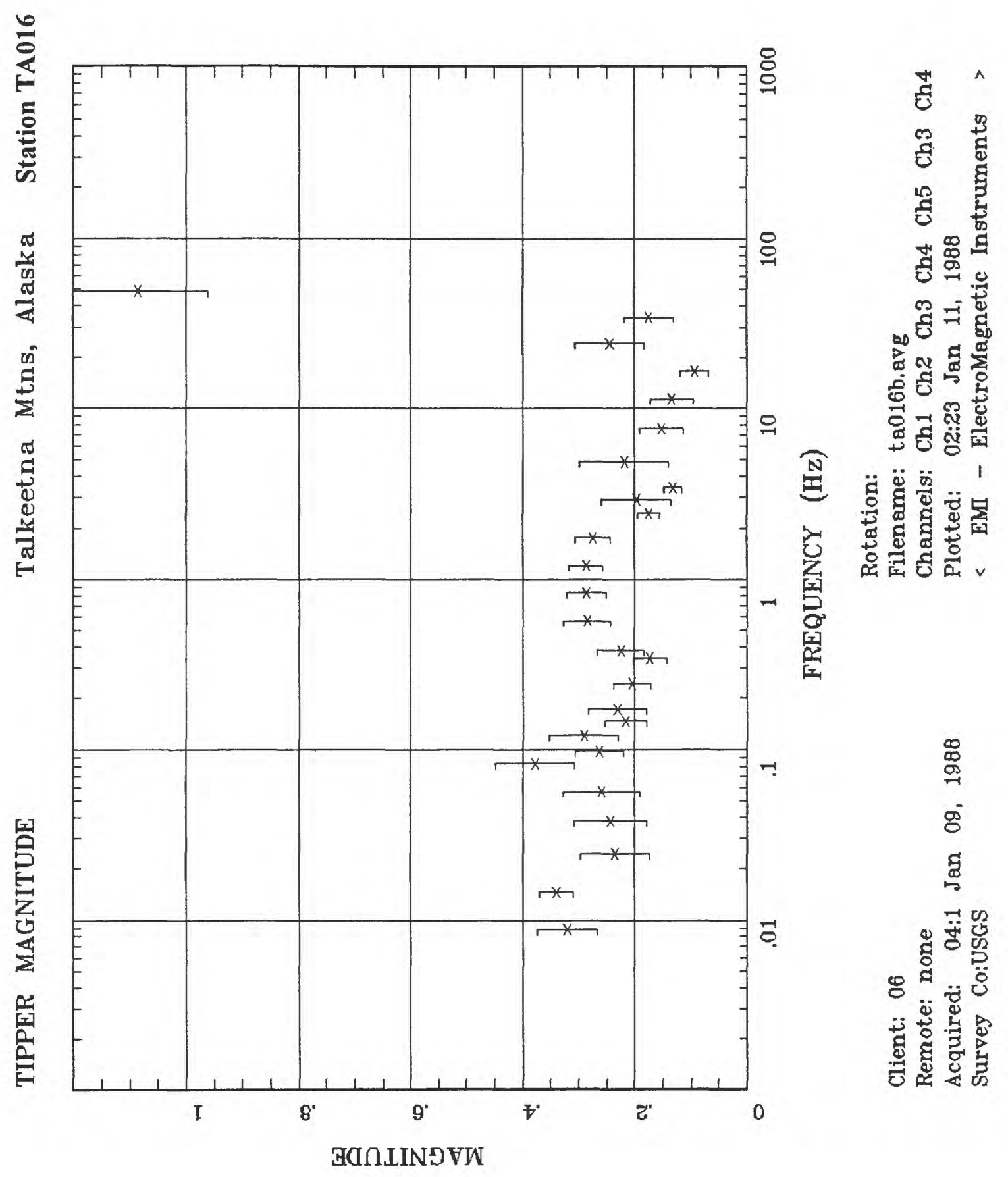




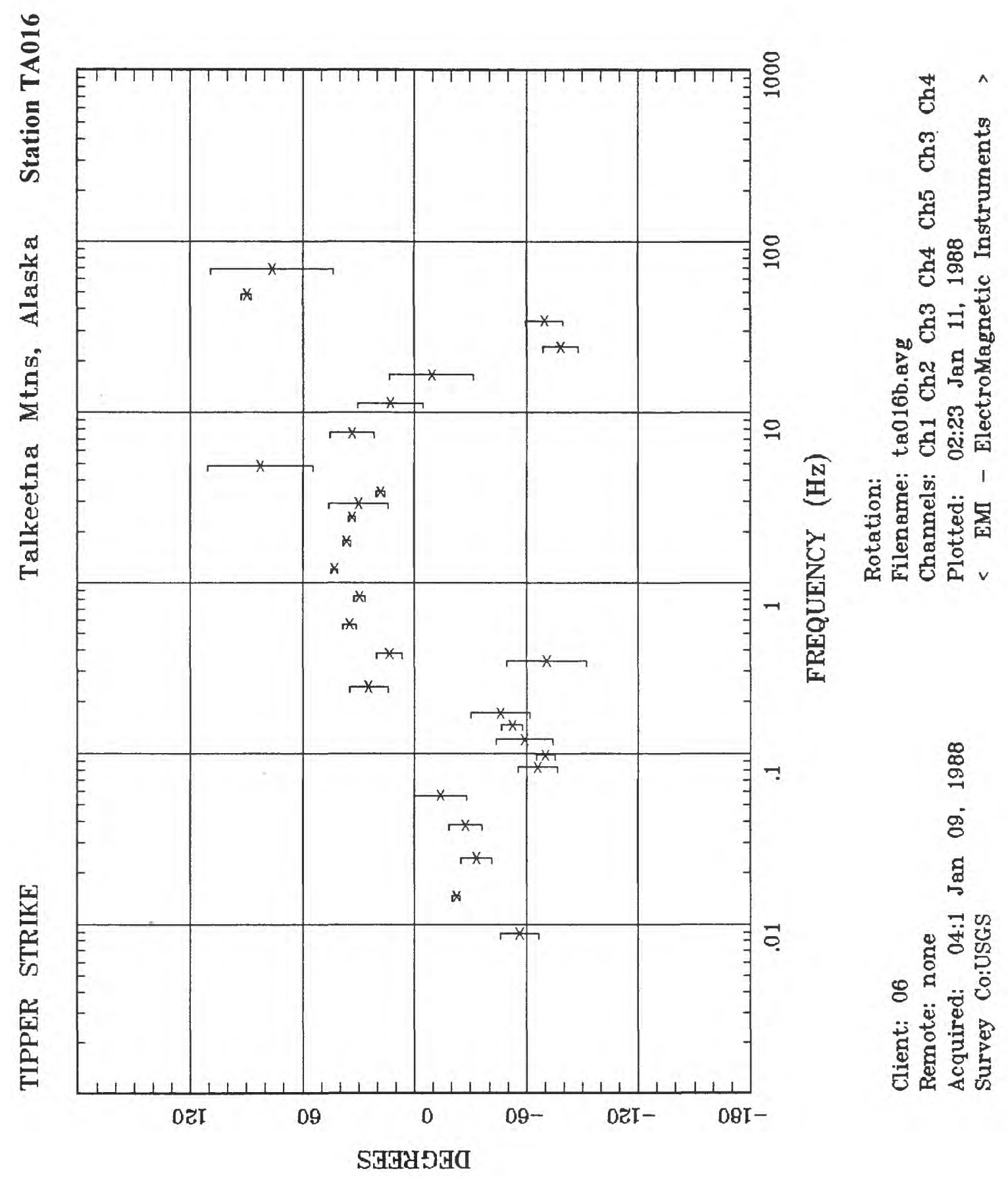




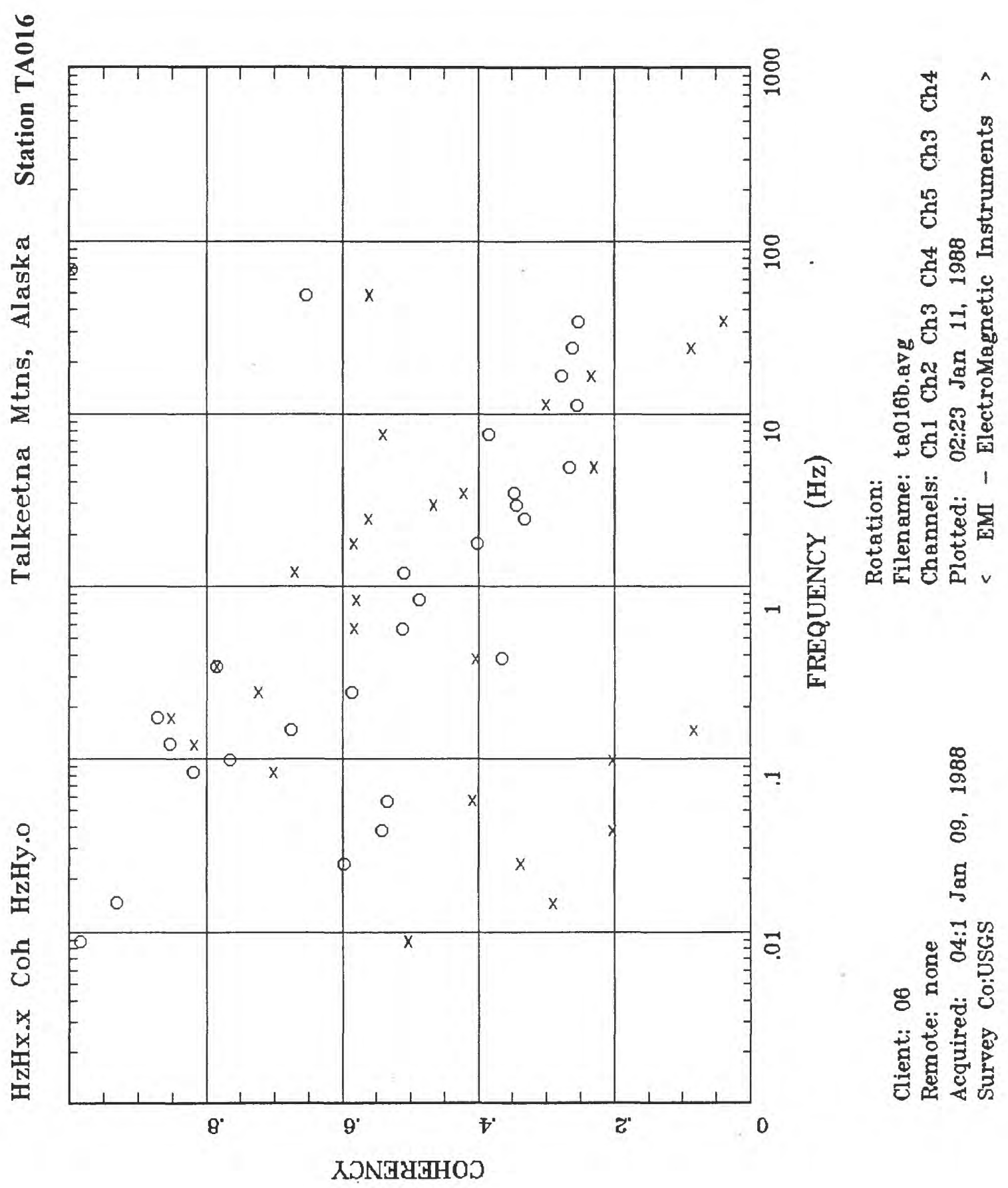




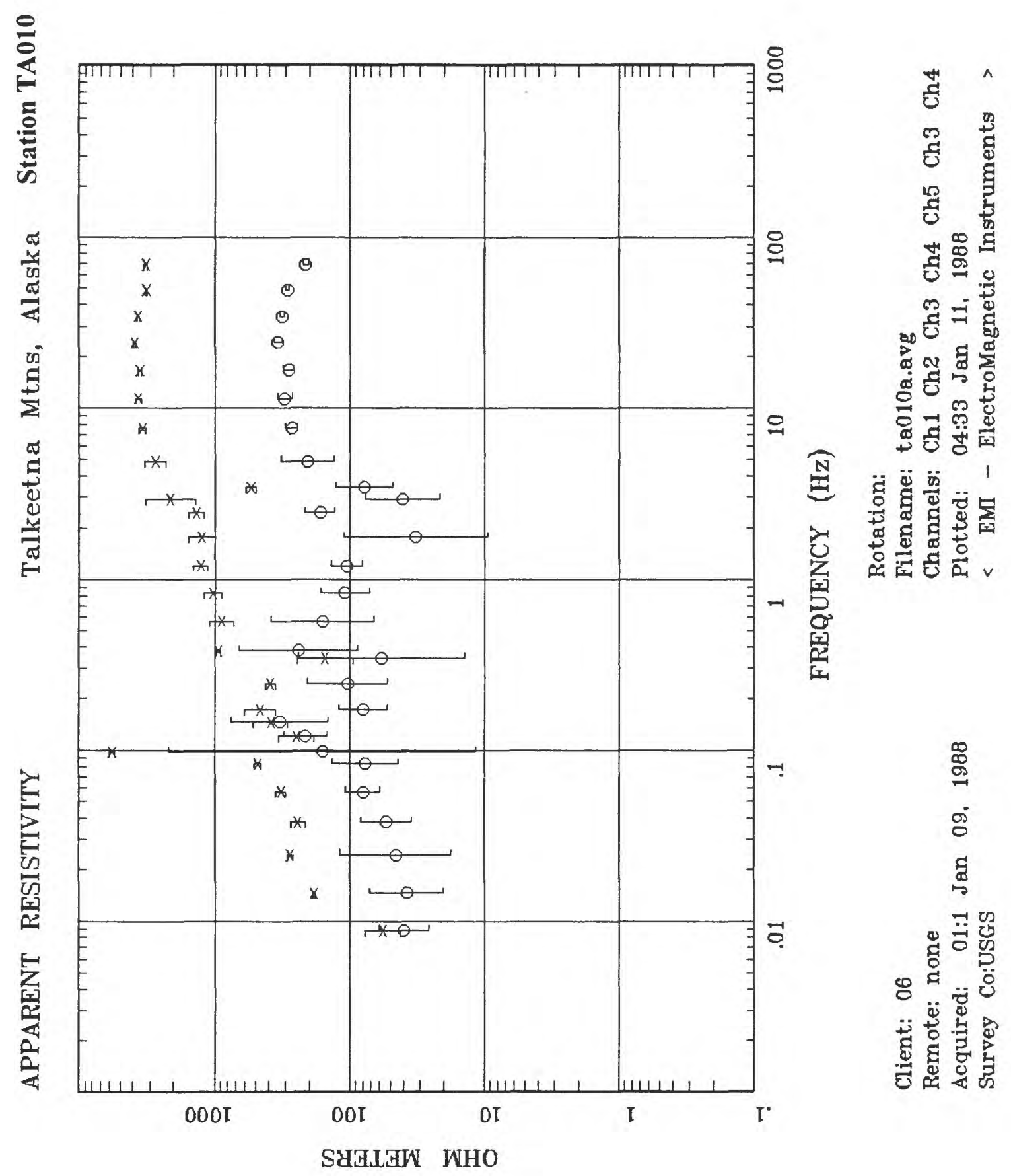




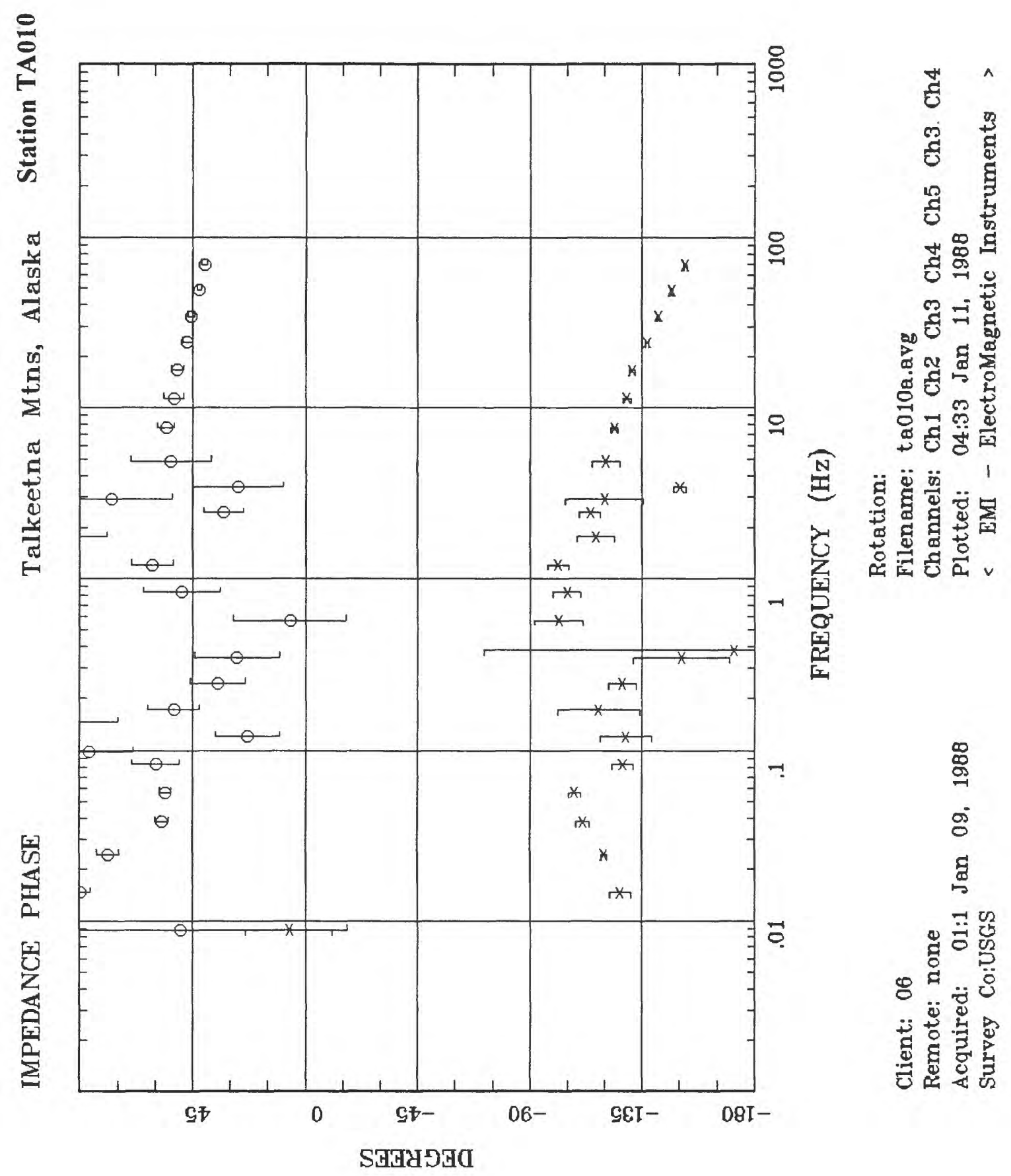




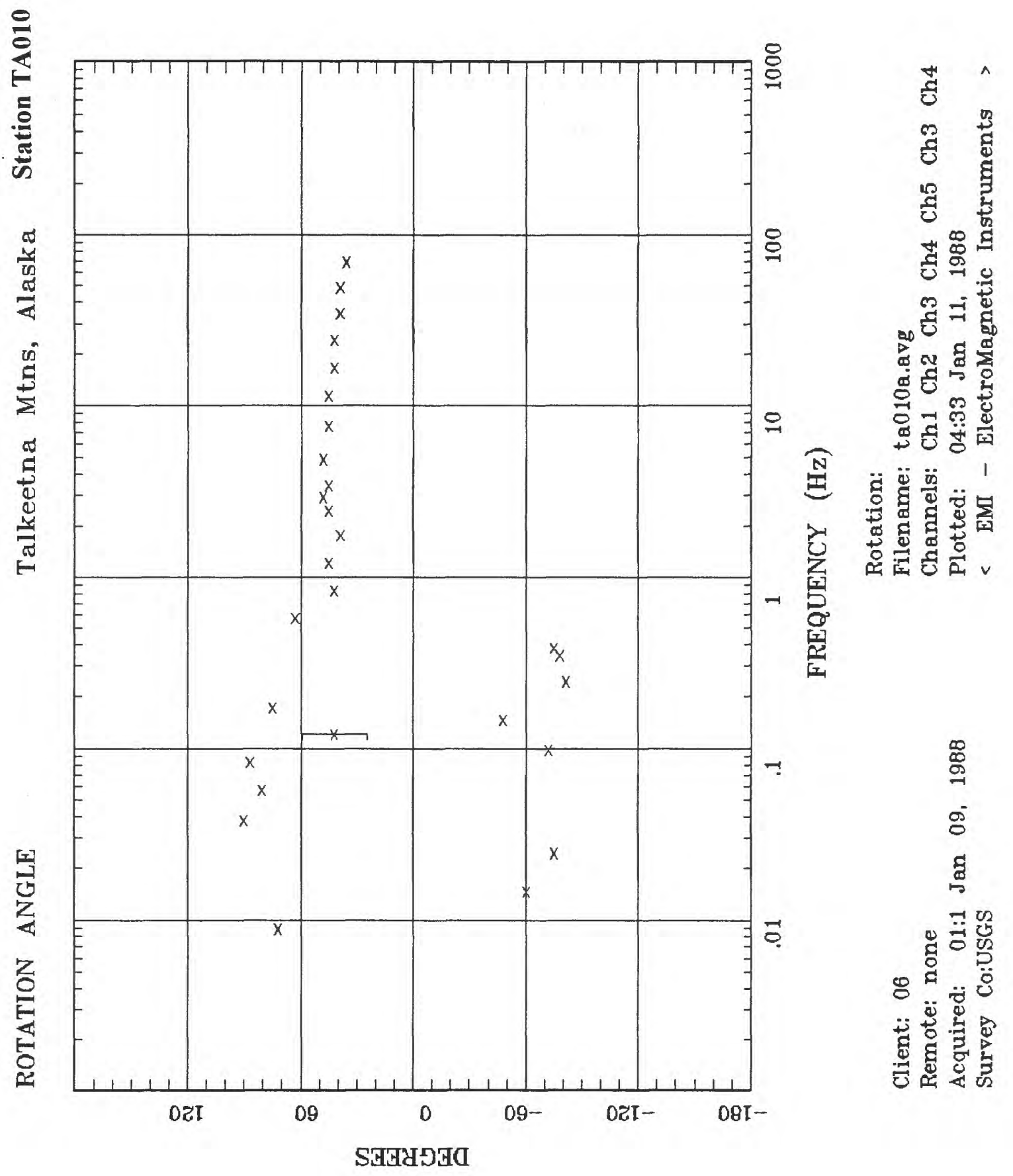




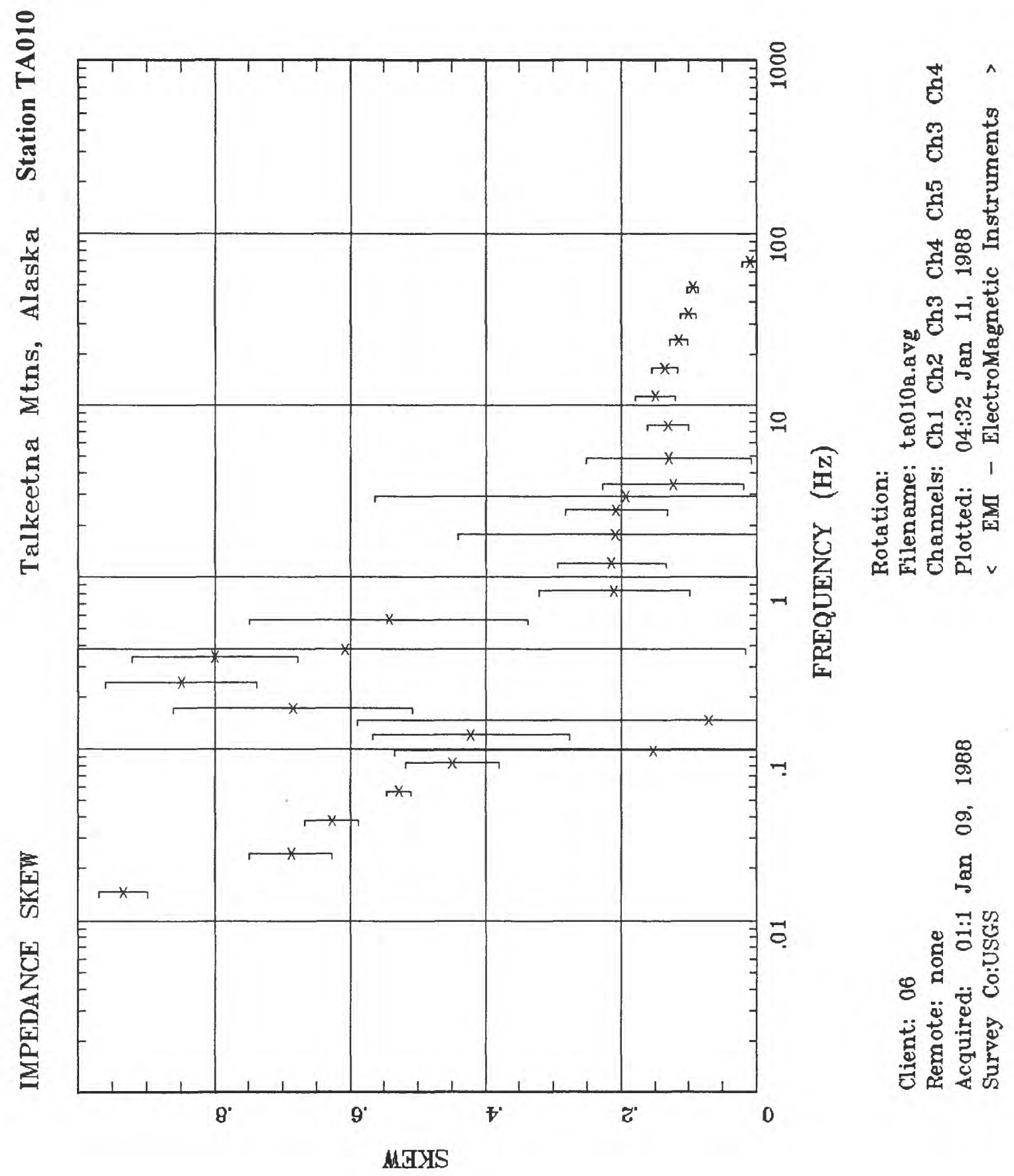




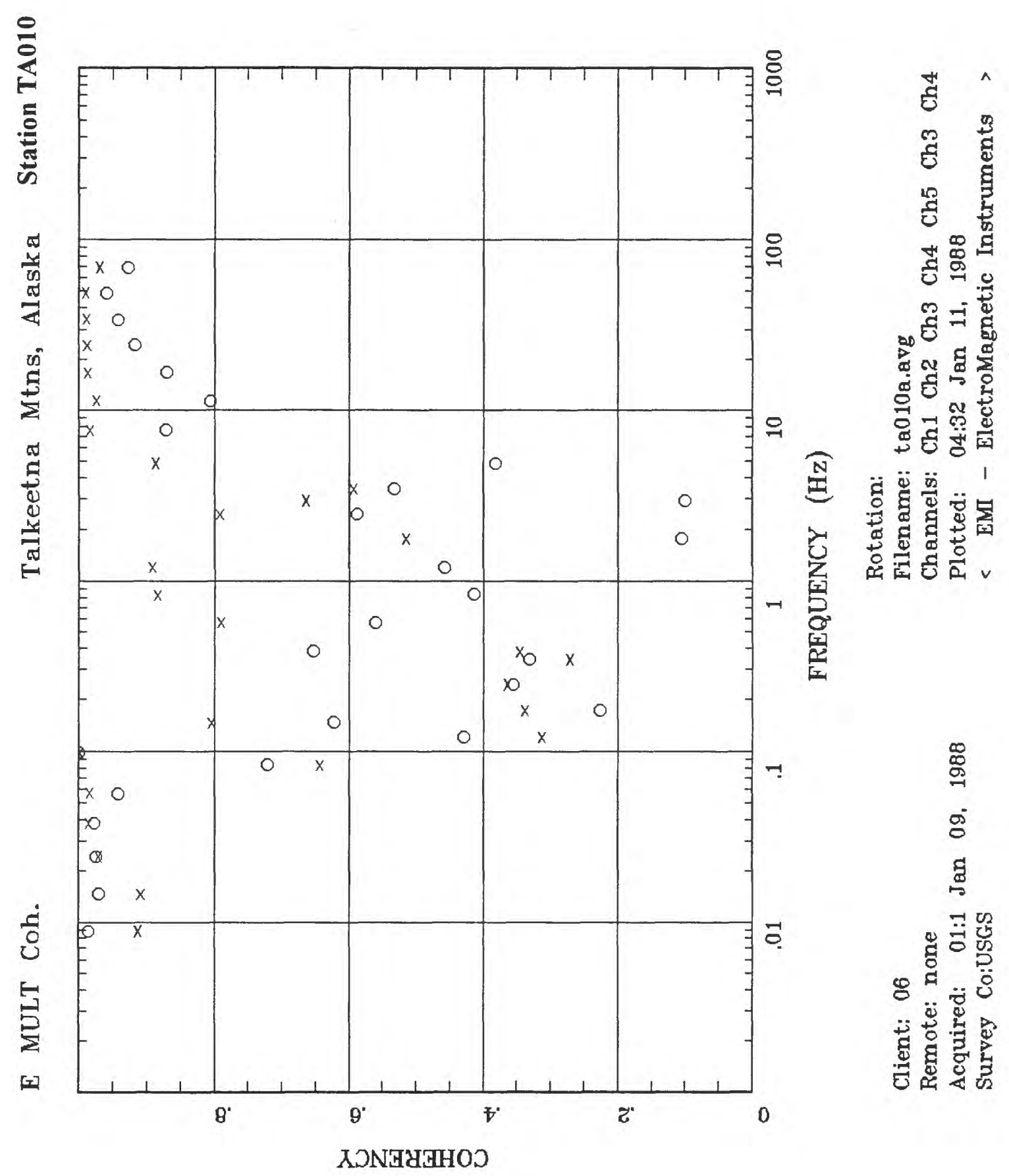


$\frac{2}{6}$

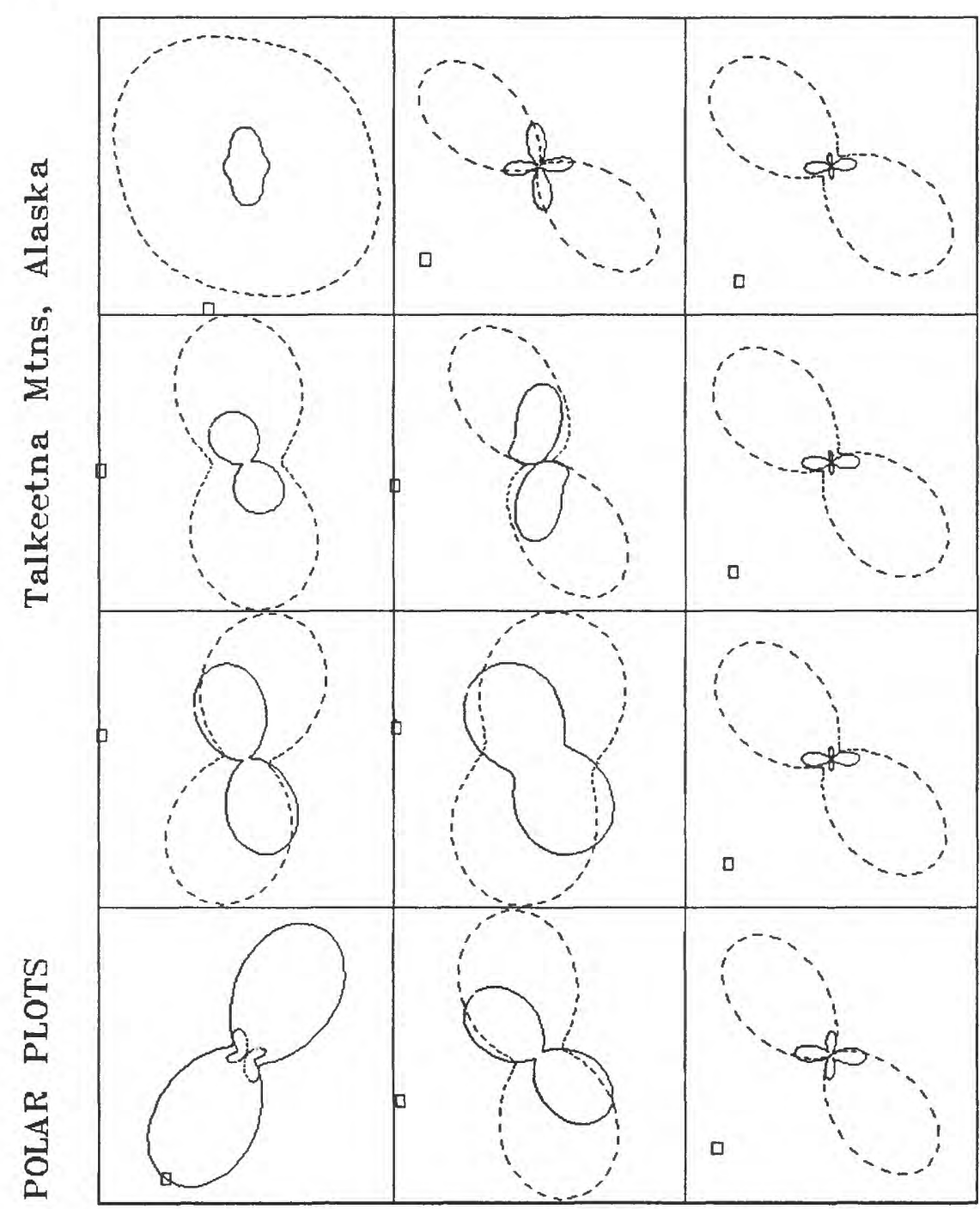

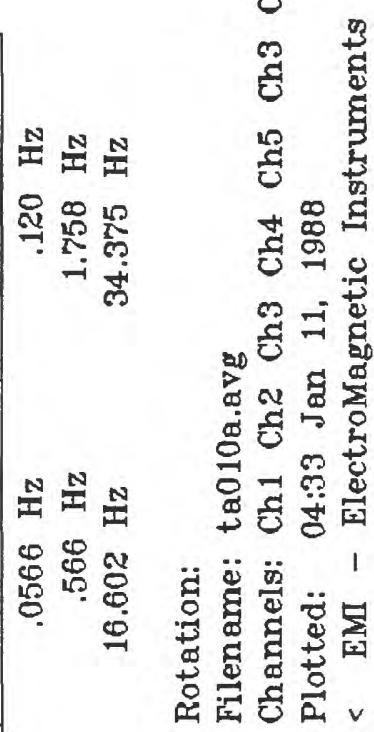

点袁

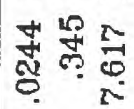

ฌ̊

5

⿷

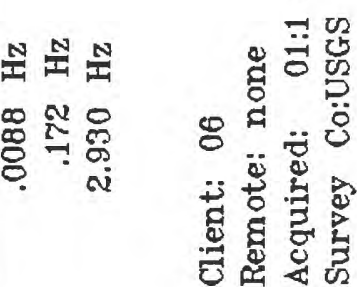




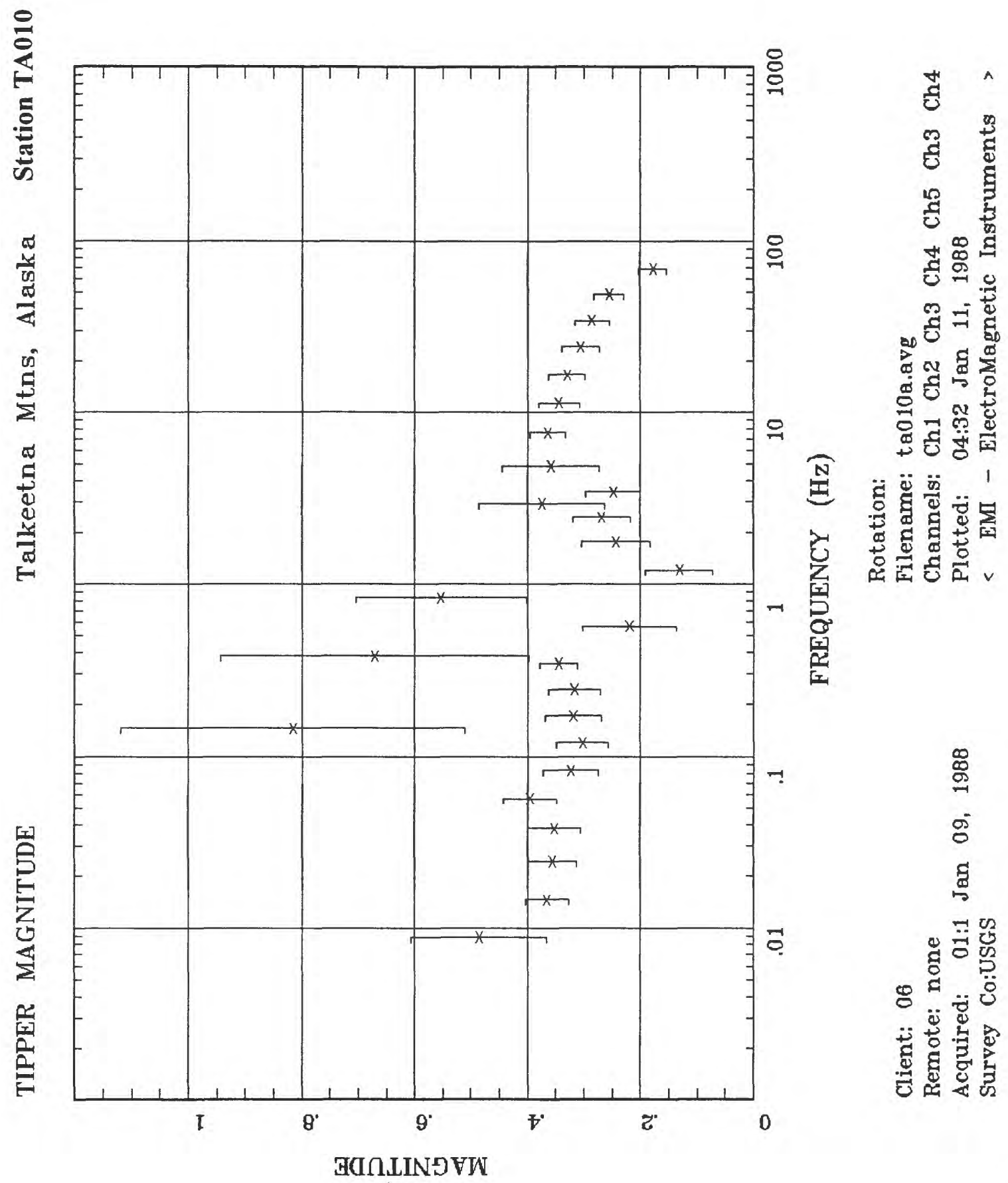




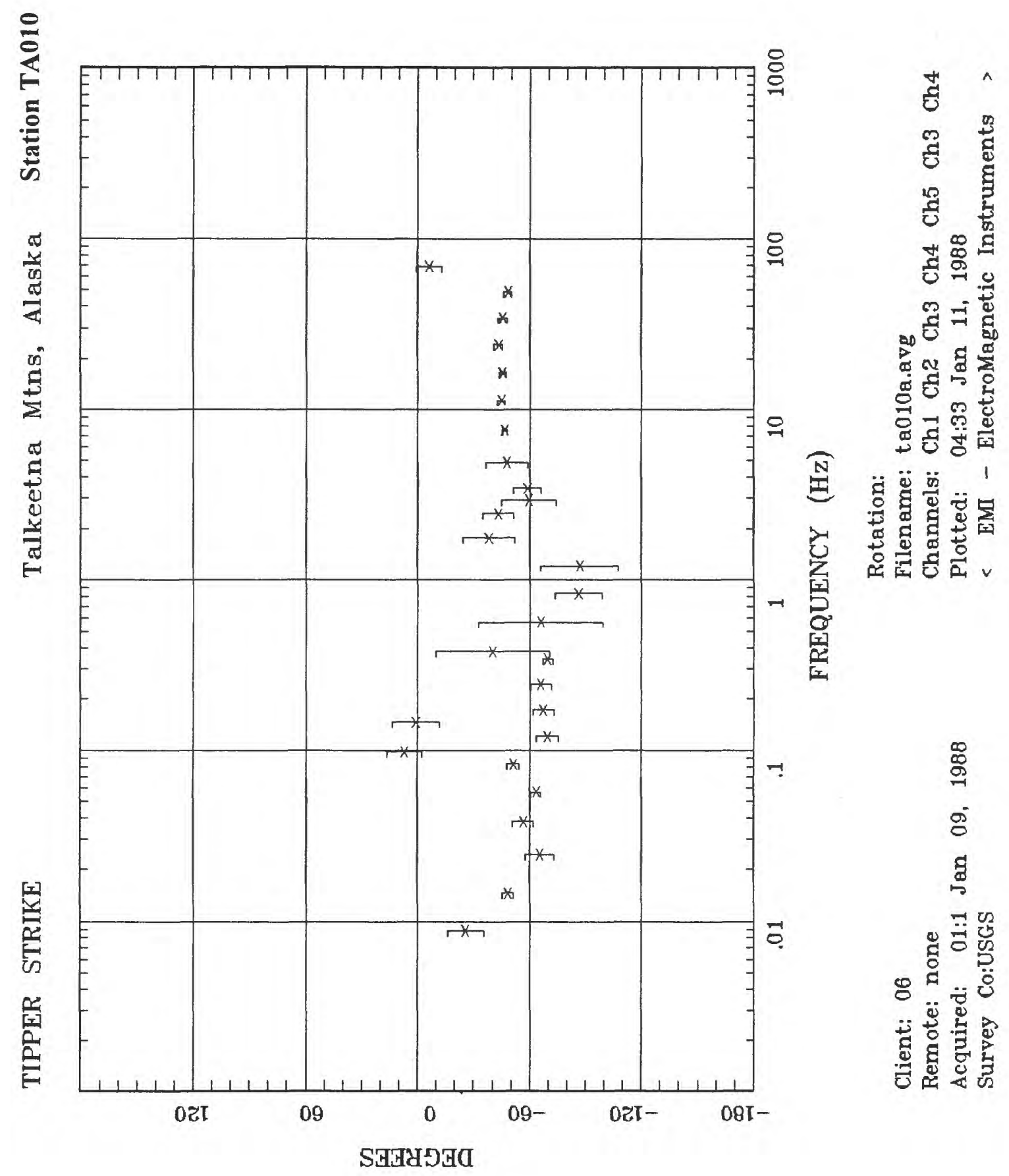




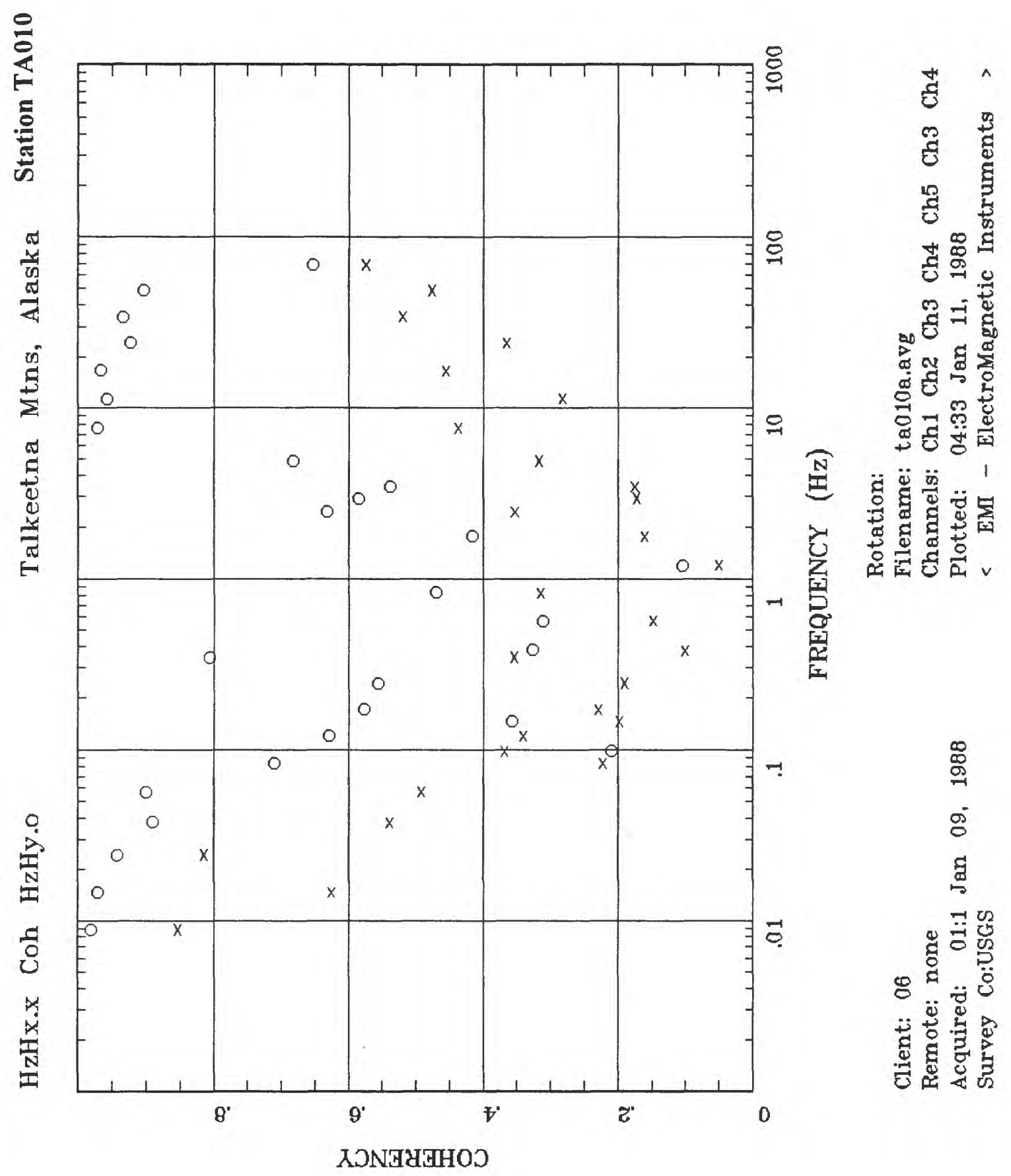




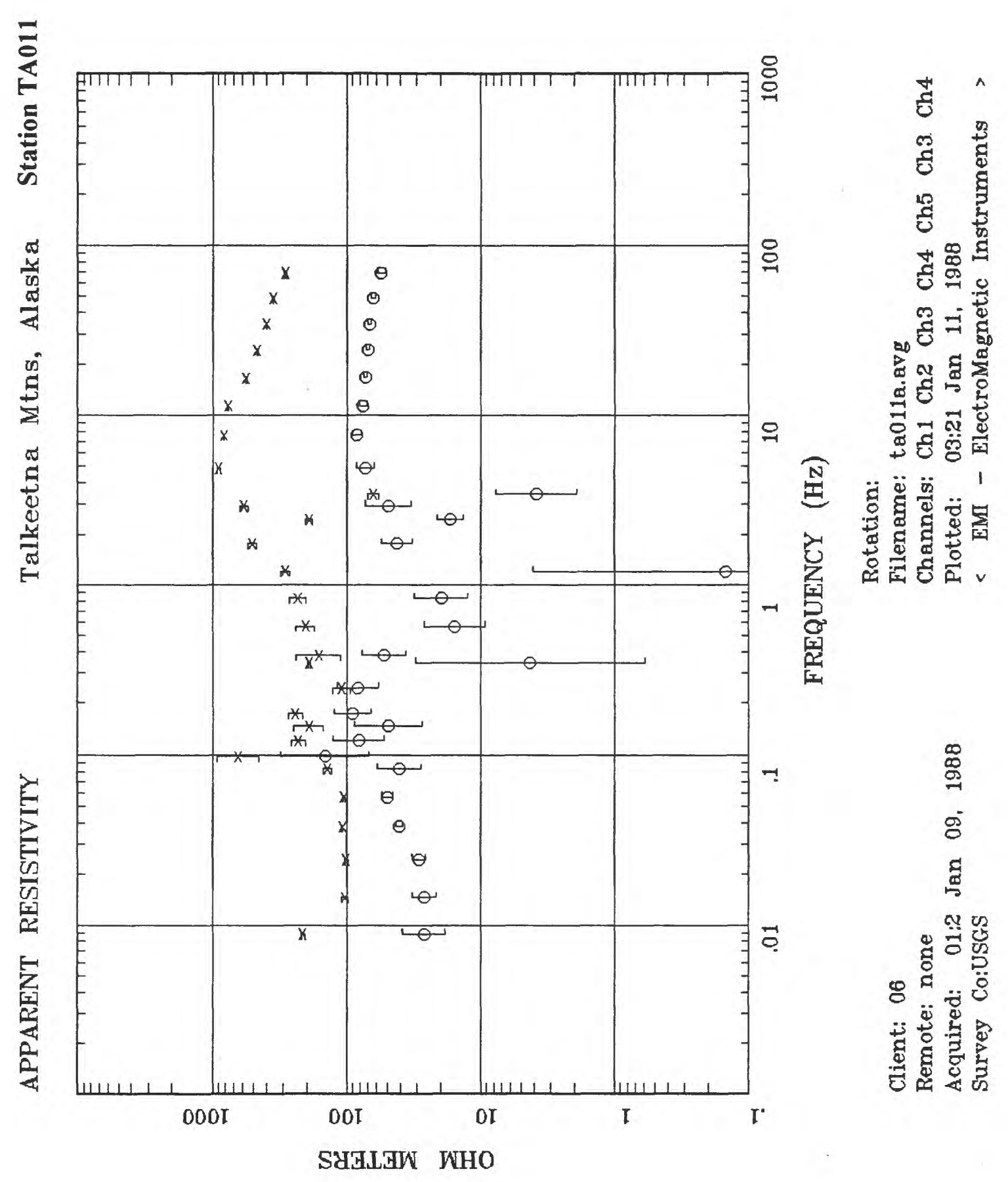




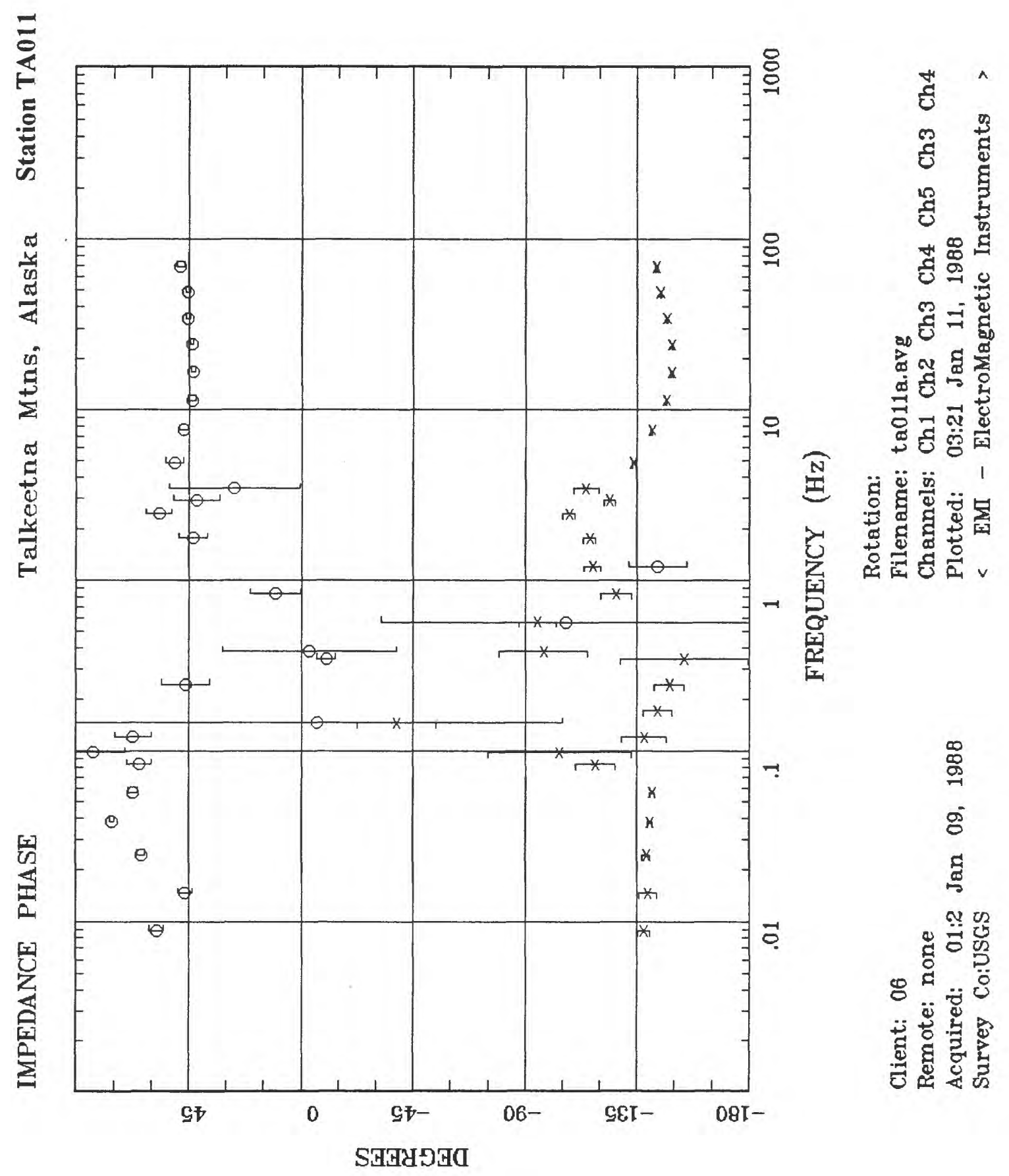




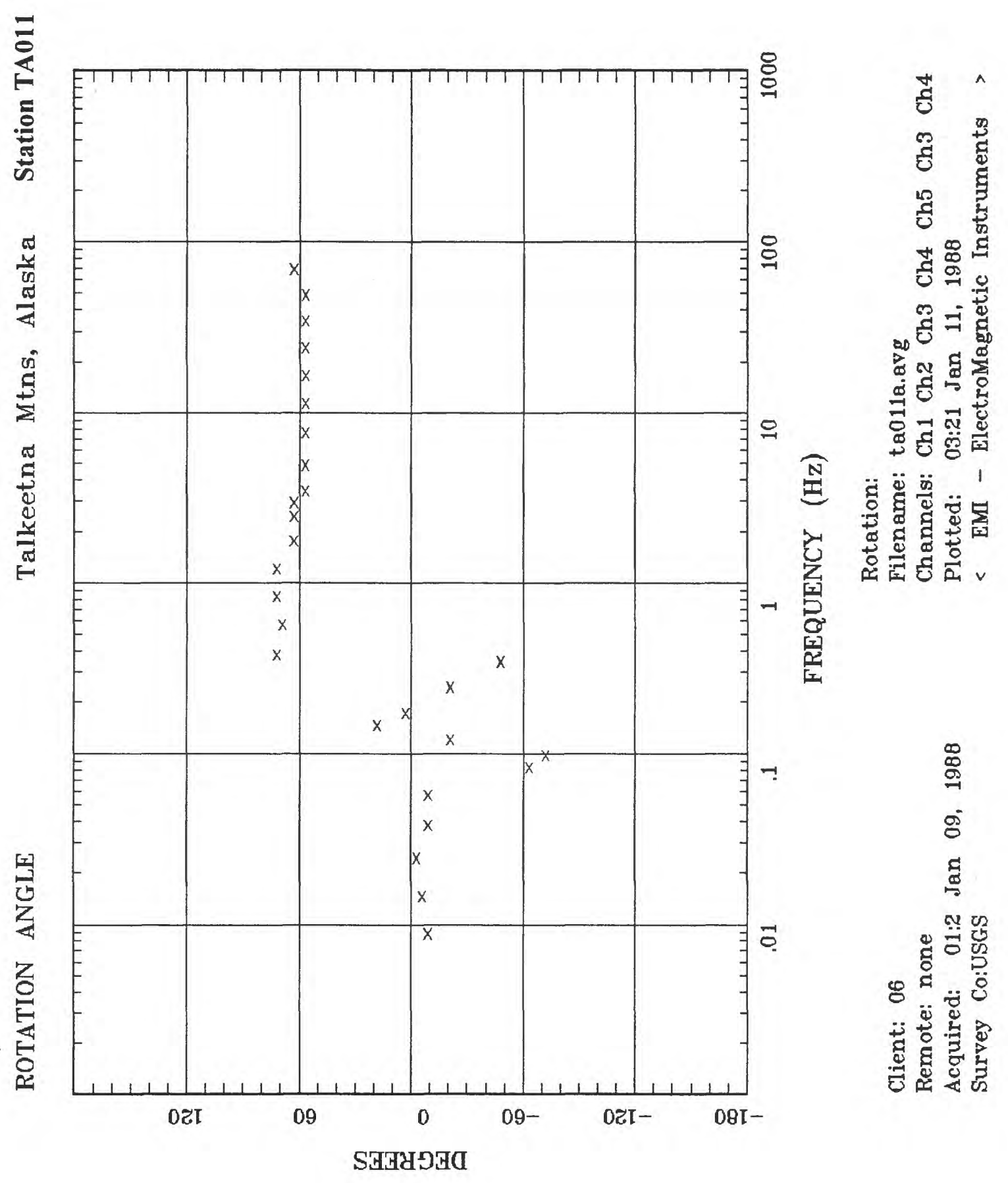




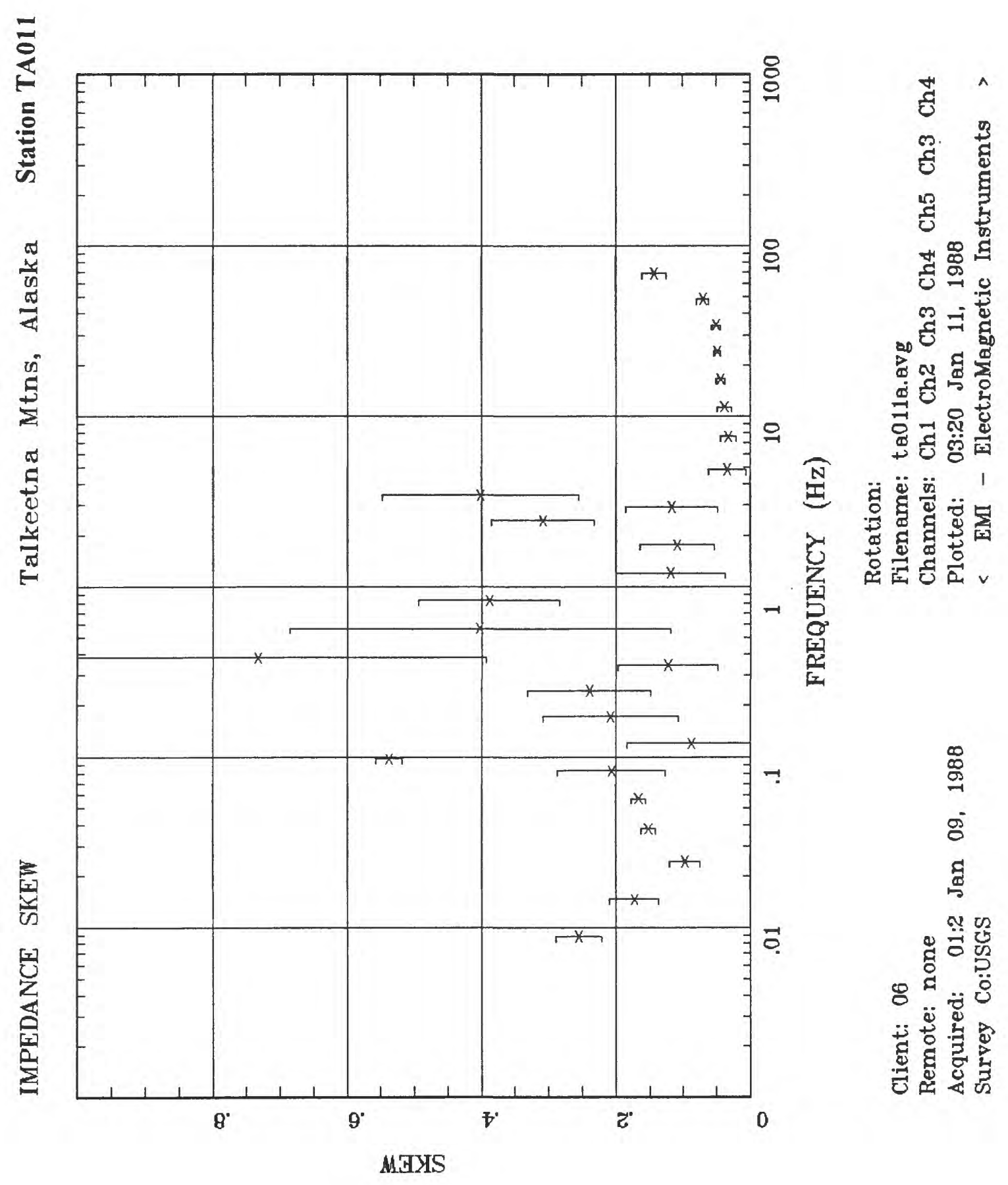




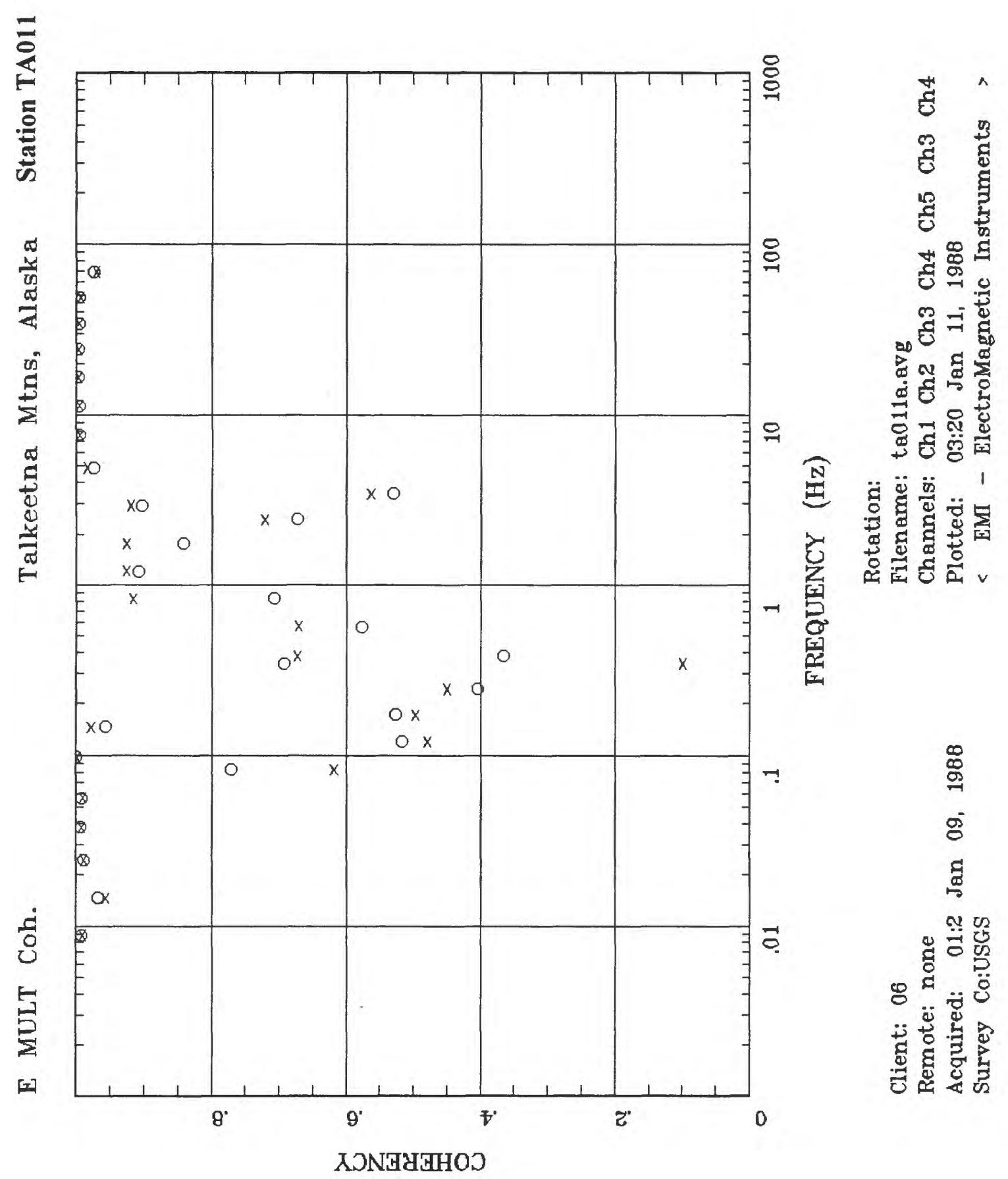




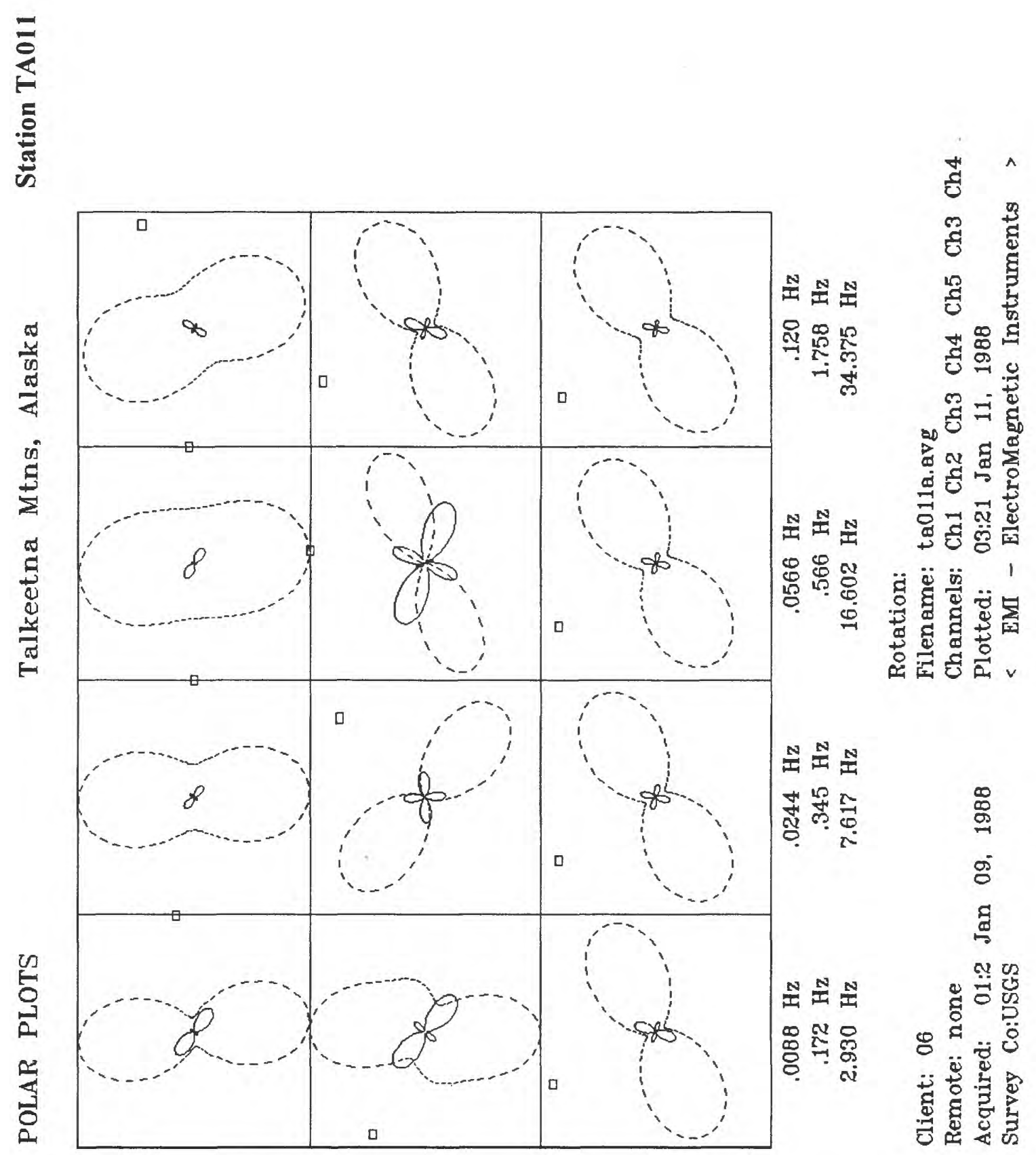




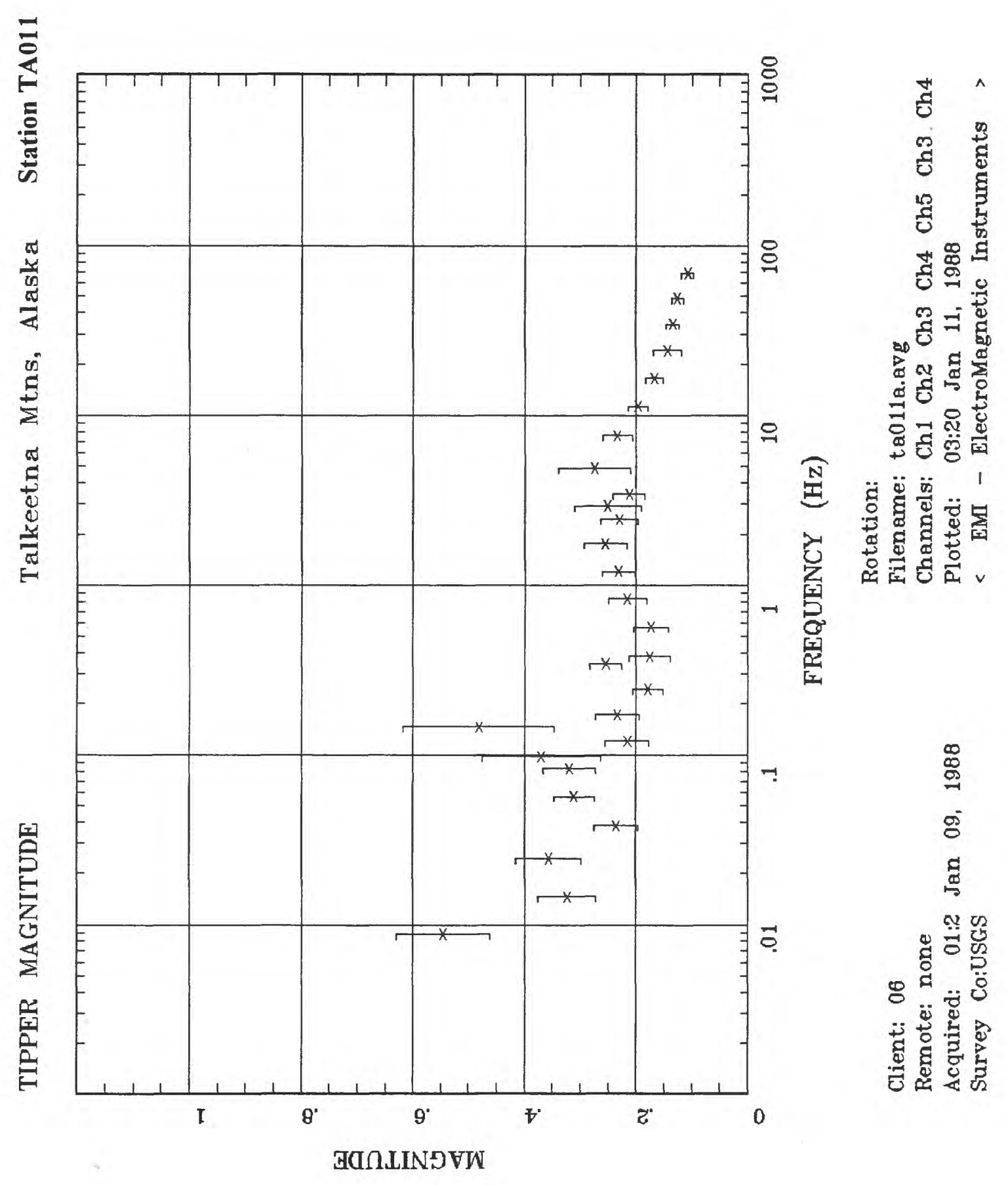




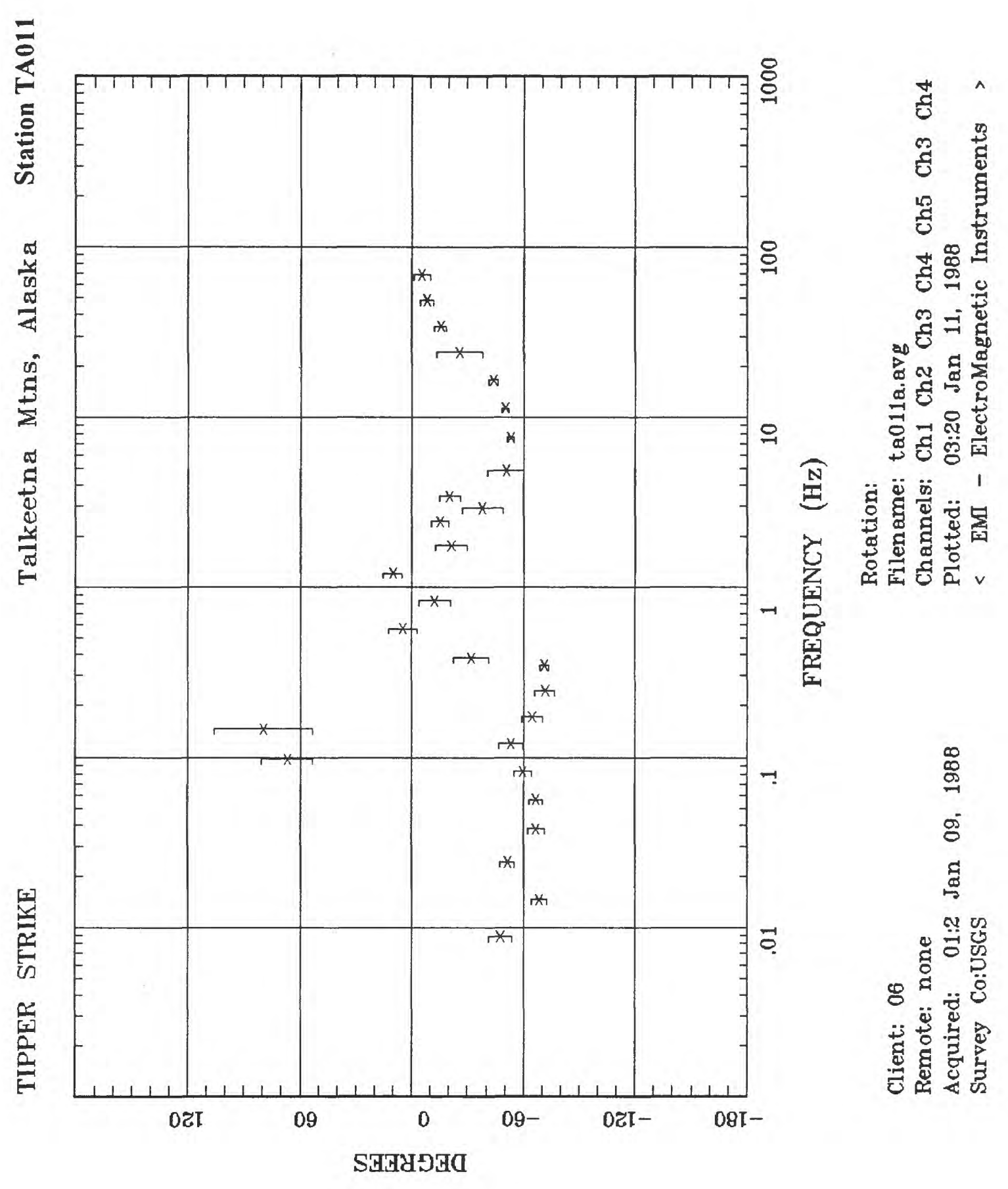




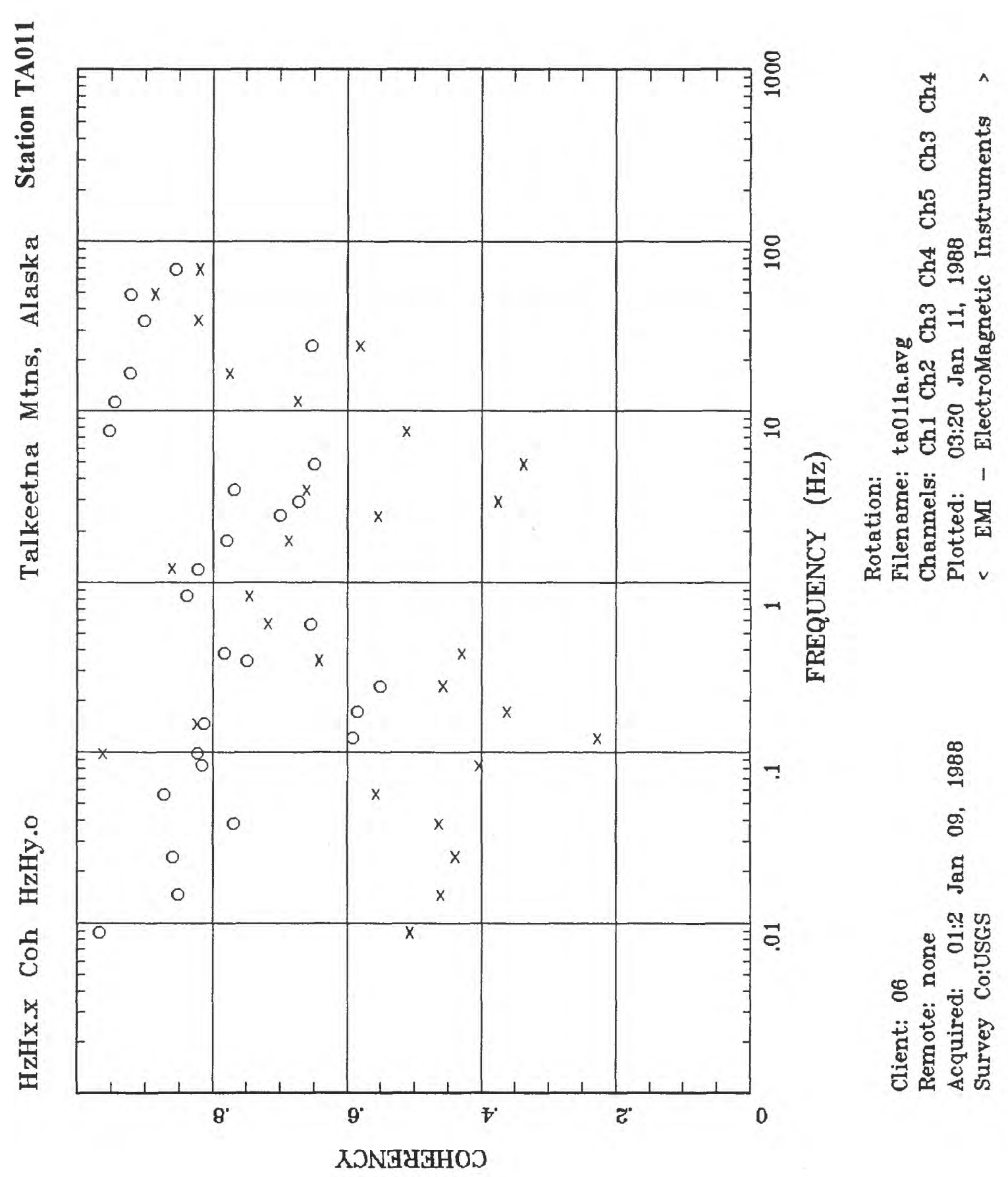




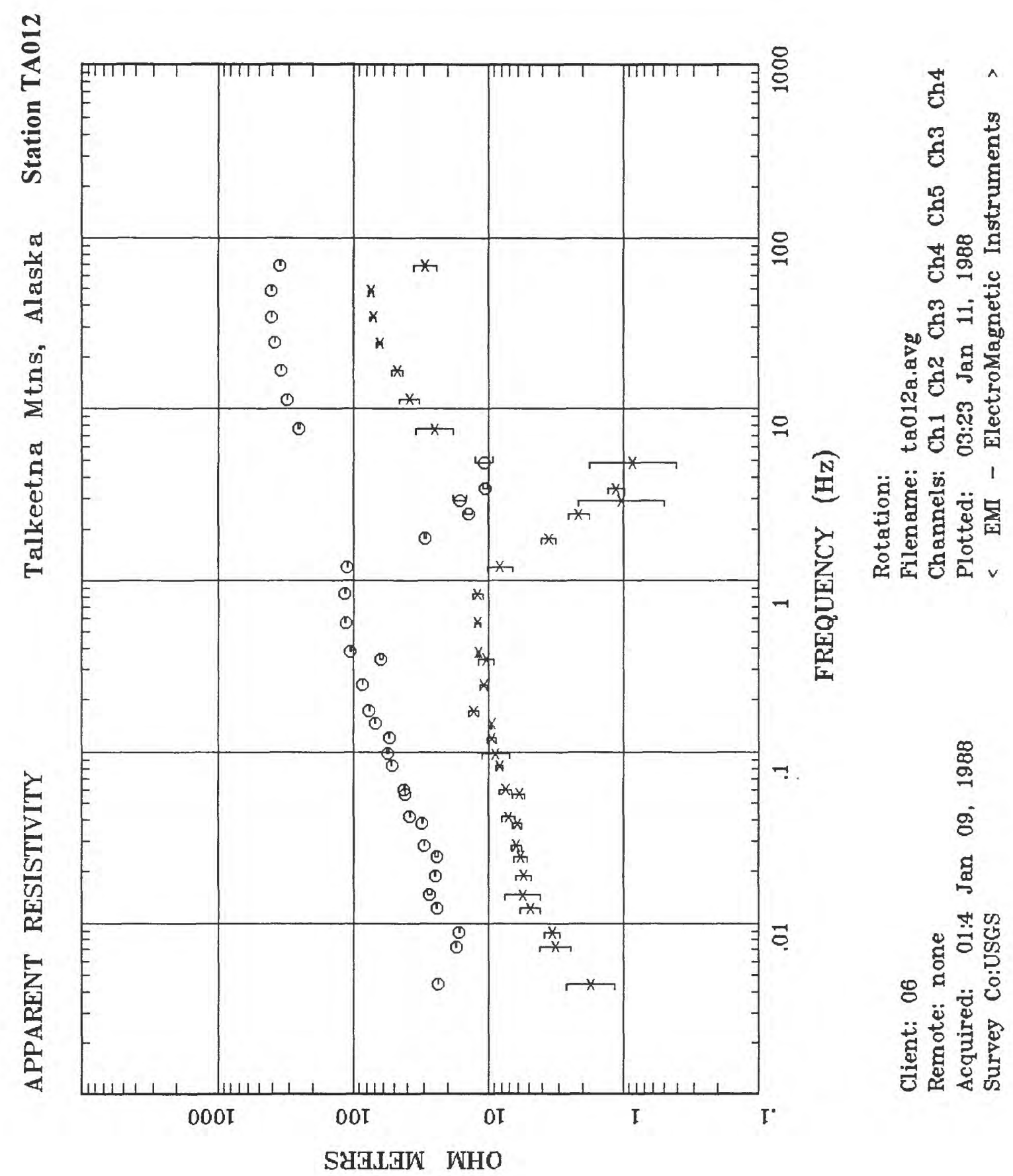




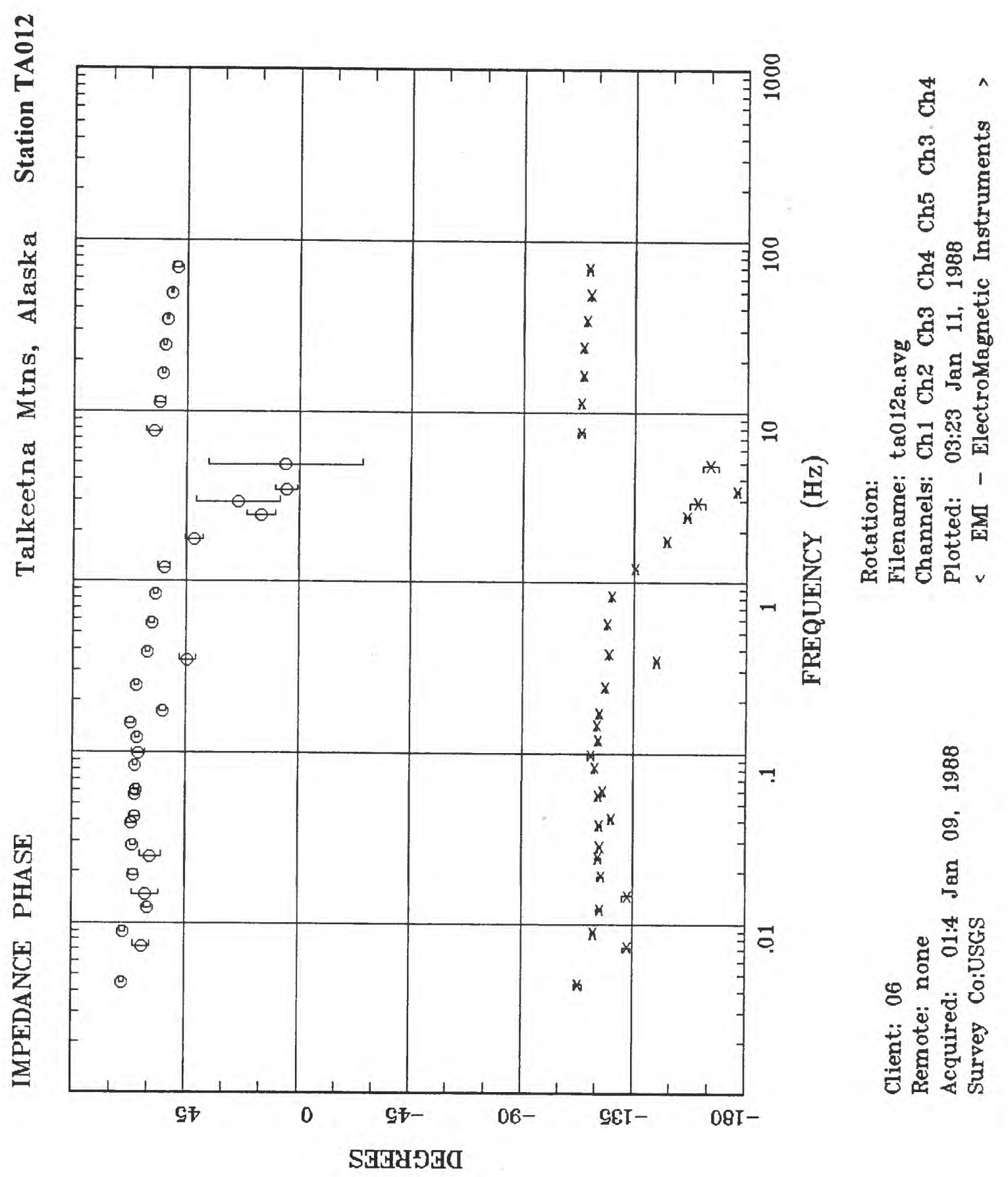




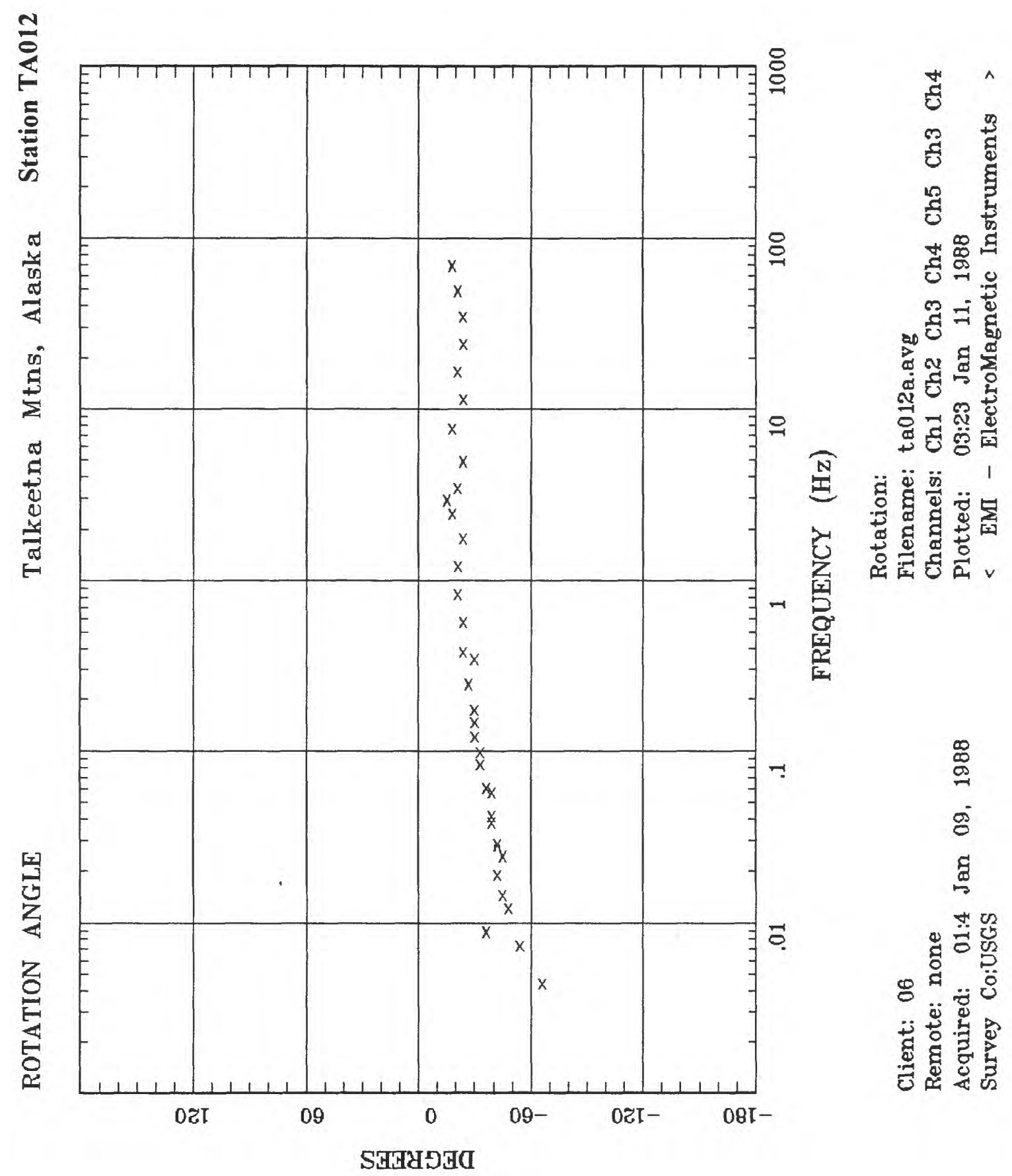




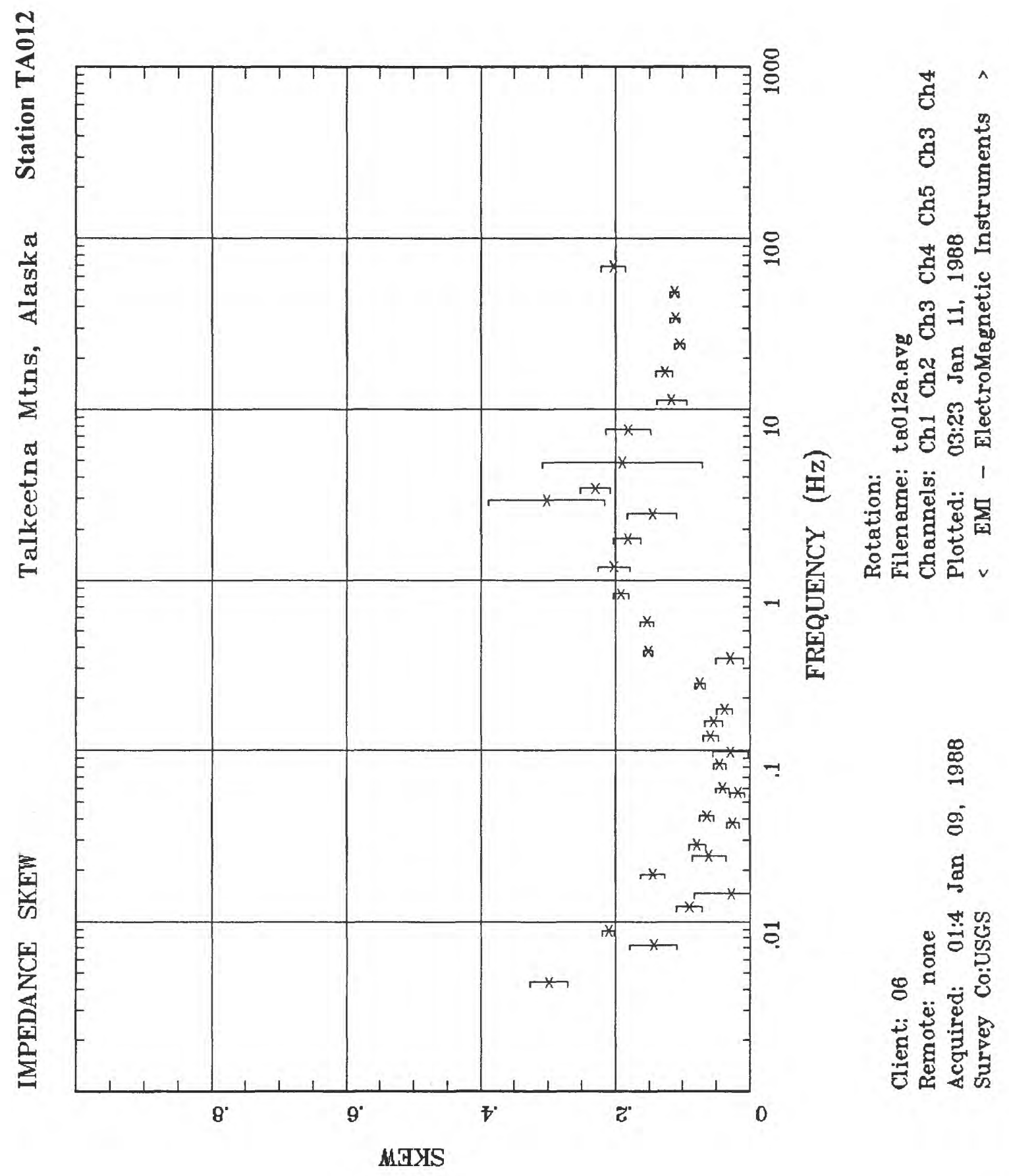




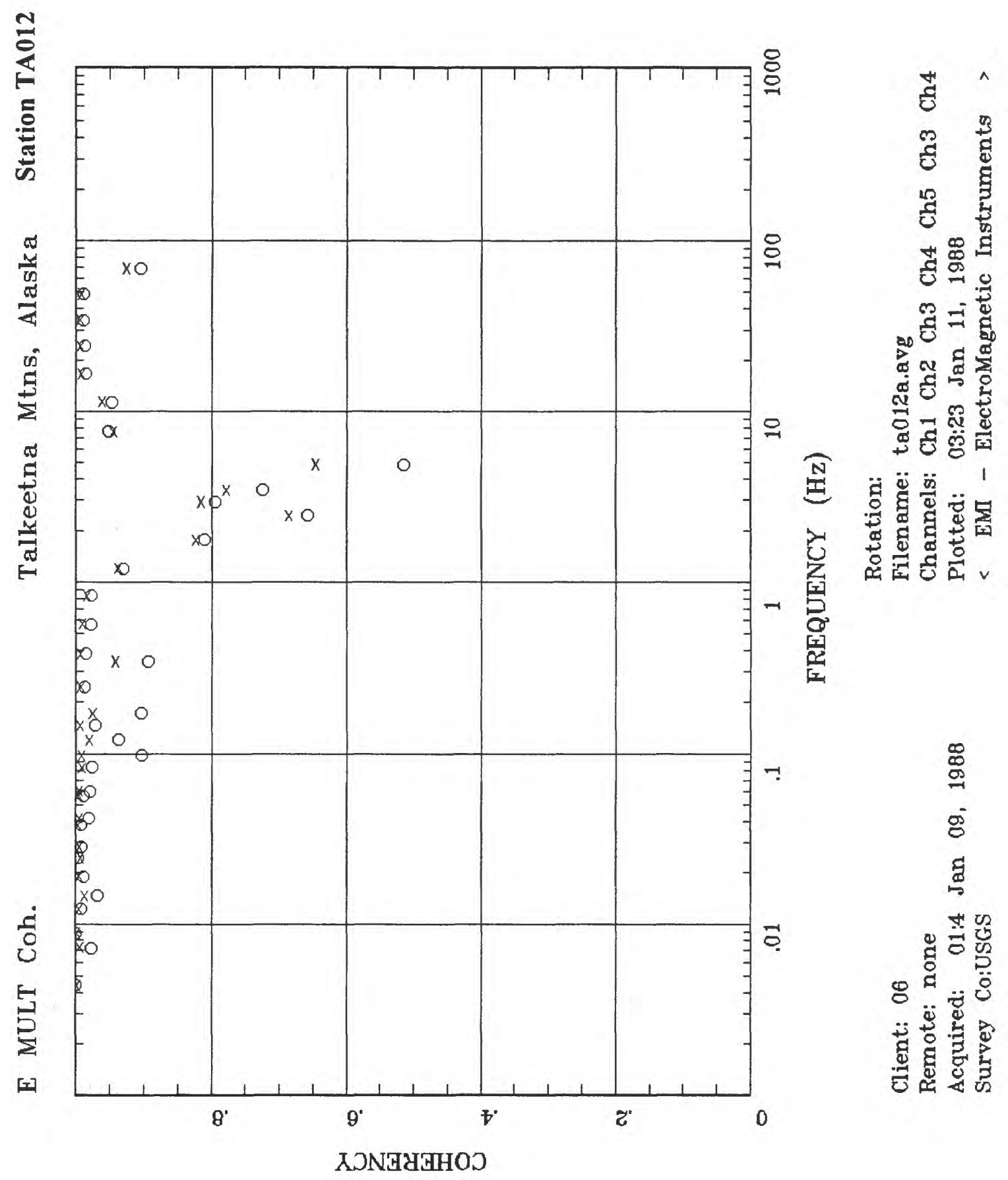




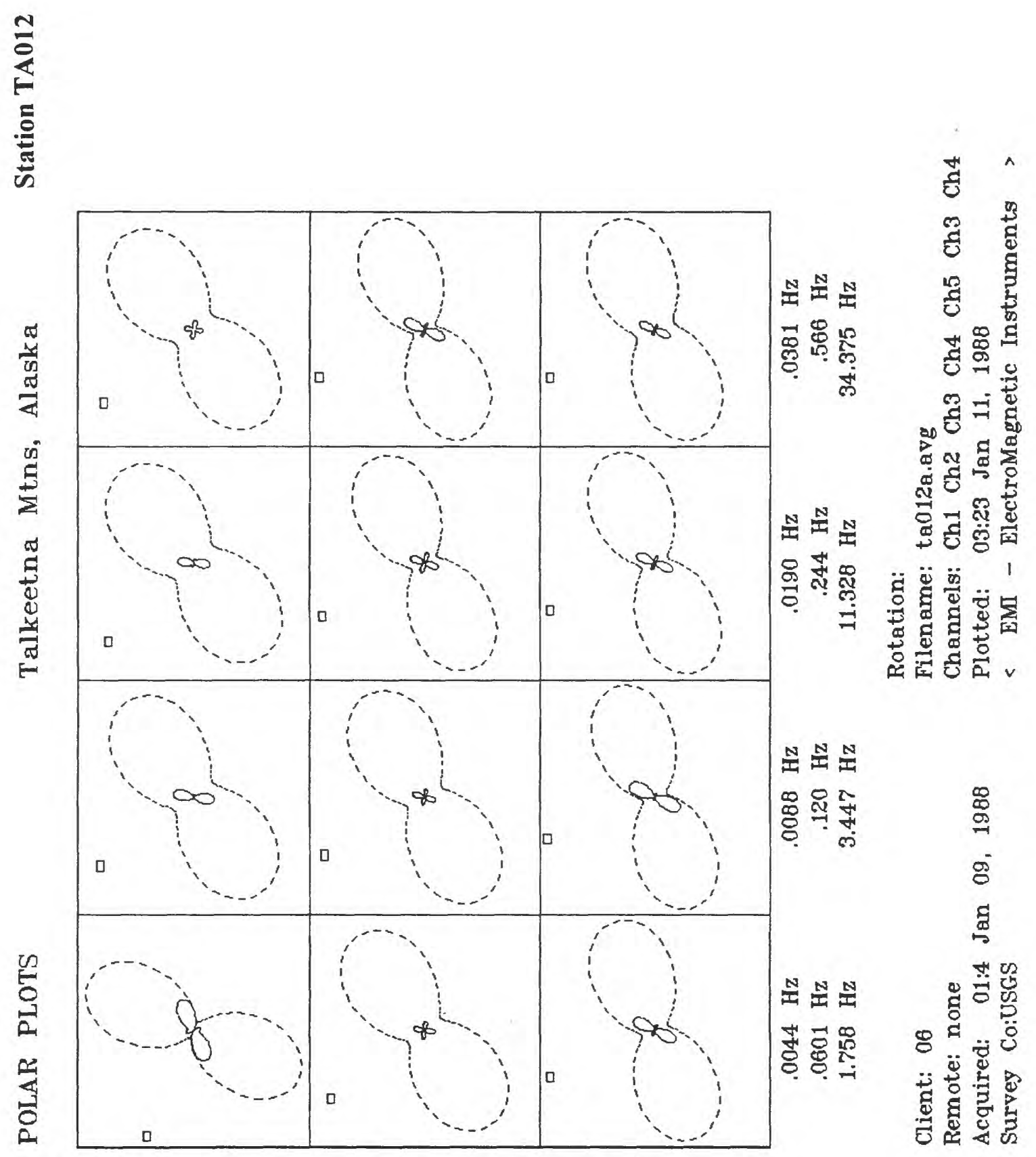




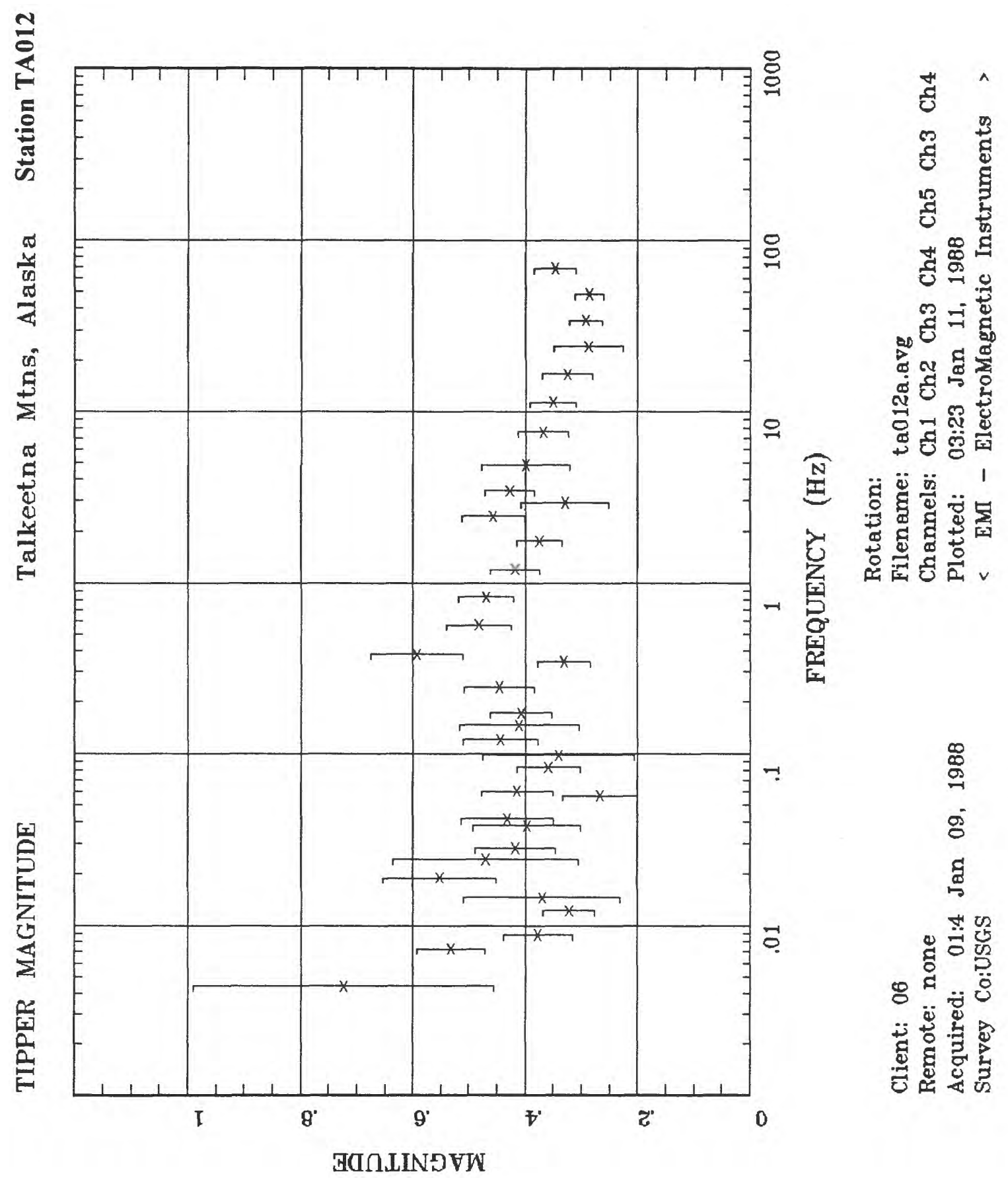




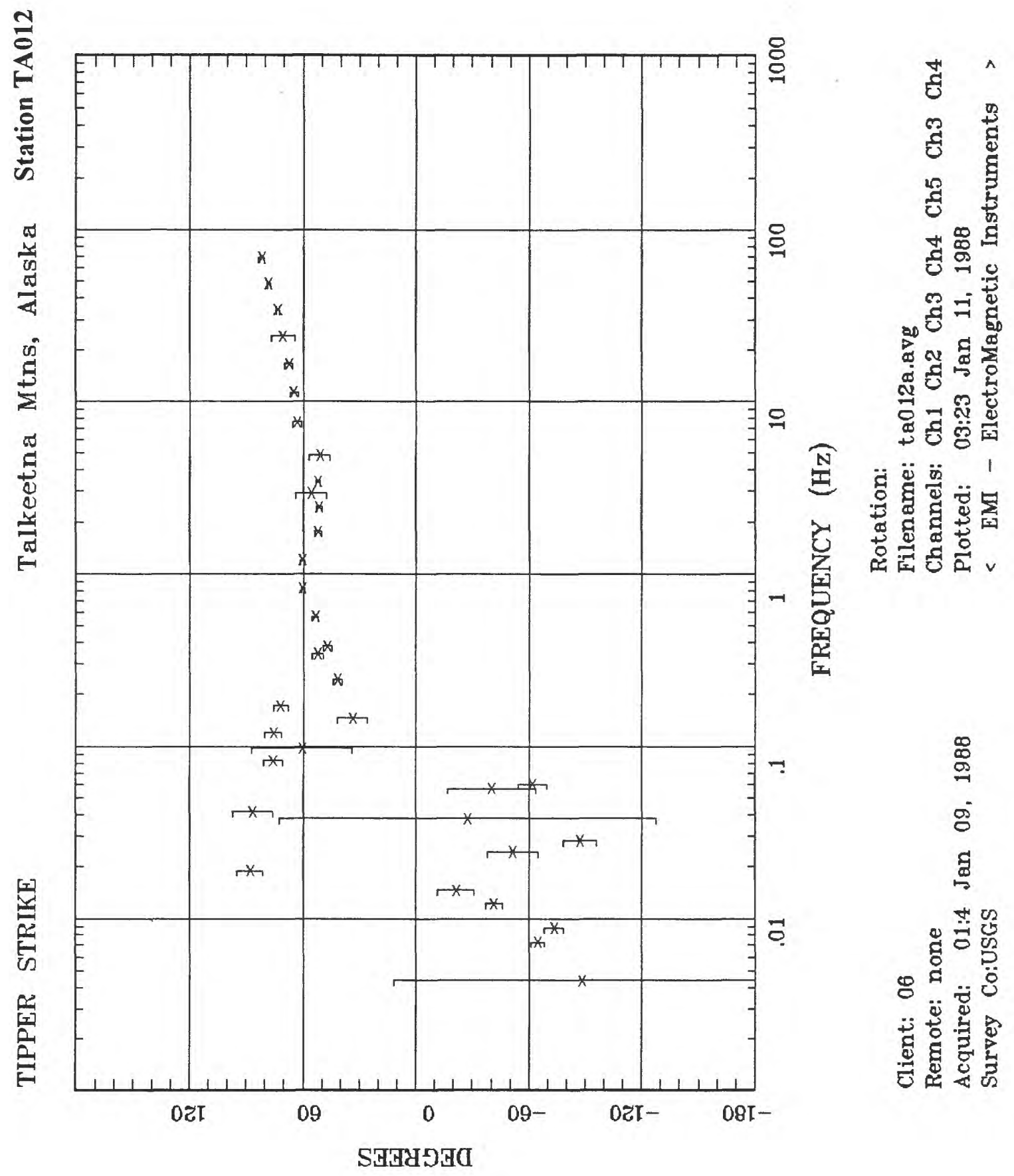




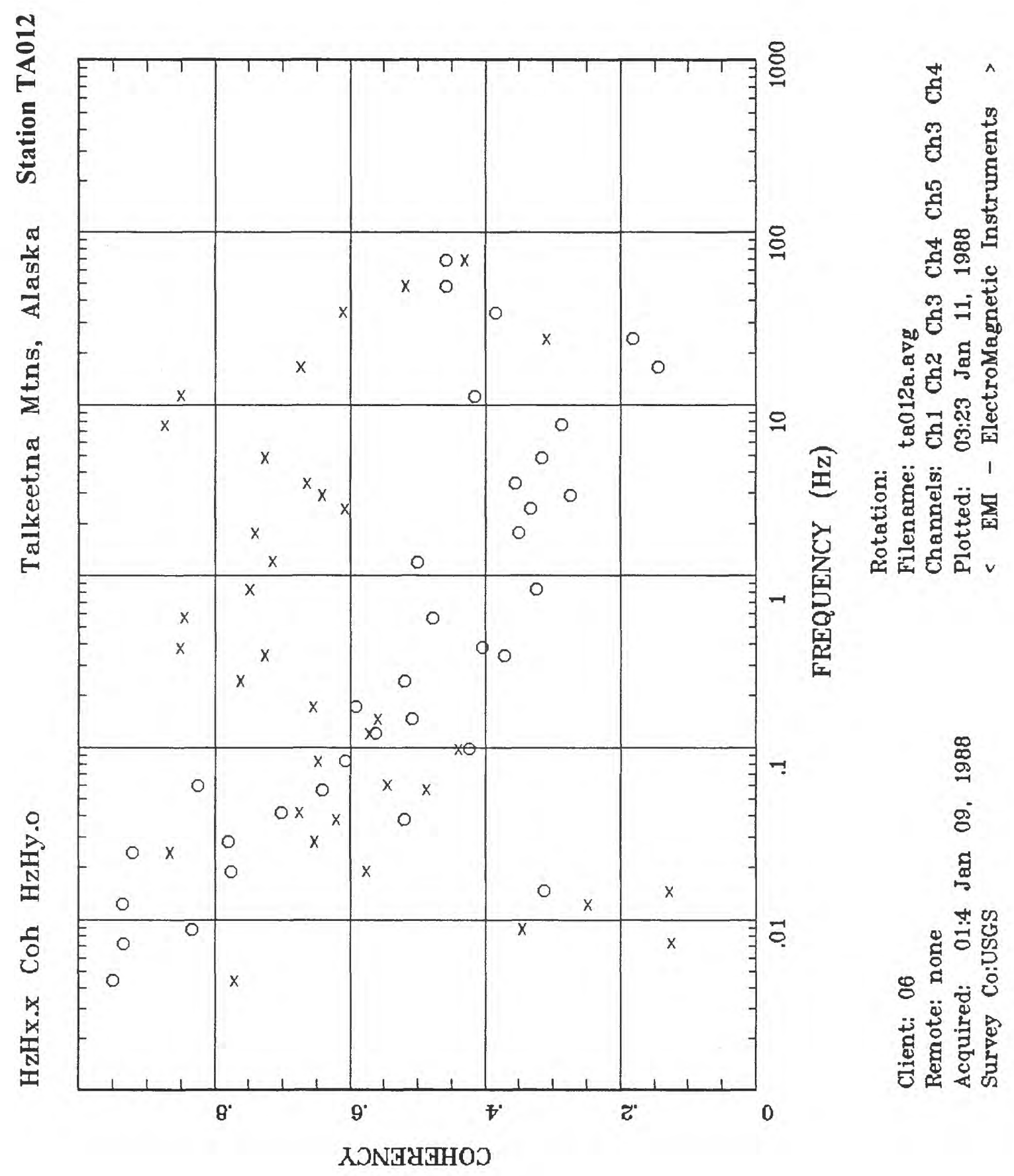




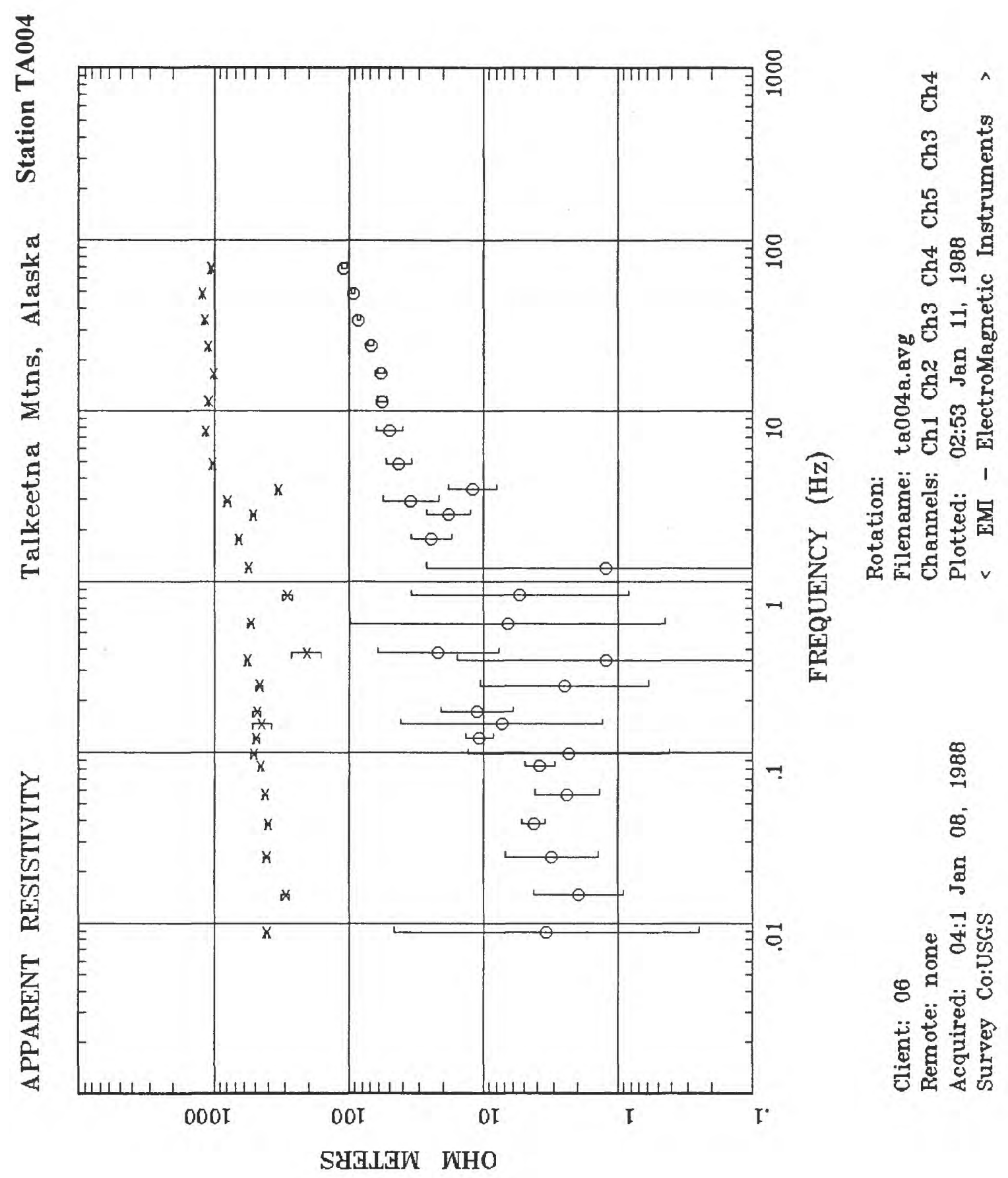




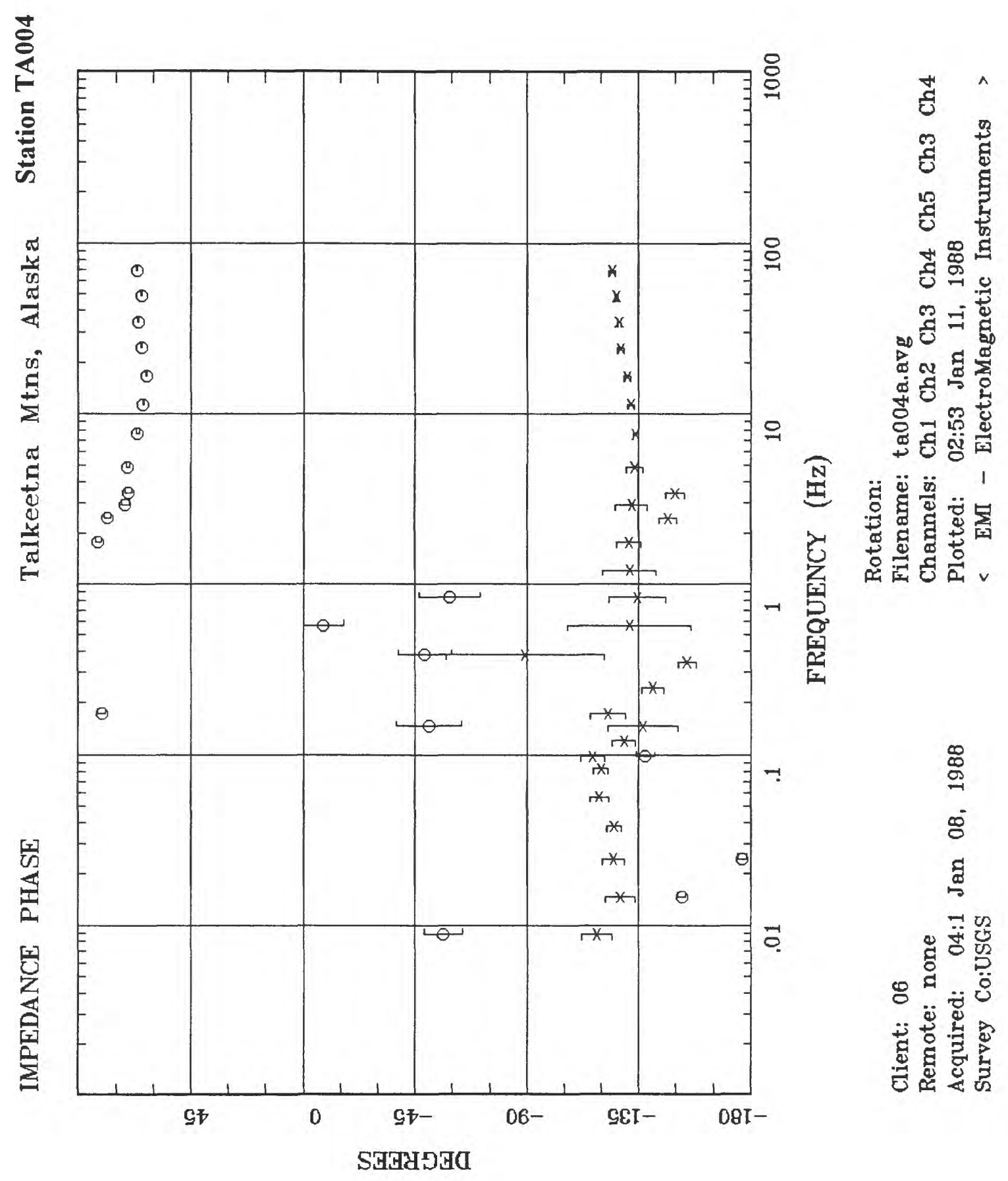




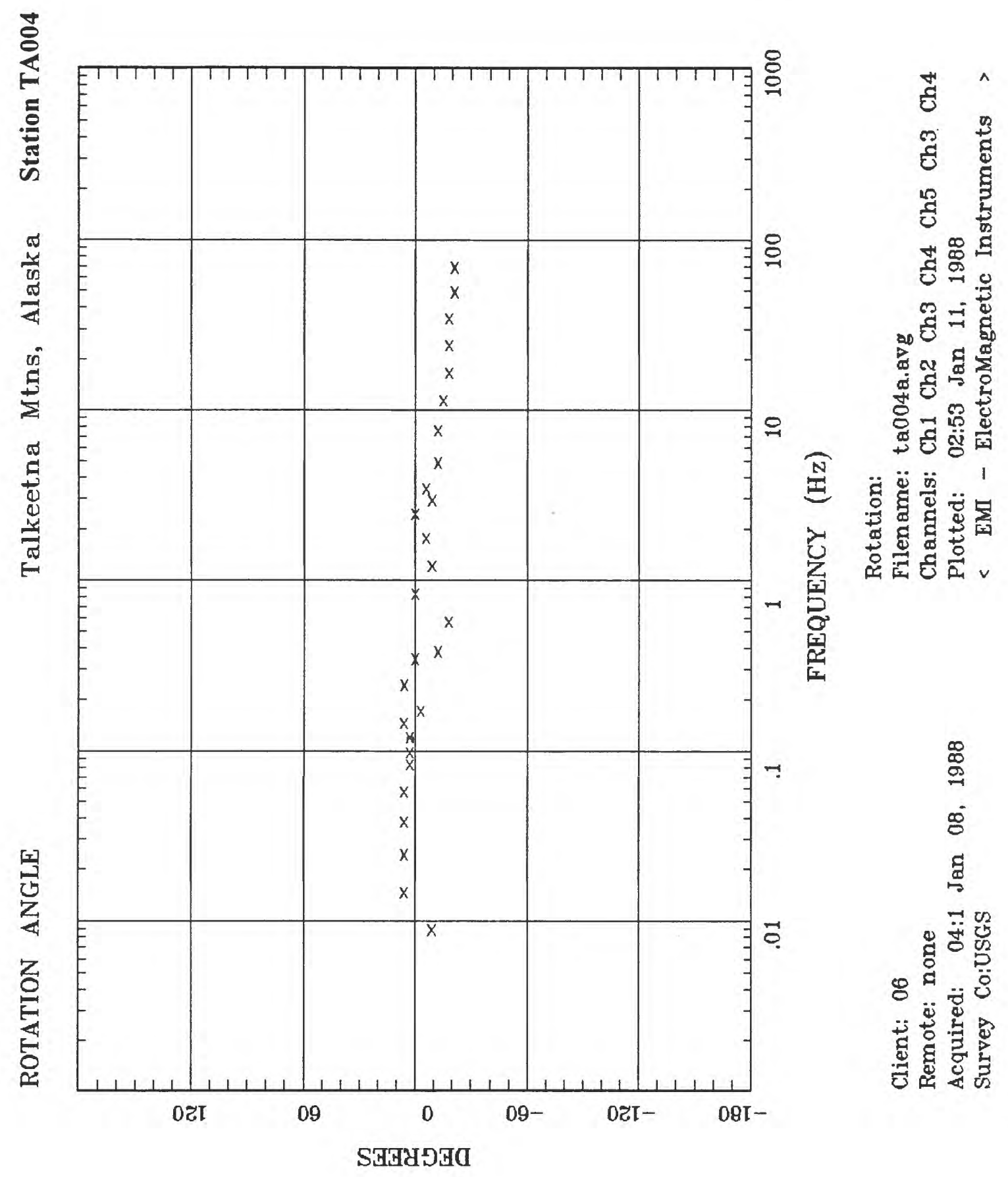




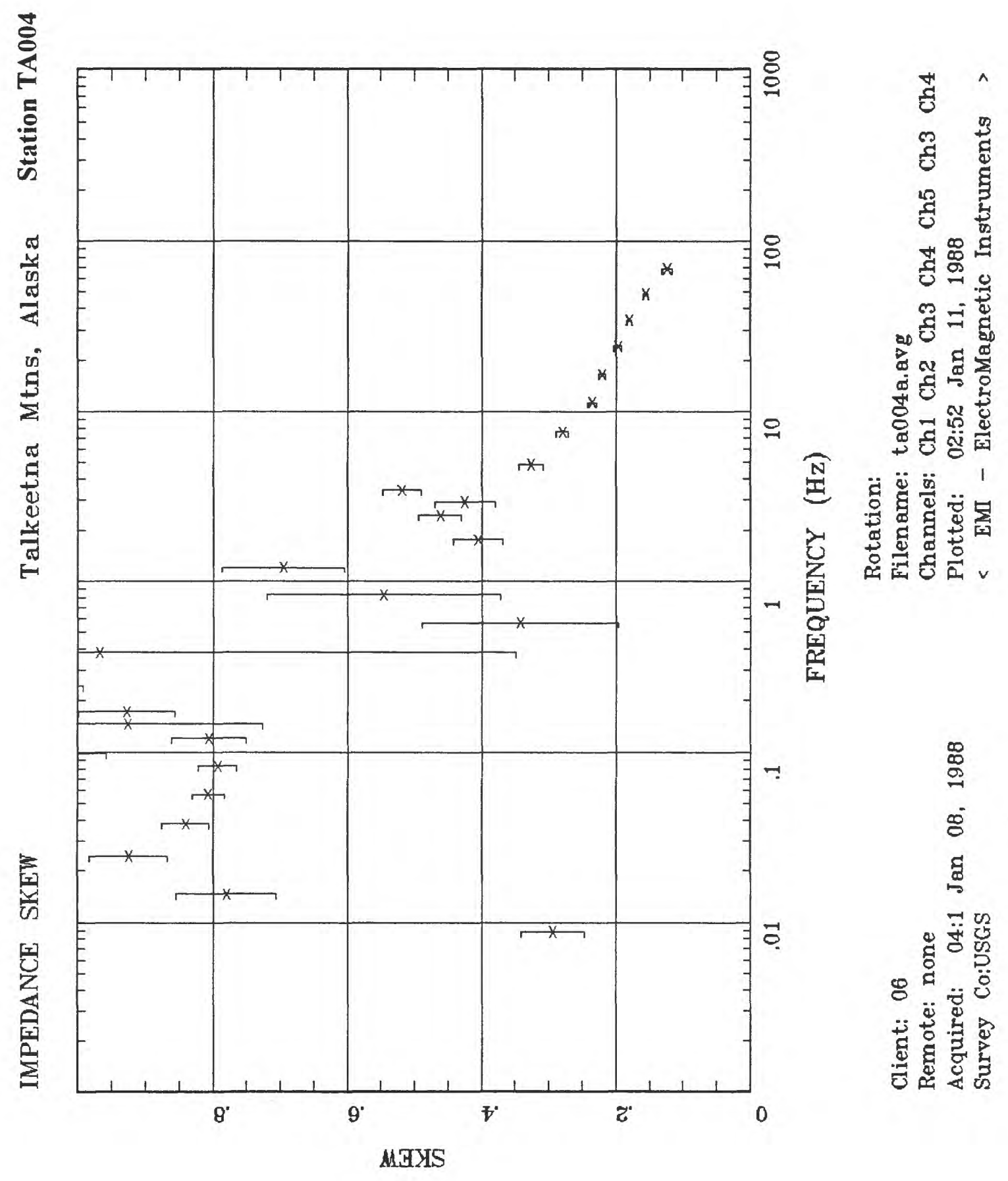




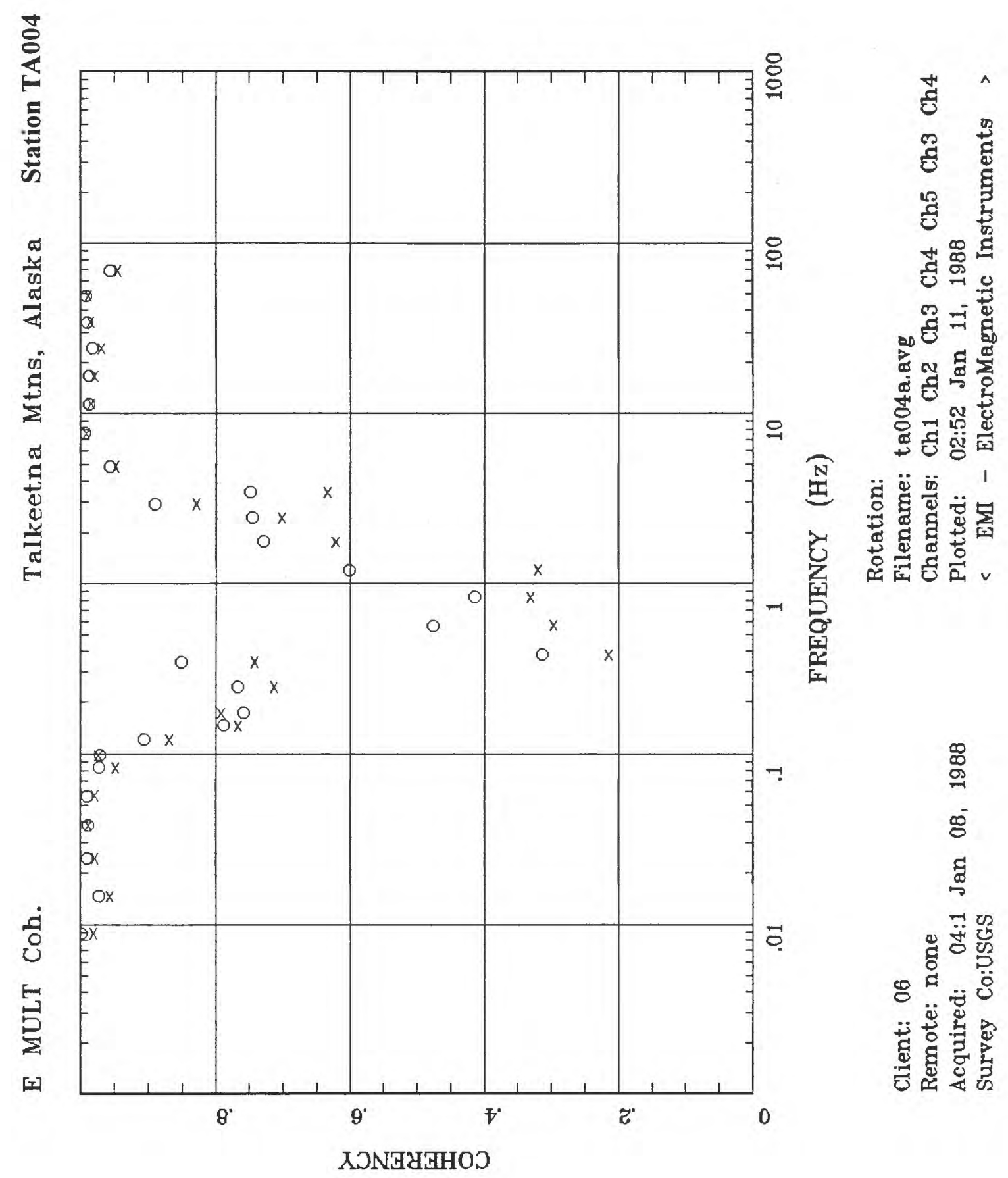




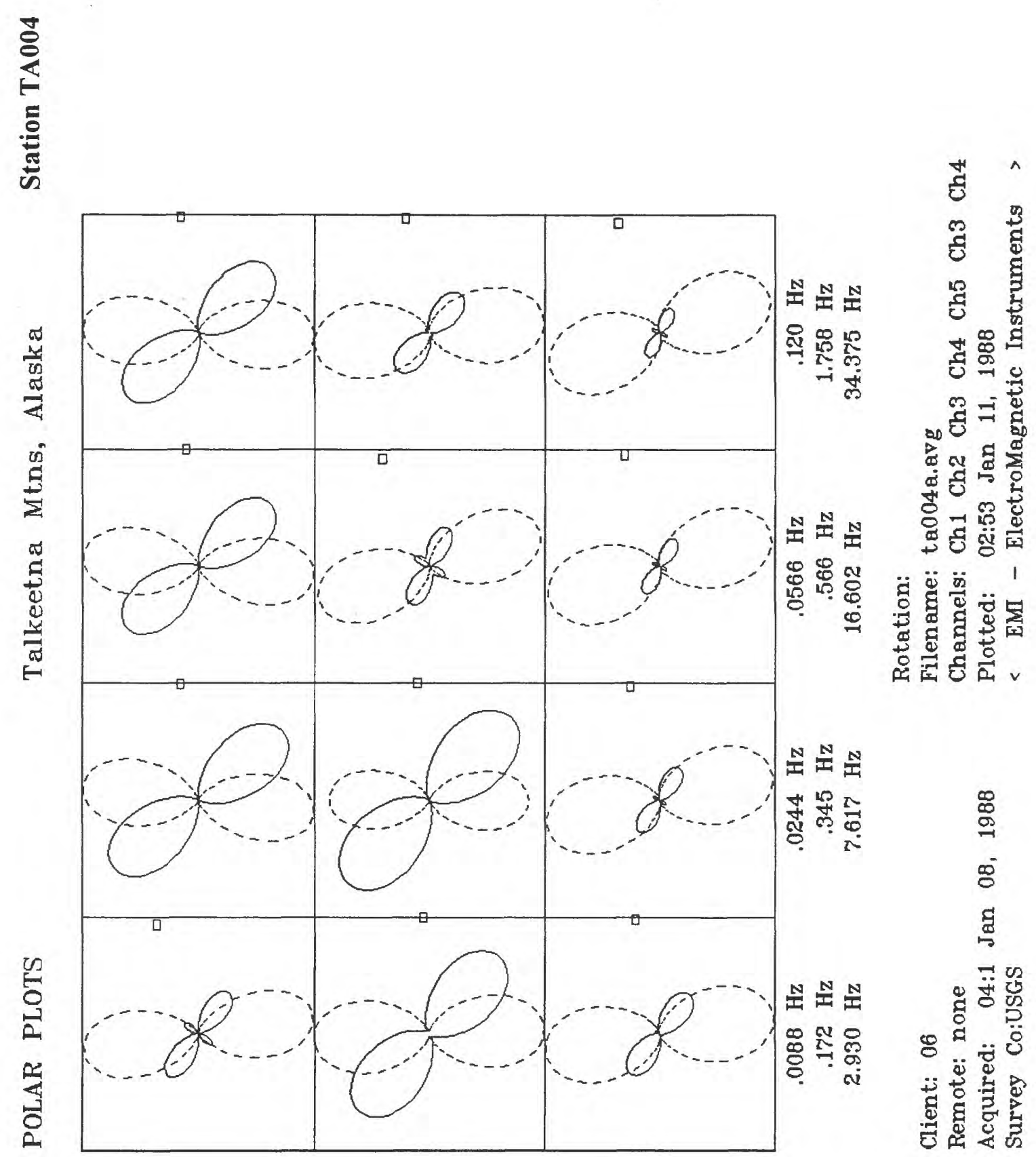




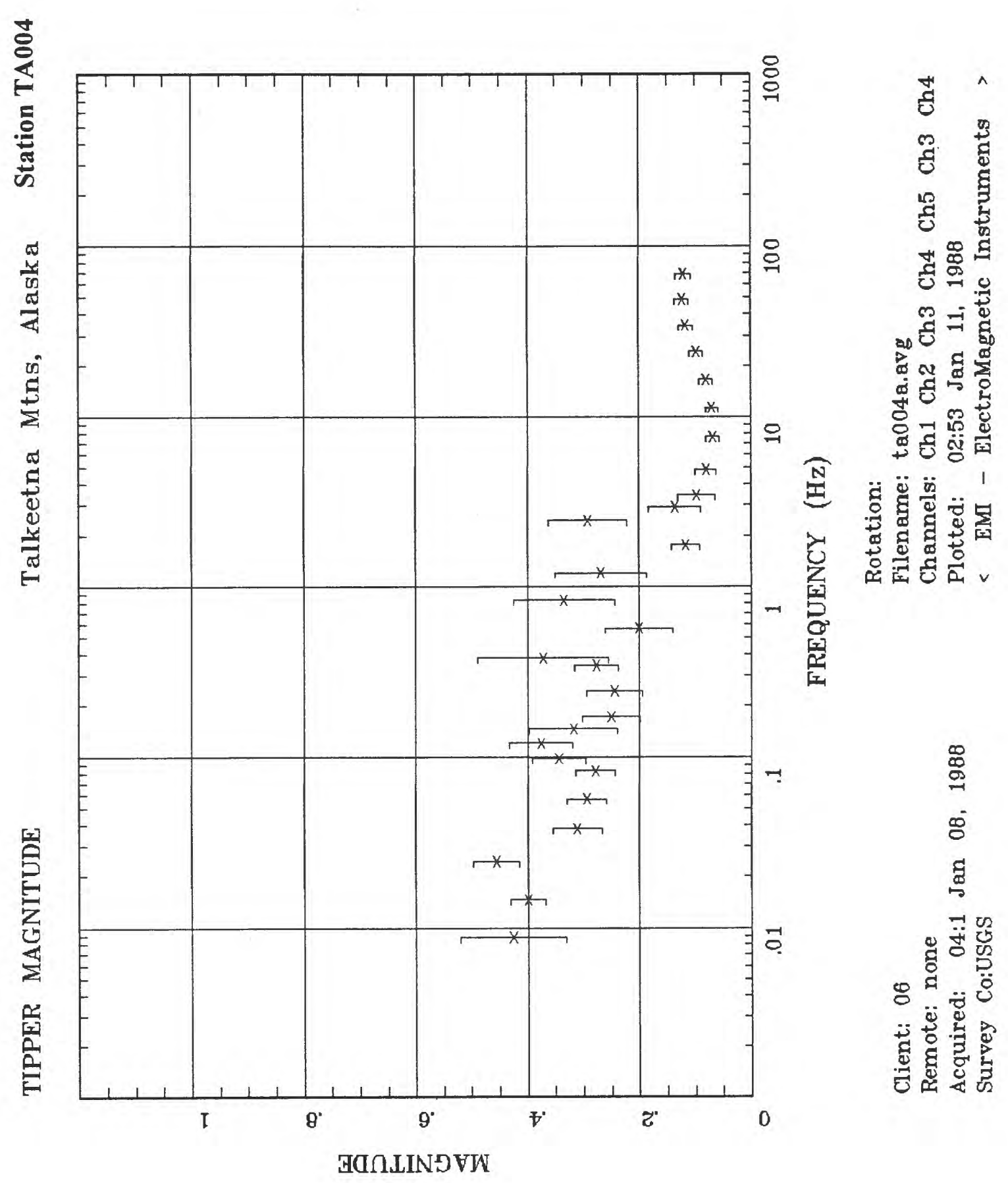




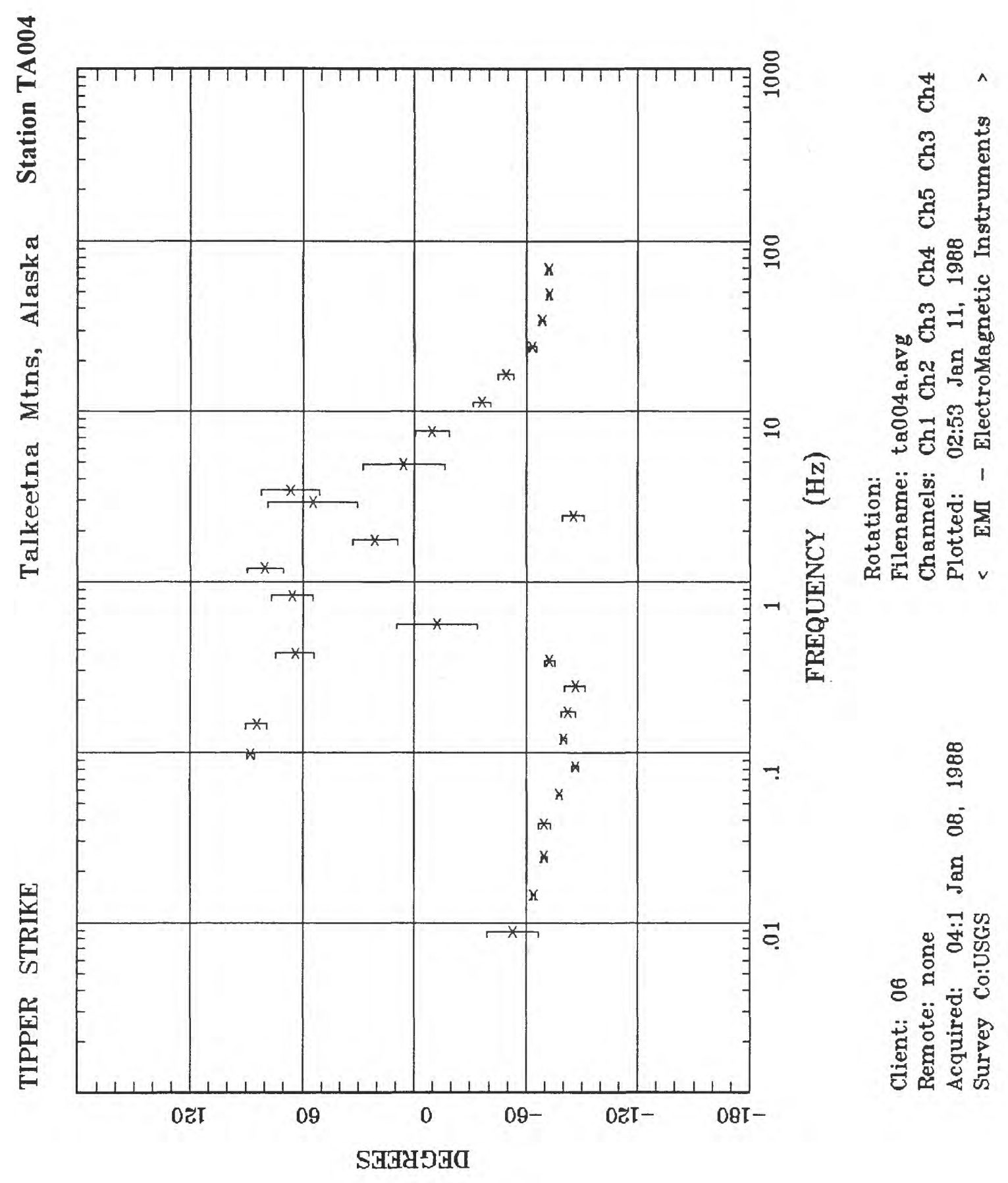




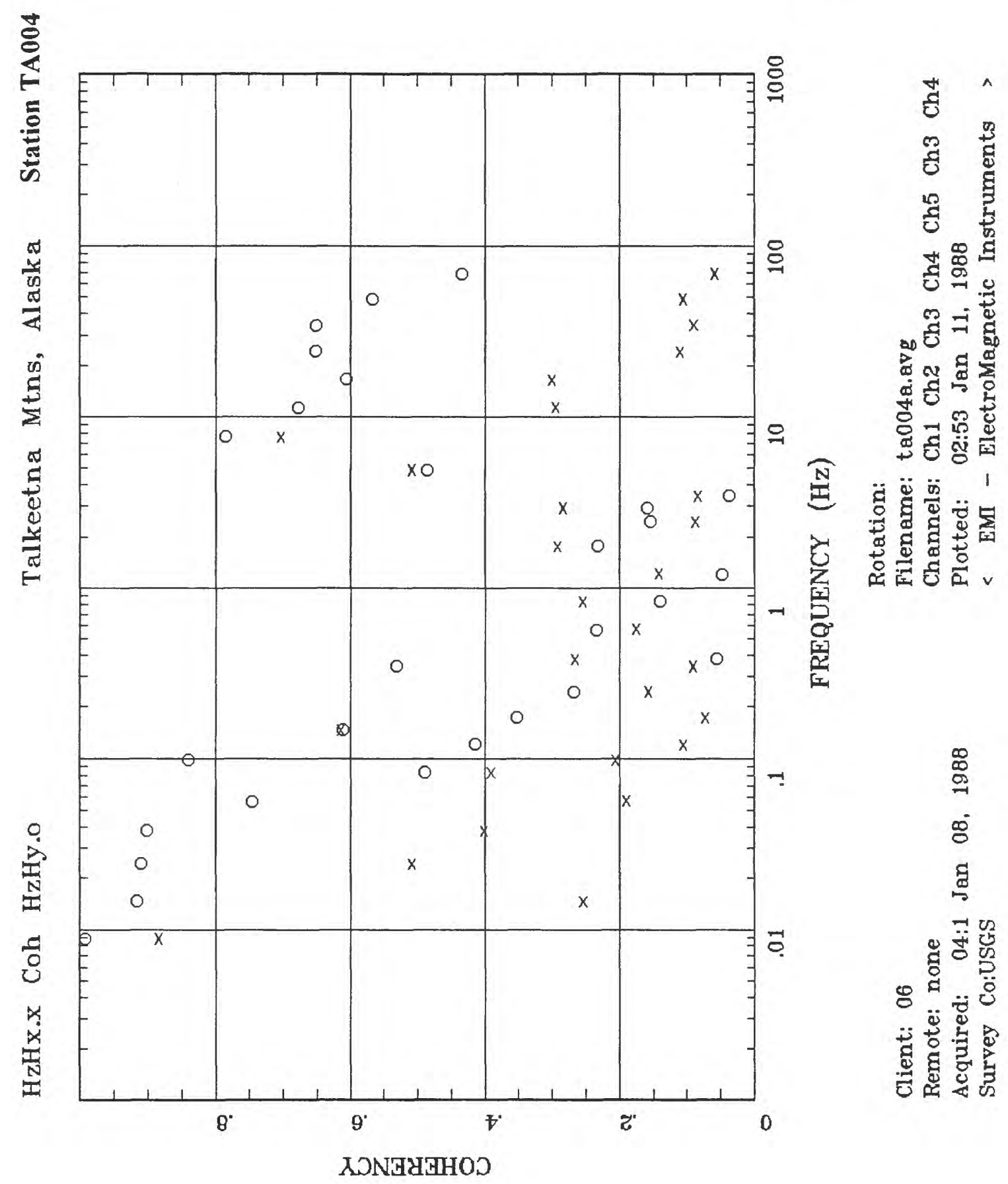




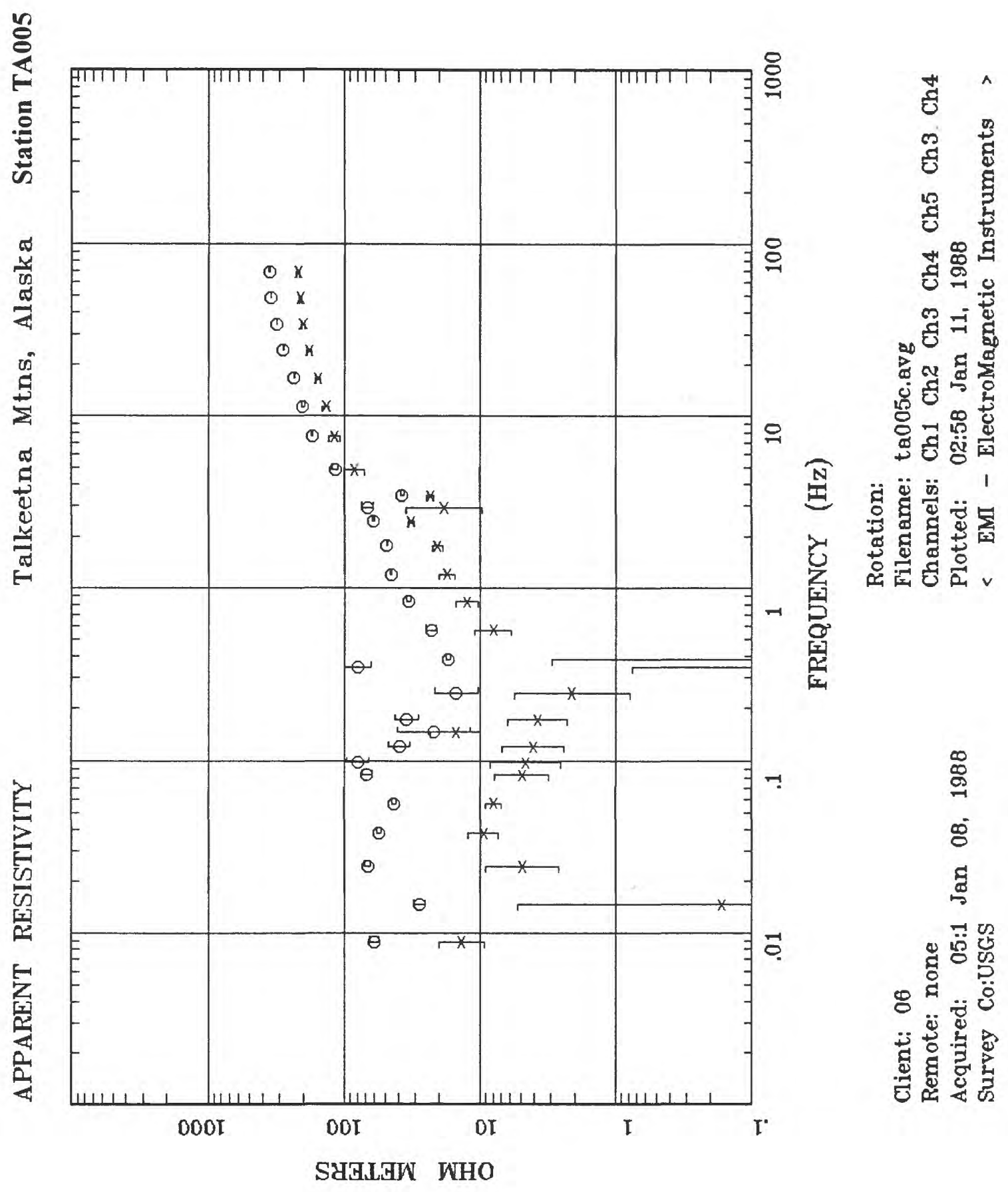




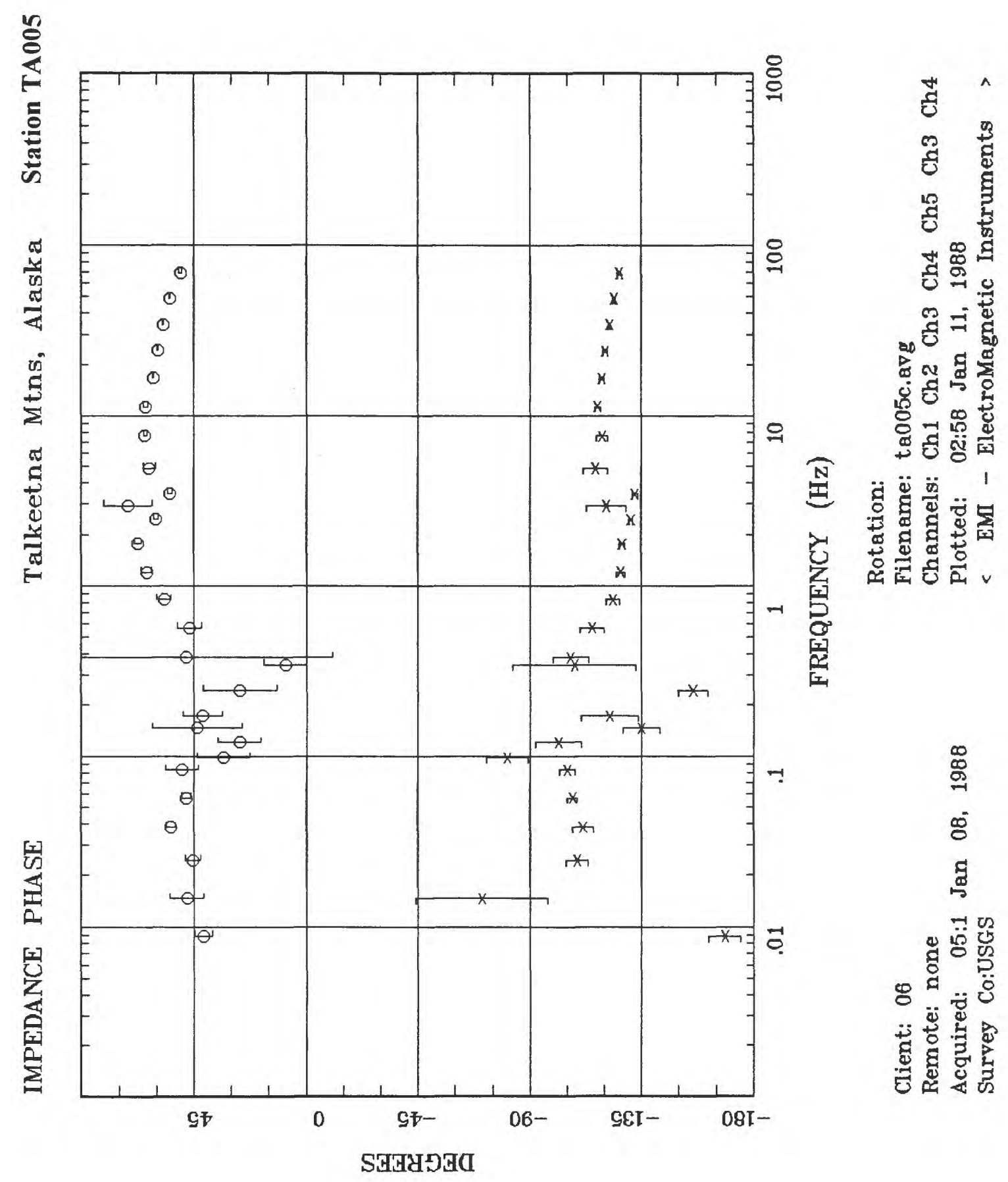




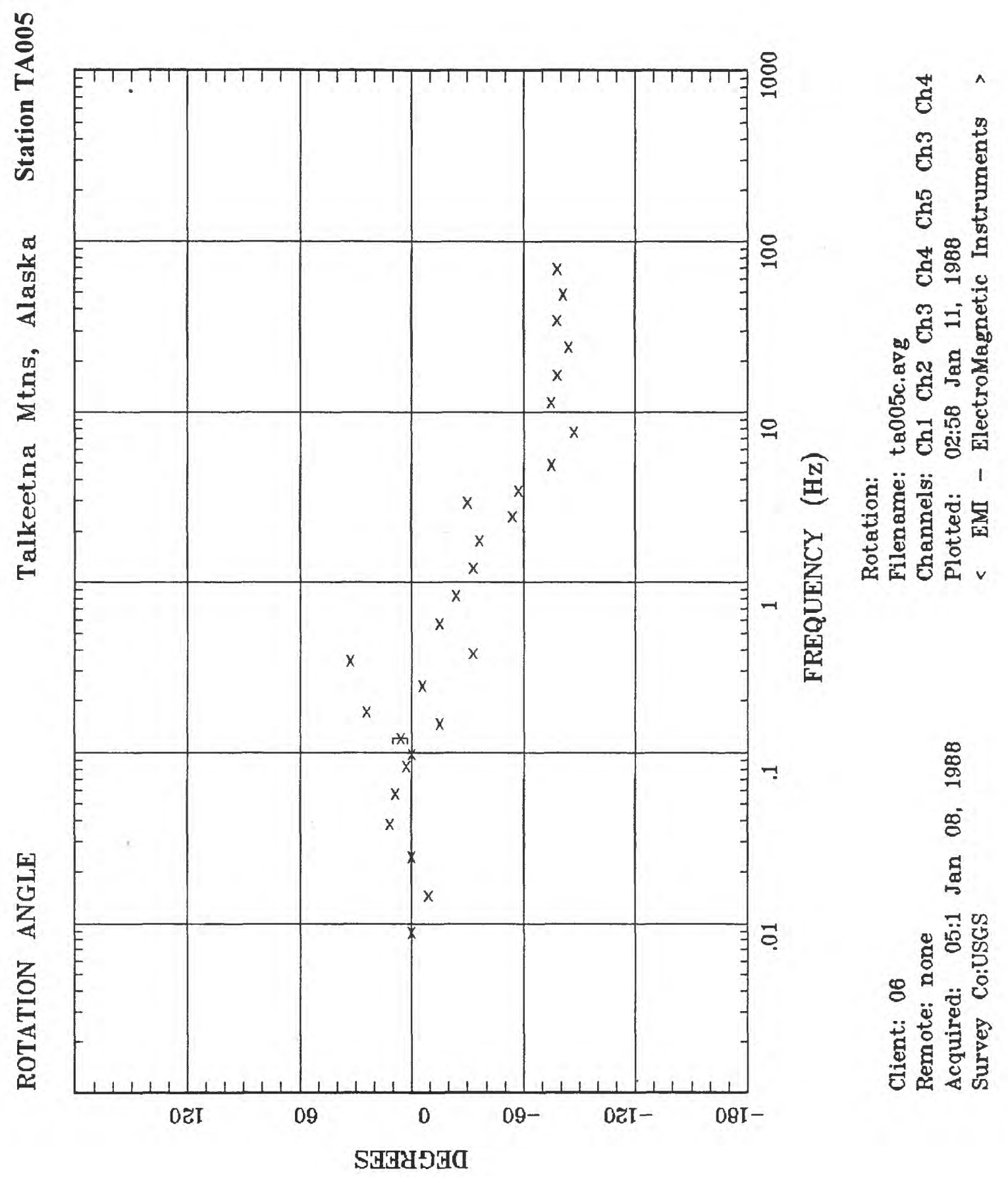




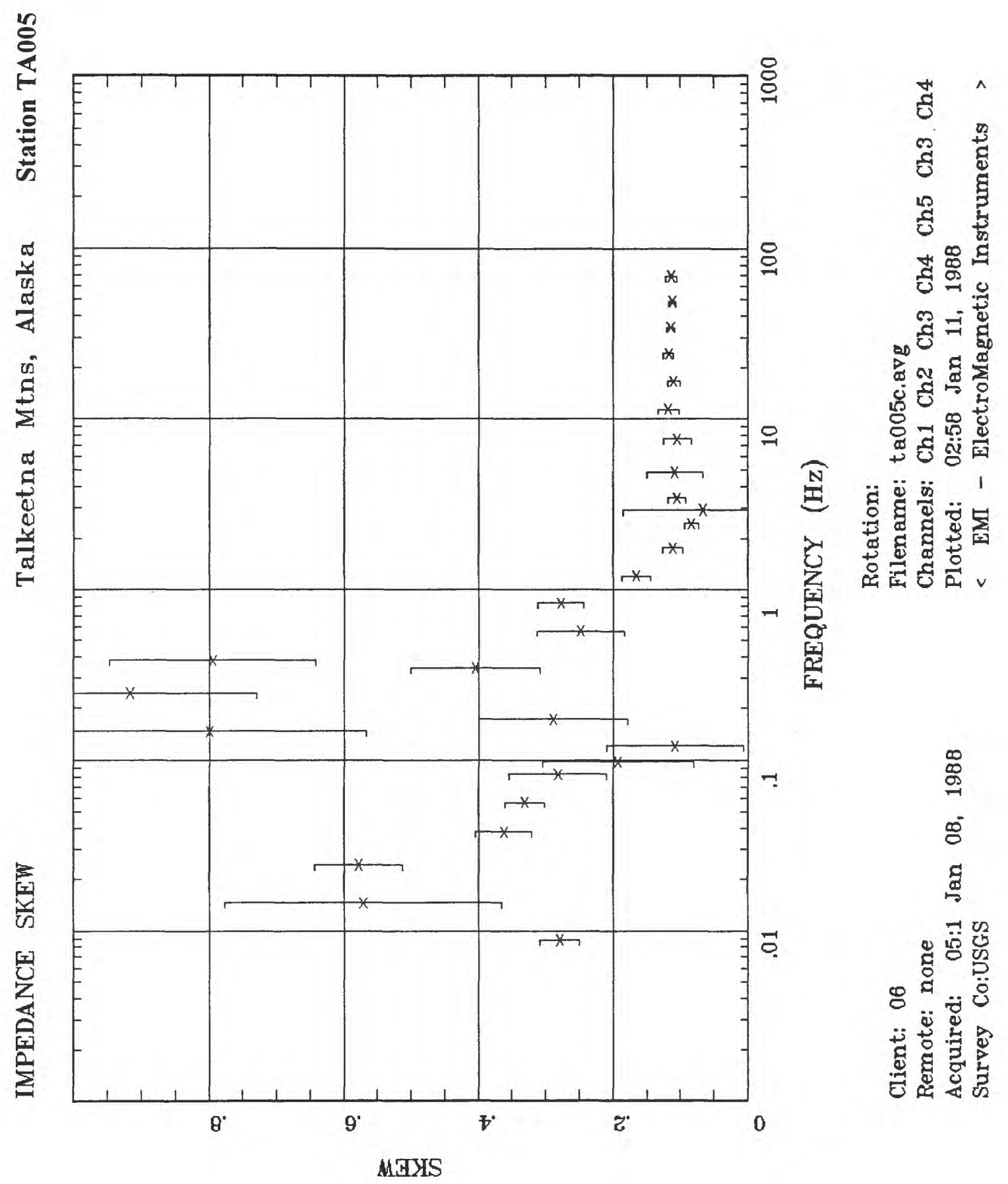




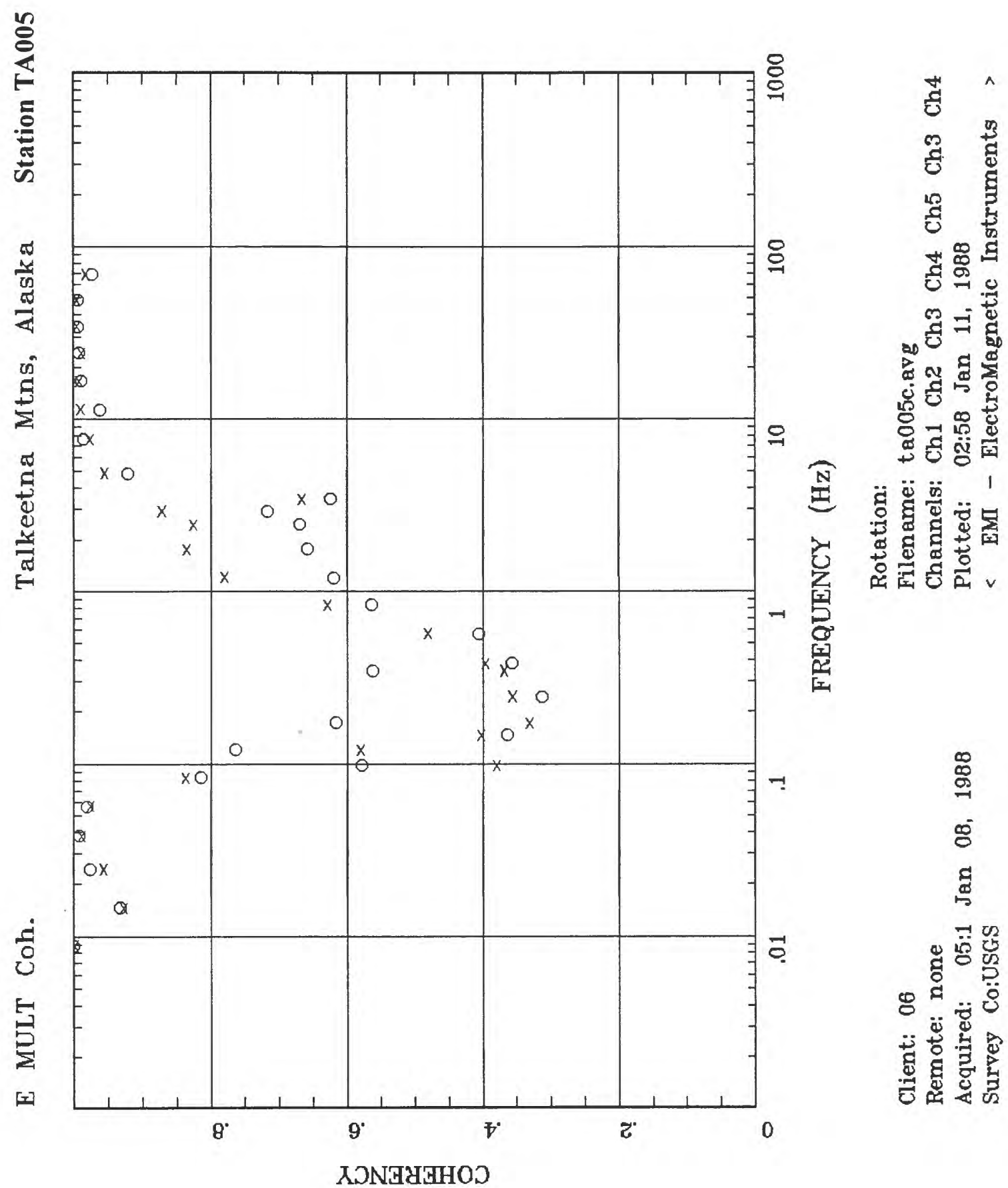




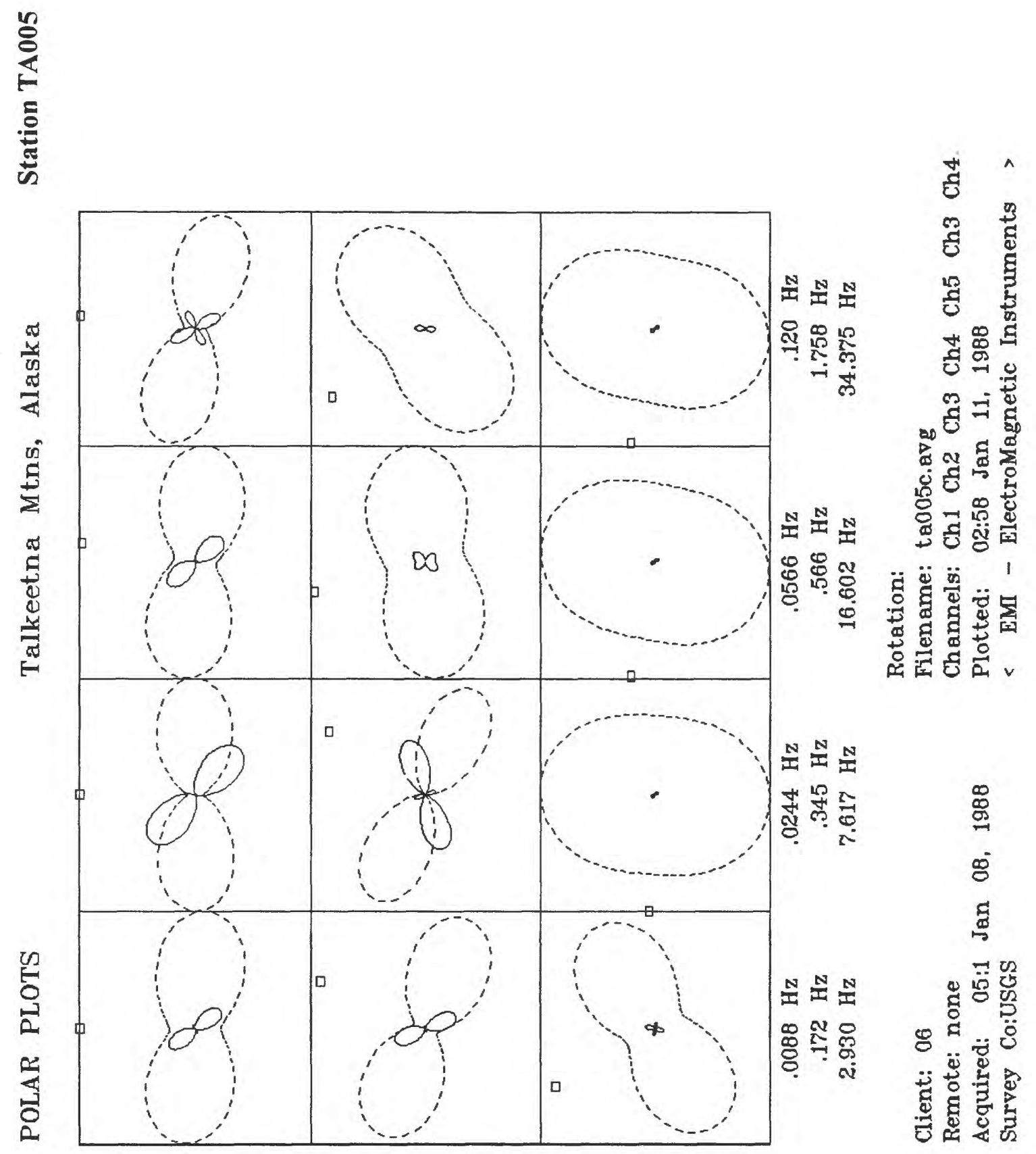




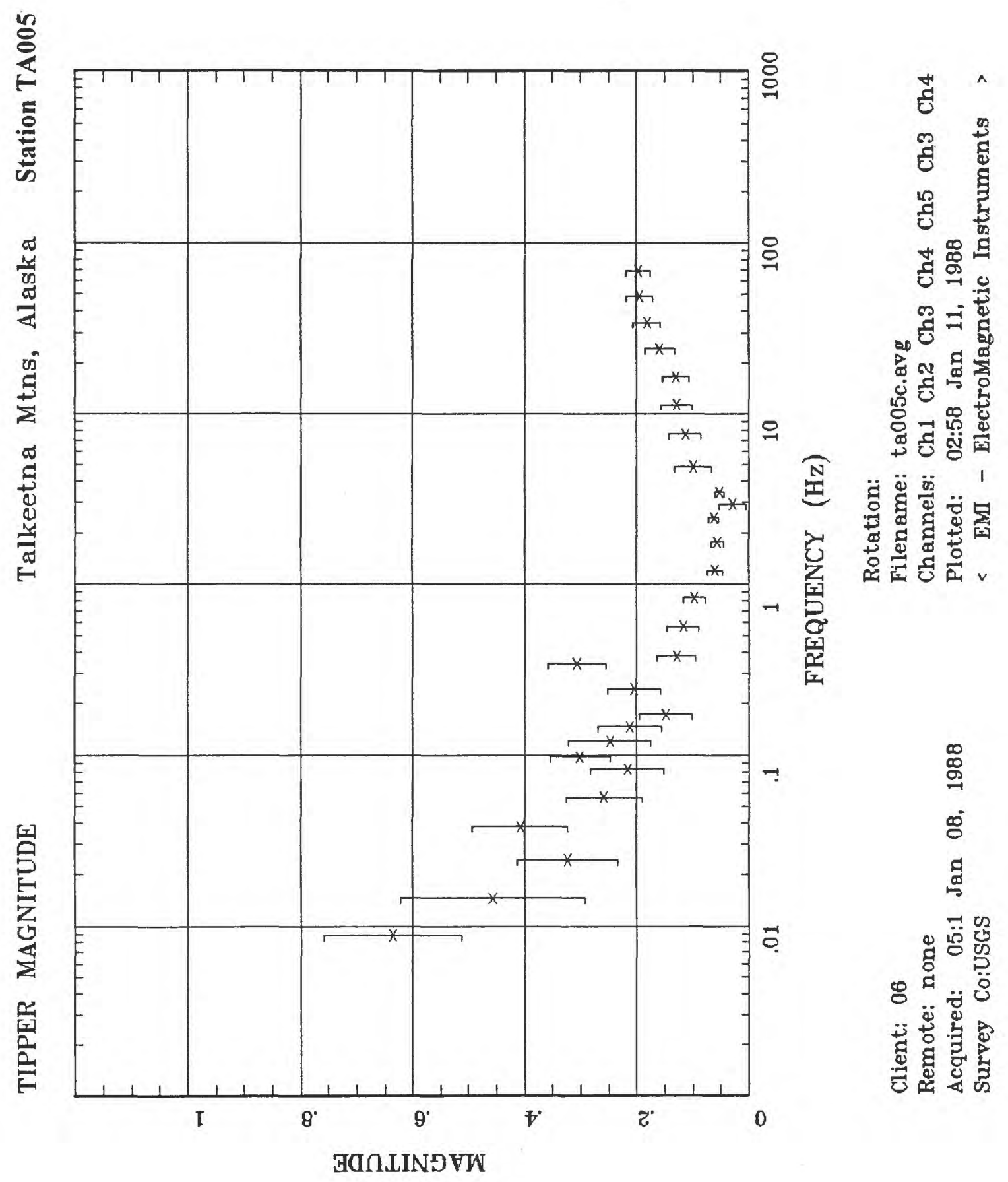




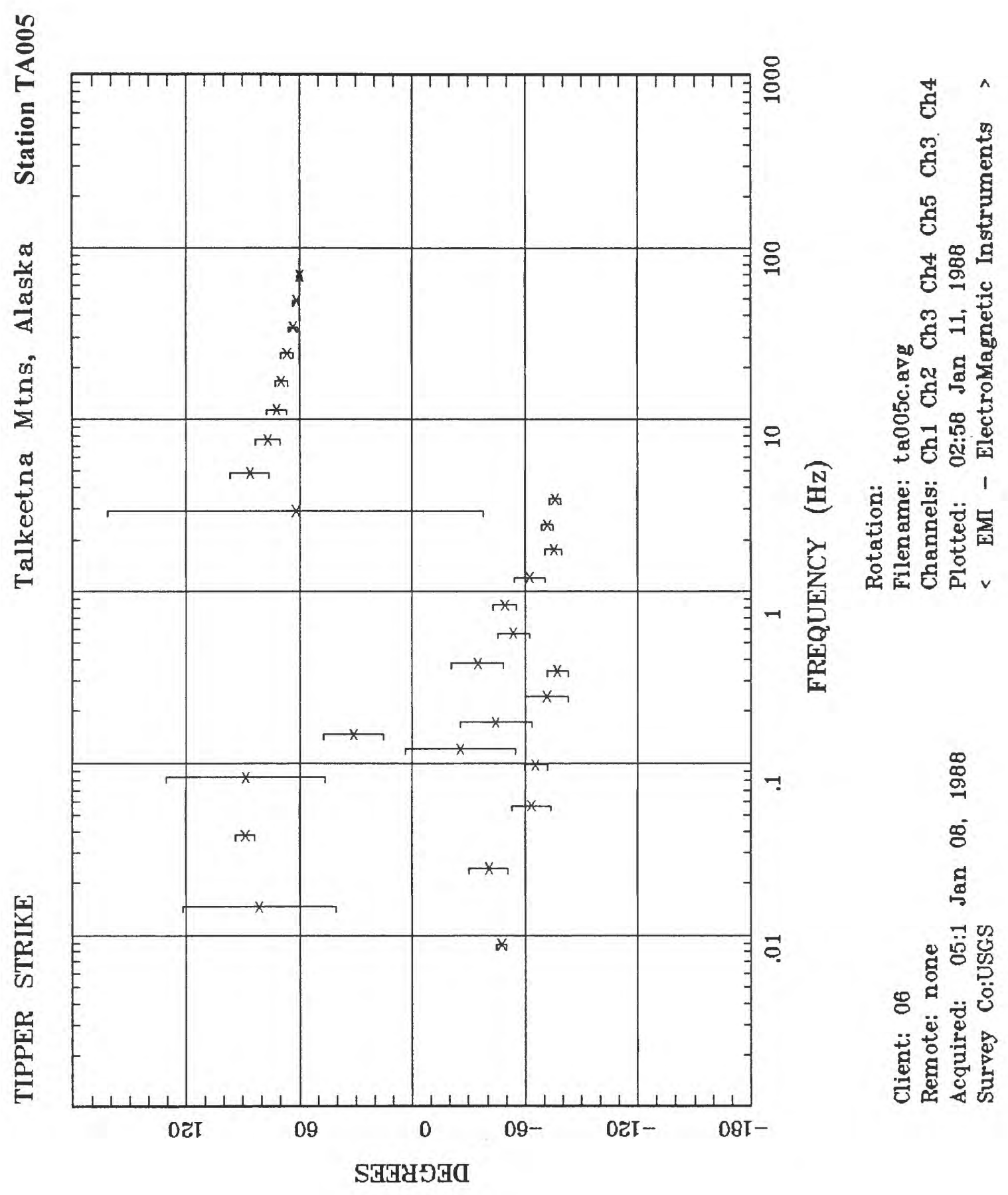




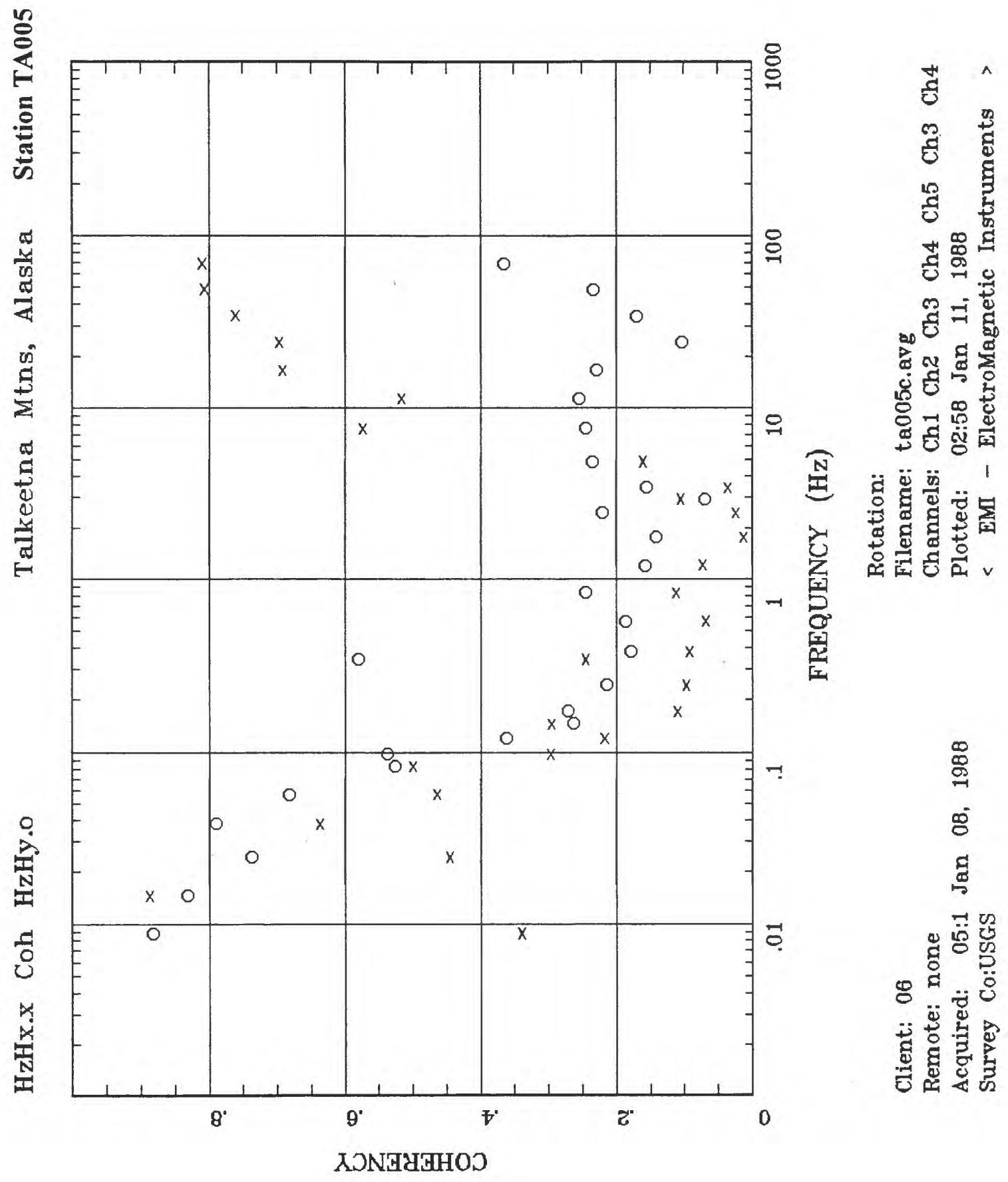




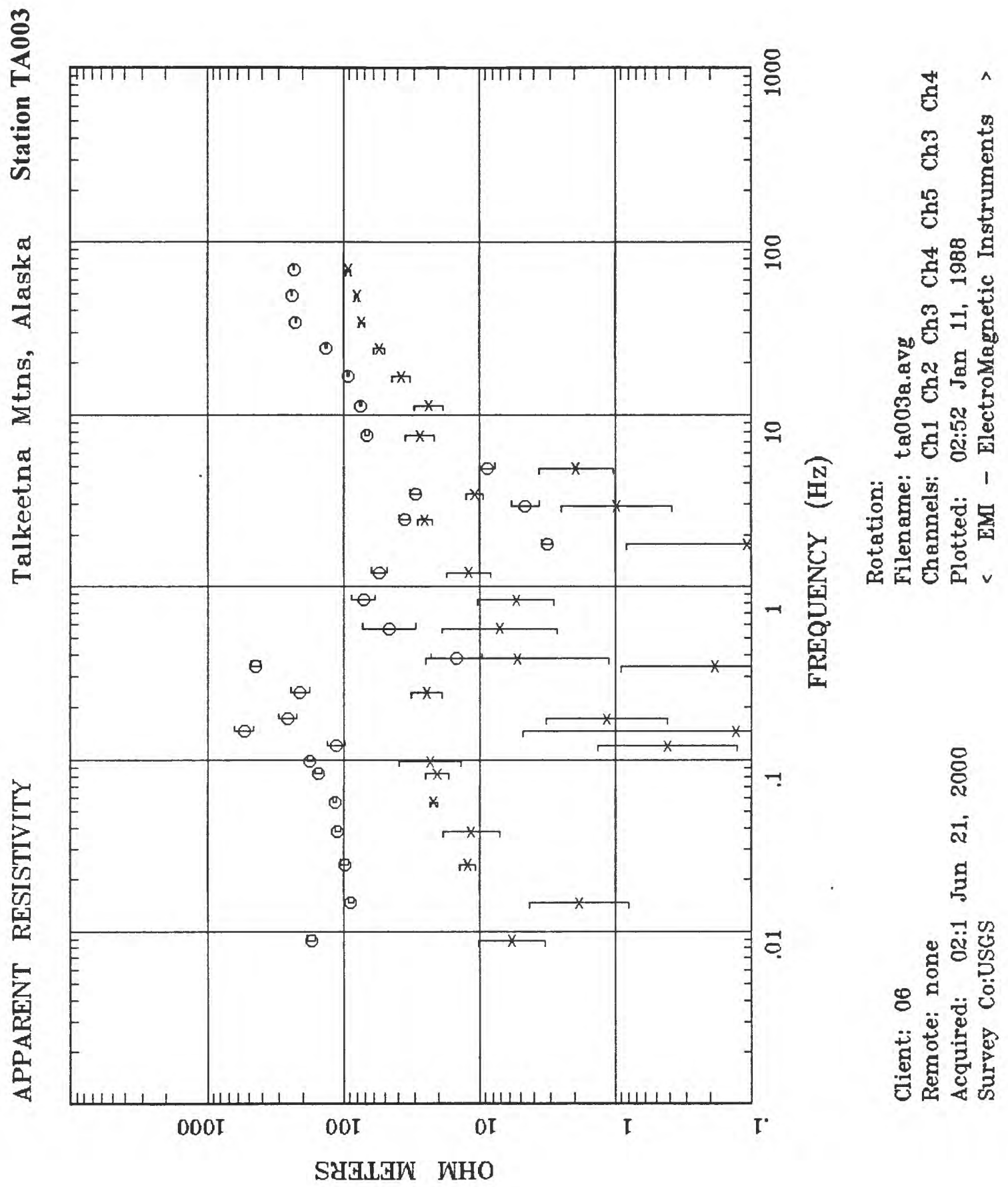




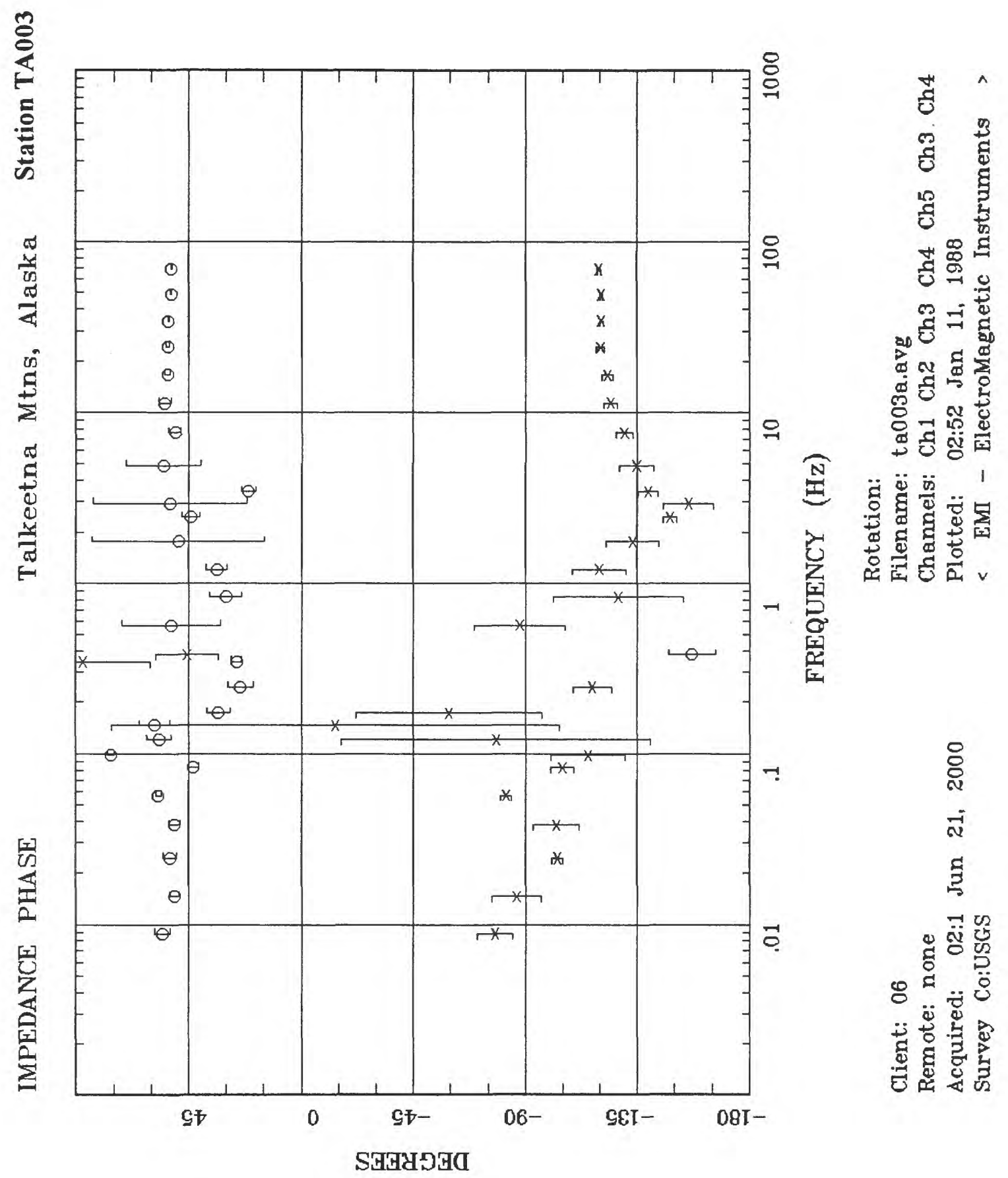




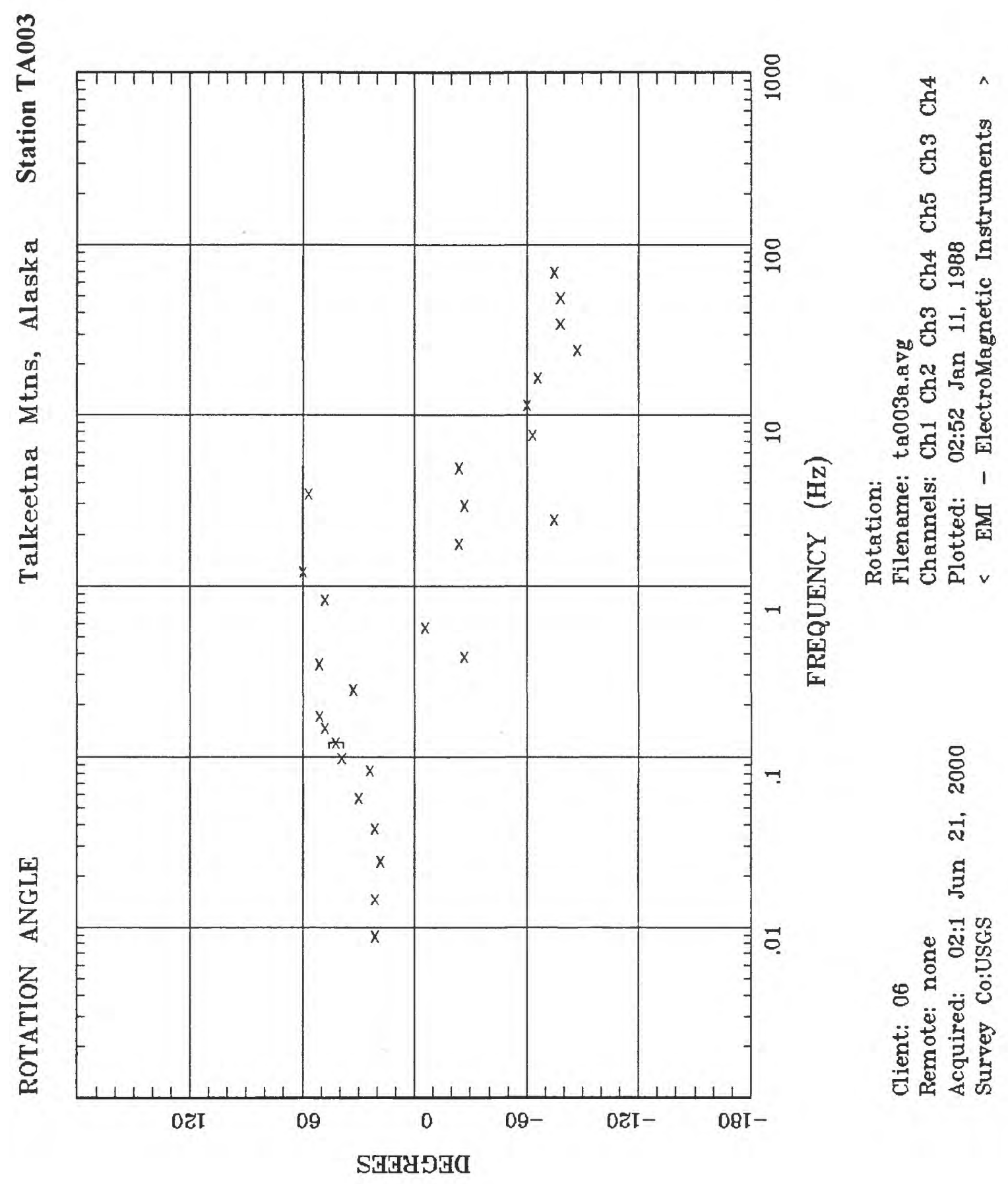




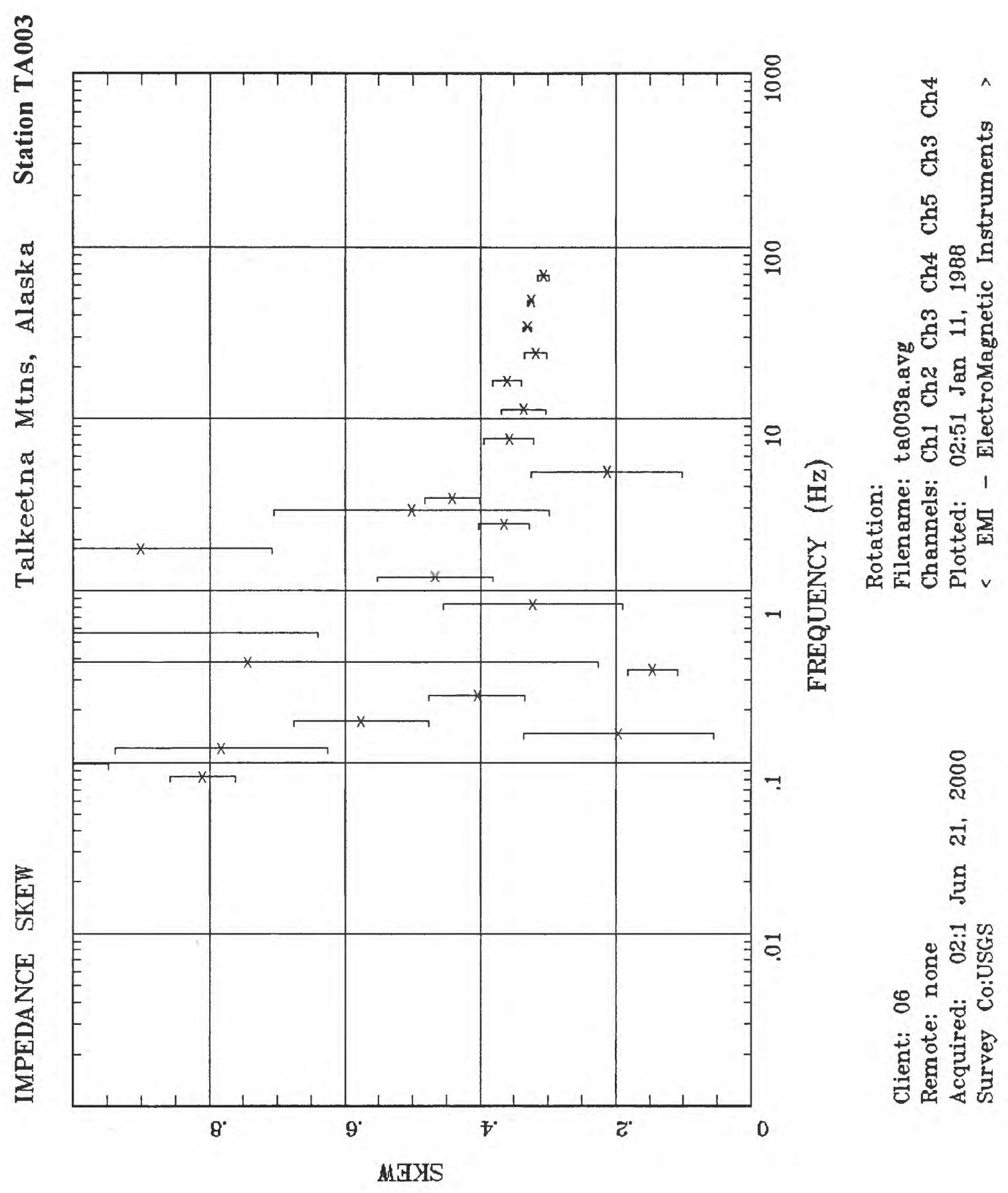




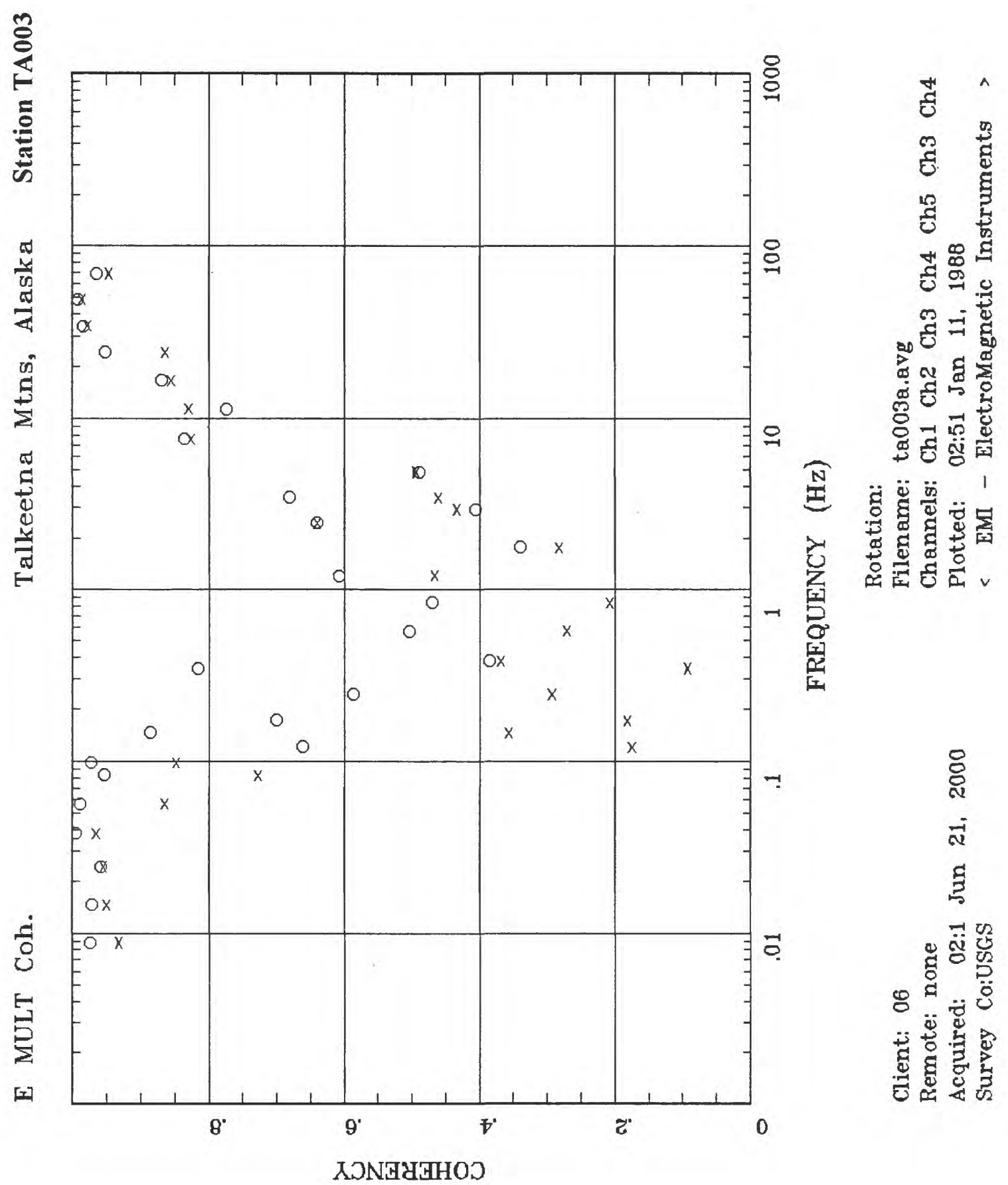


最

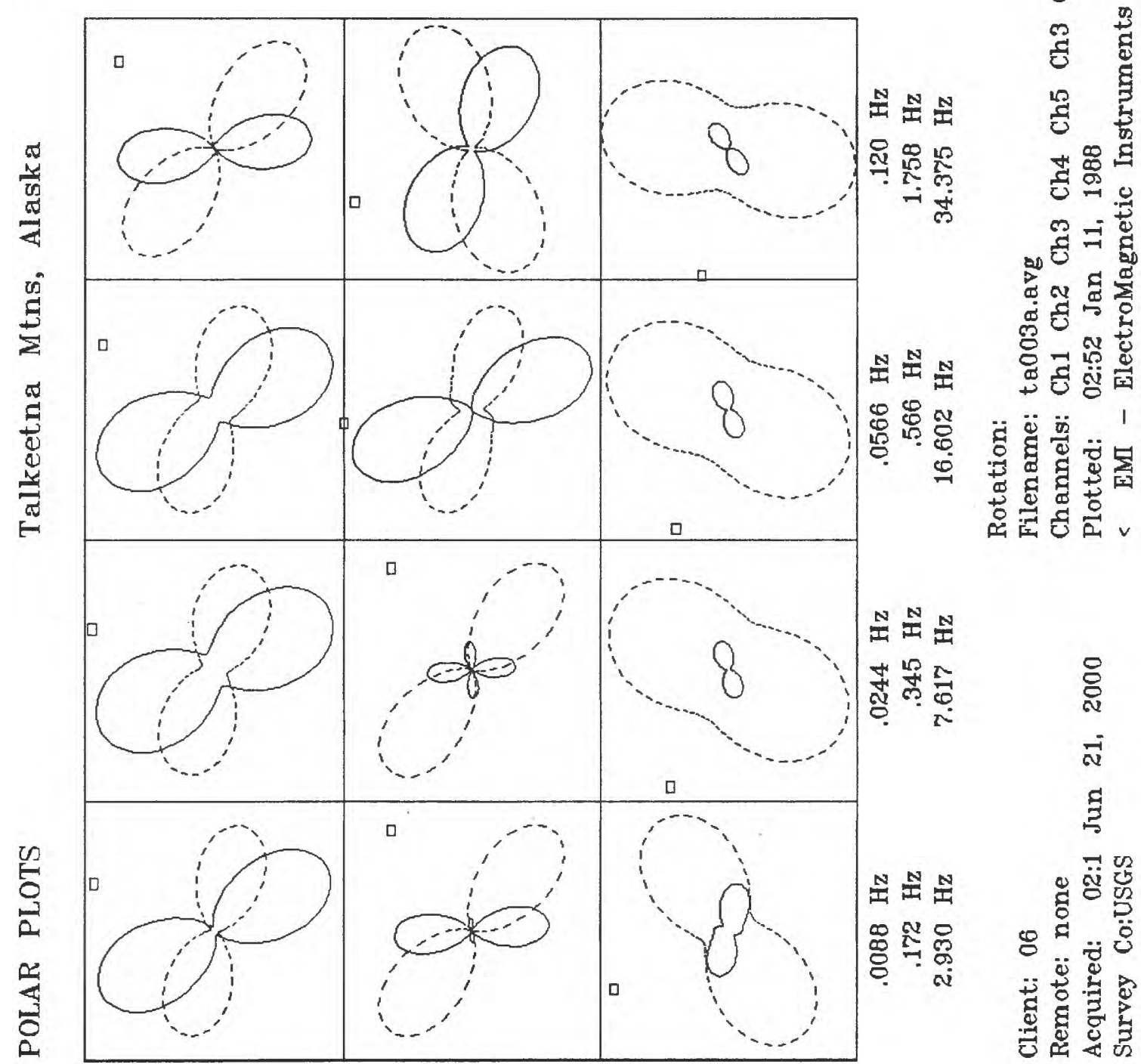




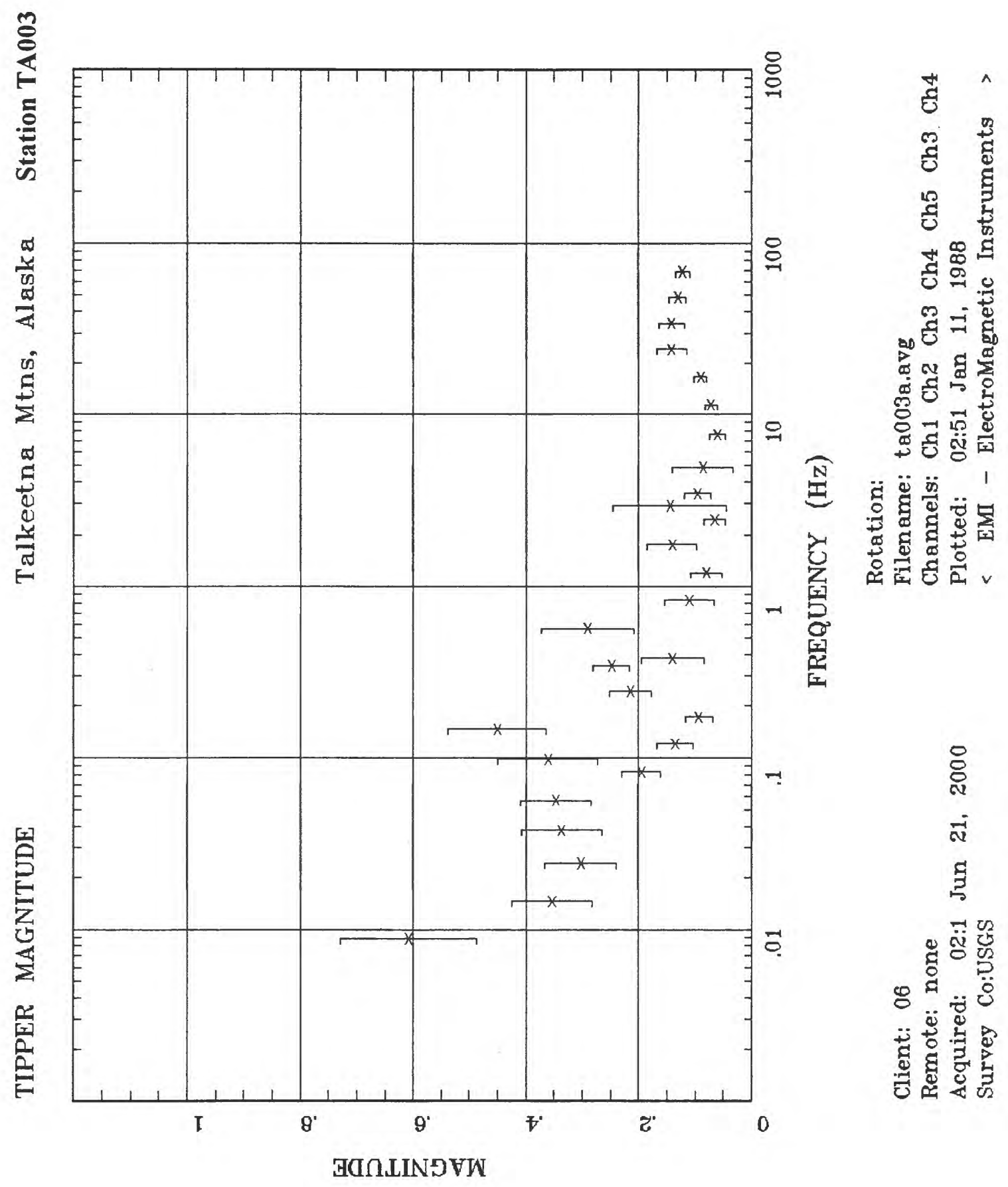




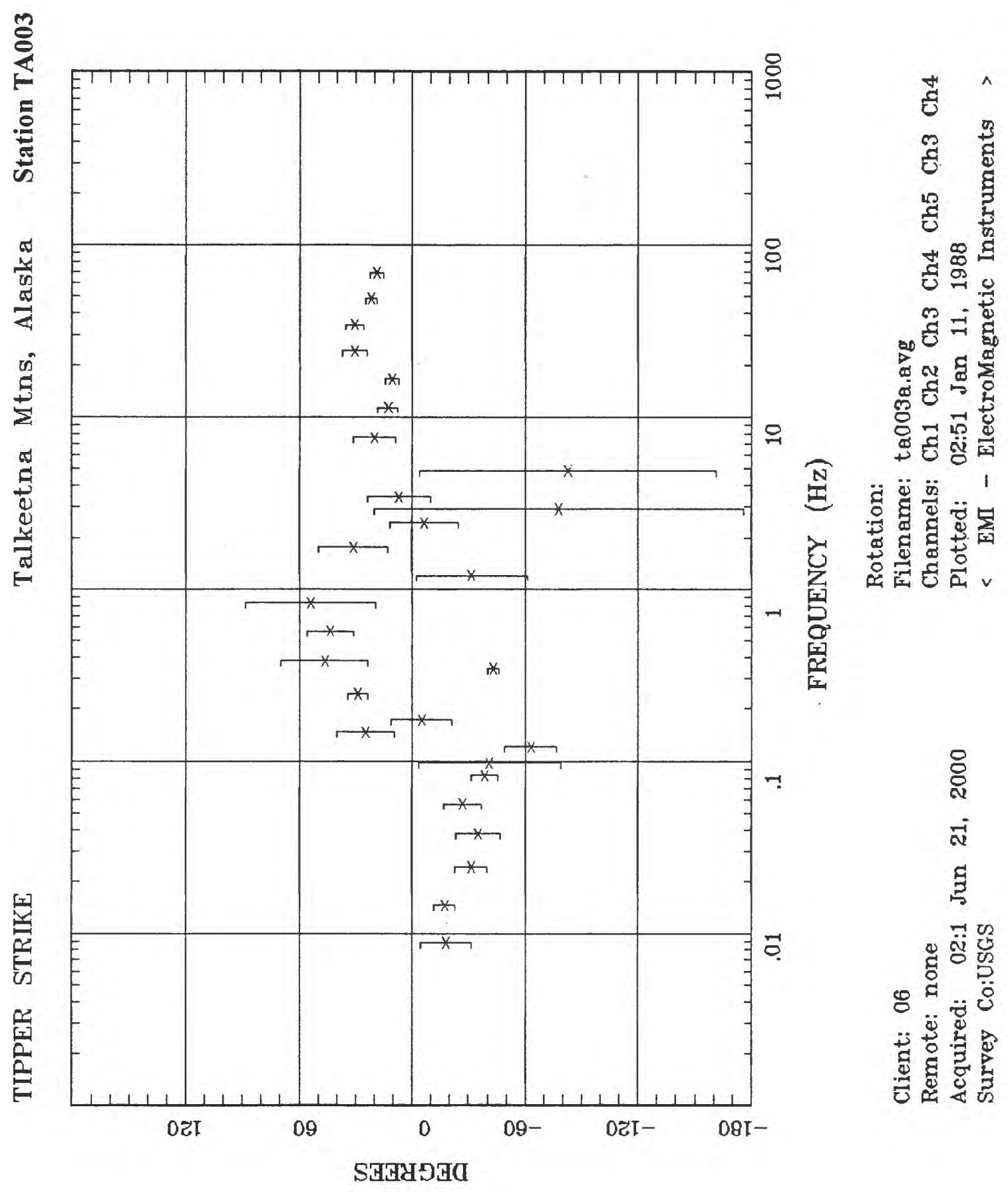




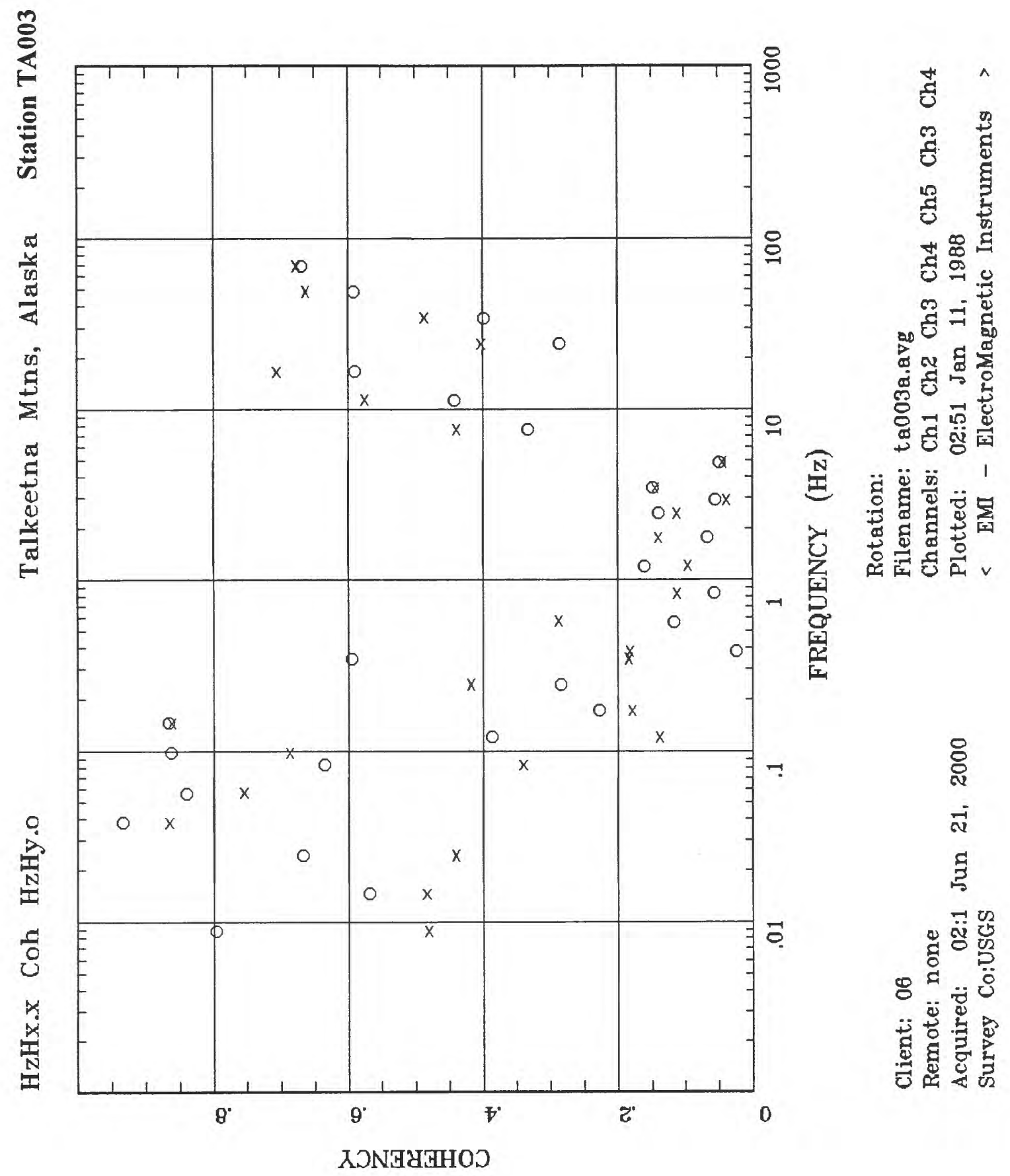




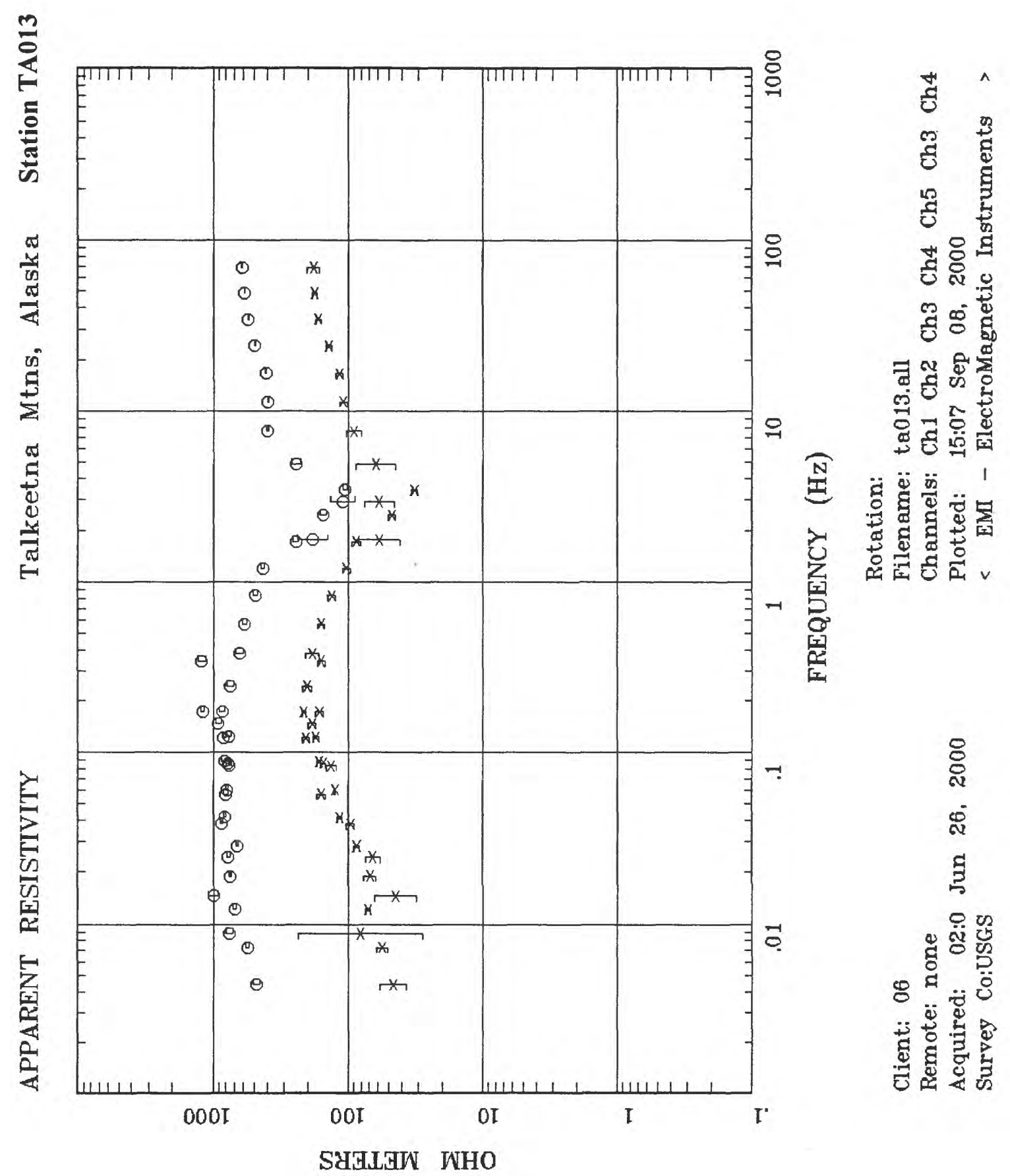




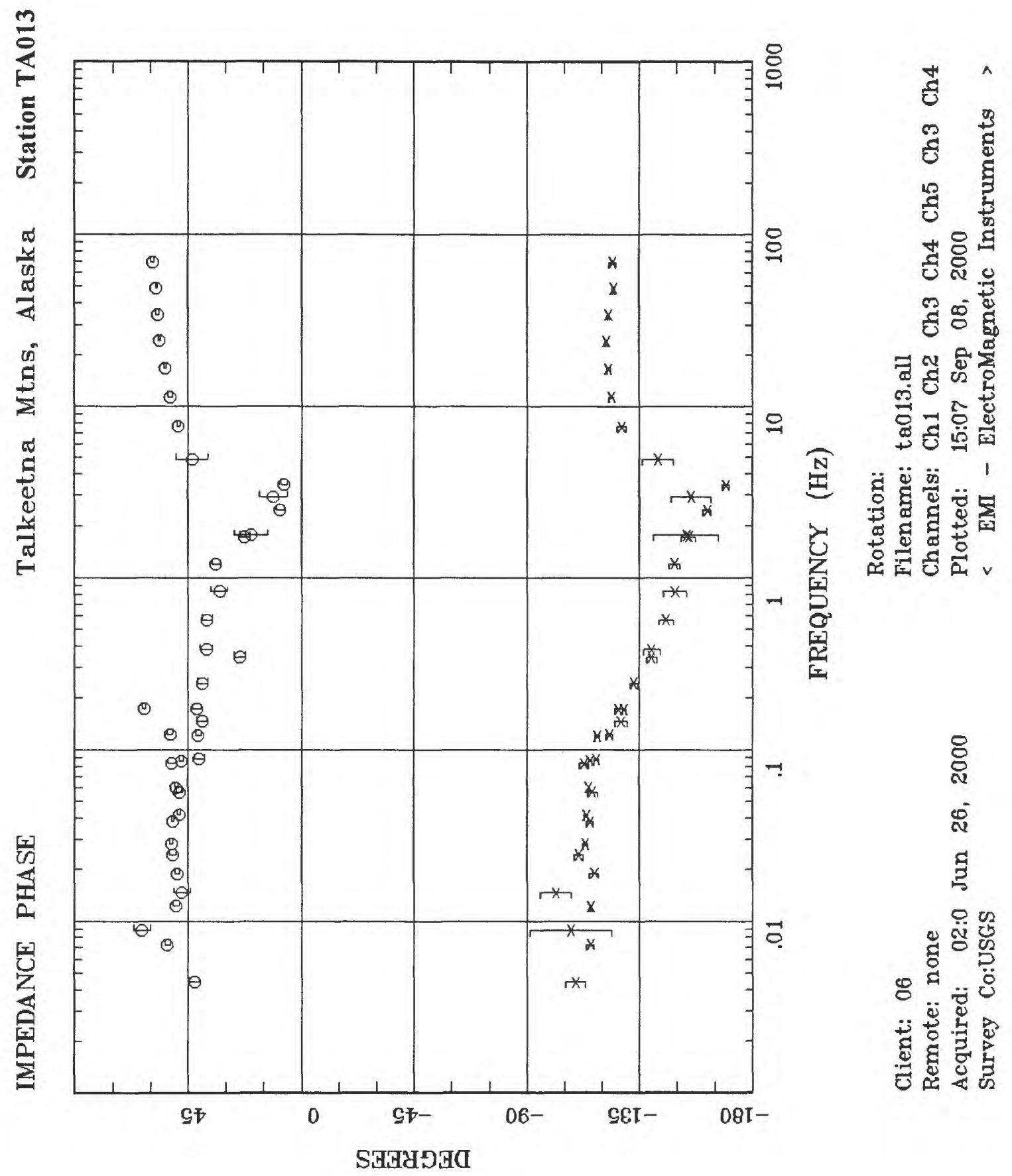




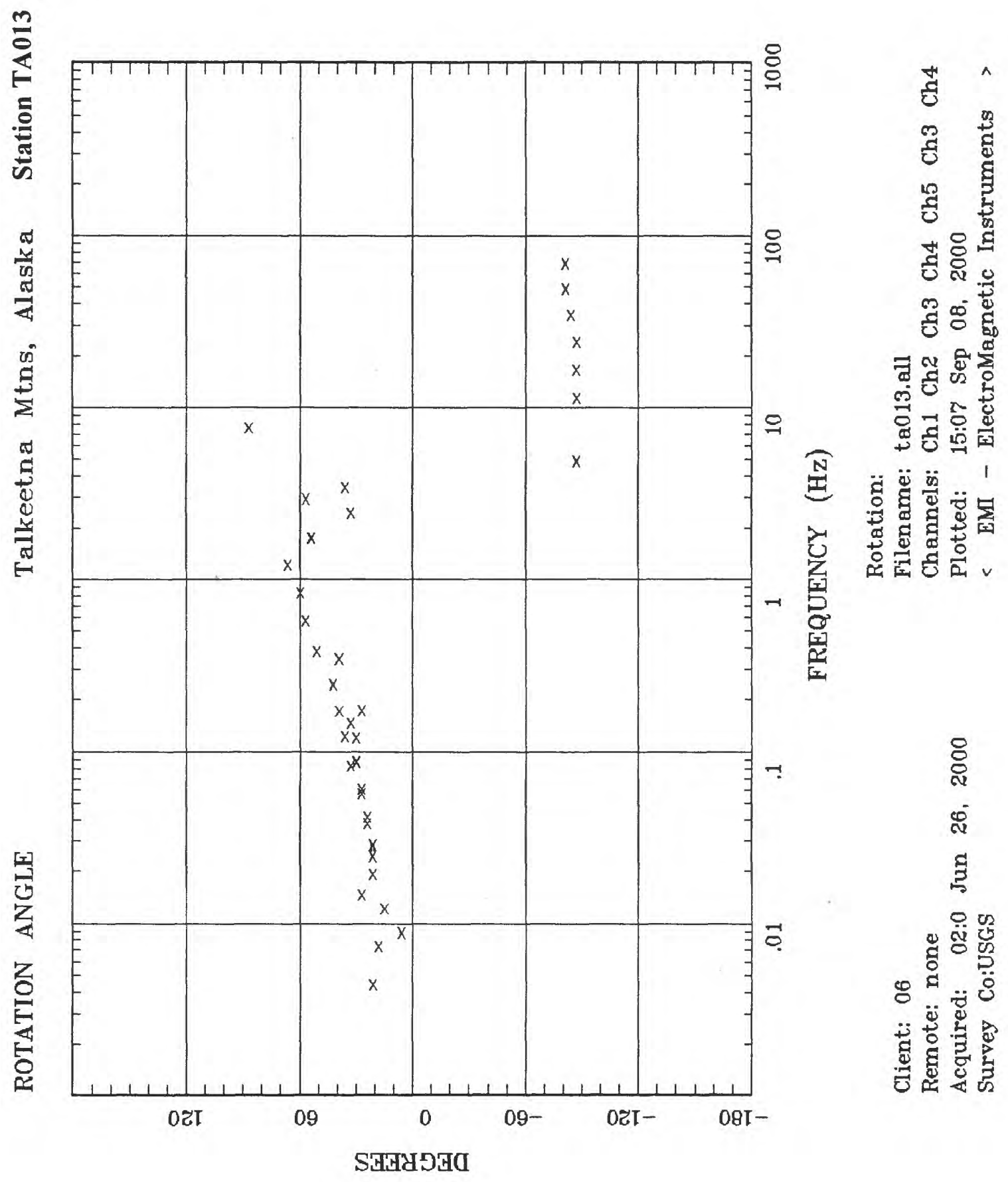




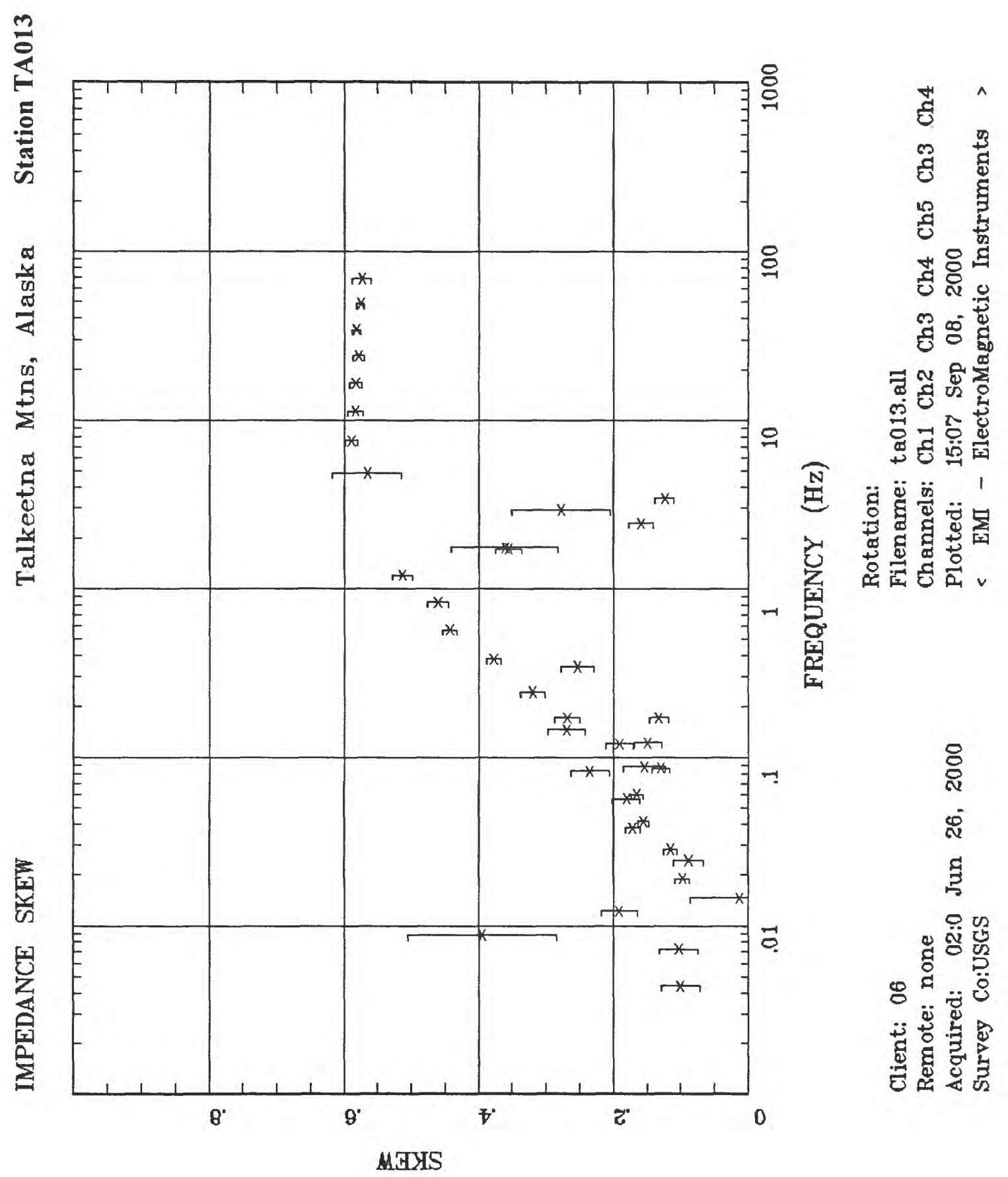




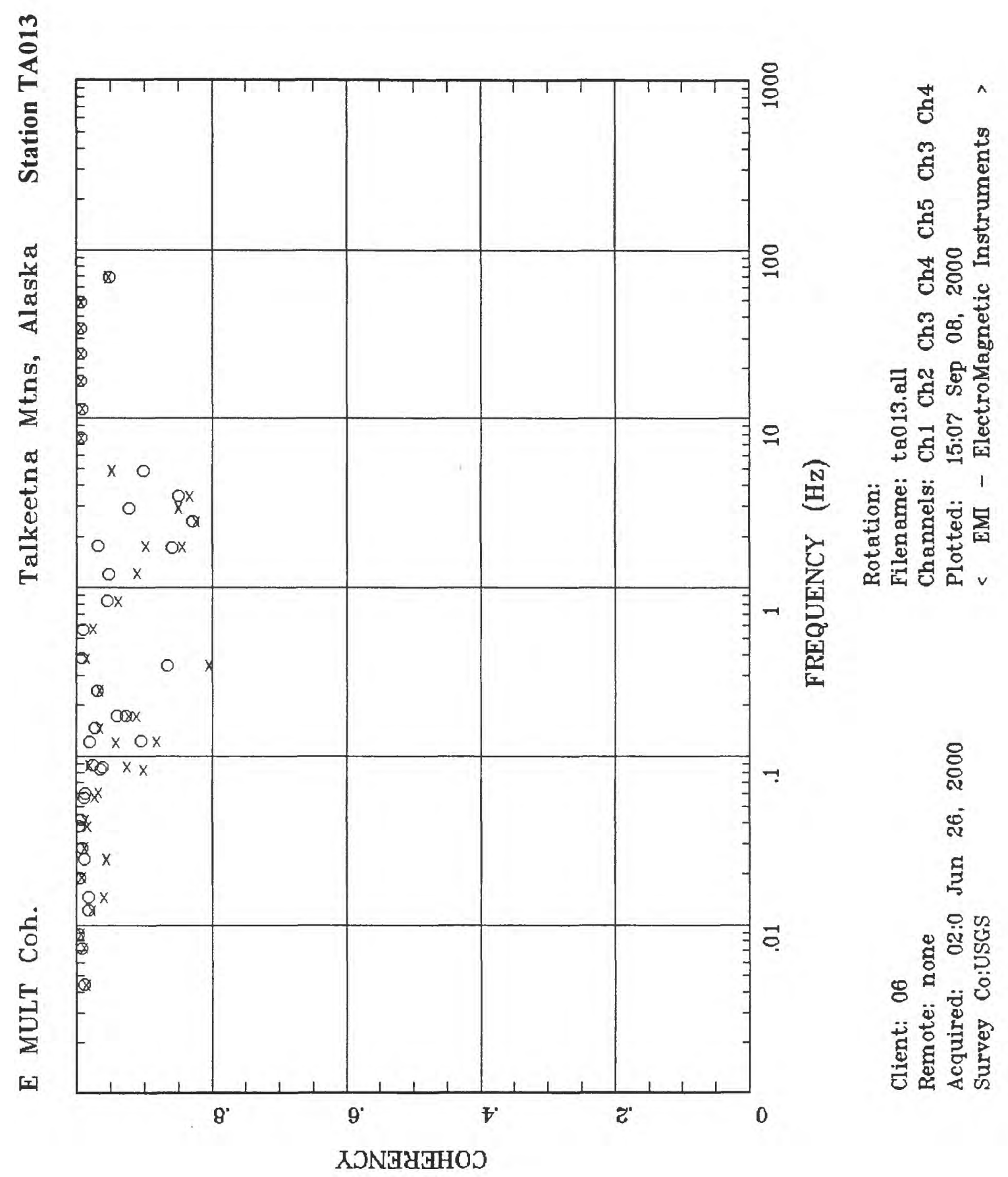




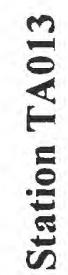

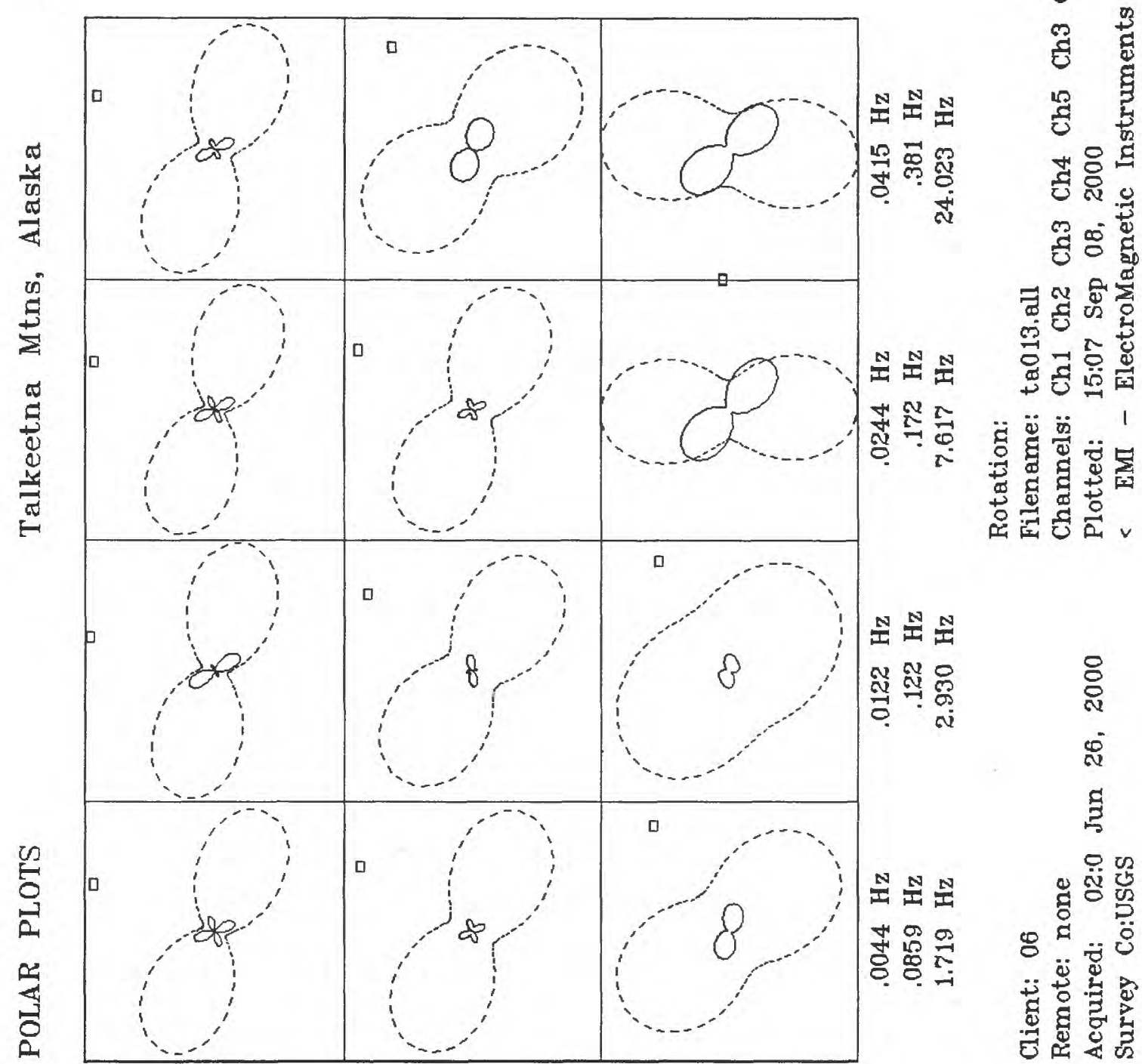




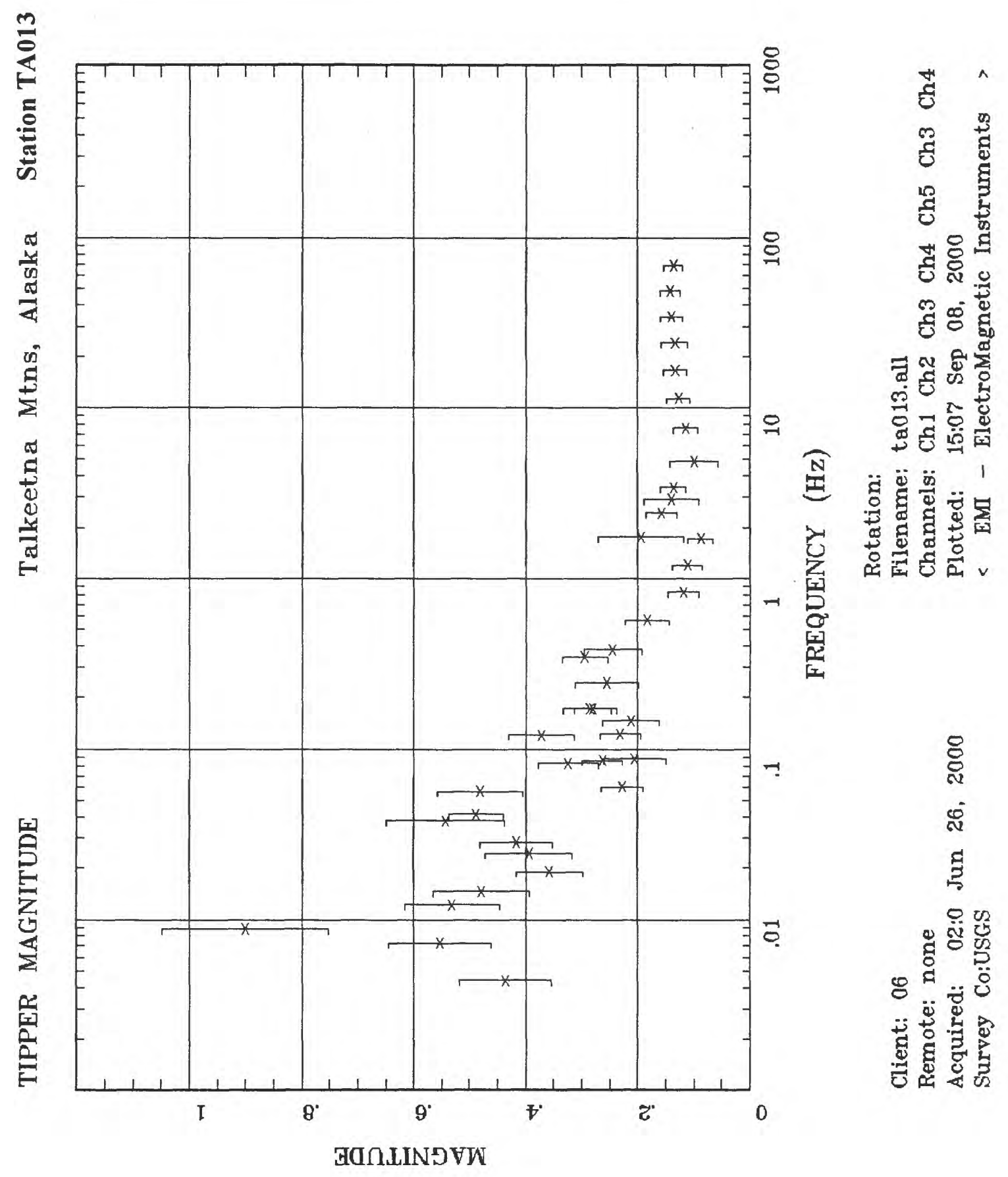




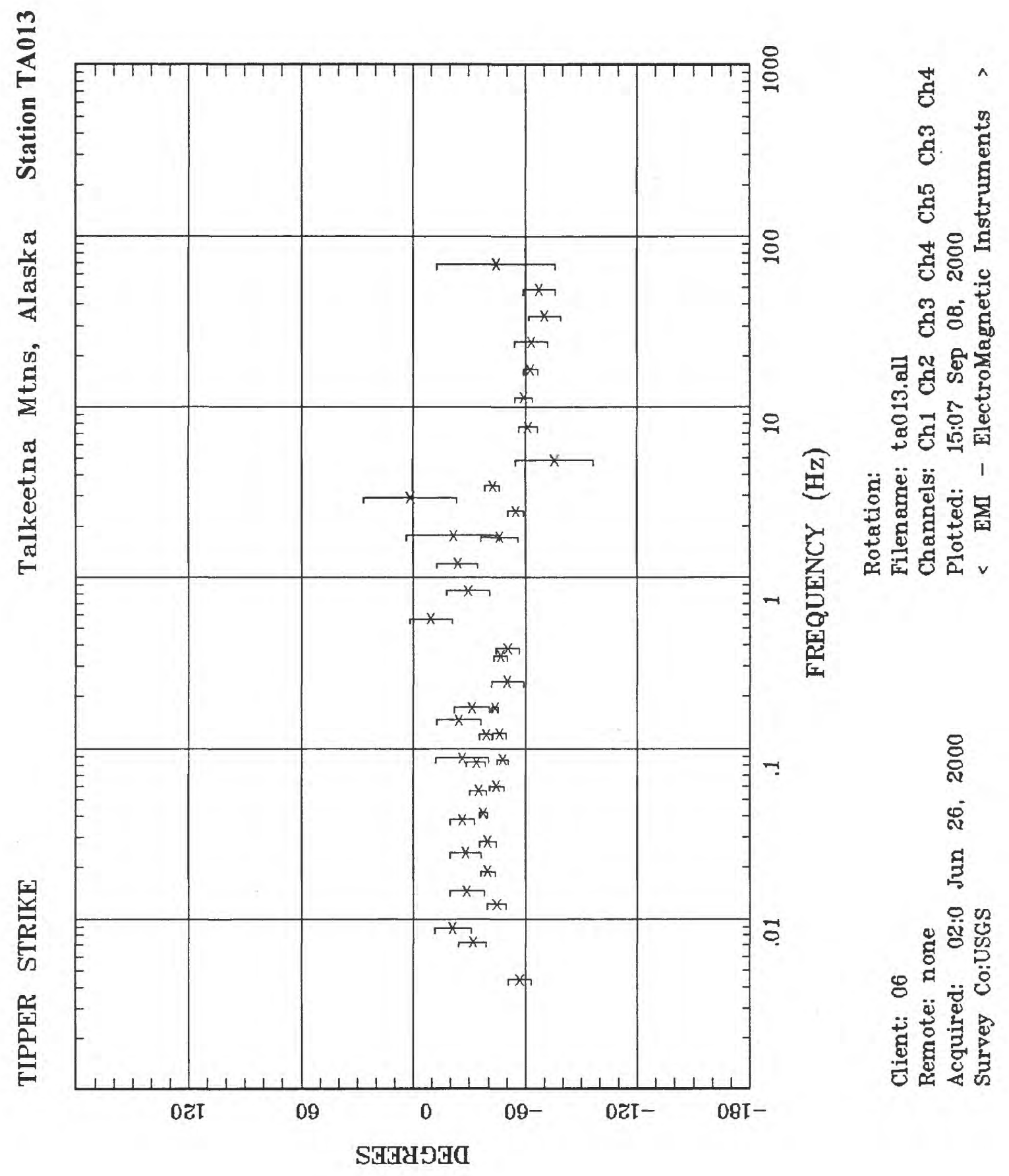




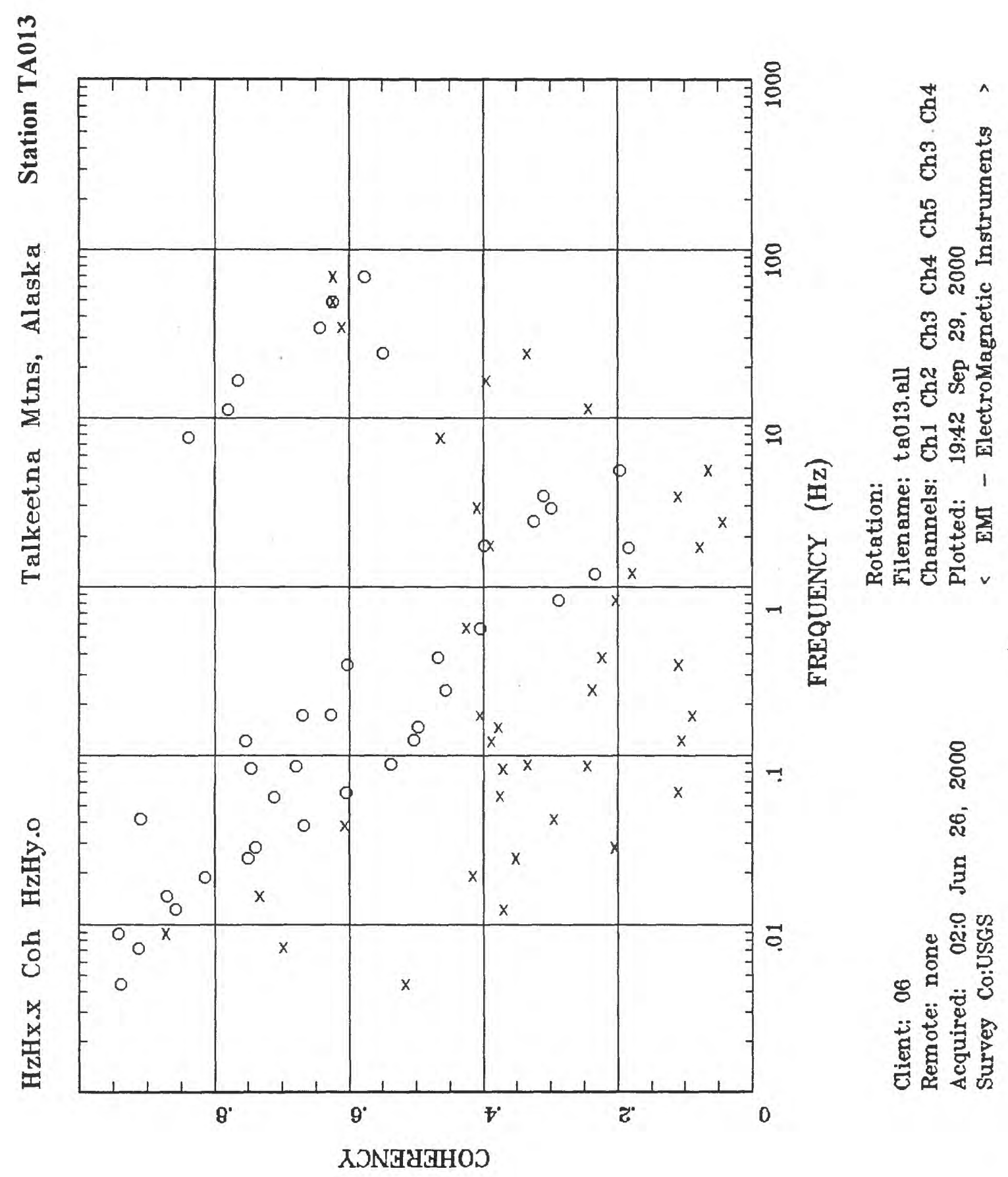




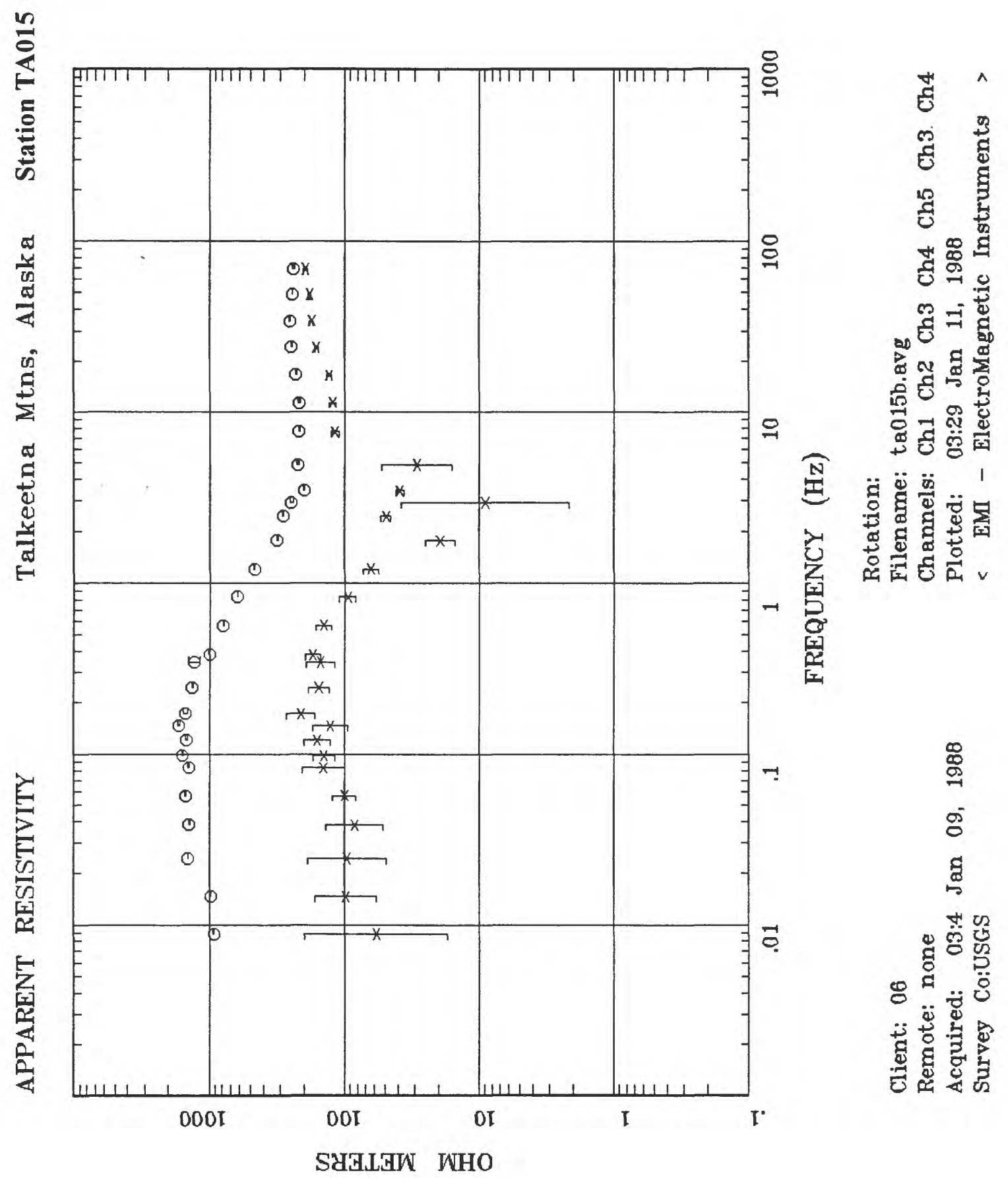




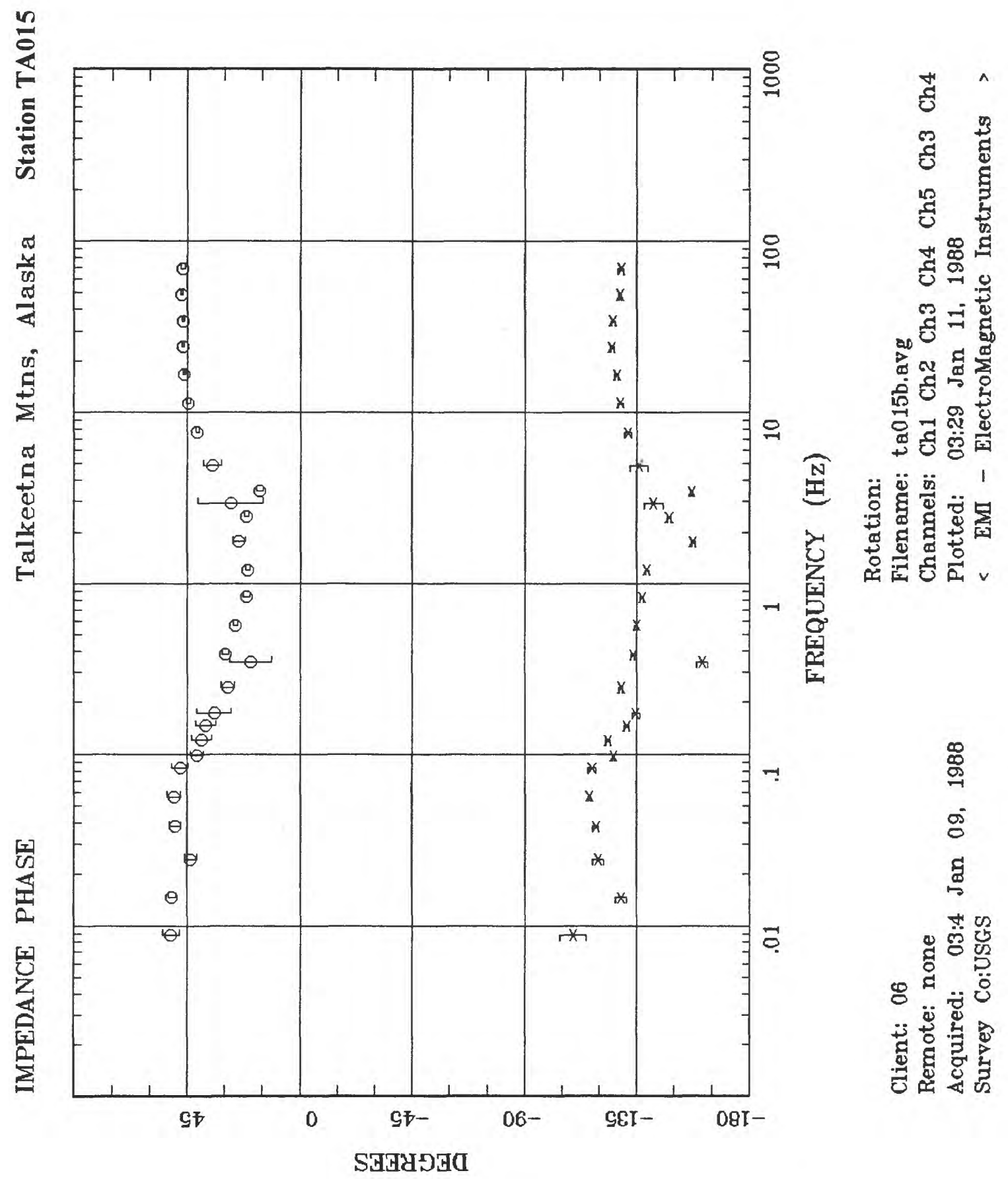




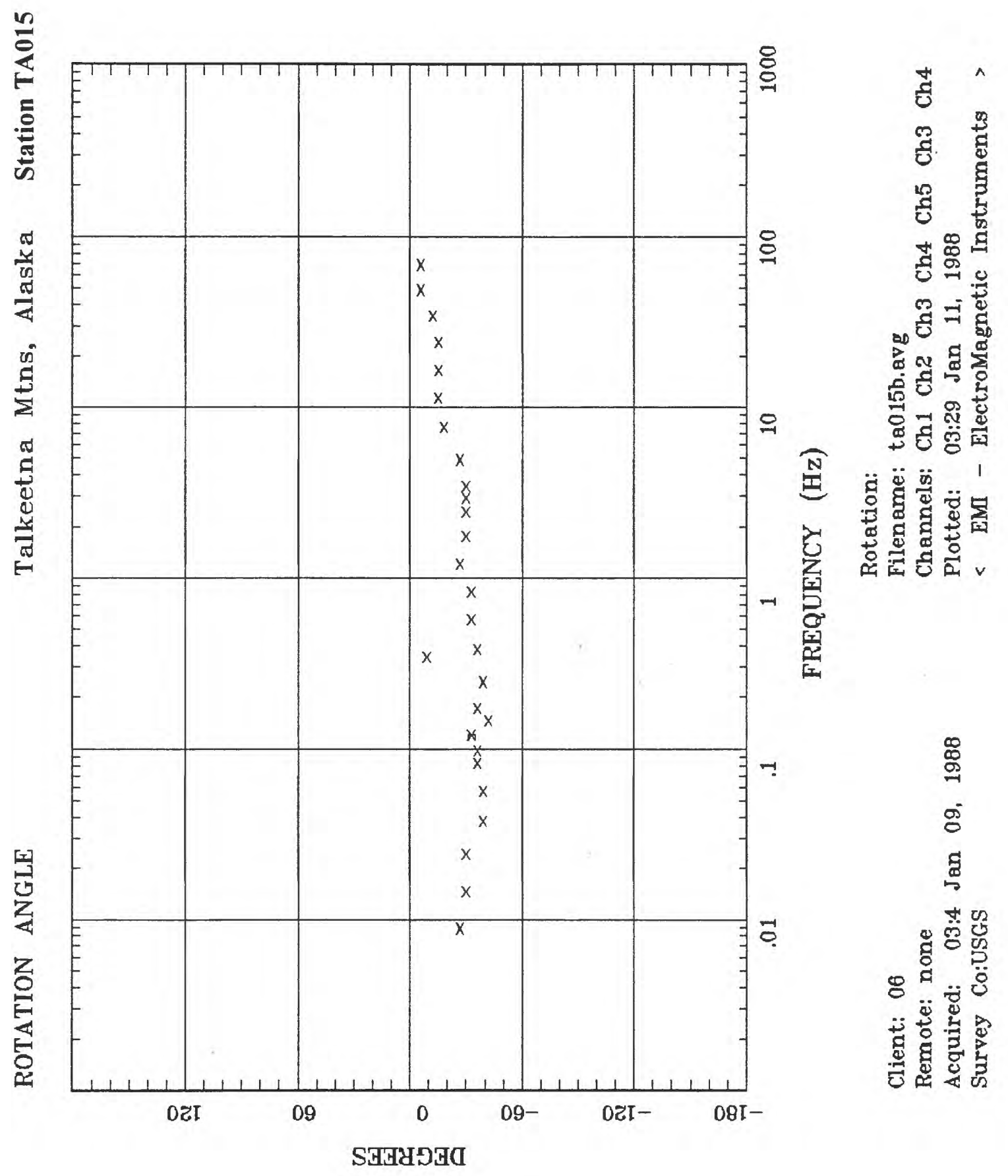




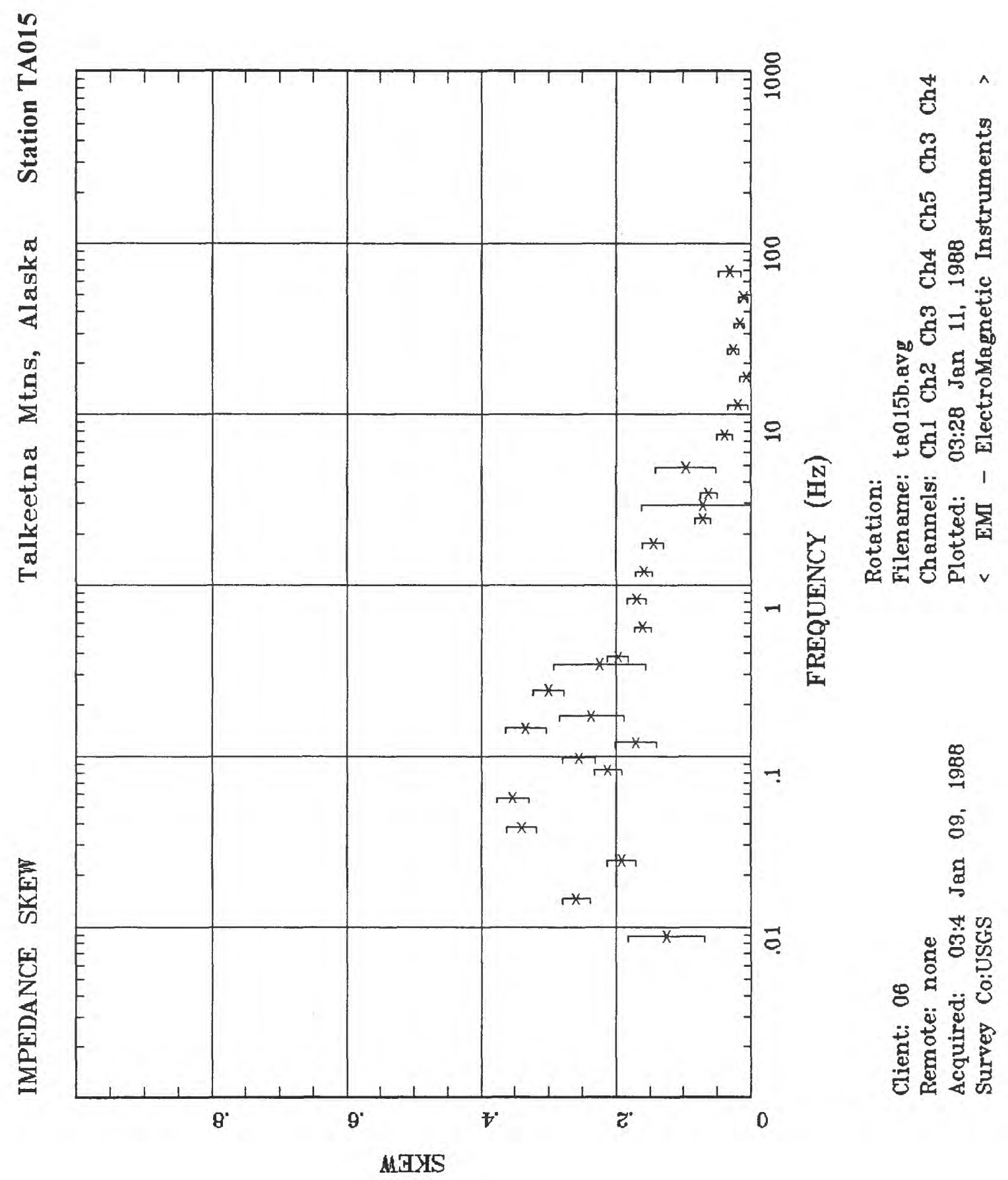




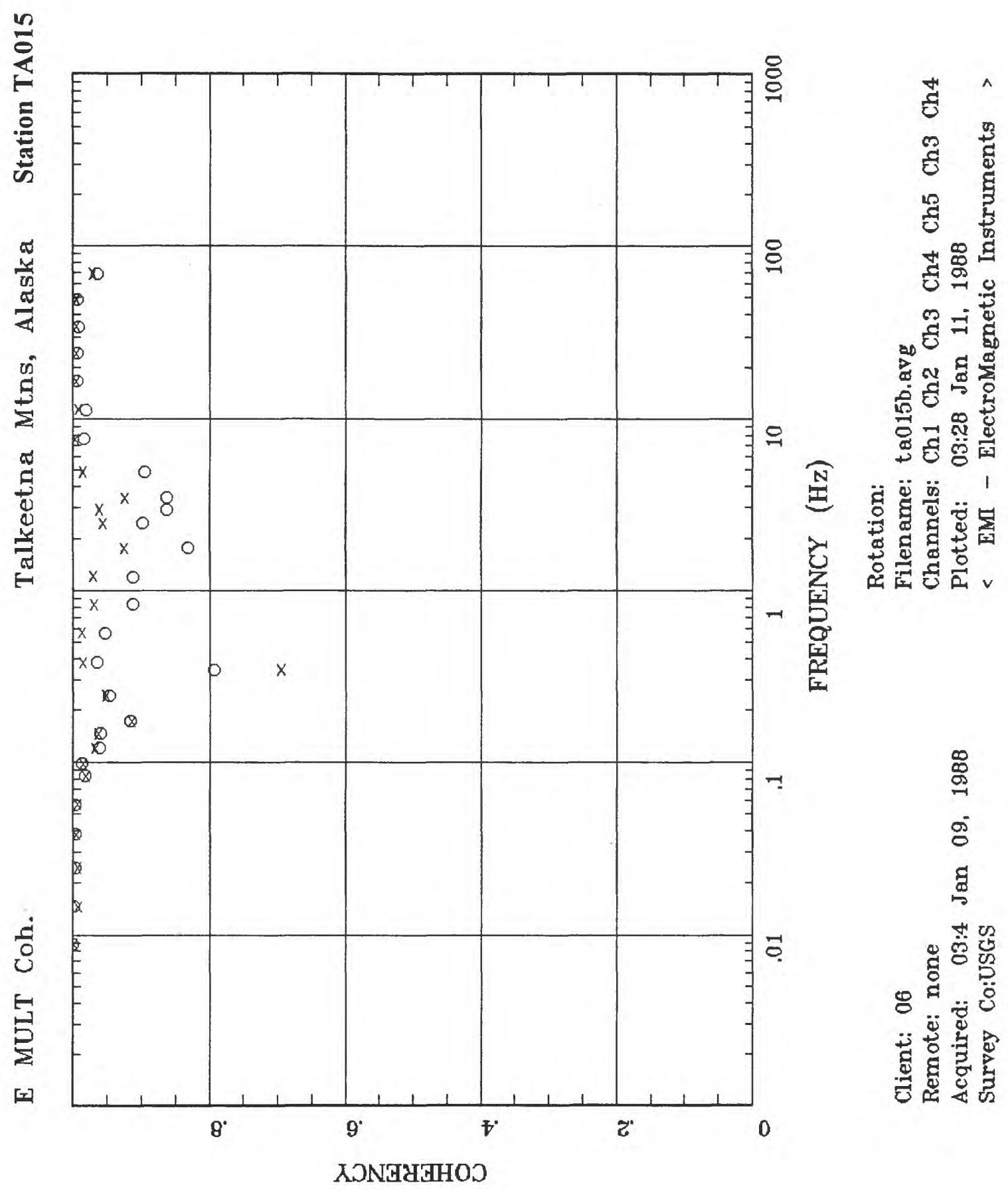




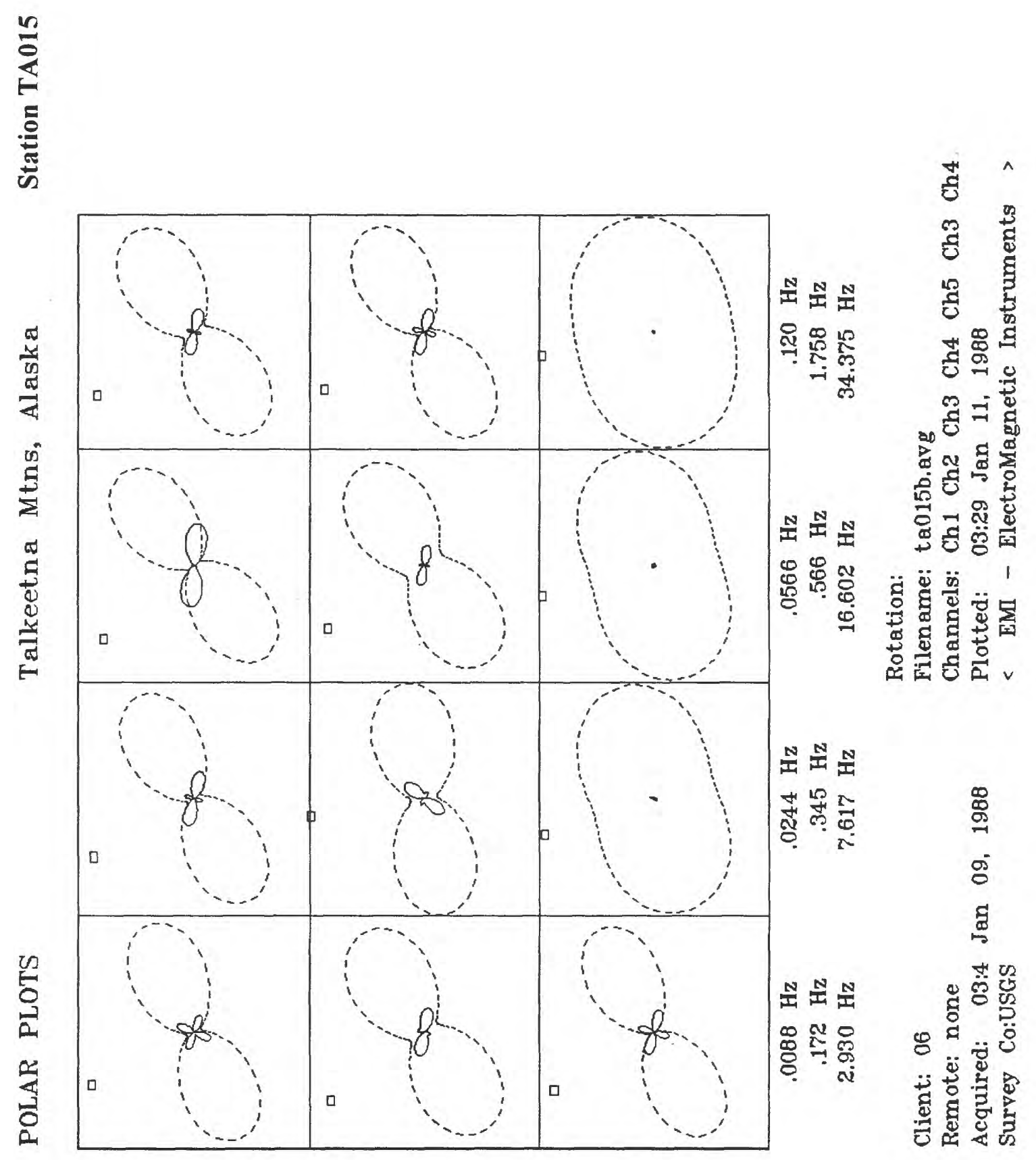




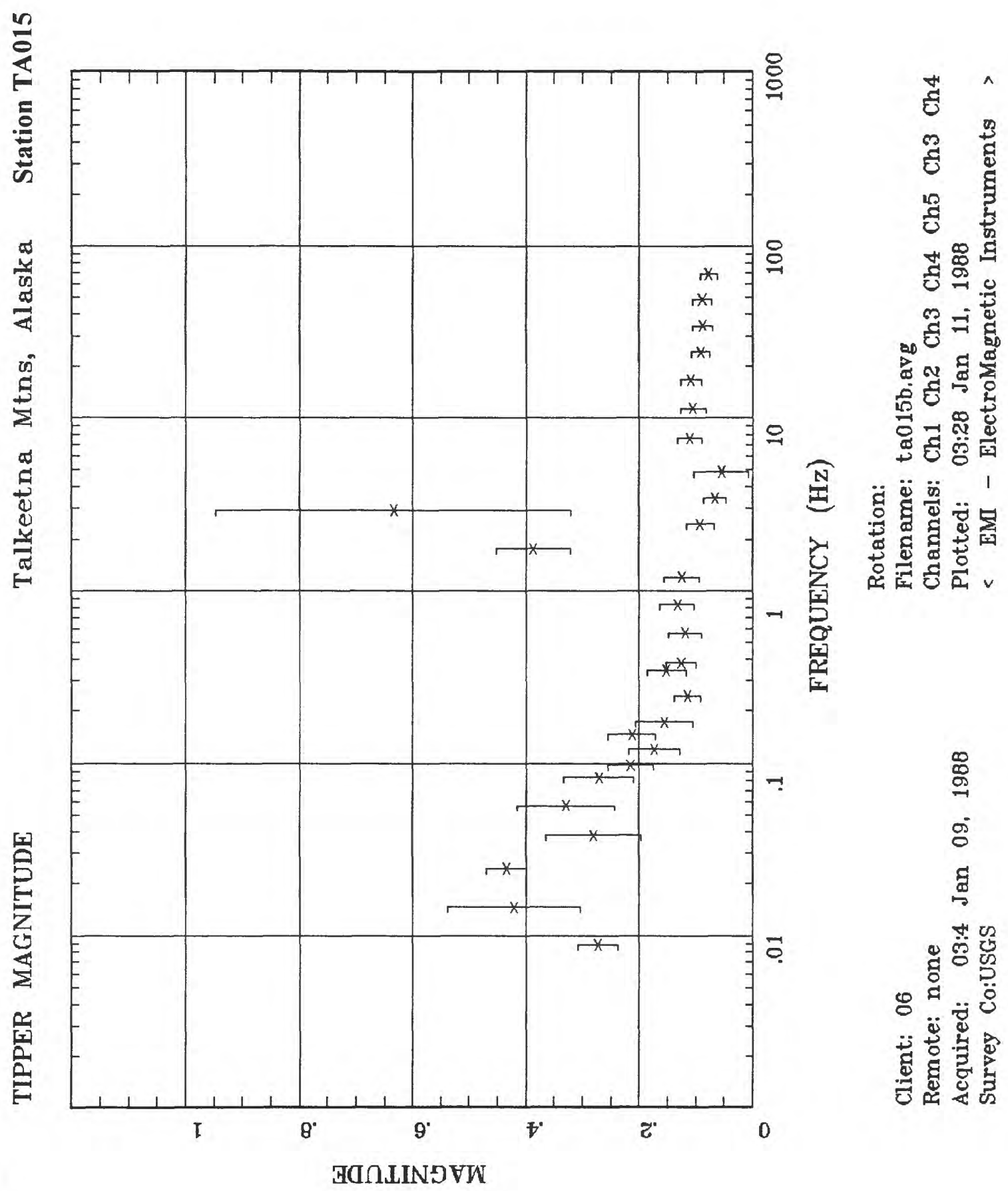




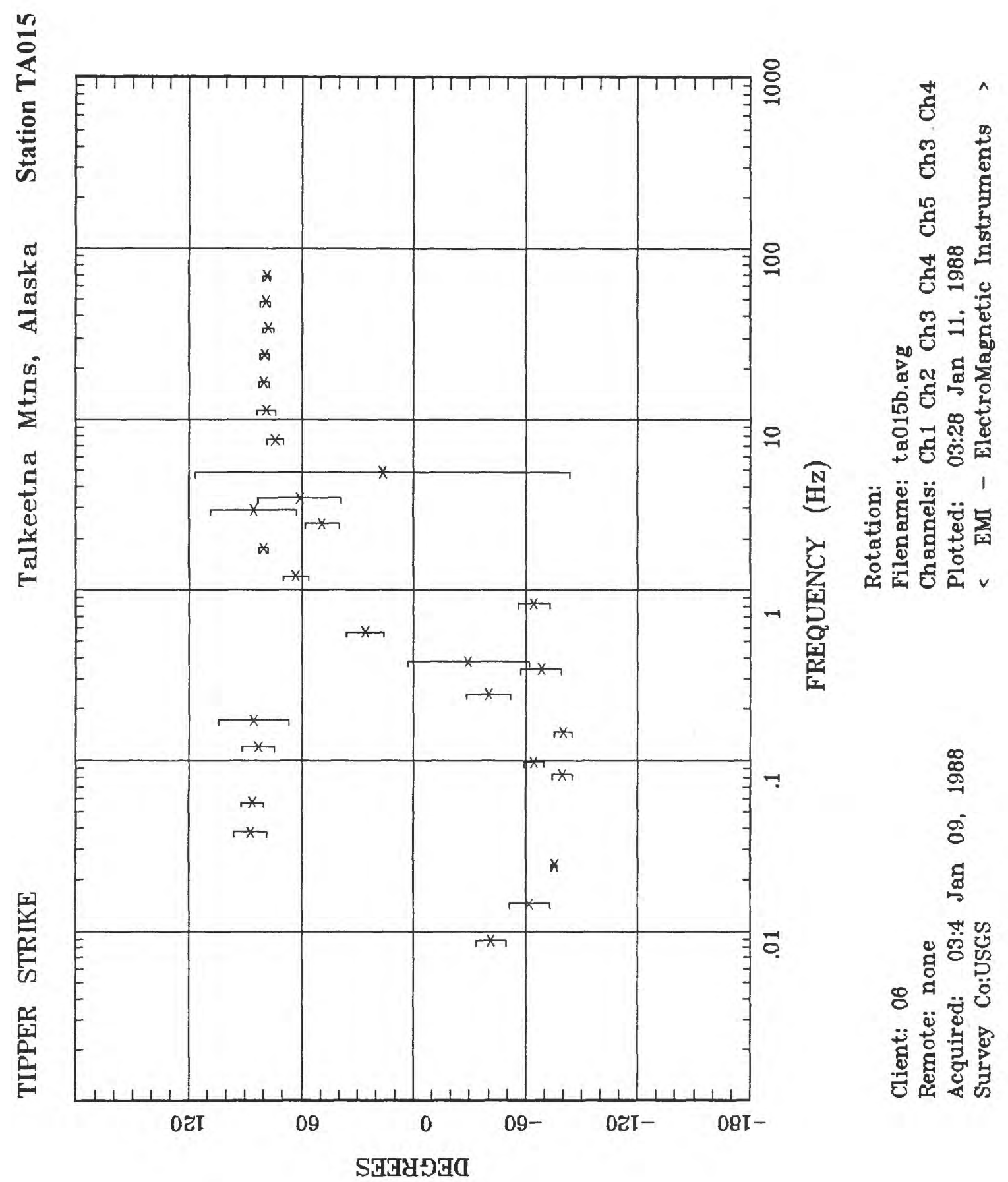




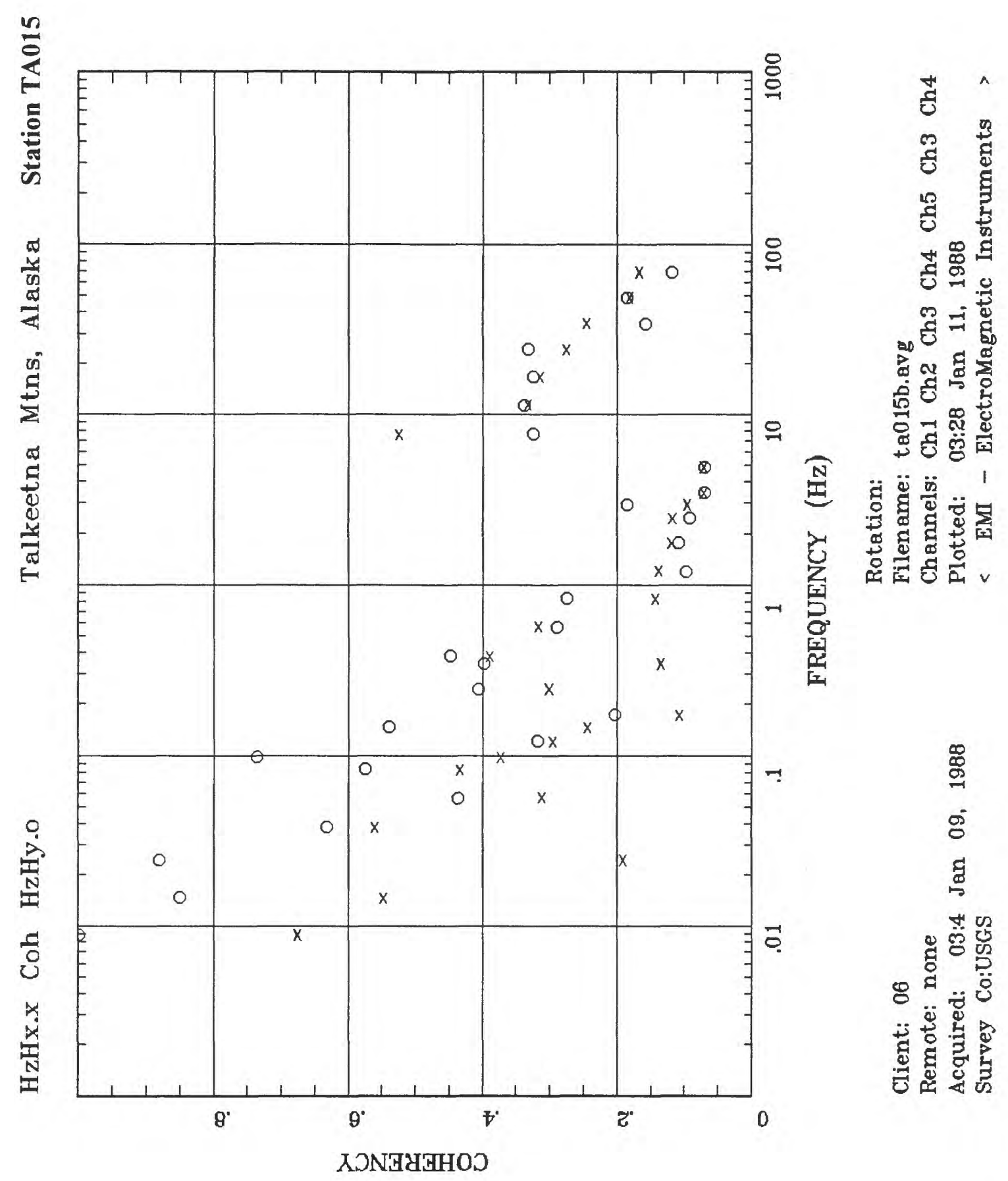




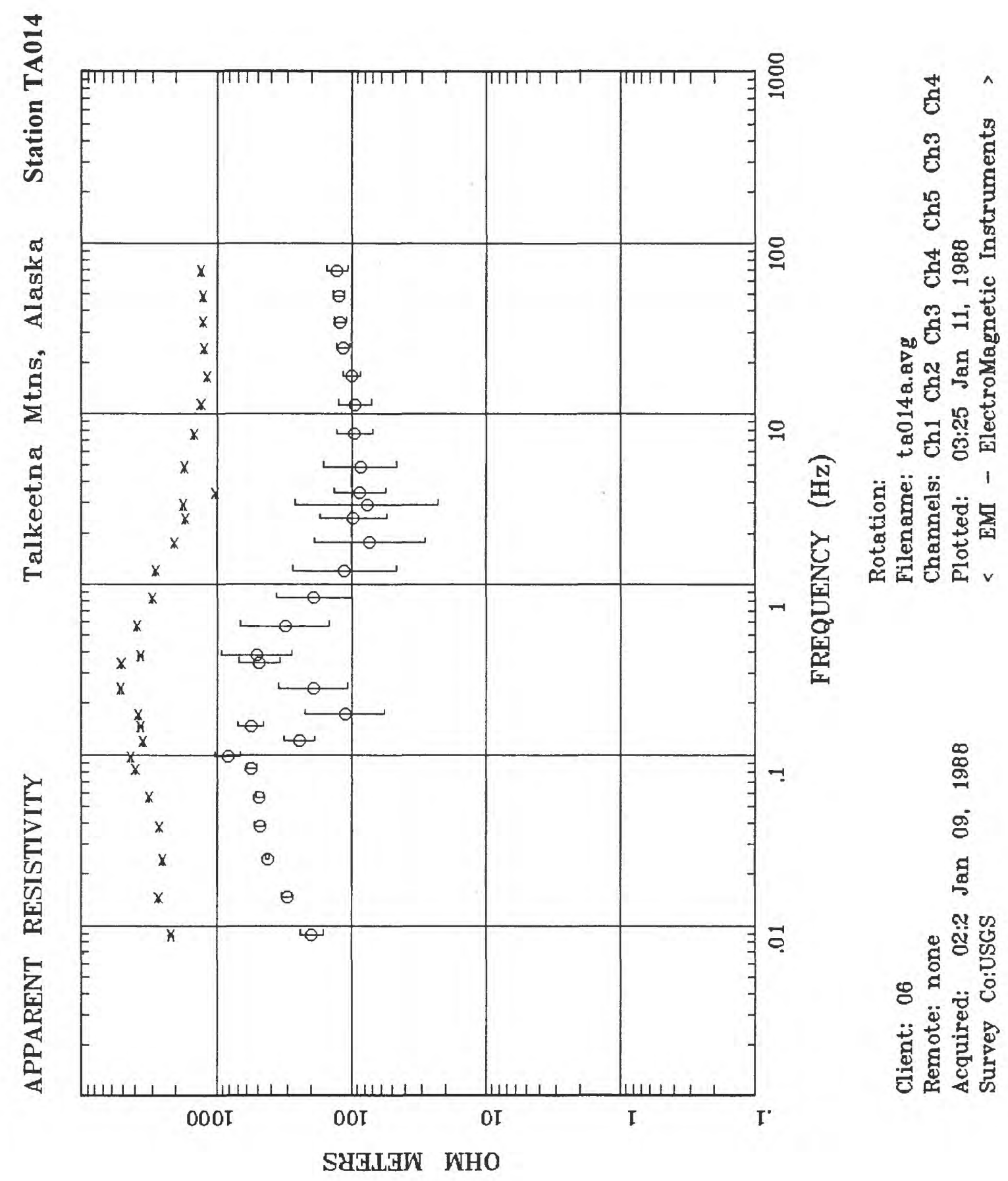




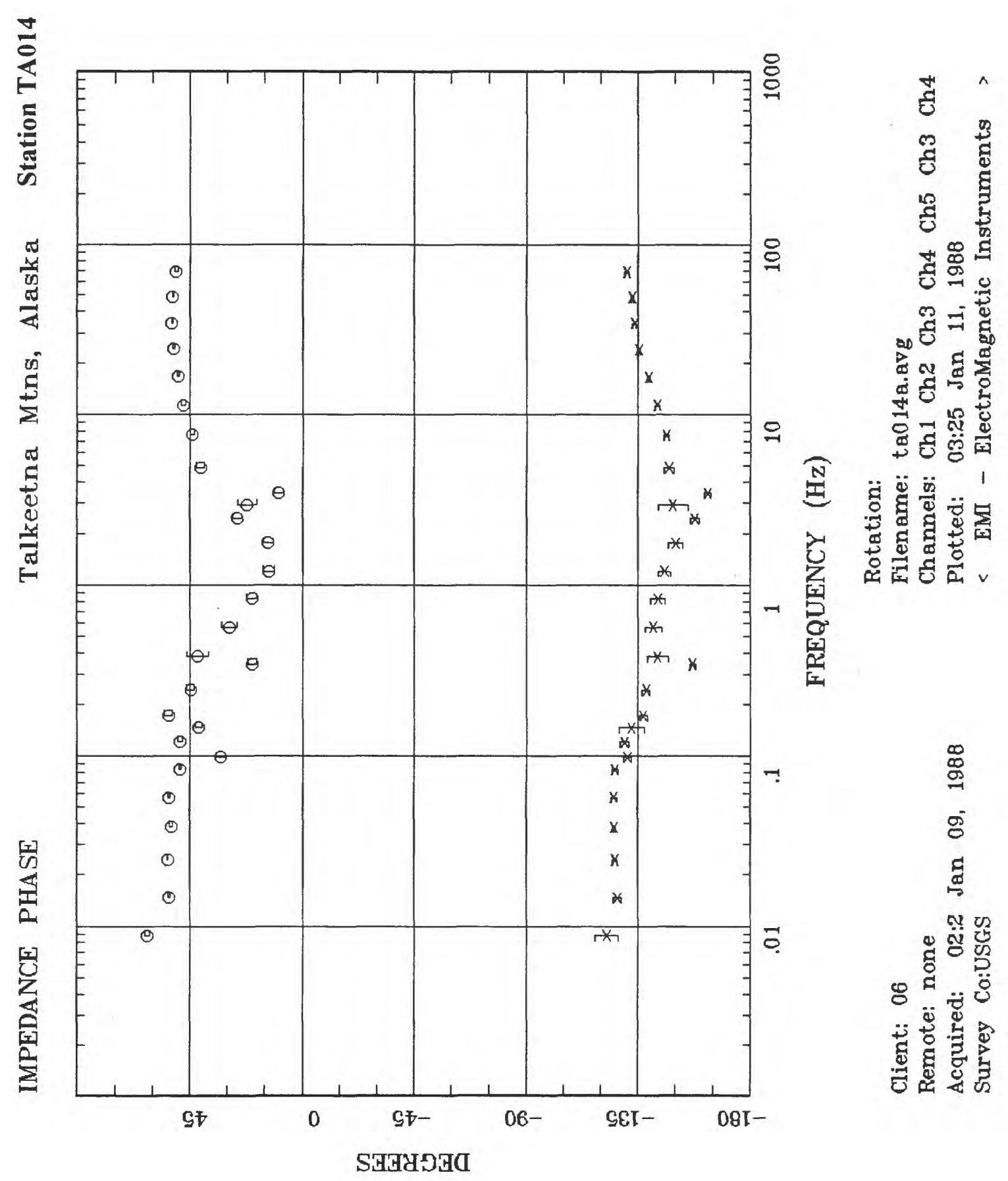




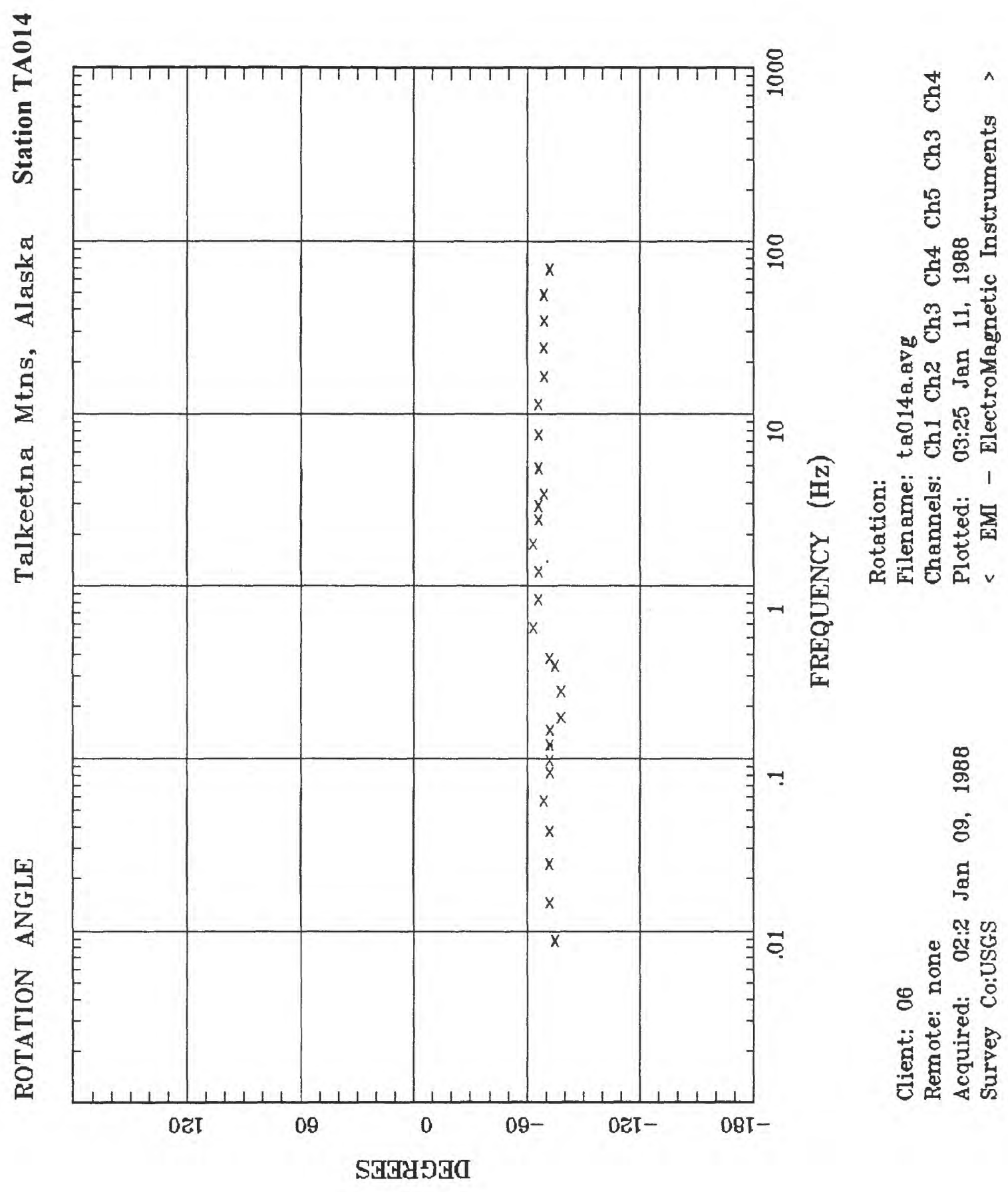




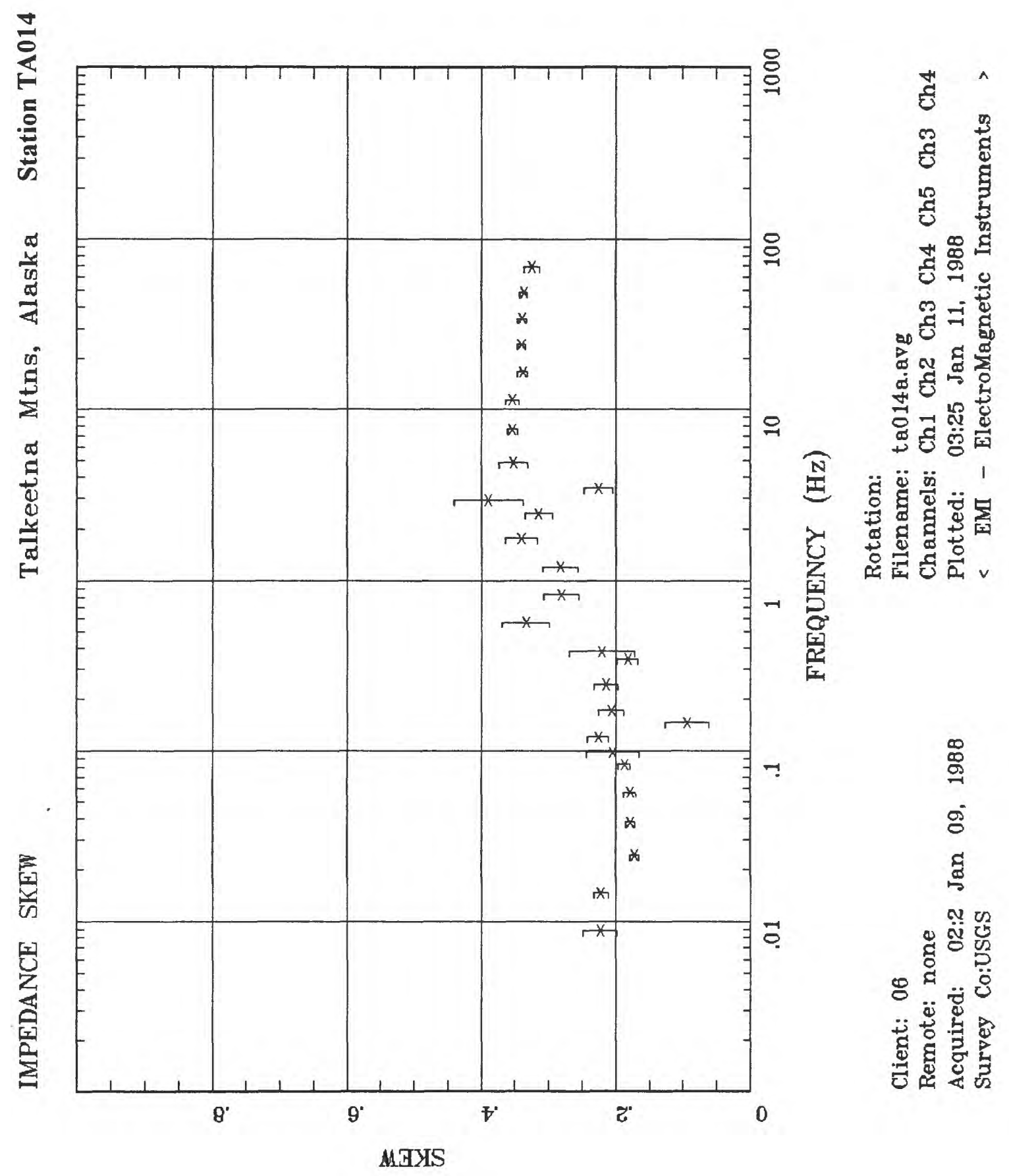




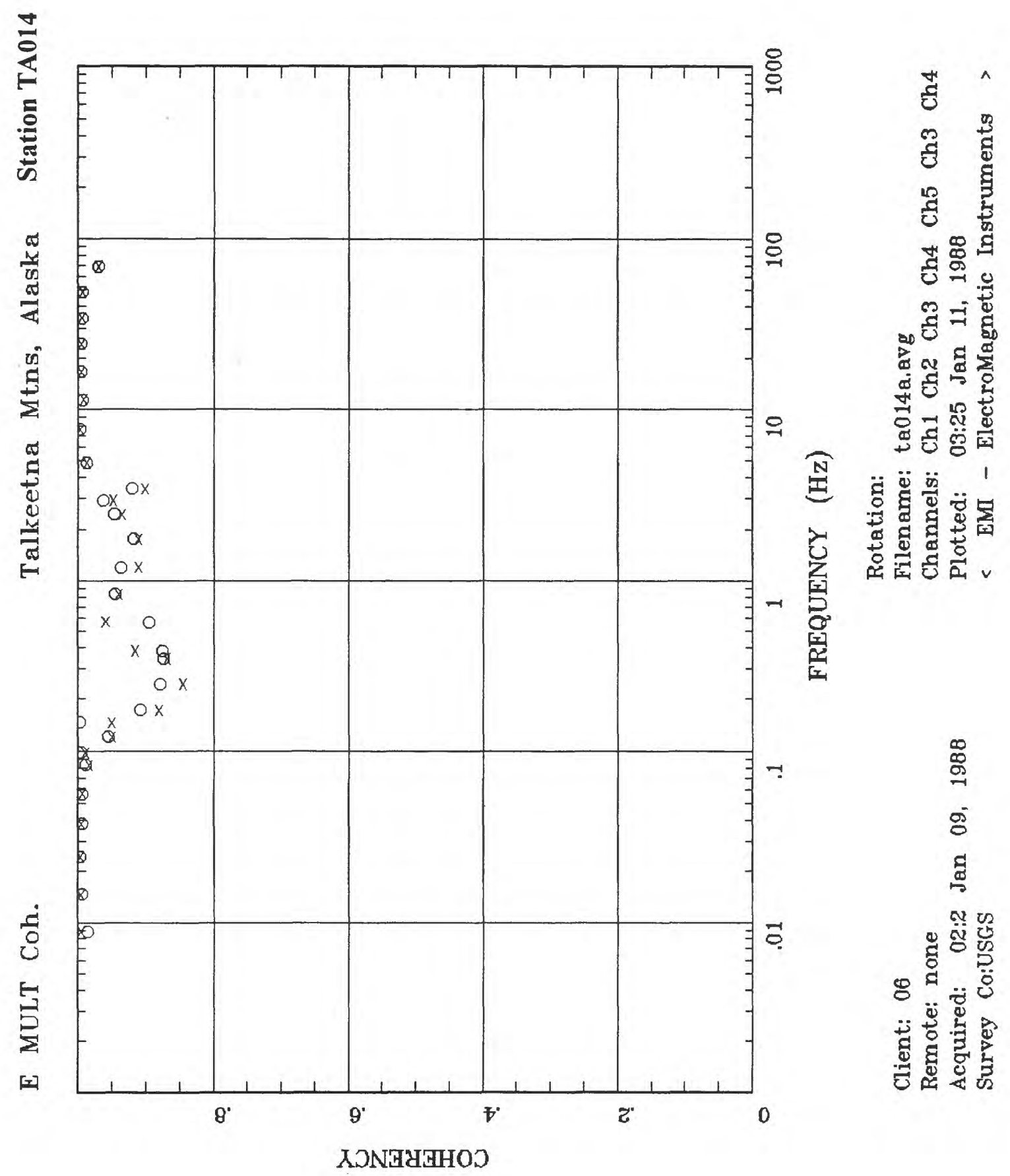




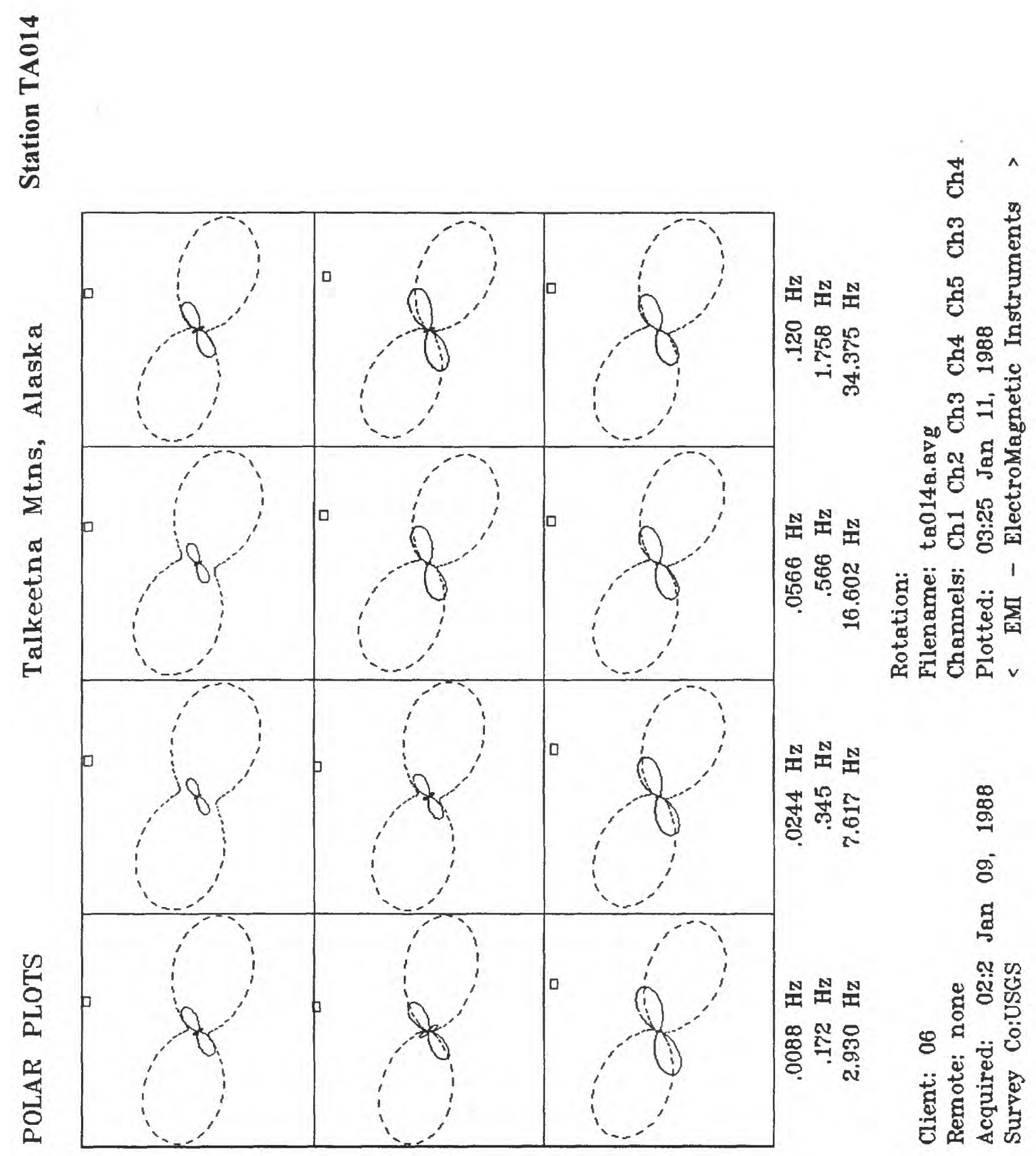




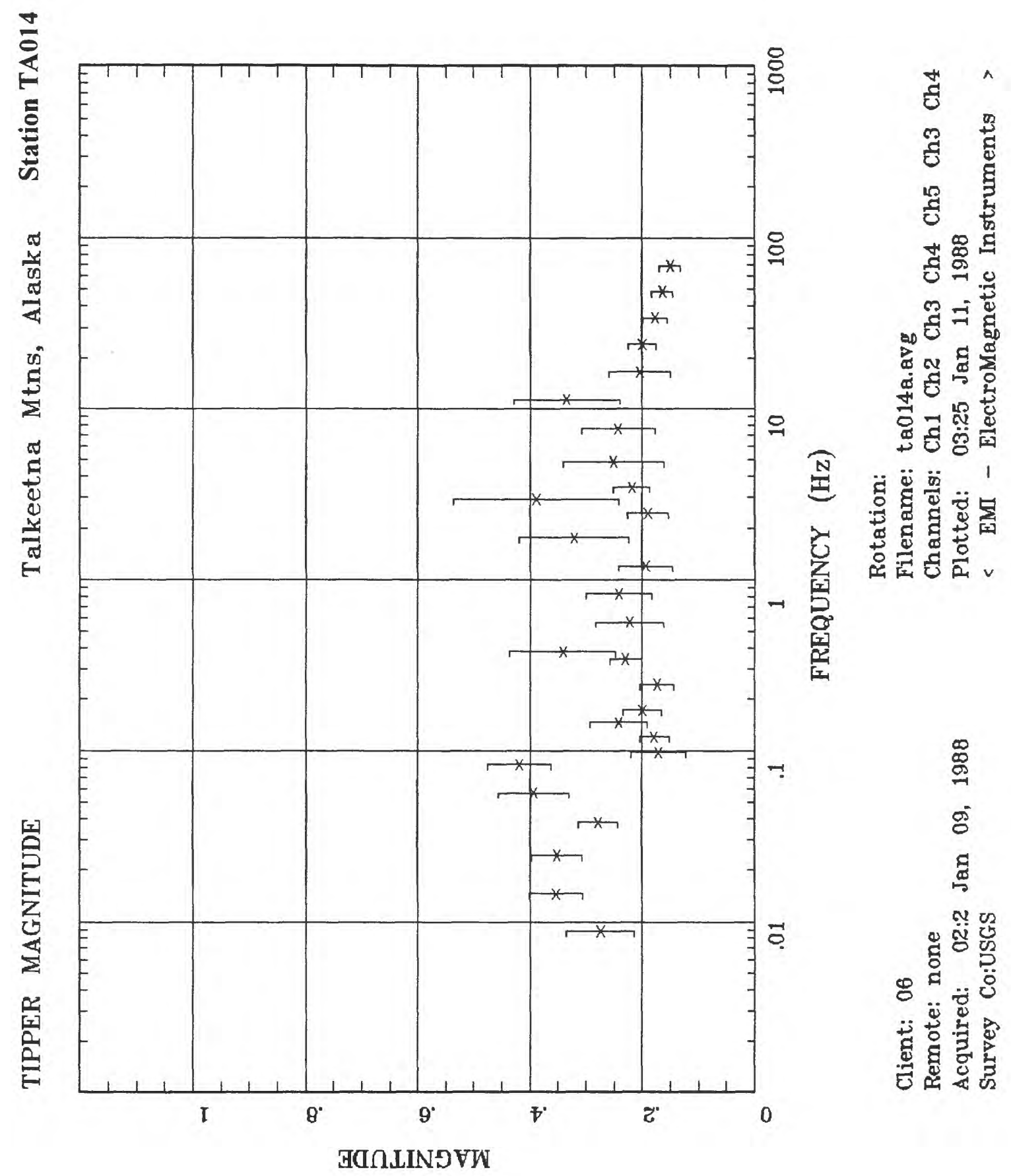




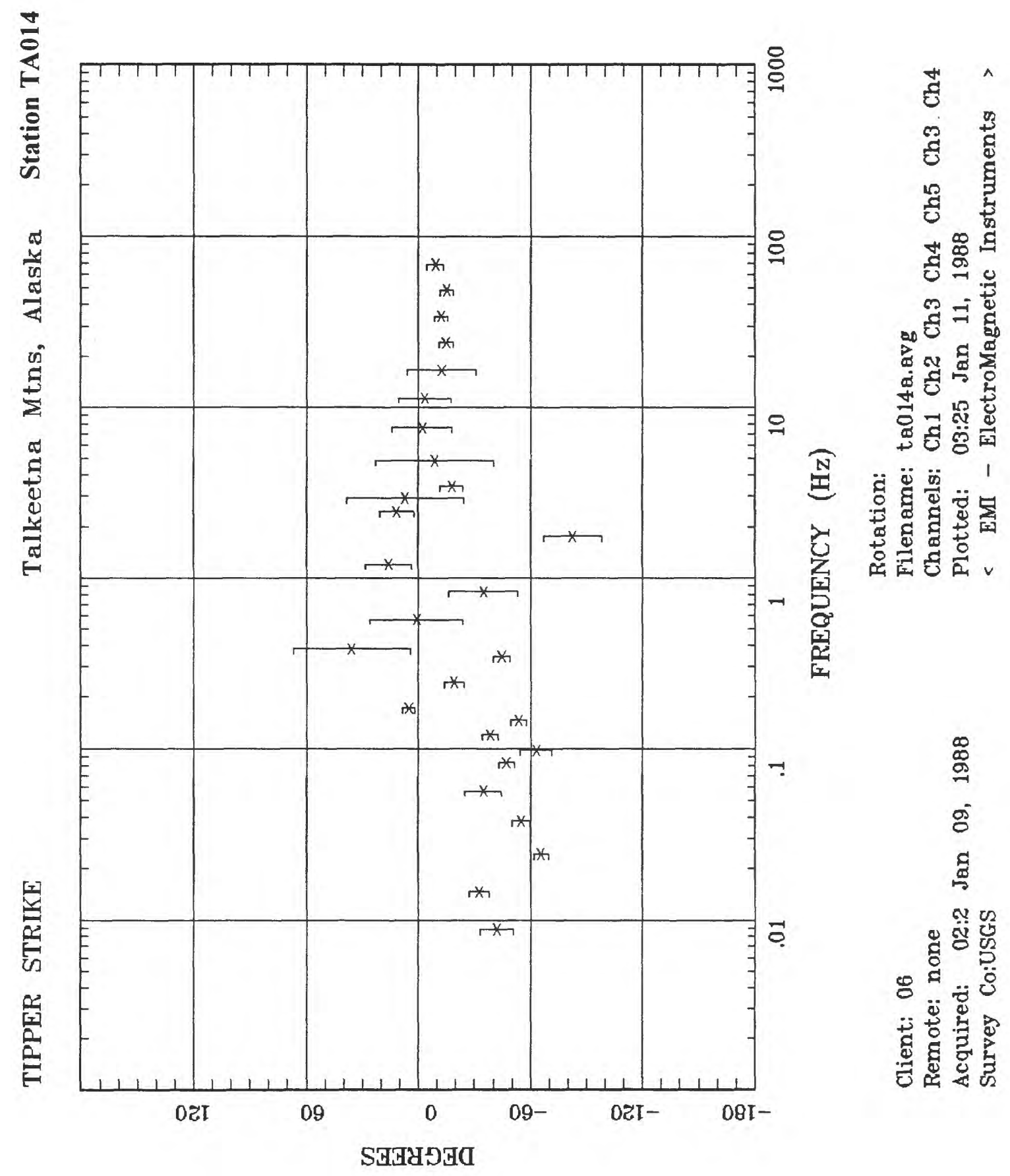




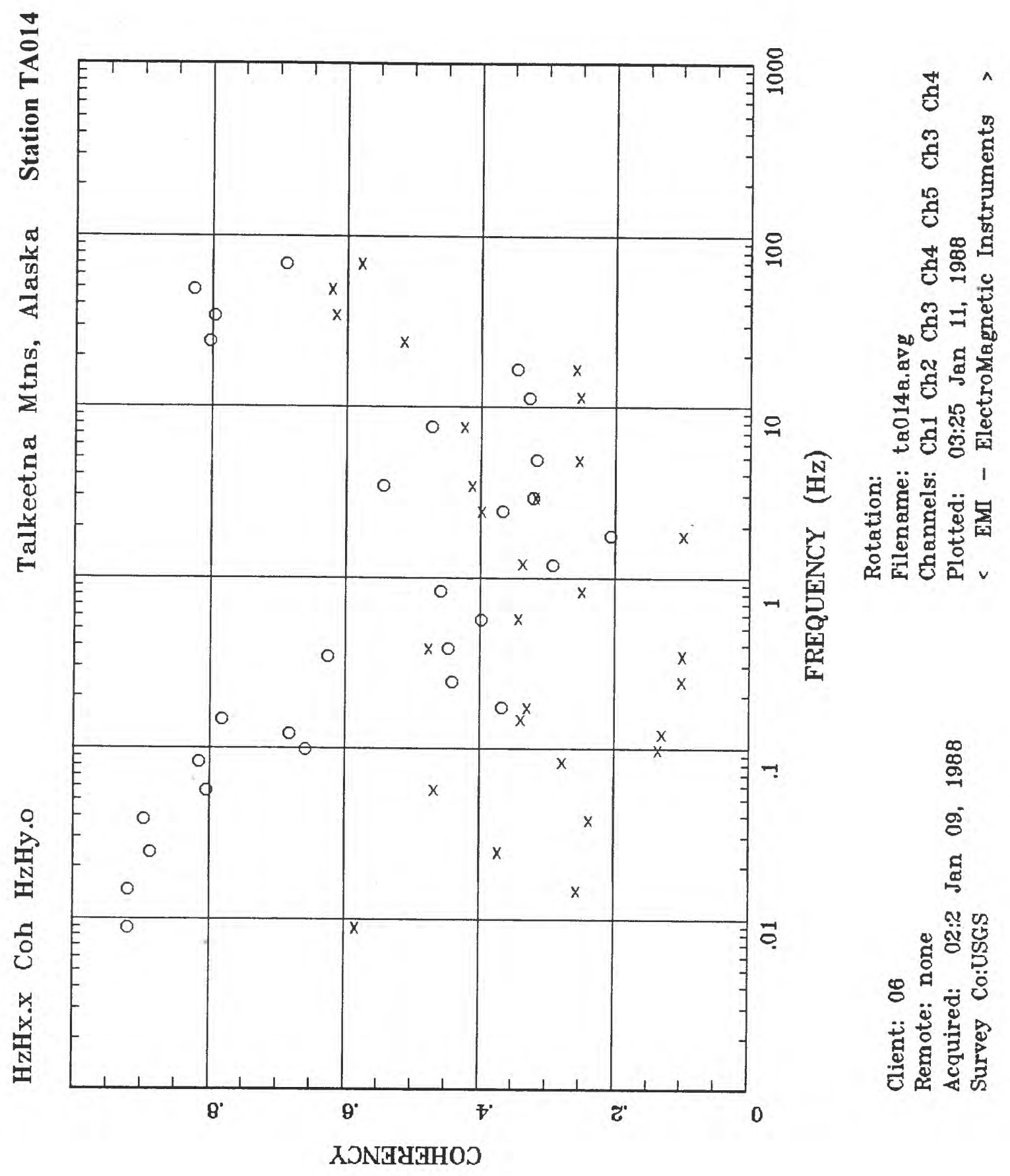




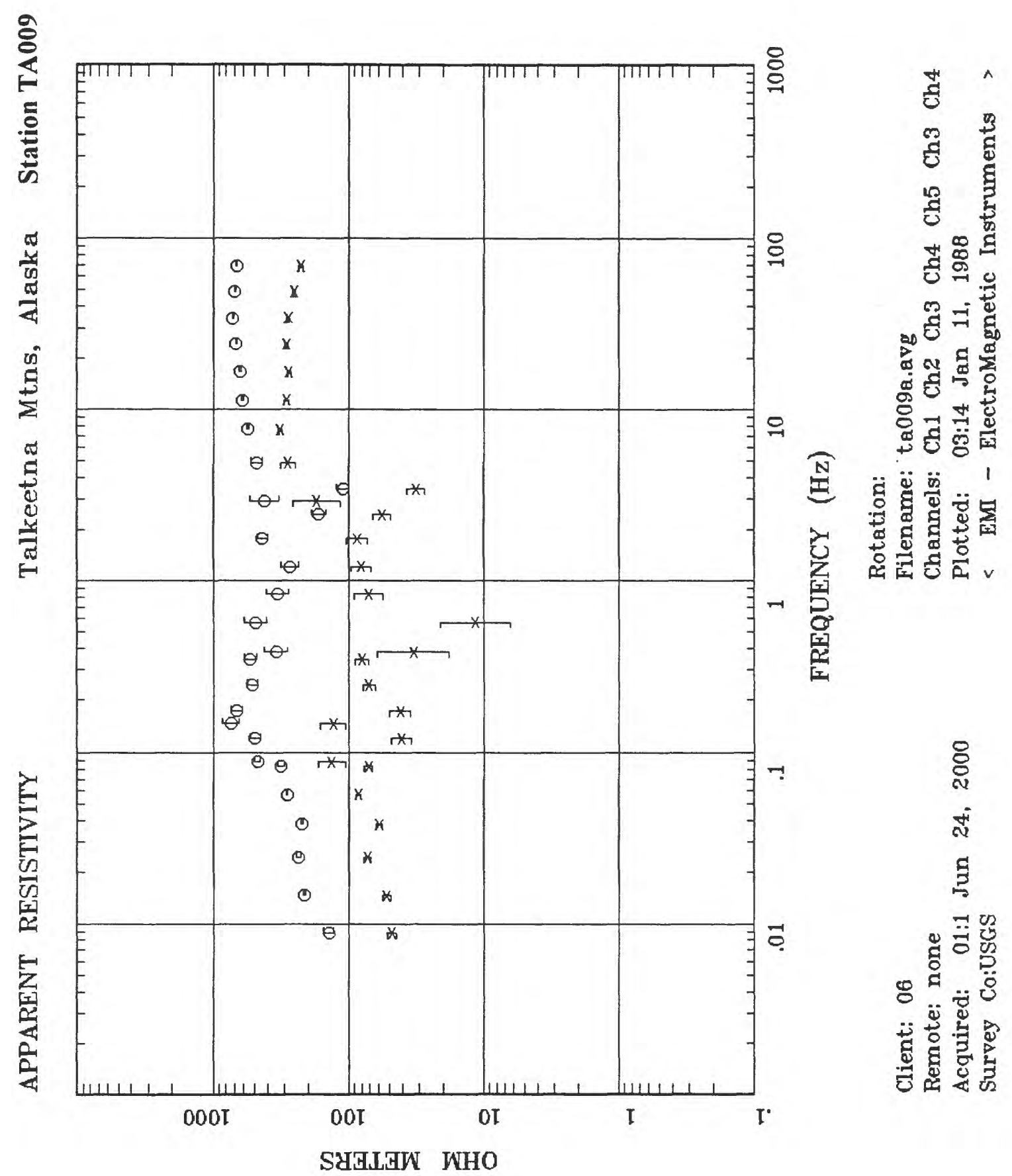




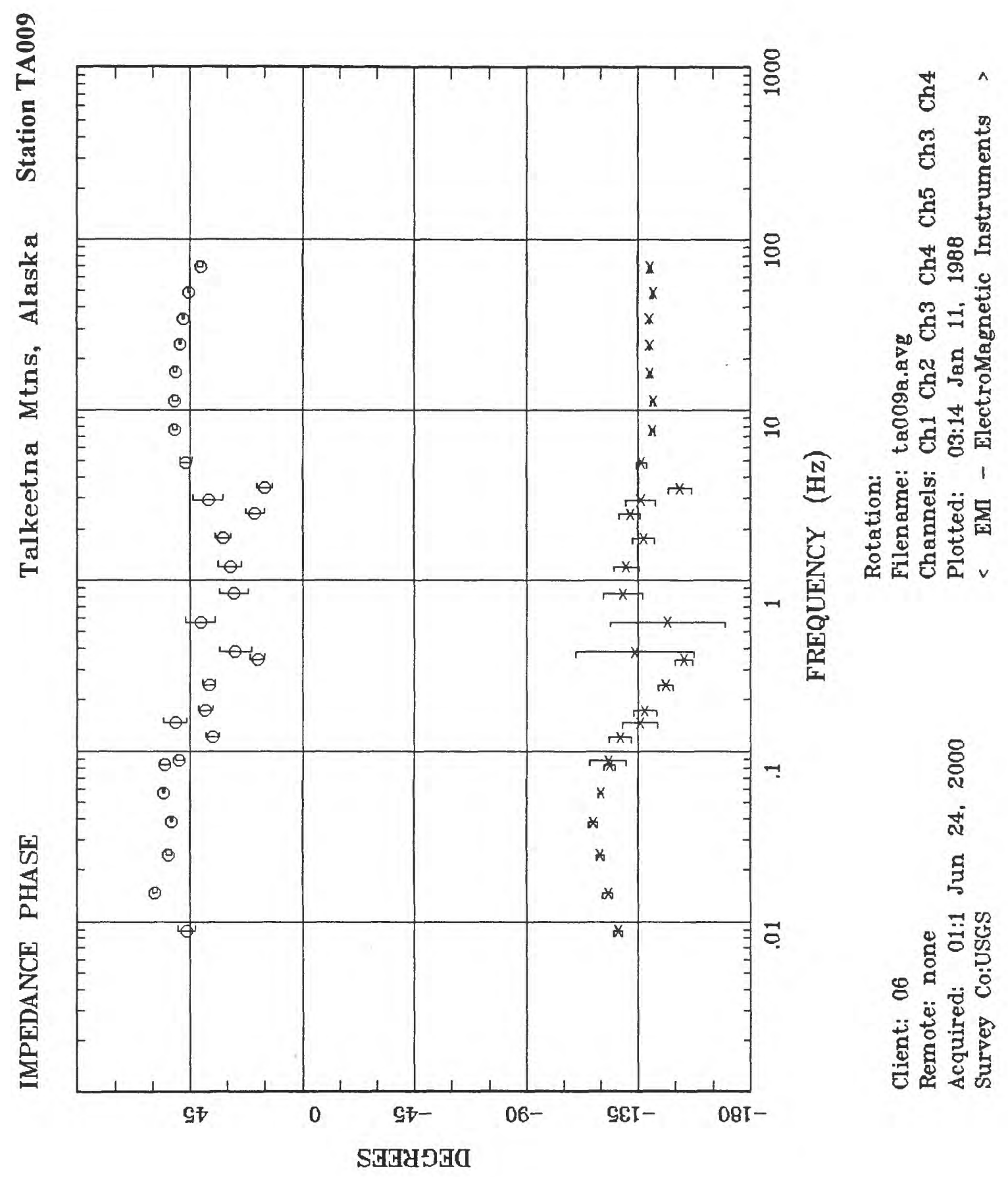




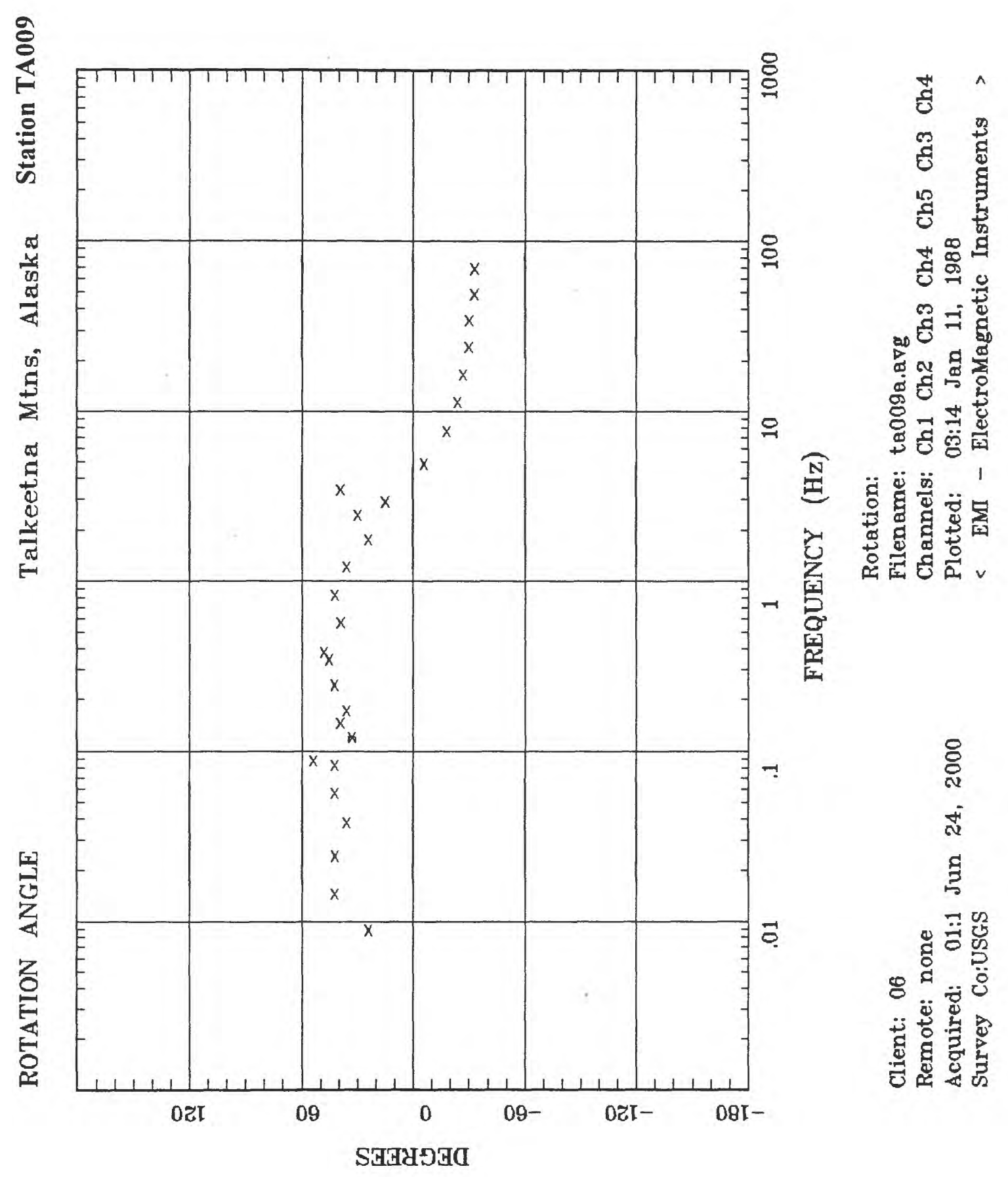




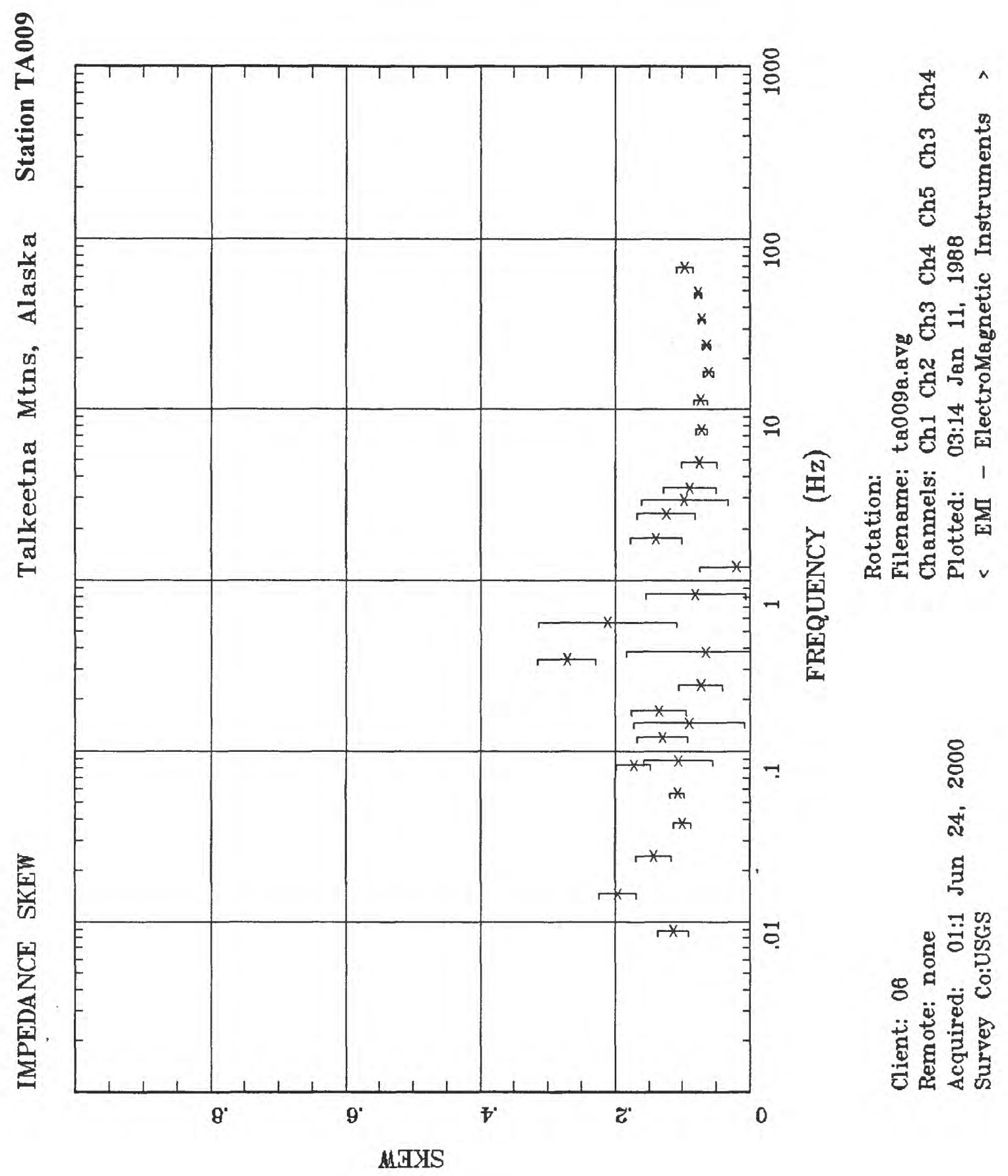




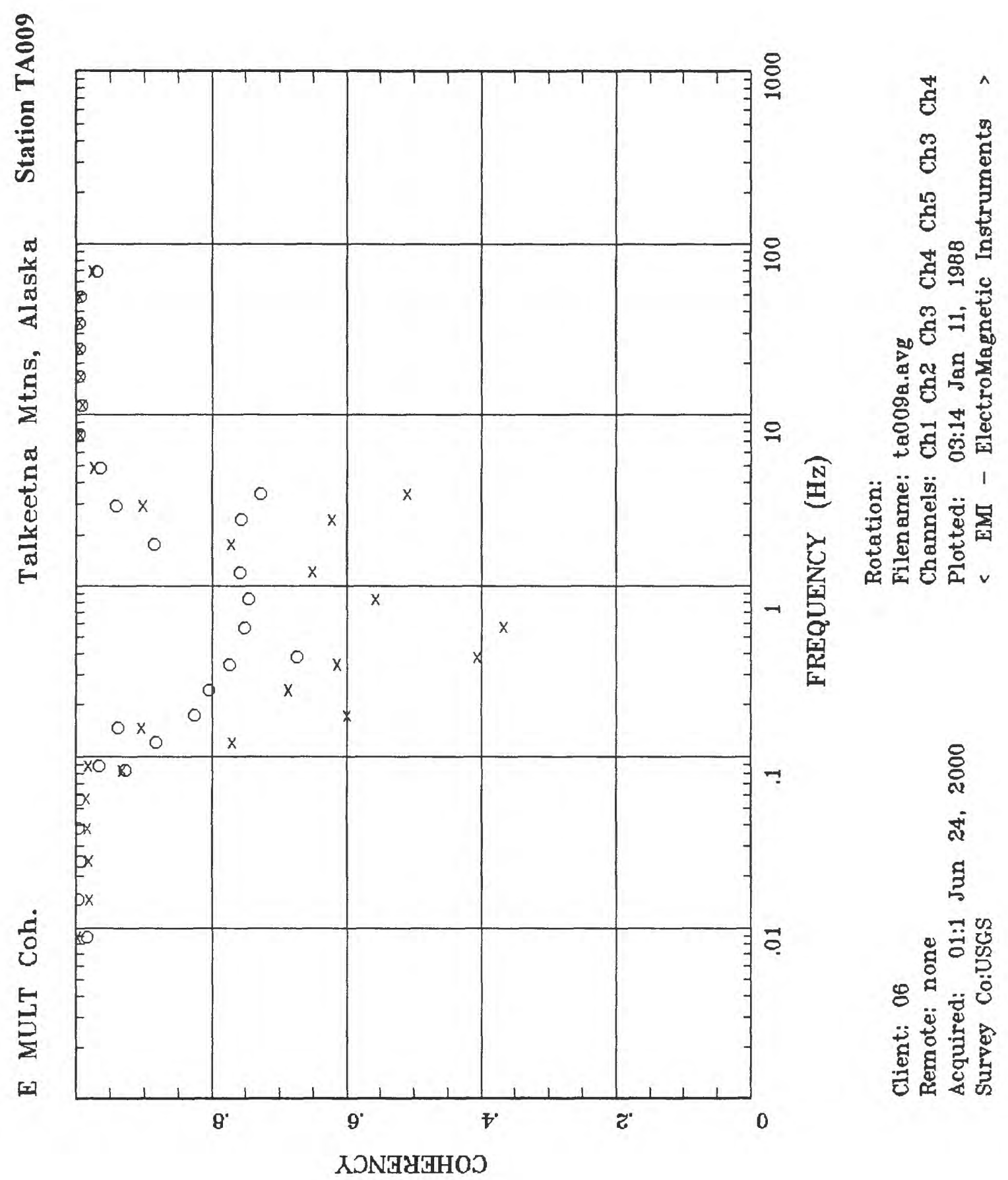


Eิ

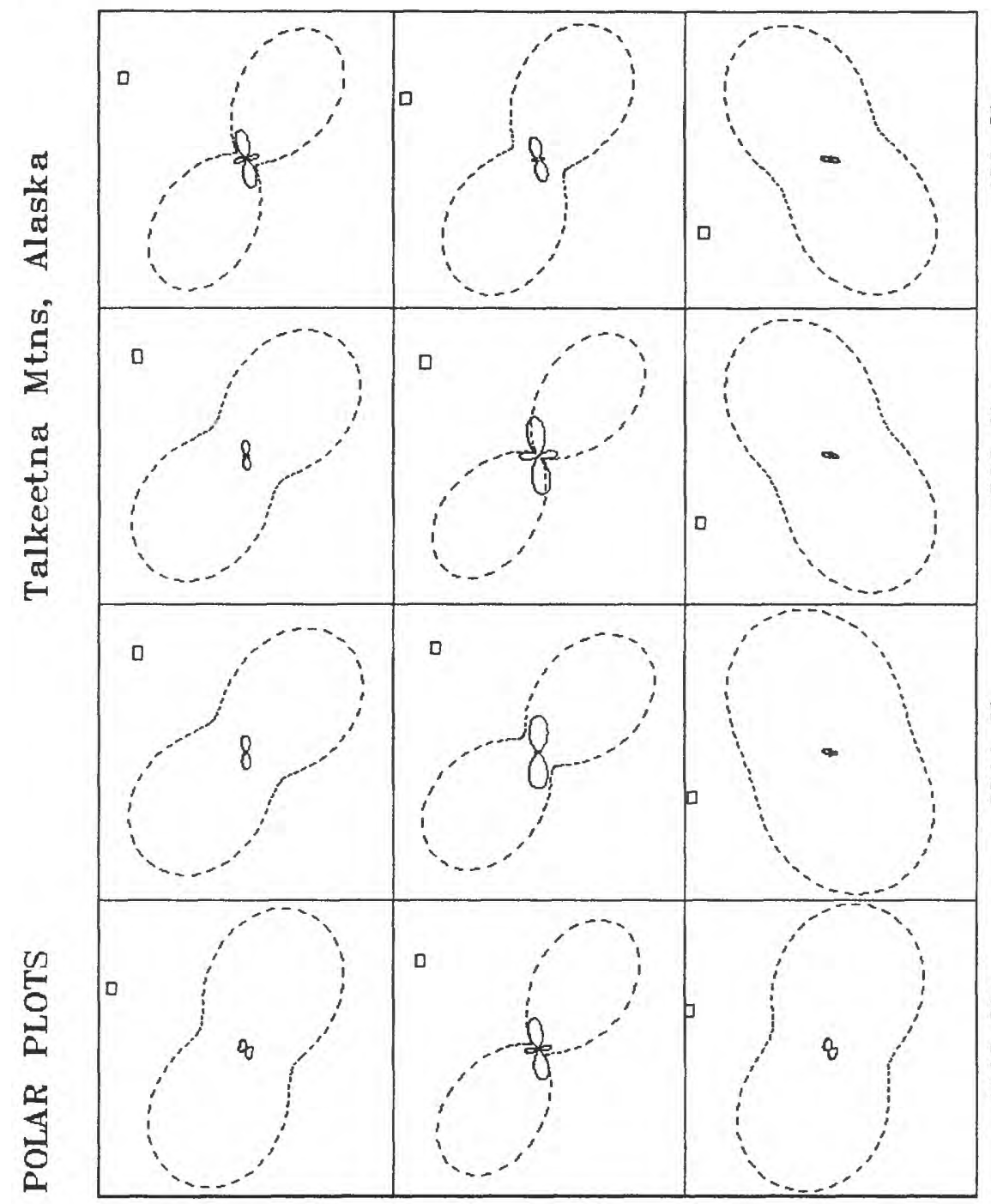

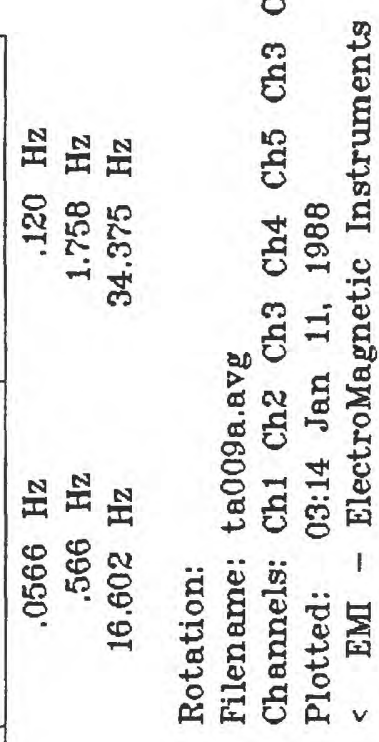

至夌

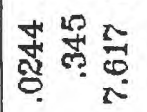

号

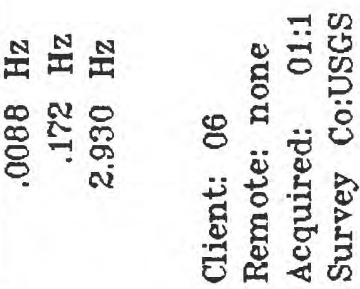




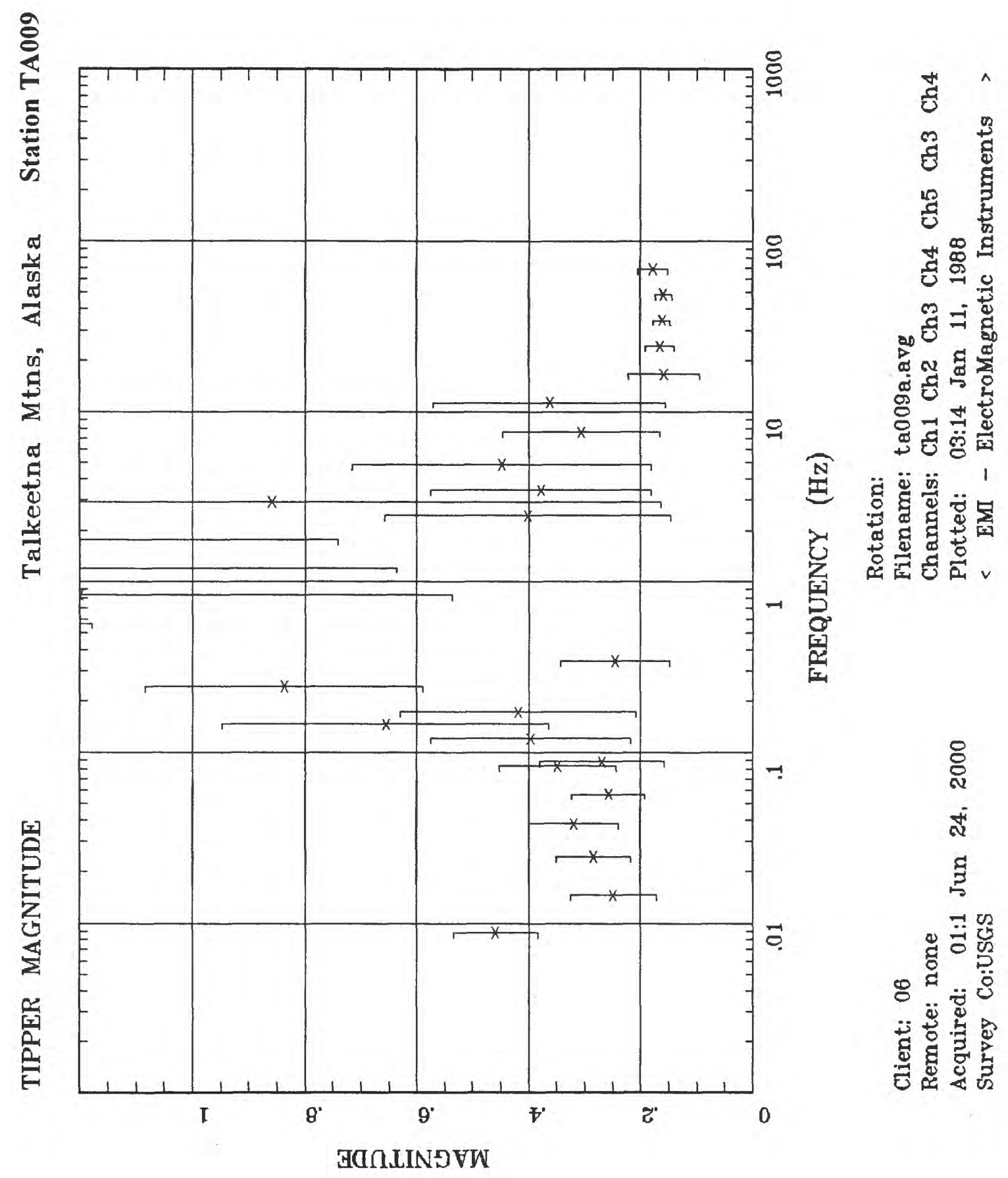




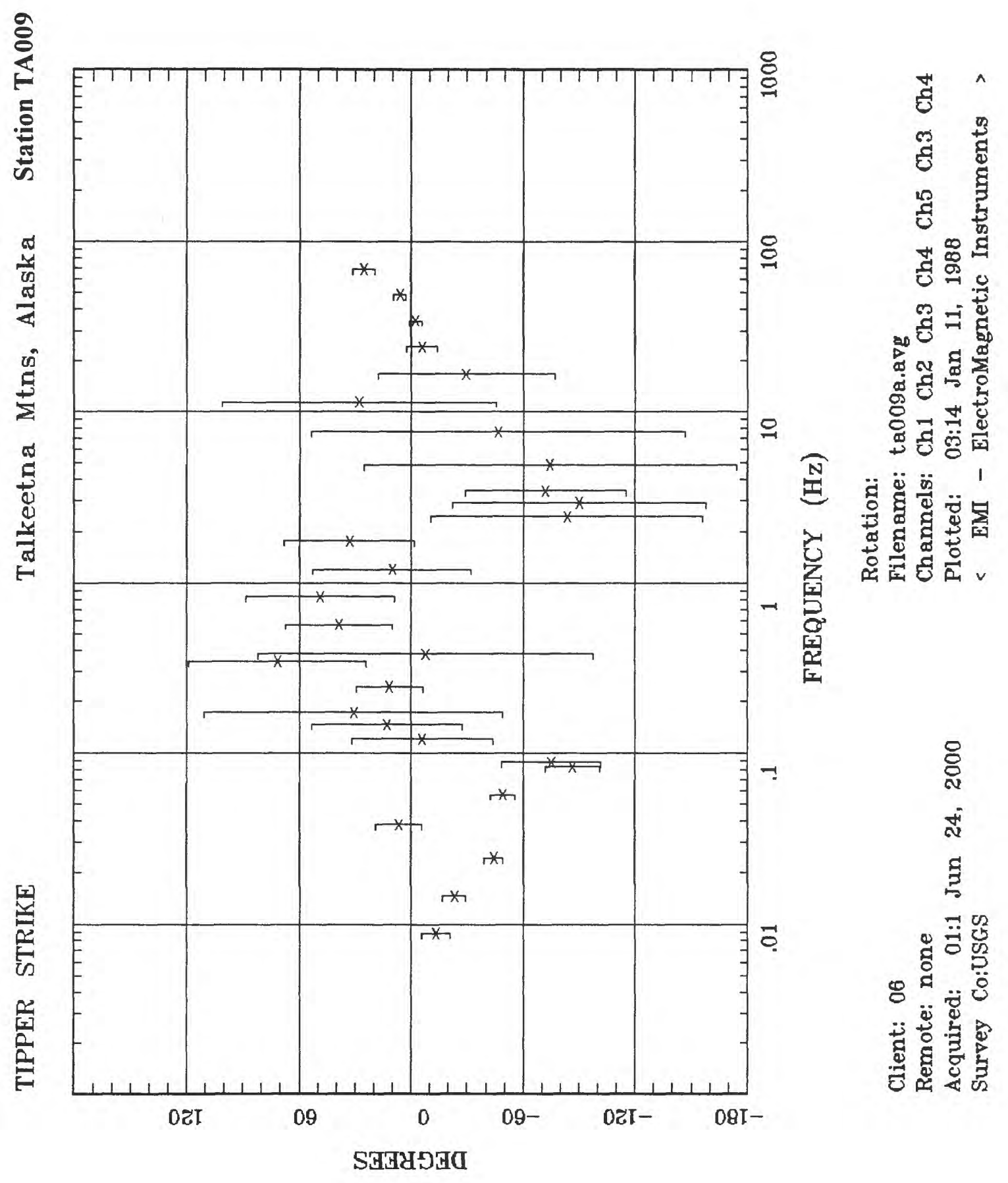




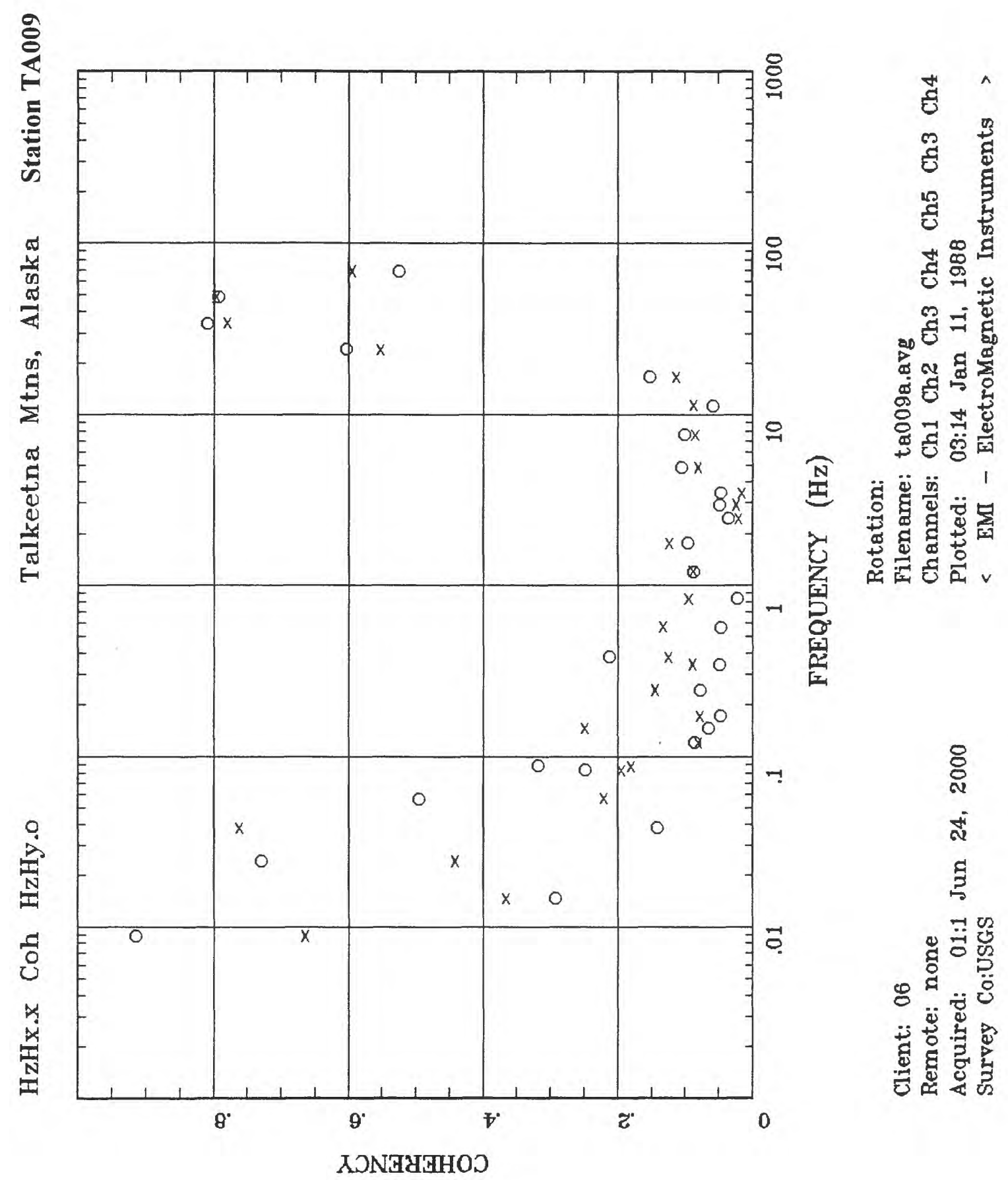




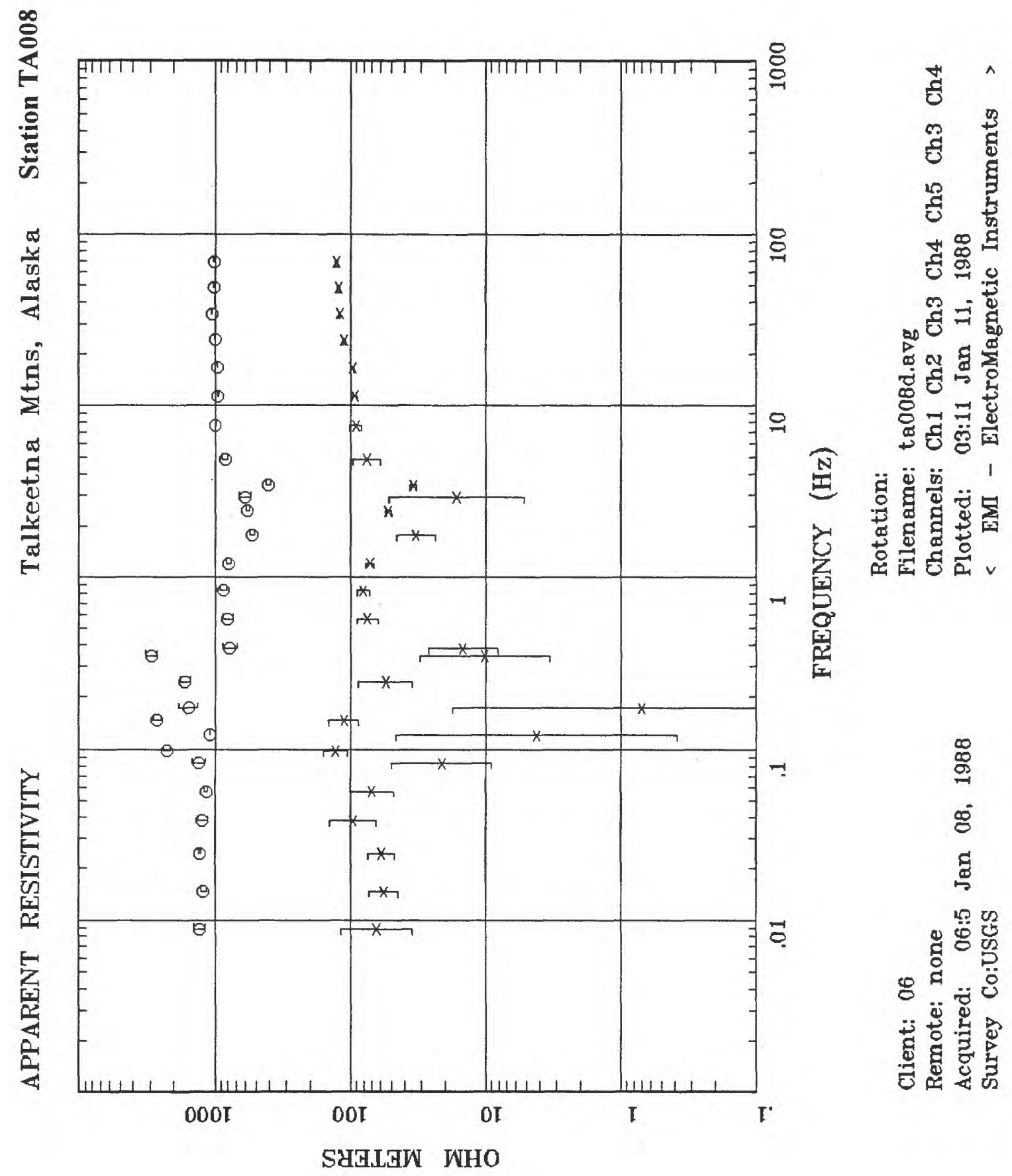




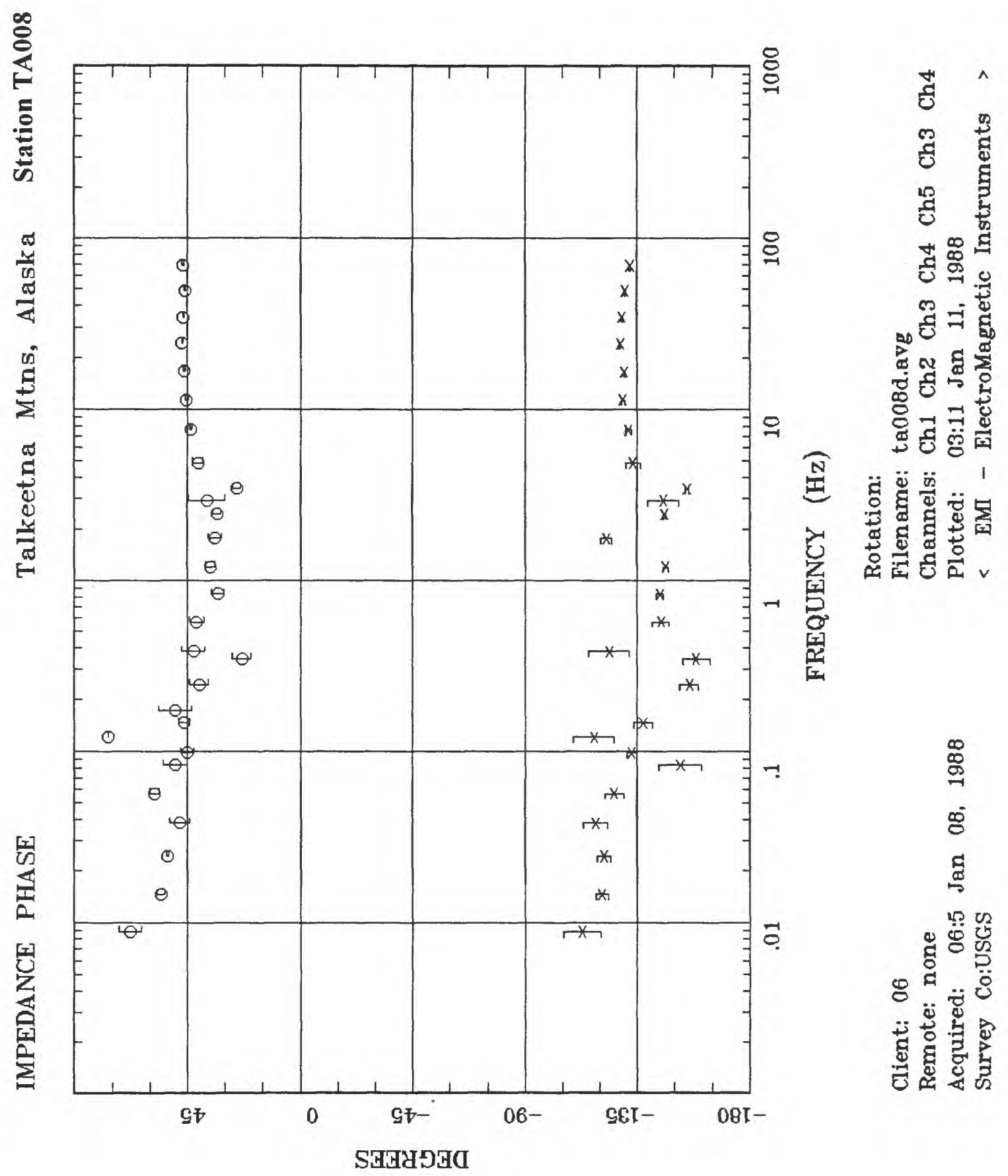




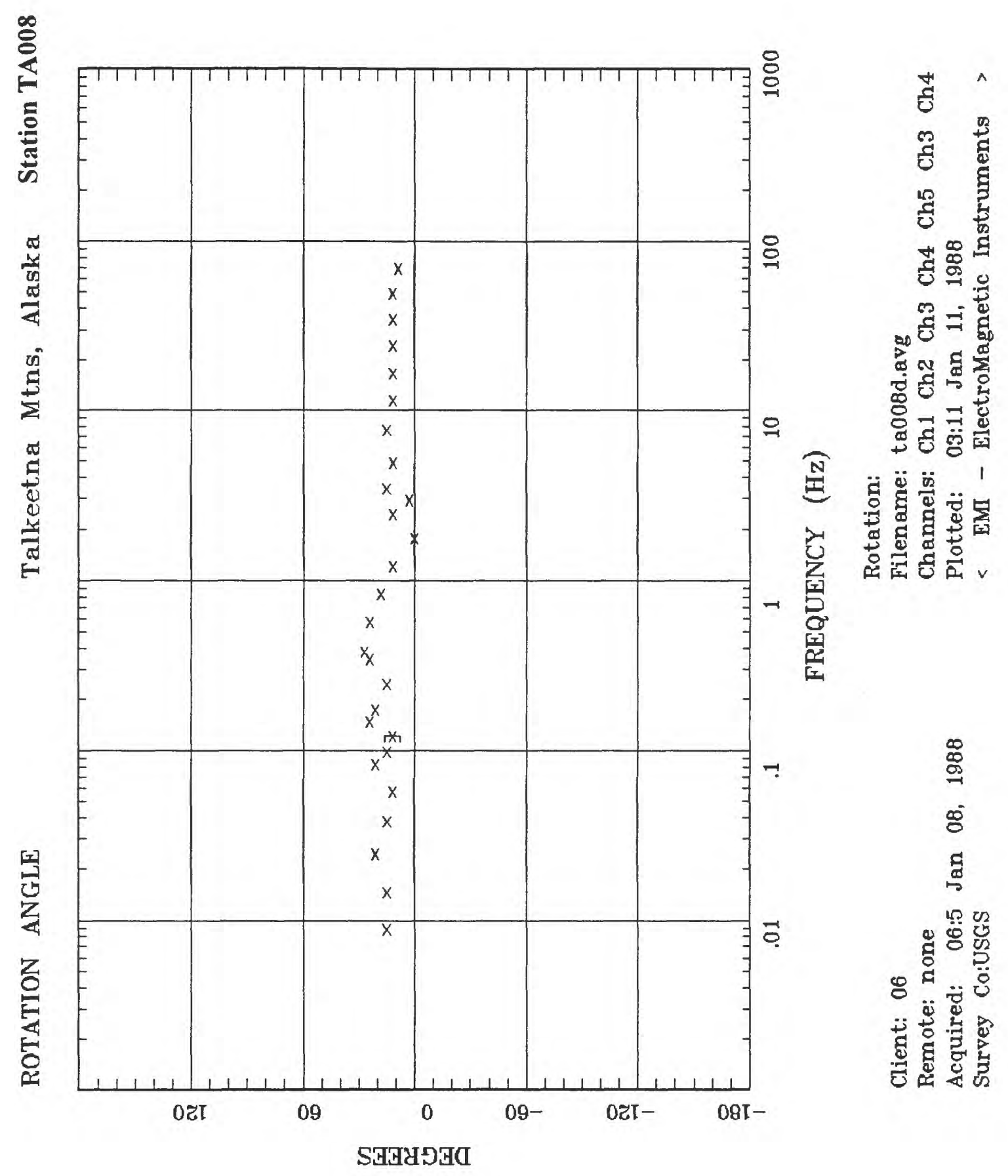




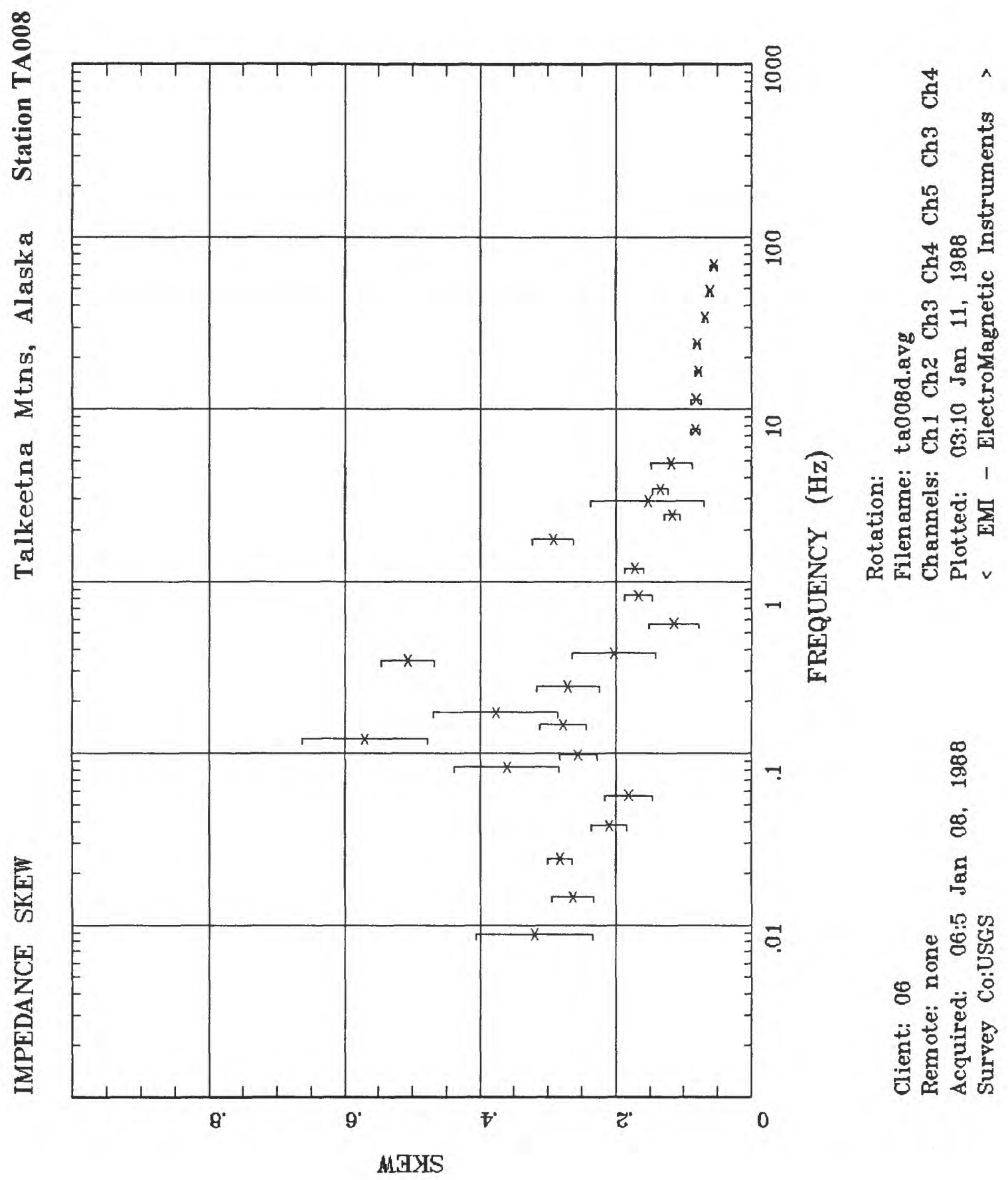




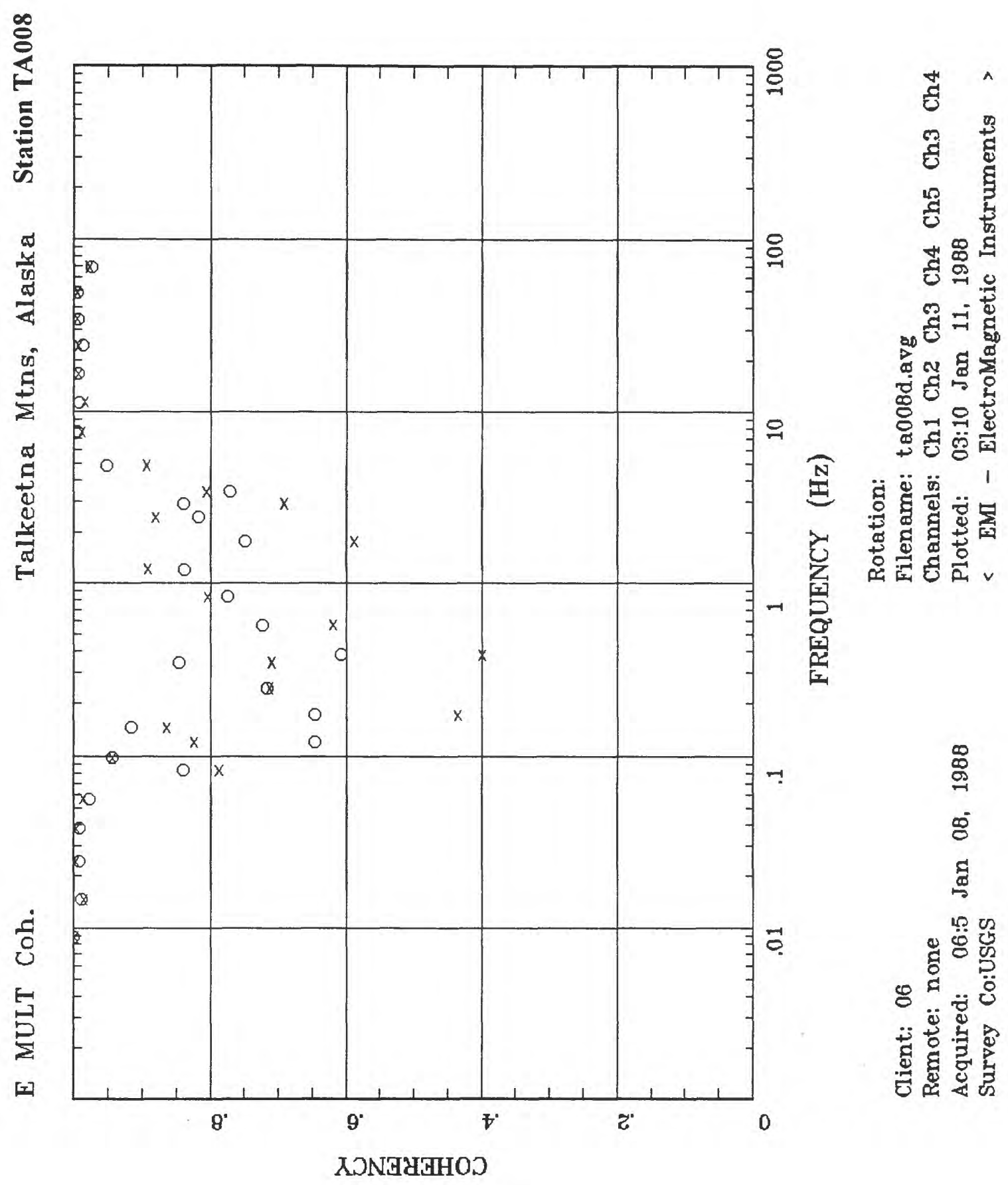




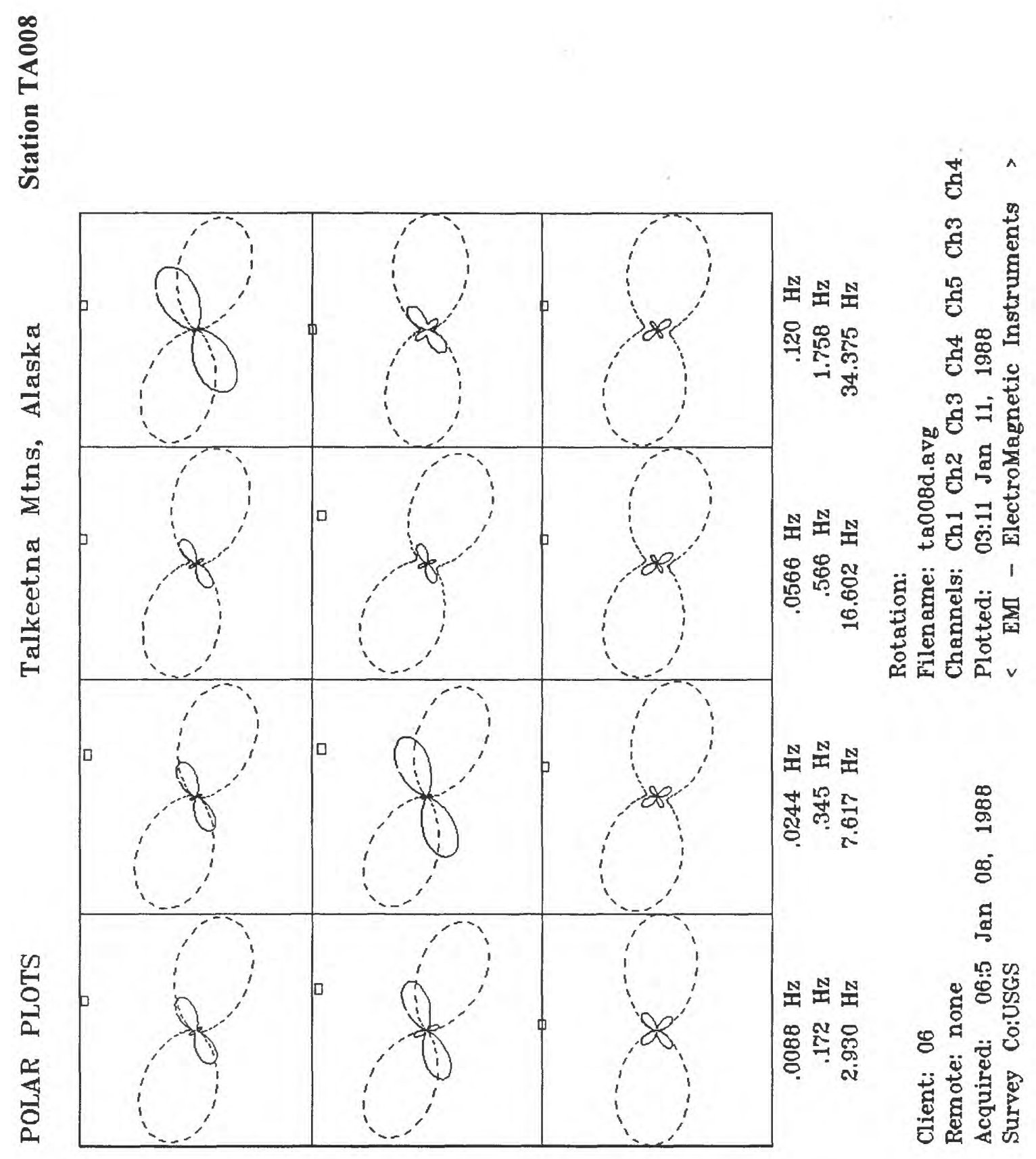




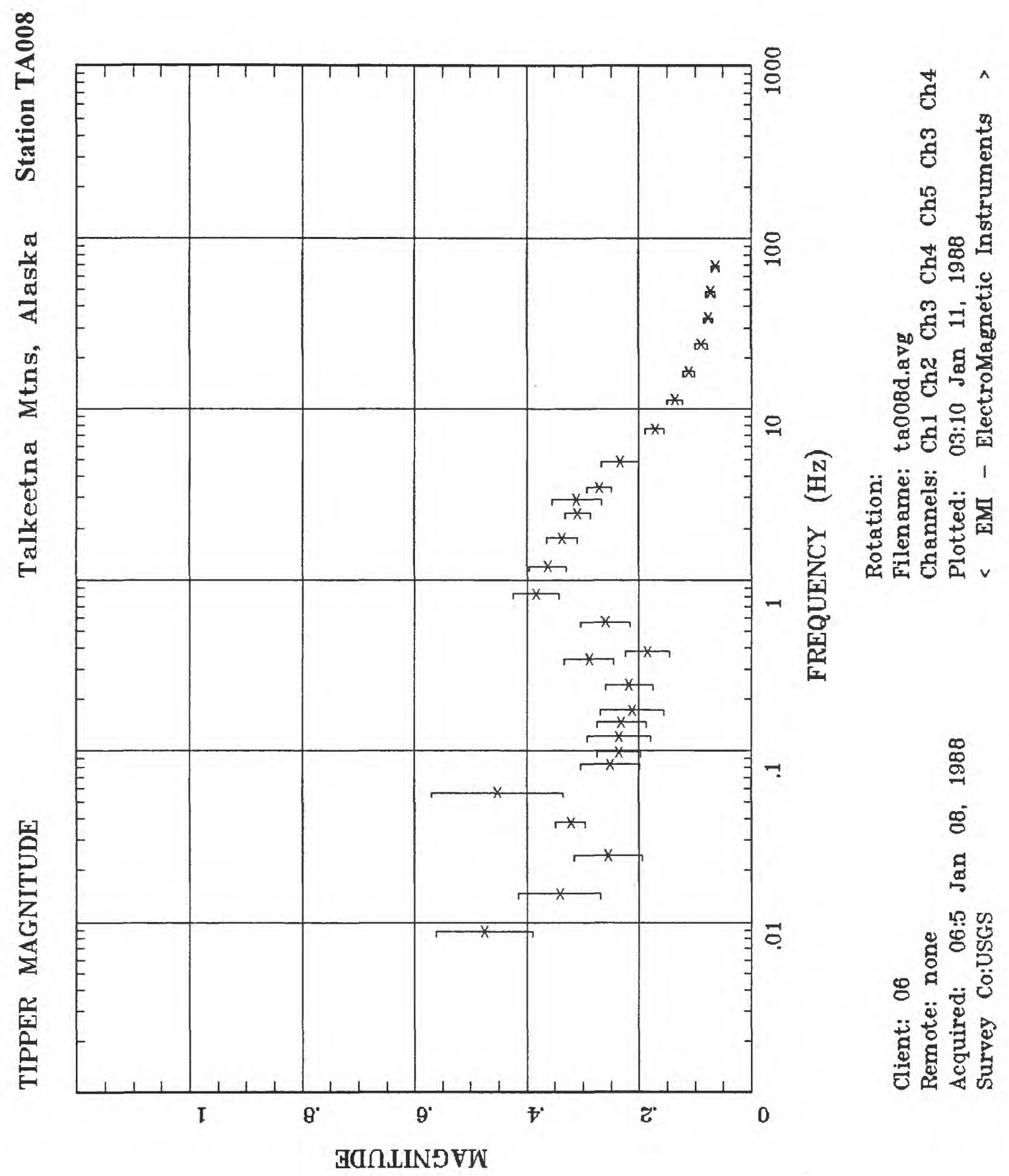




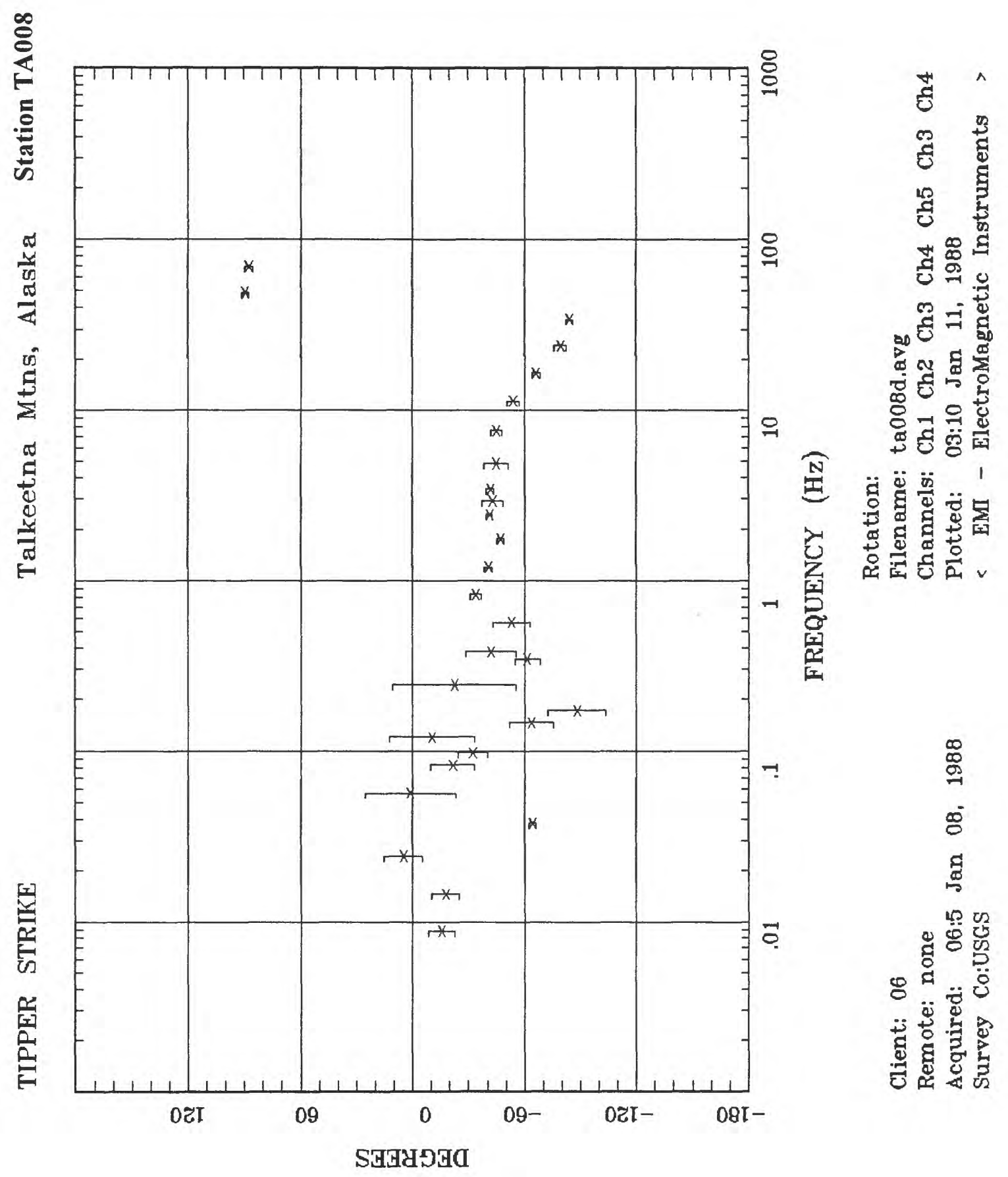




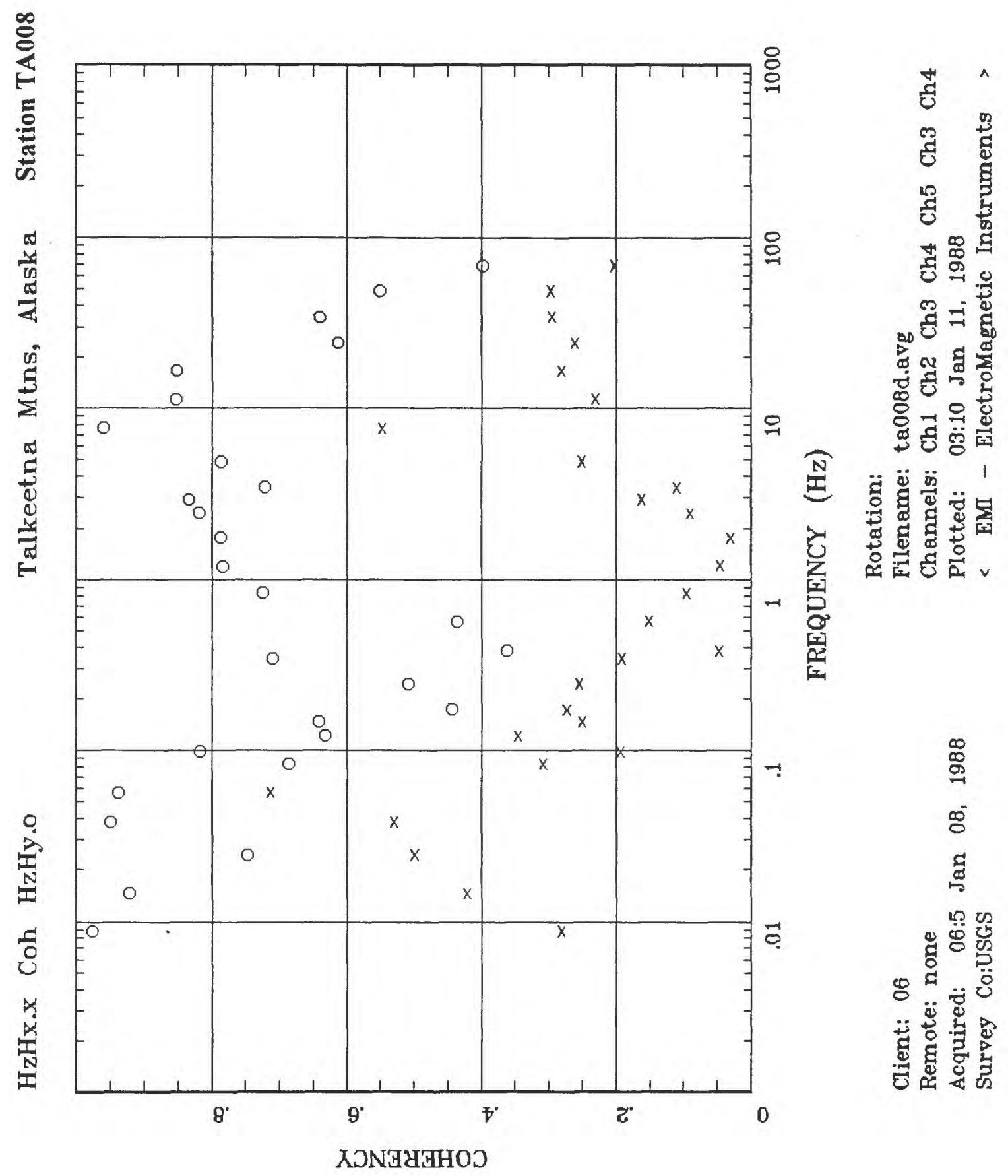




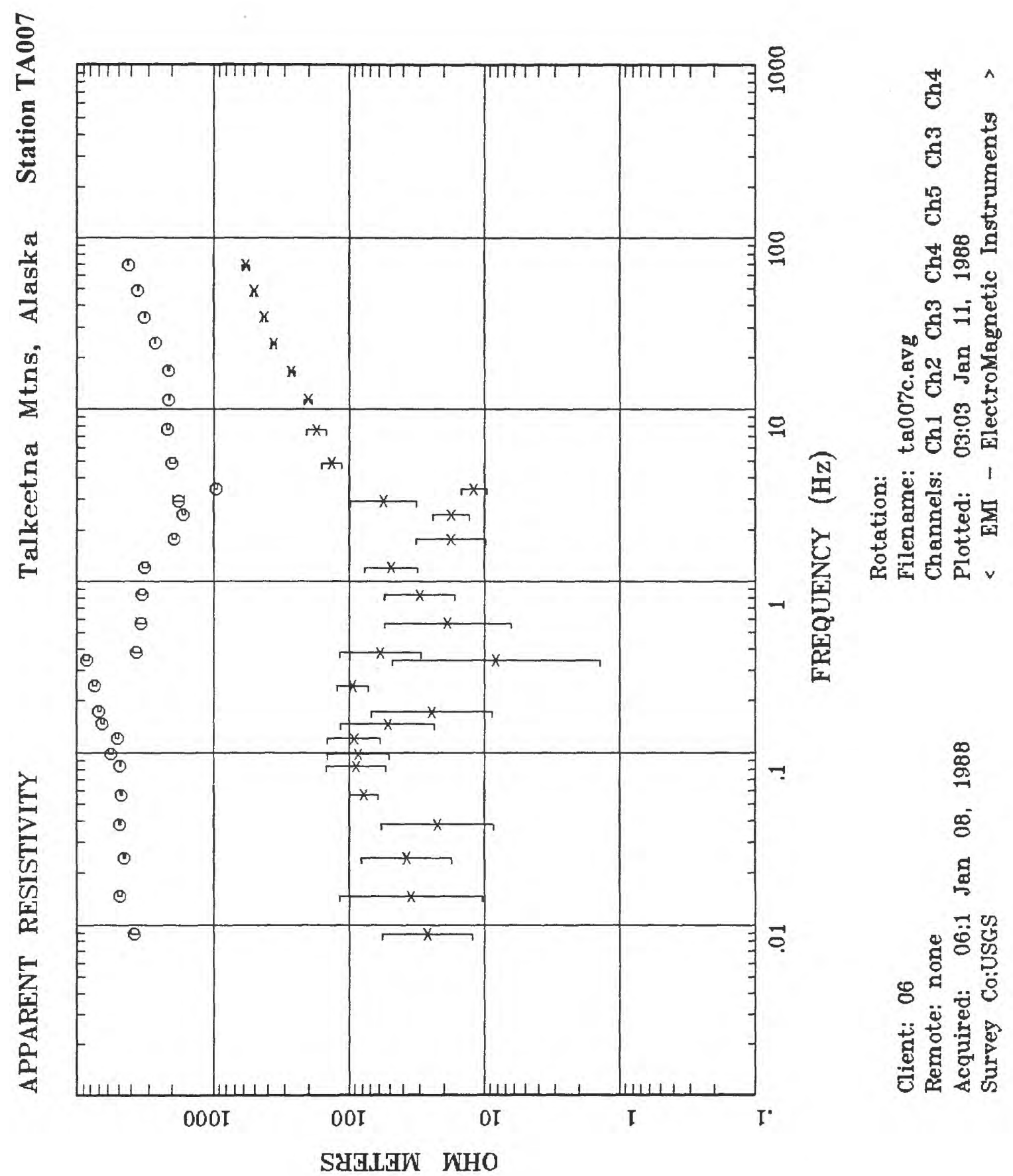




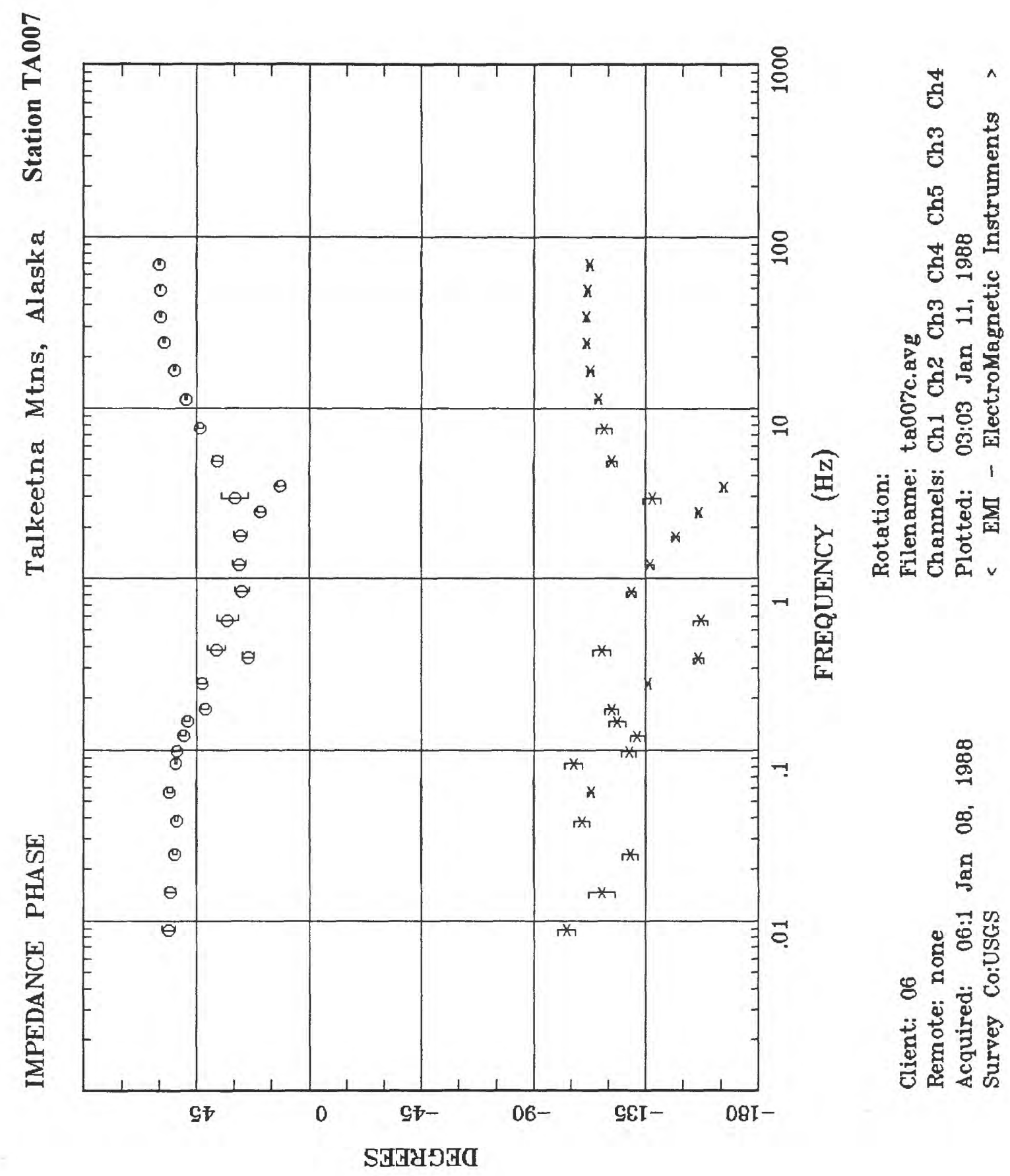




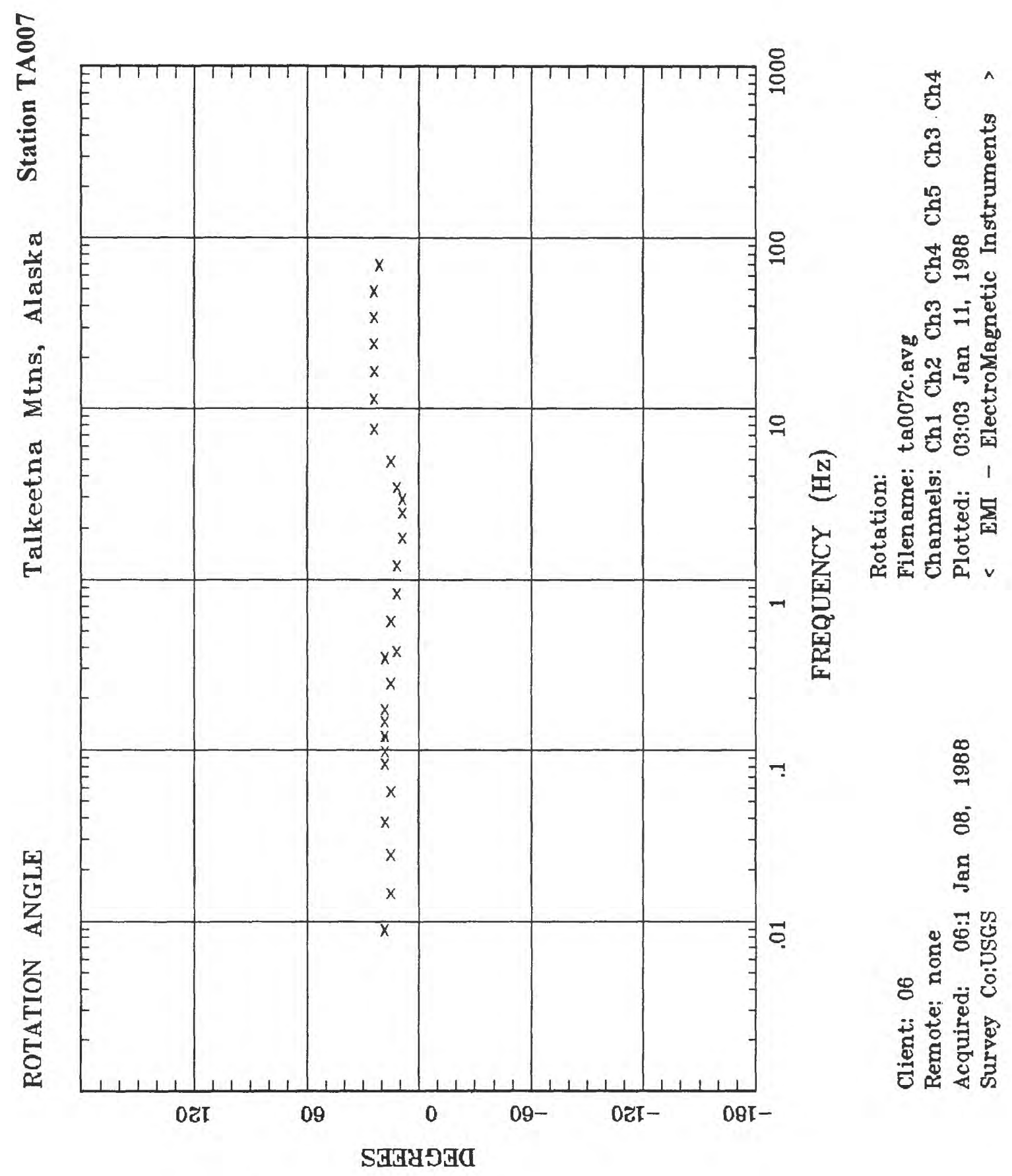




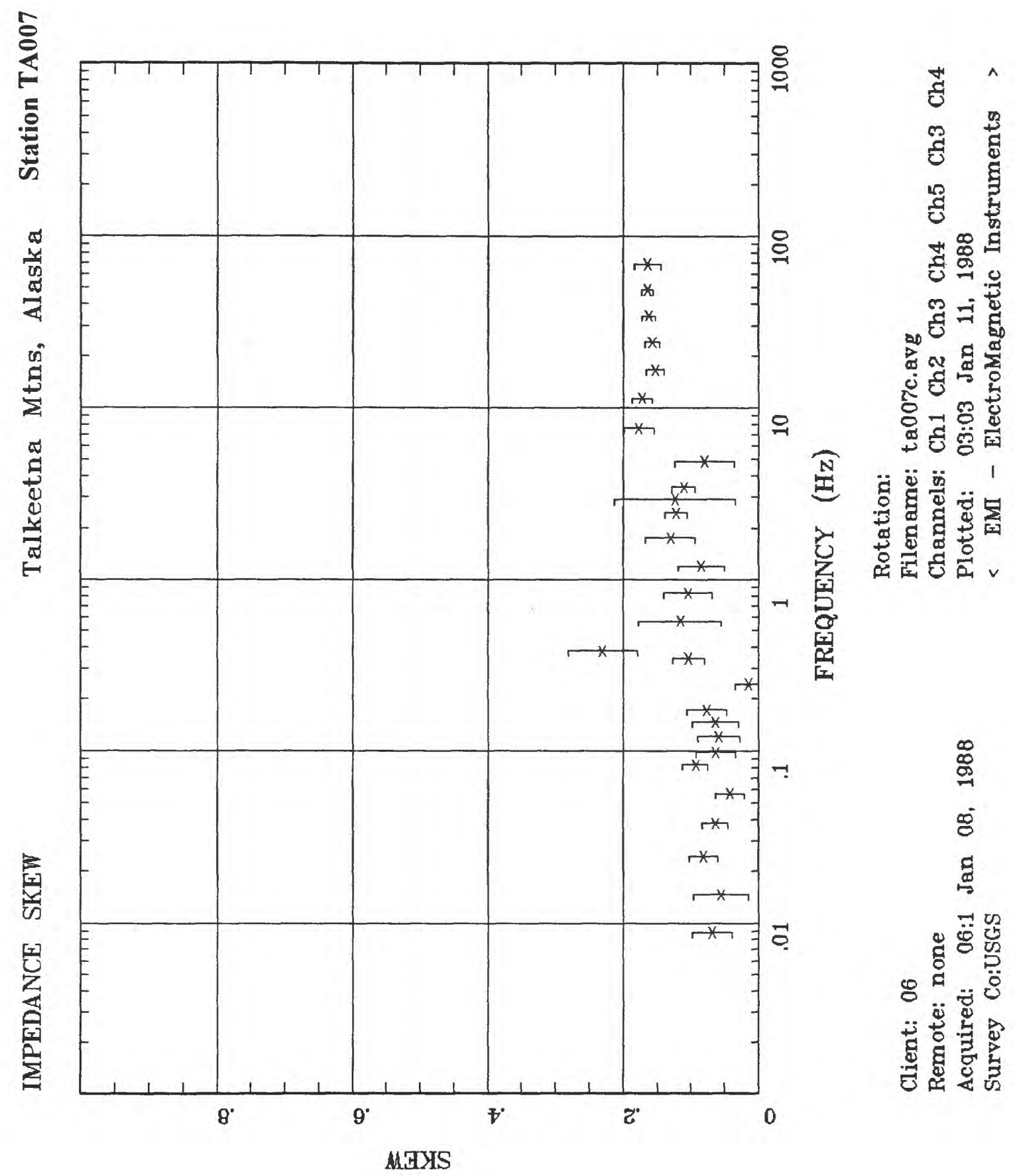




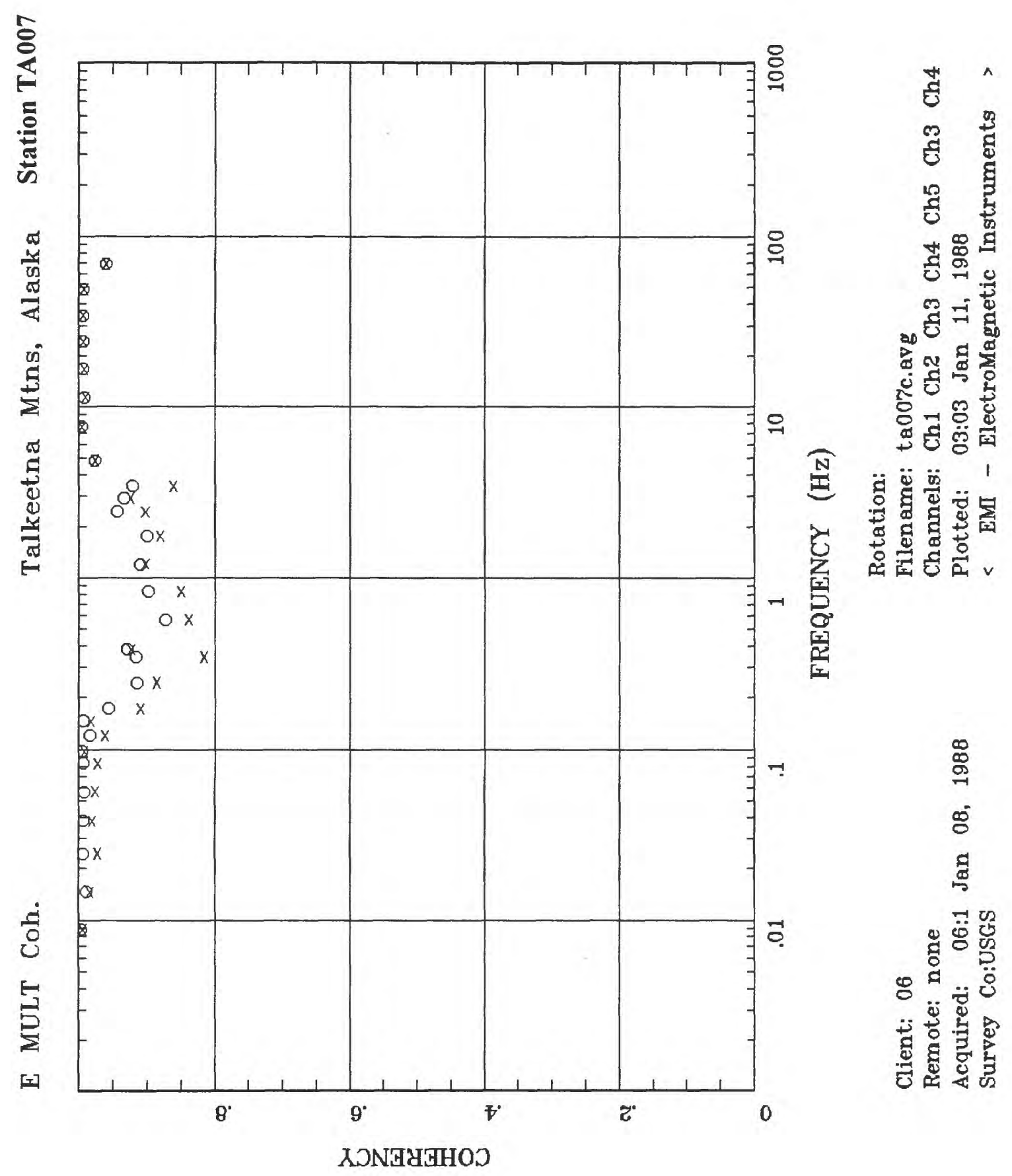




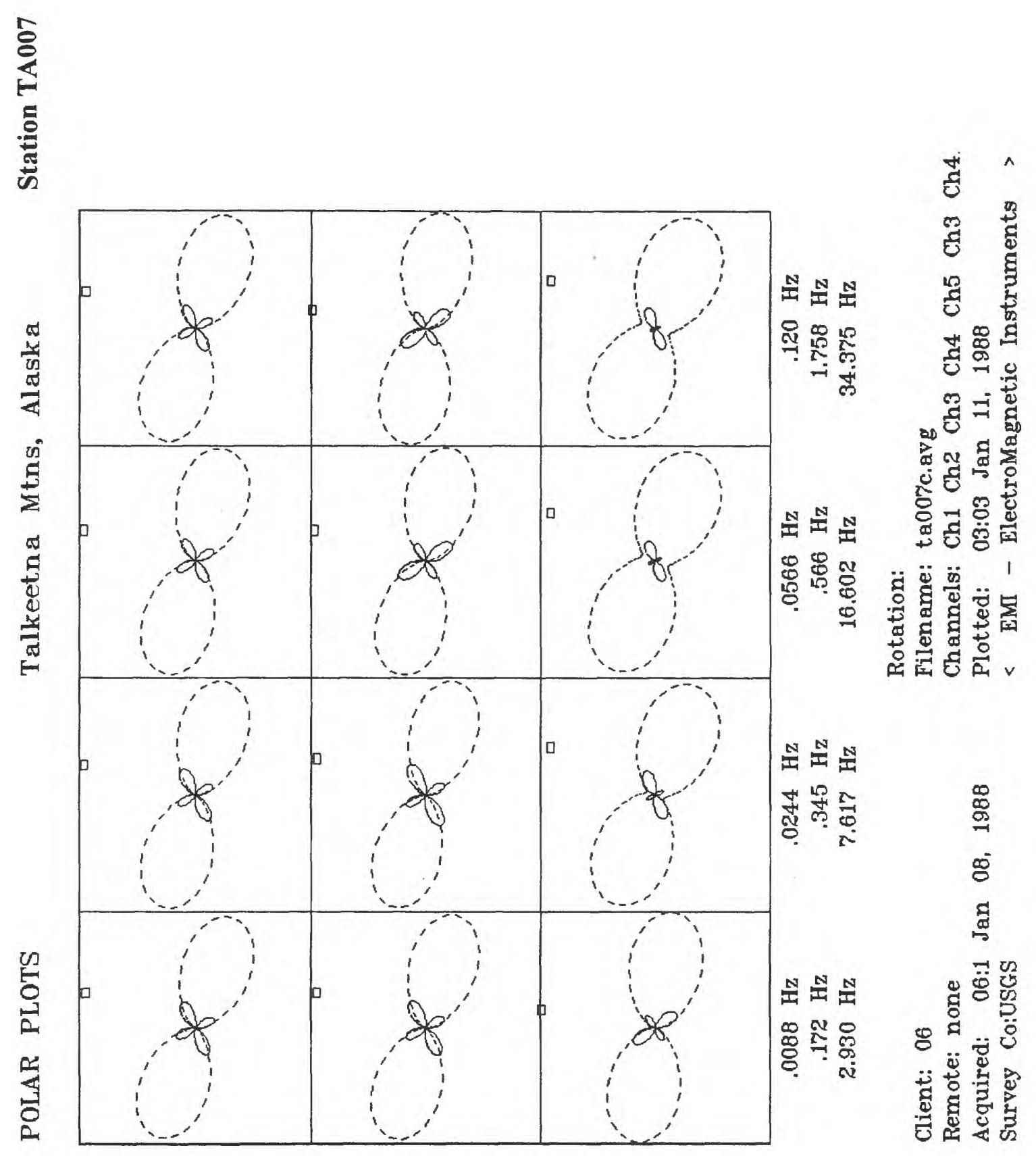




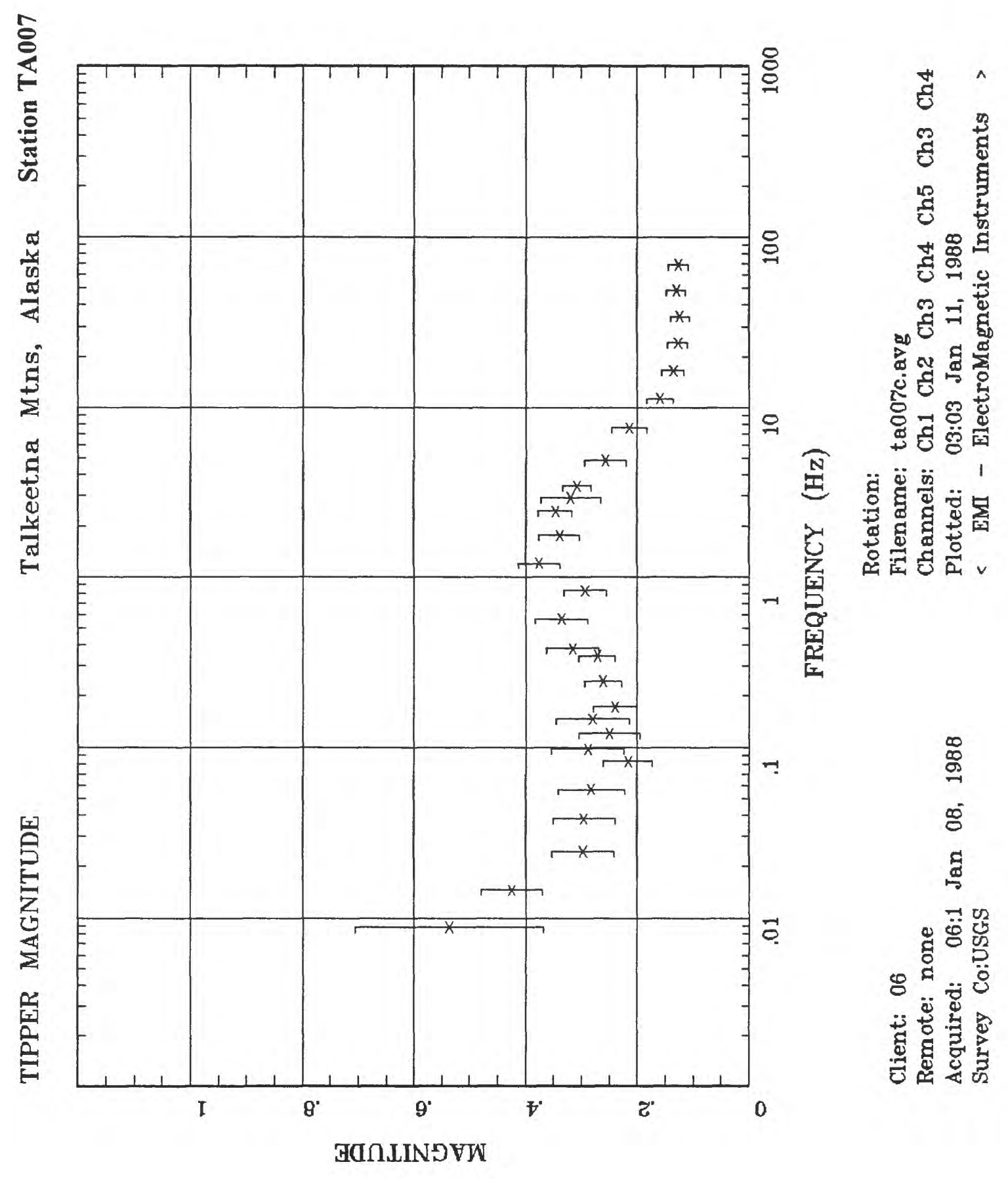




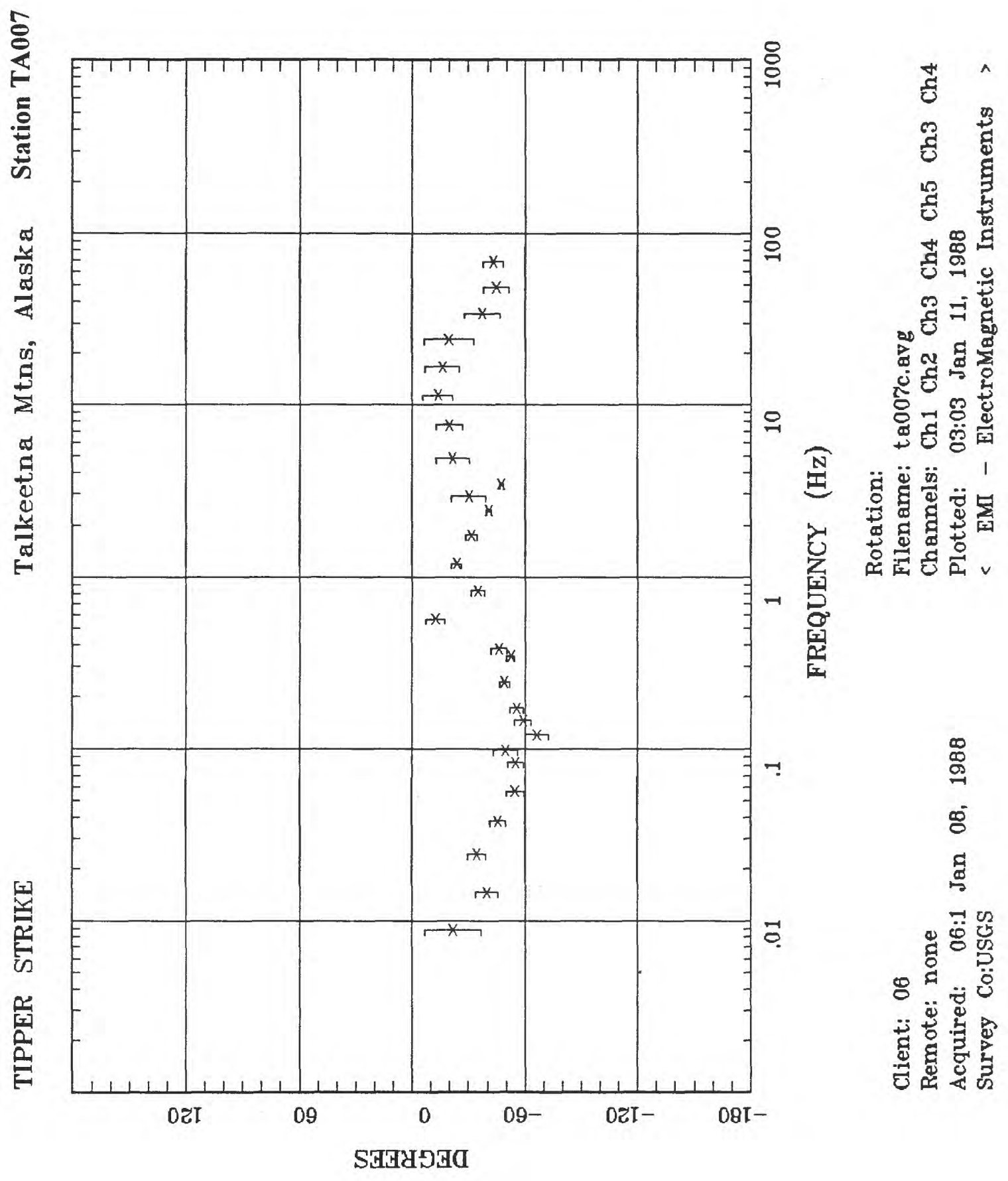




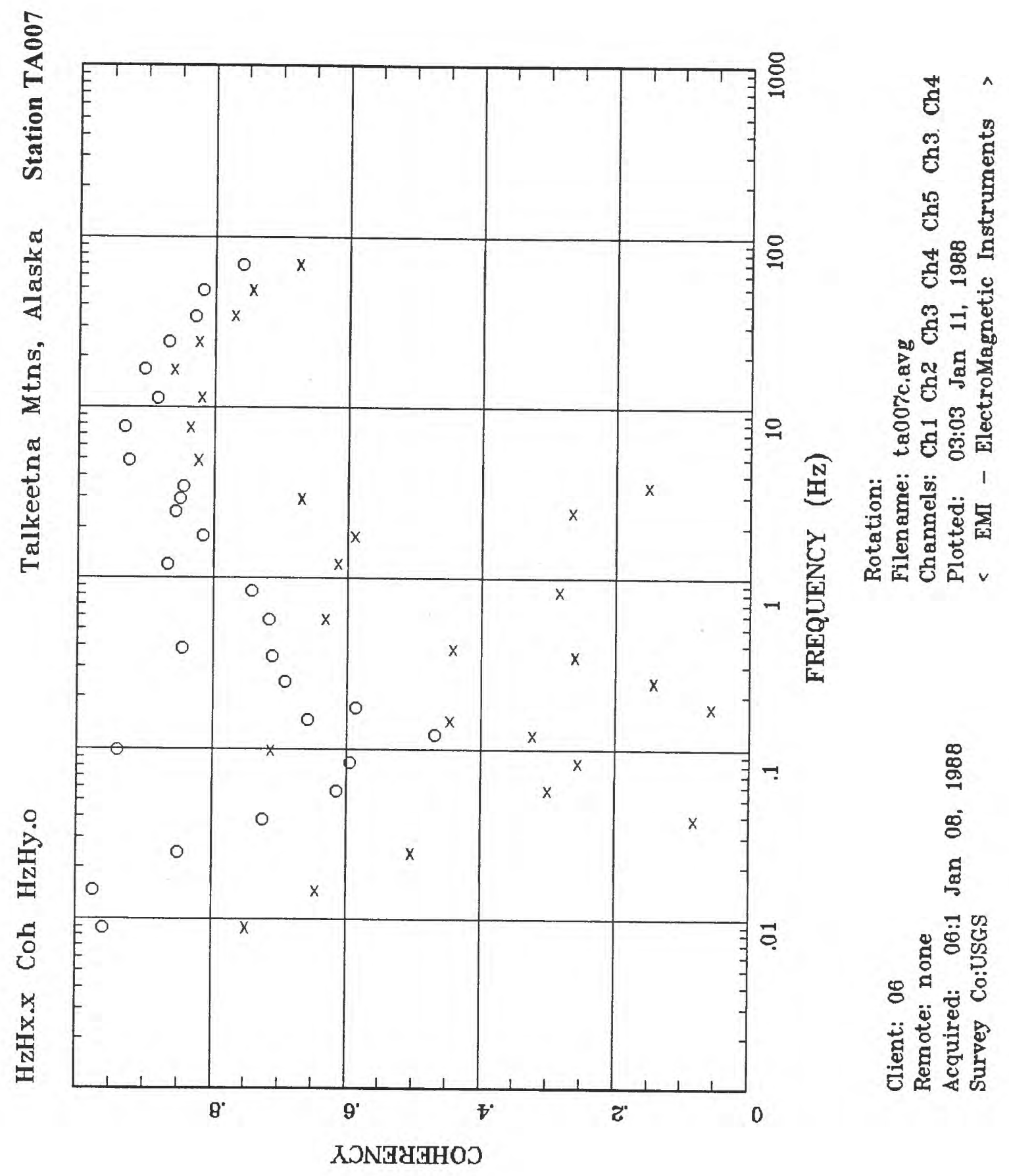




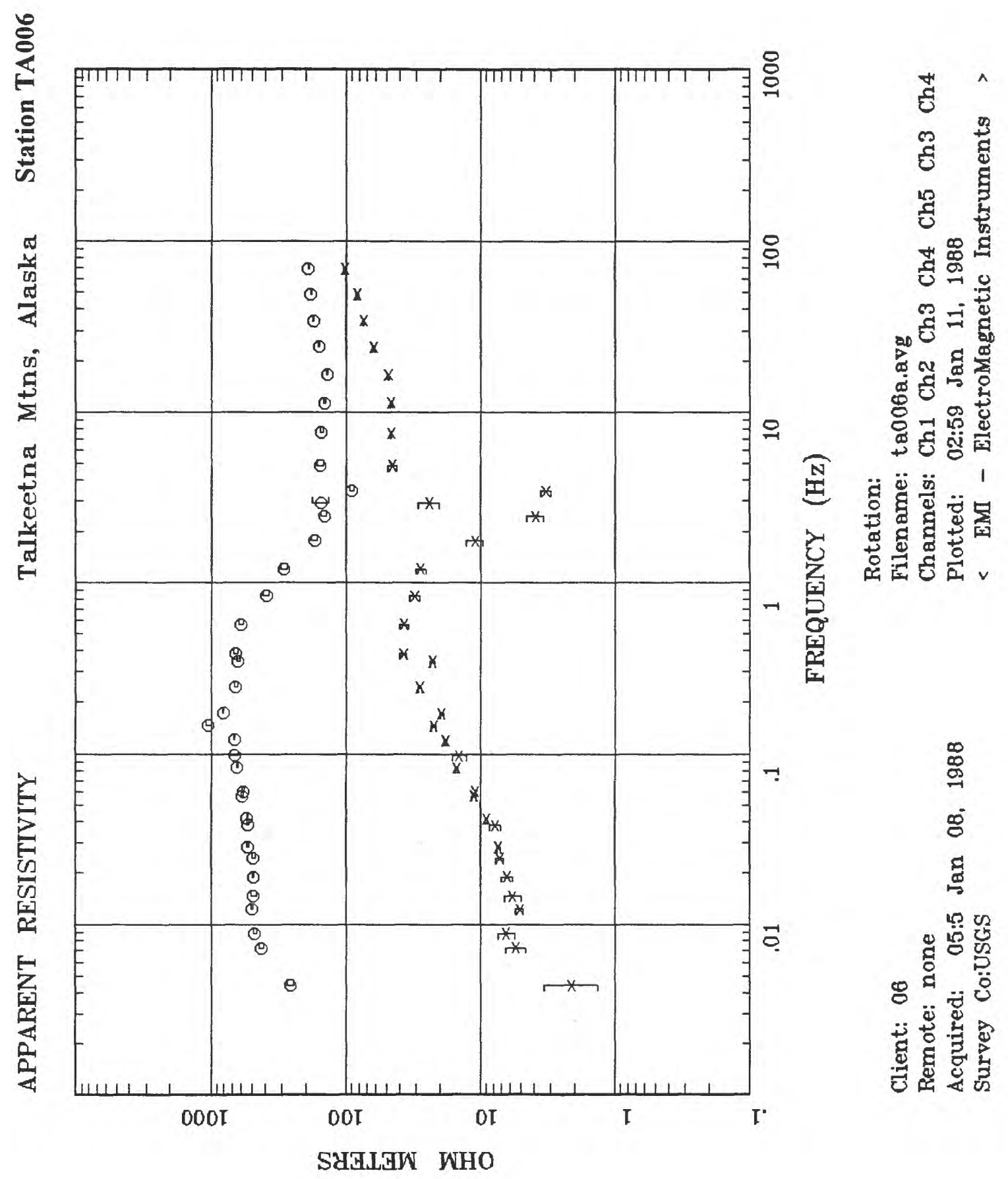




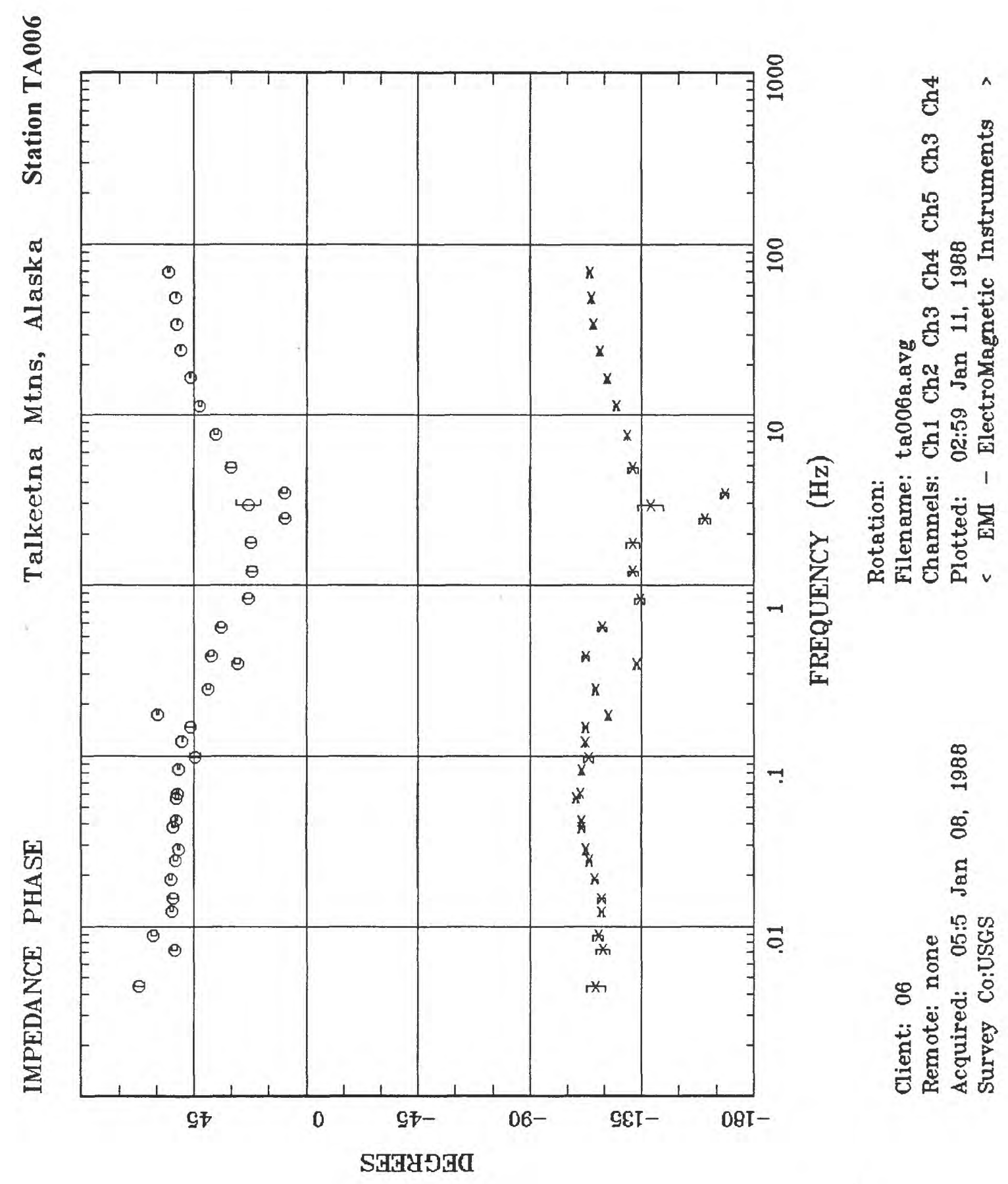




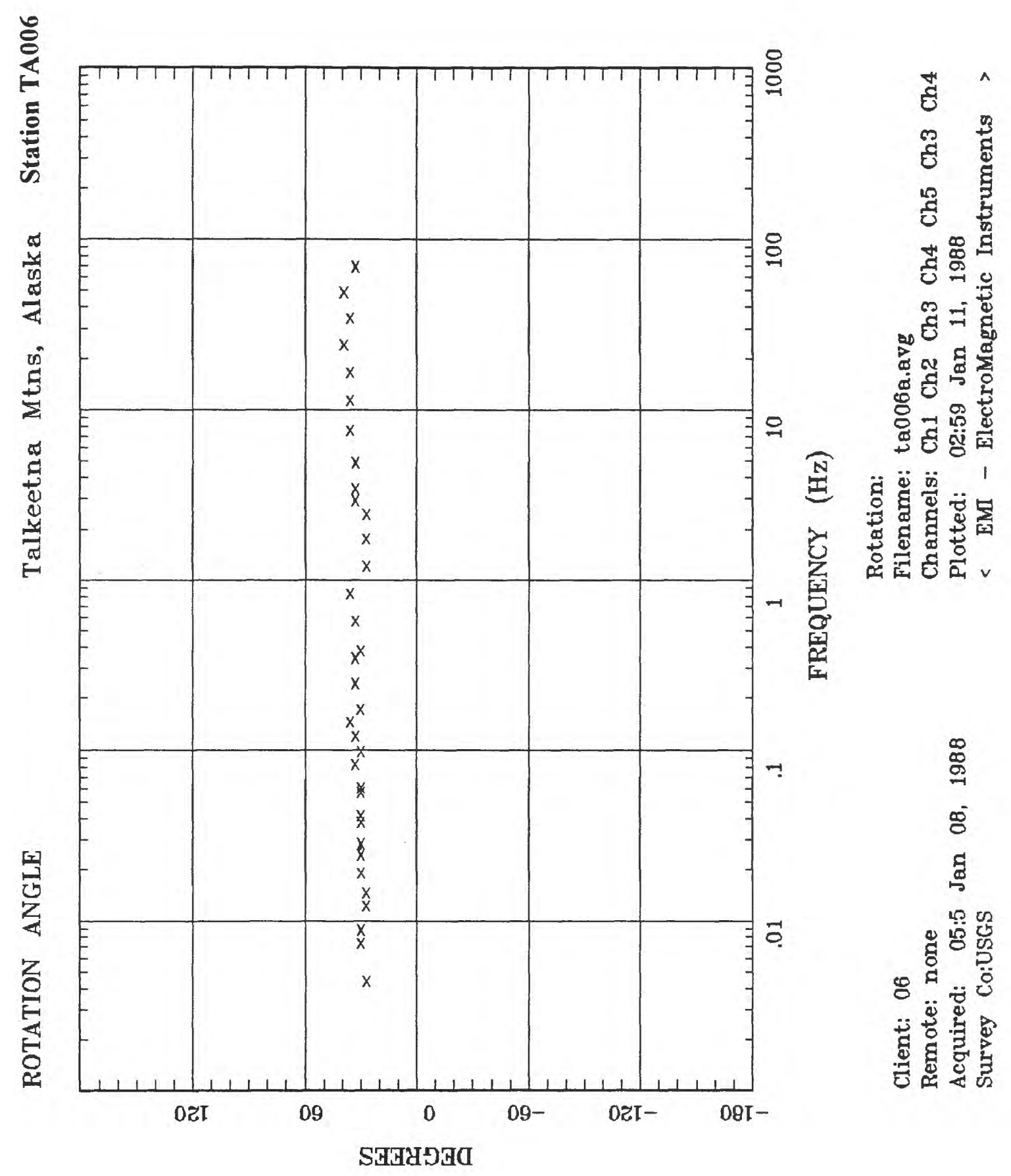




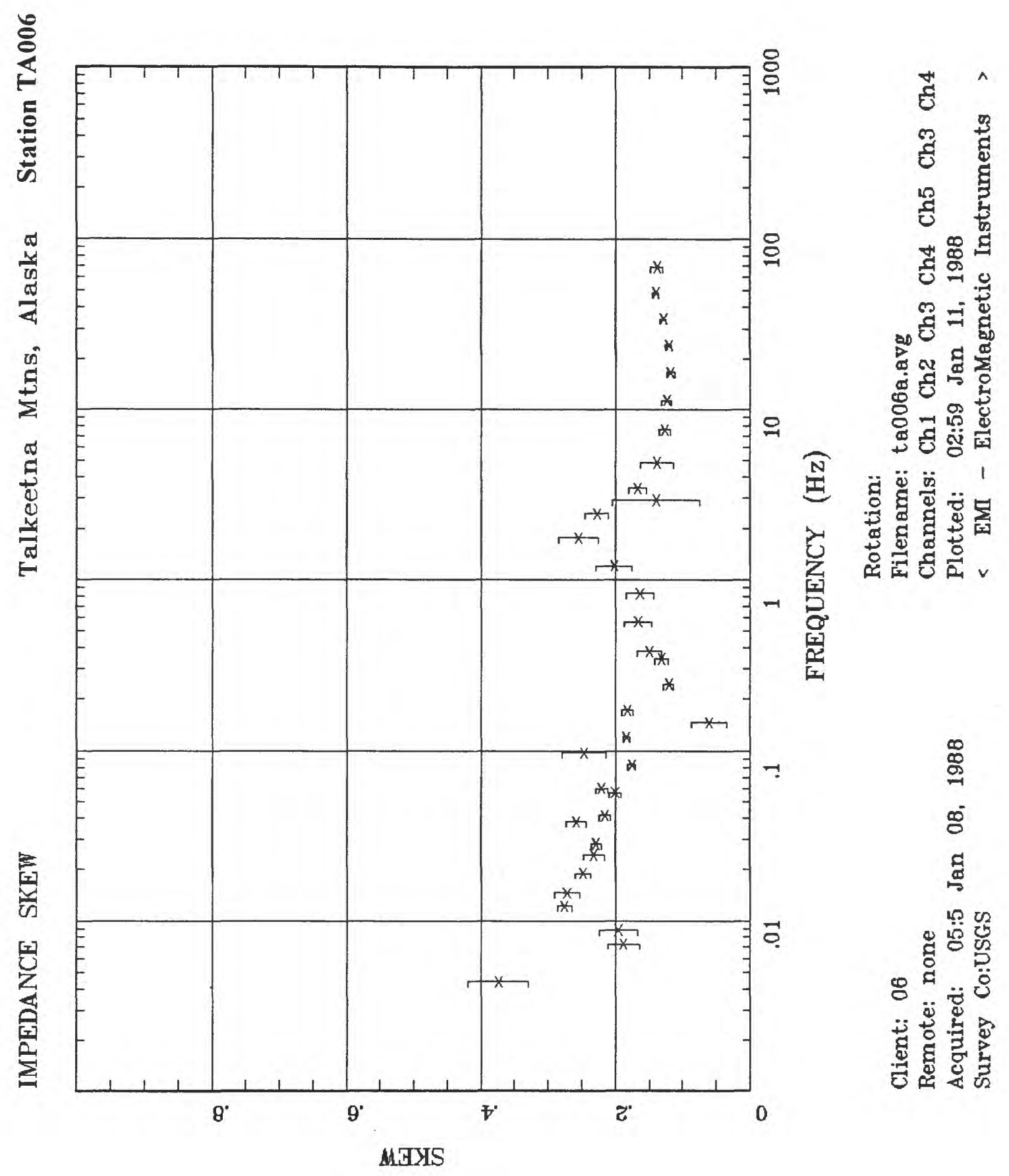




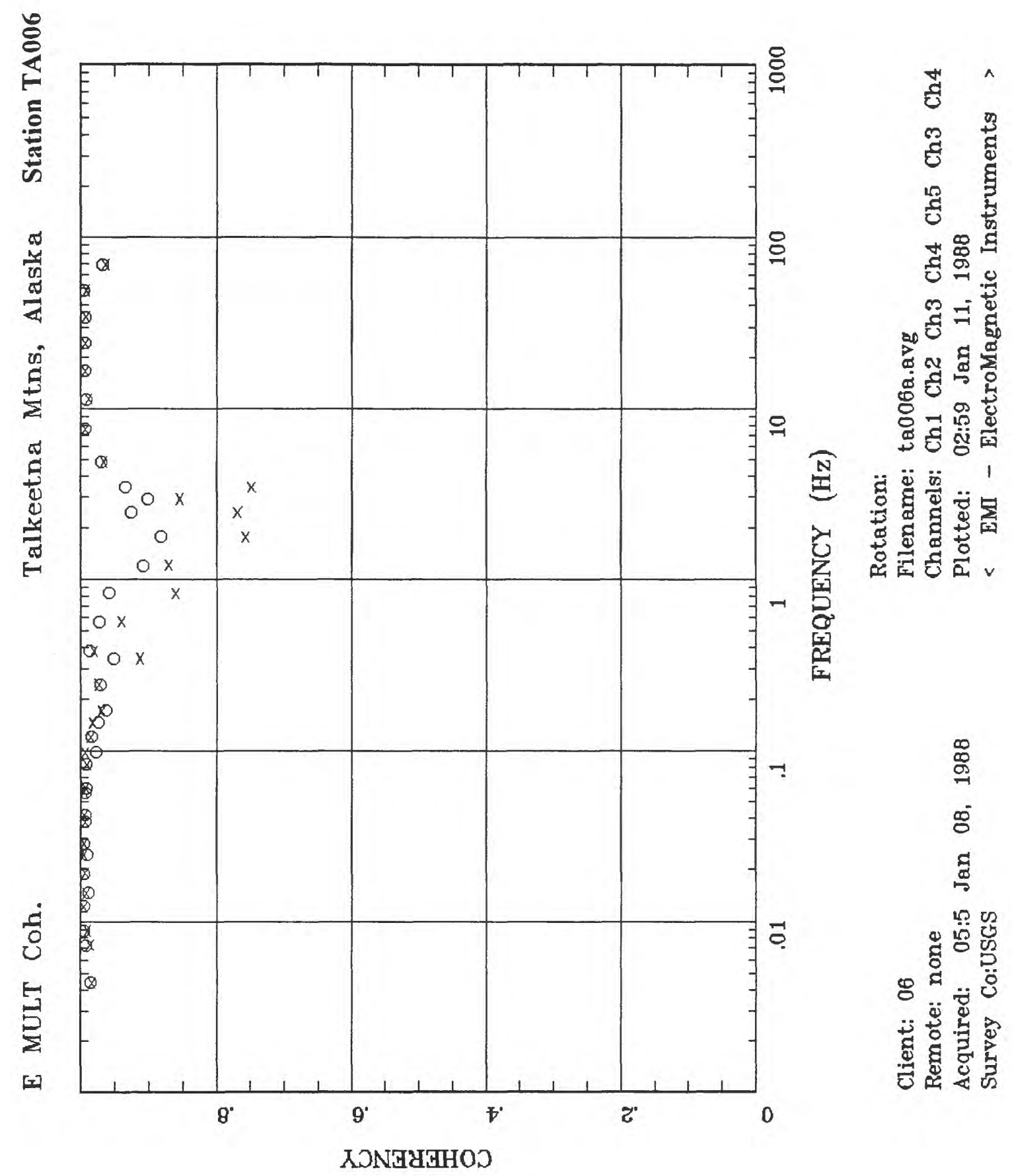




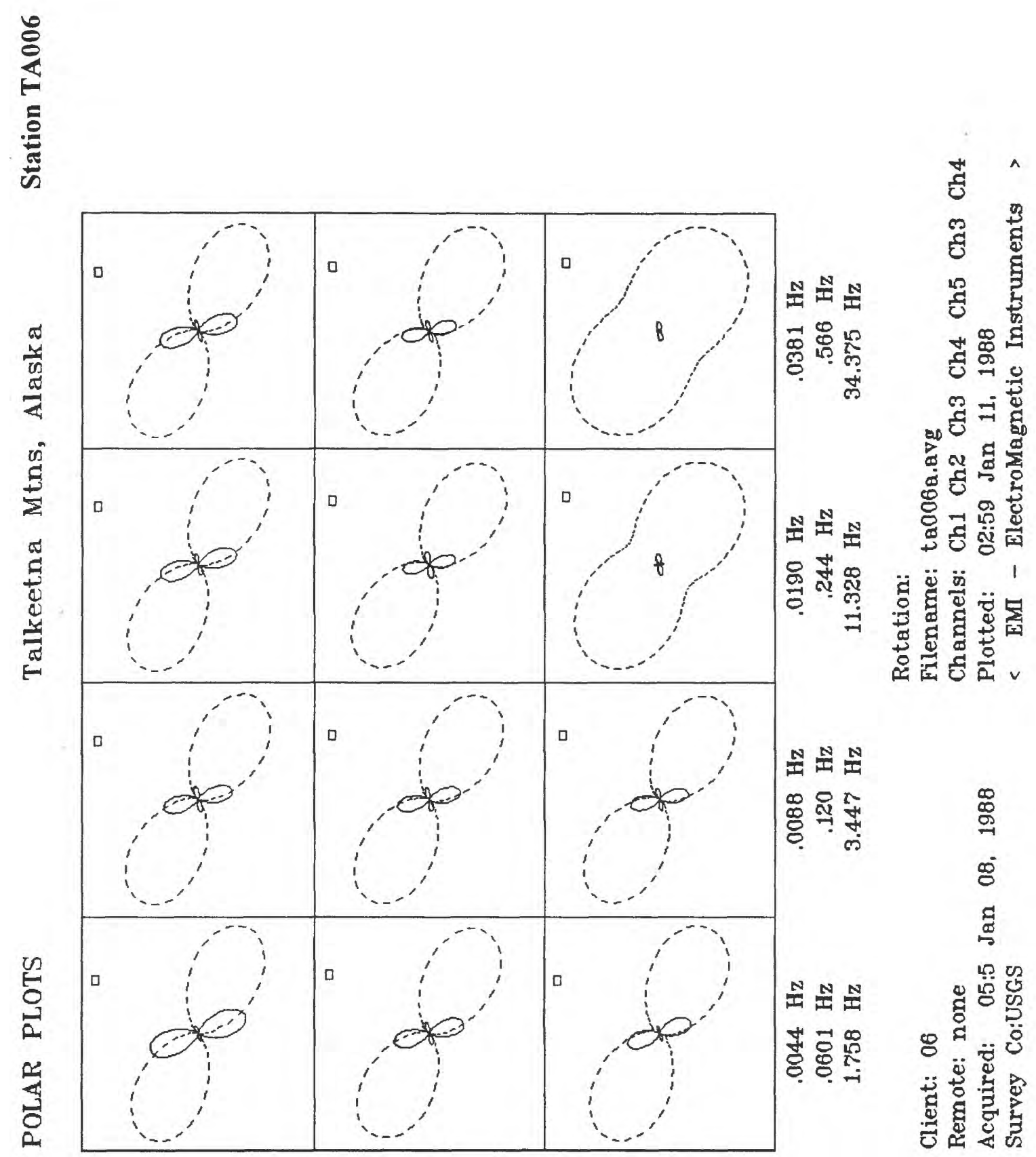




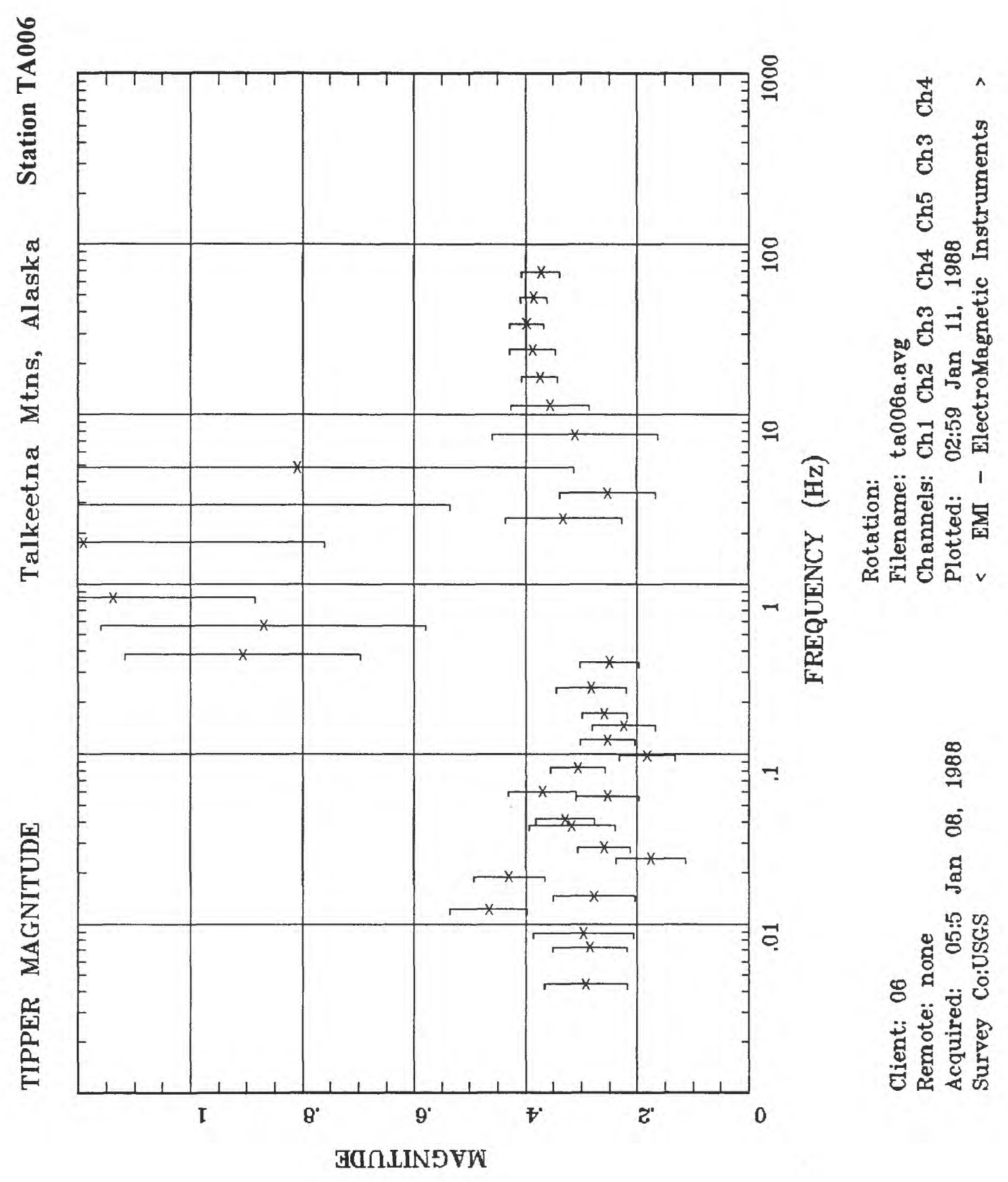




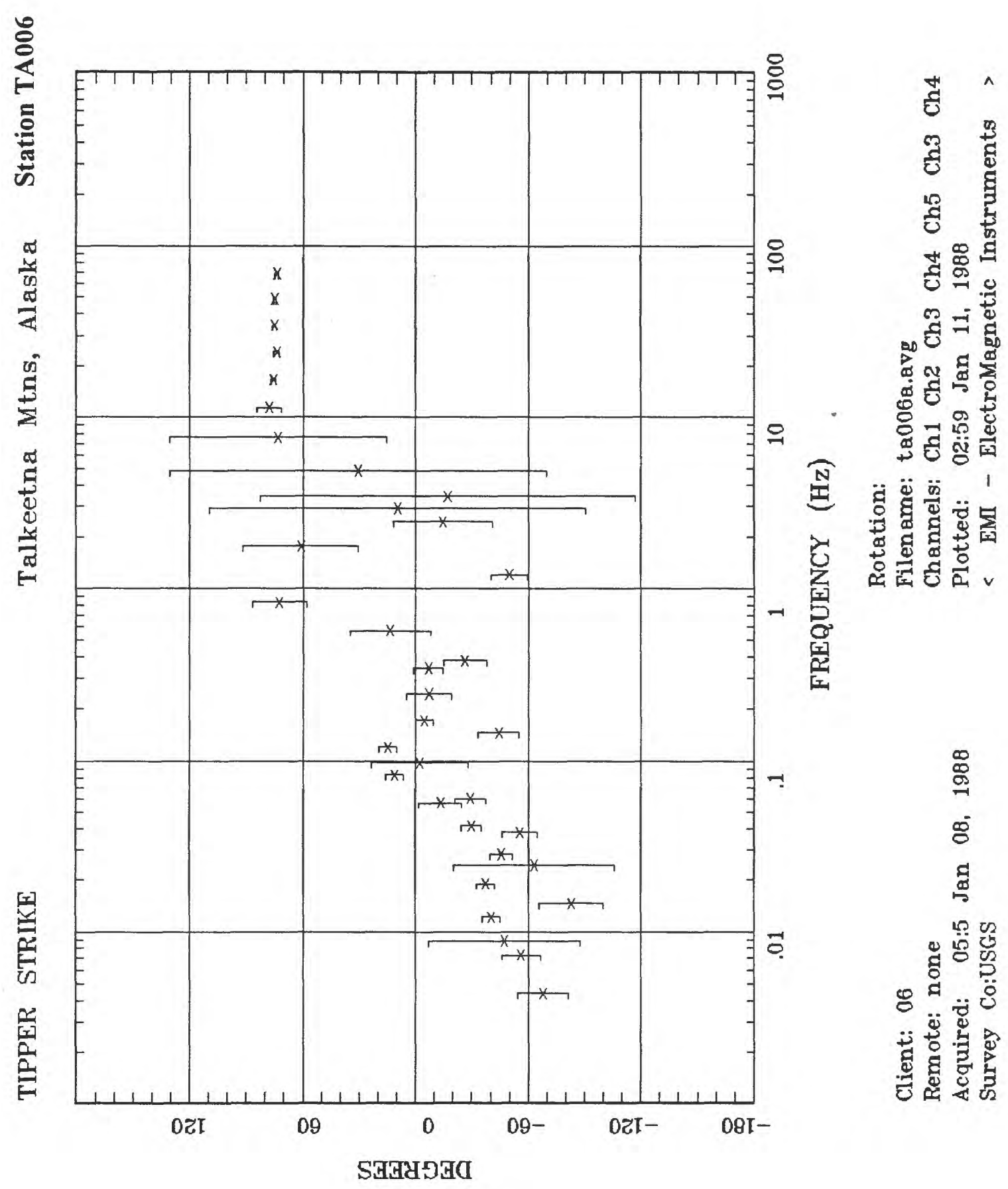




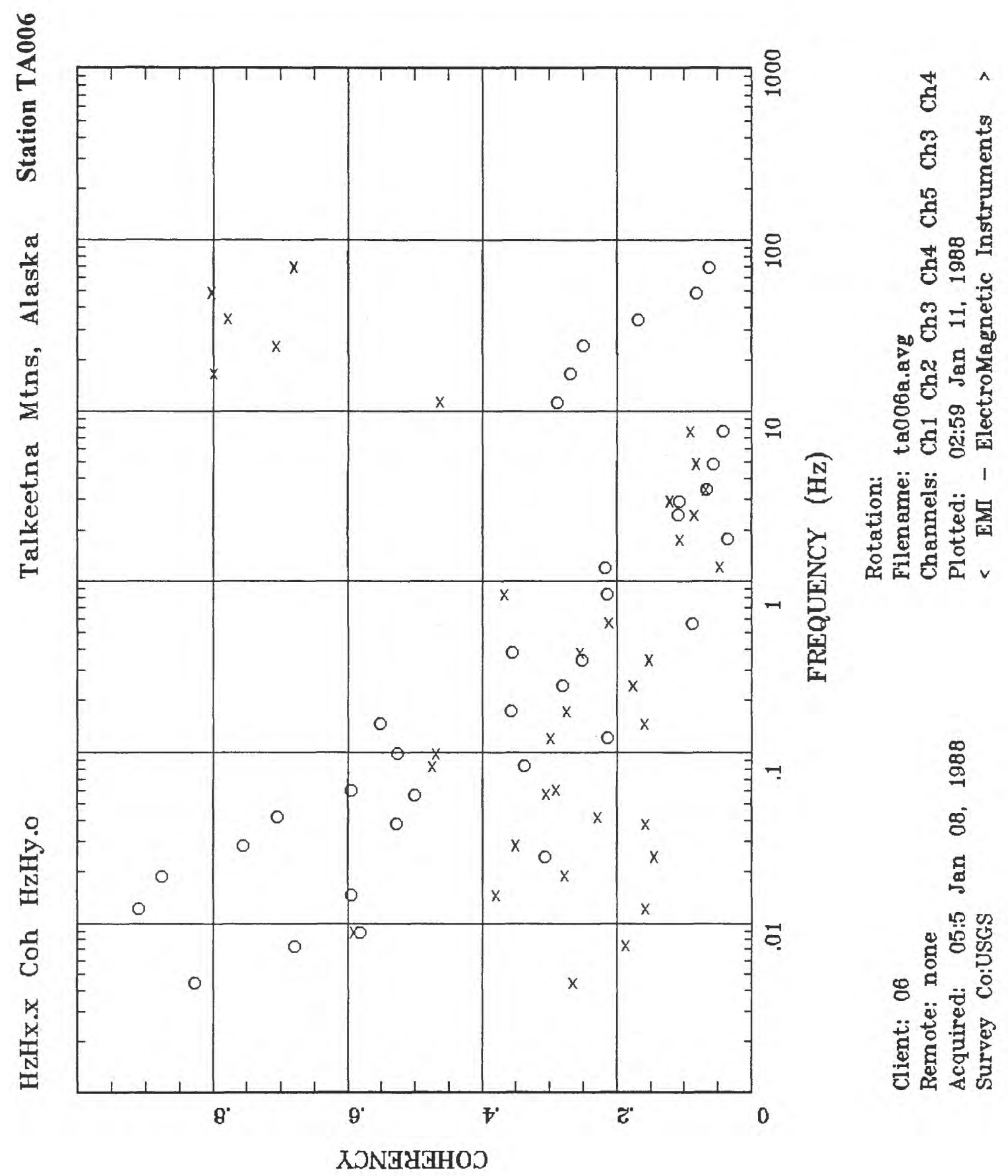

